TESIS DOCTORAL

\title{
Análisis de los factores que influyen en la práctica de la innovación en el Curso de Design de la Universidad Federal de Amazonas
}

\author{
PROGRAMA DE DOCTORADO EN DISEÑO, FABRICACIÓN Y \\ GESTIÓN DE PROYECTOS INDUSTRIALES
}

Autora:

Patrícia dos Anjos Braga Sá dos Santos

Director:

Prof. Dr. Bernabé Hernandis Ortuño

Valencia, 2013 



\section{Dedicatoria}

Dedico este trabajo a mi familia, a mi director de tesis y a todos los que de alguna manera han contribuido a su éxito. 



\section{Agradecimientos}

A Dios por todas las bendiciones recibidas y la perseverancia dada a mí a lo largo de mis estudios.

A mi esposo Roberto Sá dos Santos por su compañerismo, dedicación y amor.

A mi madre, abuela, hermanos, suegros, sobrinos y cuñados por su apoyo y aliento.

Al director de la tesis, Profesor. Dr. Bernabé Ortuño, por su valiosa orientación y dedicación durante el desarrollo de este trabajo.

A la Universidad Federal de Amazonas y a la Universidad Politécnica de Valencia por la oportunidad y apoyo recibidos en mis iniciativas de investigación.

A los Profesores Dimas Lasmar, Claudete Barbosa, Socorro Chaves y Márcia Perales por las orientaciones y disponibilidad.

A Profesora Begoña Agudo por su colaboración en los estudios estadísticos de la tesis.

A los profesores y compañeros del Programa de Doctorado en Diseño, Fabricación y Gestión de Productos.

A todos los amigos del Departamento de Diseño y Expresión Gráfica/UFAM, en especial al jefe del Departamento Jefferson Oliveira y a la Coordinadora e al Vice-Coordinador del Curso de Design, Profesores Sheila Cordeiro e Nelson Kwahara.

A los amigos Karla Mazarelo, Almir Pacheco, Susana Paixão y Daniel y Silvana Castro por el apoyo y compañía durante nuestra estancia en la ciudad de Valencia. 



\section{SUMÁRIO}

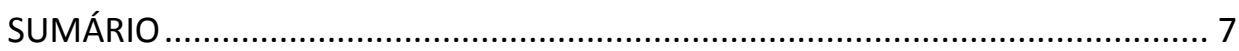

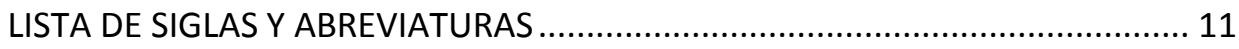

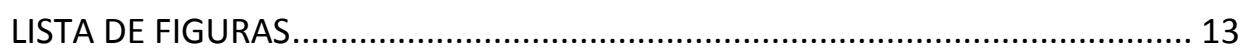

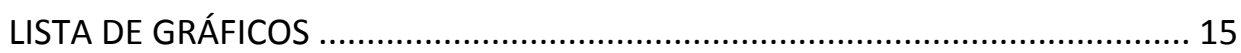

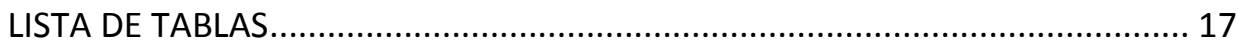

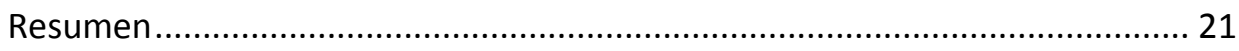

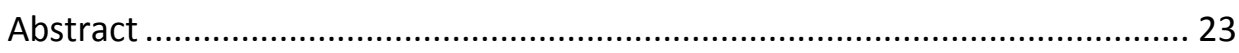

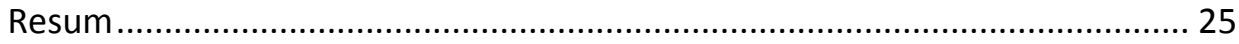

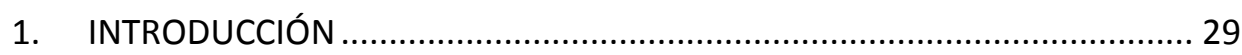

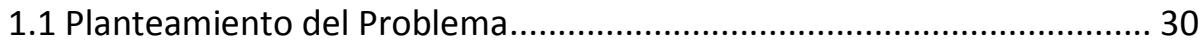

1.2 Objetivos de investigación ................................................................. 33

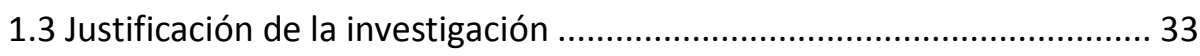

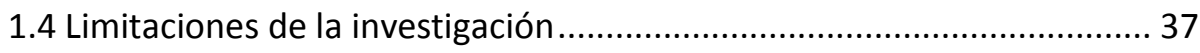

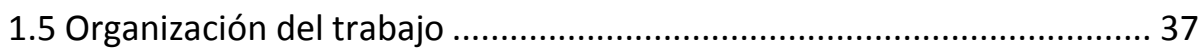

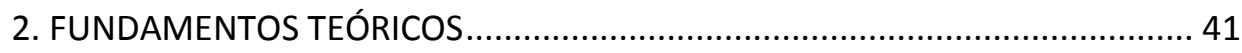

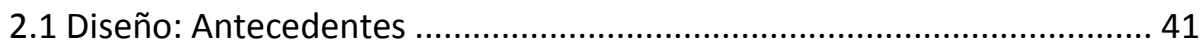

2.1.1 Conceptos de Diseño .................................................................. 41

2.1.2 Origen y contextualización del diseño en Brasil y Amazonas............ 43

2.1.3 La Educación Superior en Diseño: Lineamientos Curriculares para los

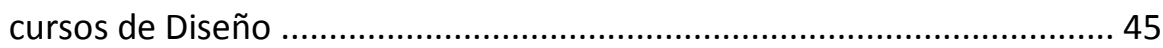

2.2 Innovación: Conceptos y fundamentos teóricos.................................... 49

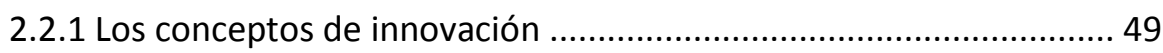

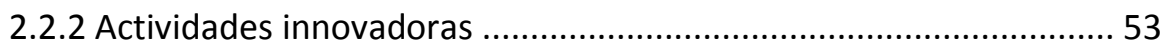

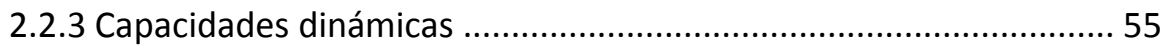

2.2.4 Los Sistemas de Gestión de la Innovación (SGI) .............................. 57

2.2.4.1 Elementos básicos de un Sistema de Gestión .......................... 57

2.2.5 Definición de empresa y organización ..................................... 58

2.2.6 La Relación entre Academia e Industria en Brasil ...................... 59

2.2.6.1 El Enfoque de la Triple Hélice .................................................. 60

2.2.7 Resumen de los fundamentos teóricos sobre innovación ......... 61

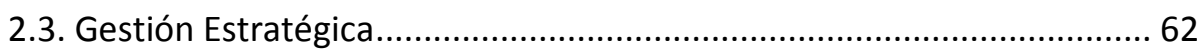


2.3.1 La Gestión Estratégica del Conocimiento y de la Innovación 64

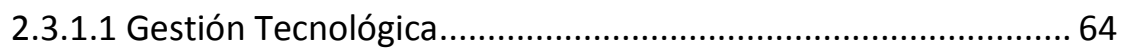

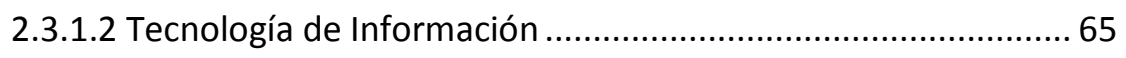

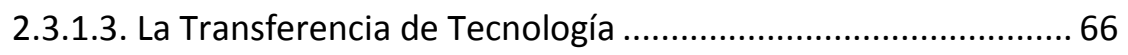

2.4. El Enfoque Sistémico en la evaluación de la innovación ..........................68

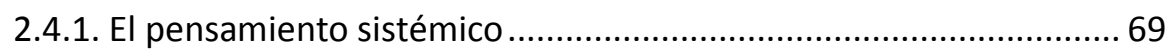

2.4.2. La sistémica y la gestión de la Innovación ......................................... 70

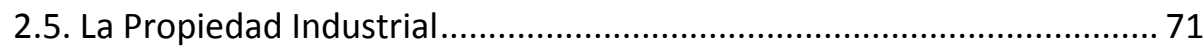

2.5.1. La Patente de invención ........................................................ 71

2.5.2. La Patente de Modelo de Utilidad ............................................ 72

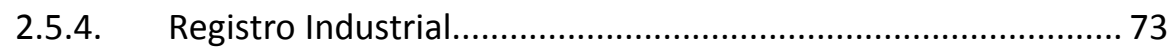

2.5.4.1. El Diseño Industrial ("Design")............................................... 73

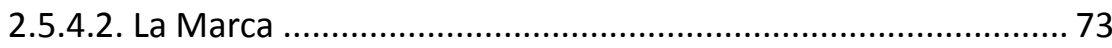

2.5.5. Las indicaciones geográficas .................................................. 74

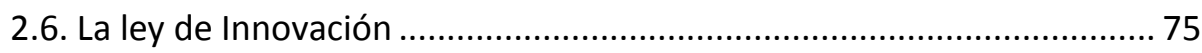

2.7. Evaluación de la Educación Superior en Brasil ....................................... 76

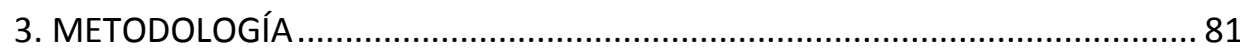

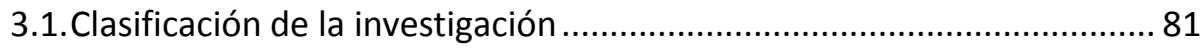

3.2. Universo de estudio, selección y tamaño de la muestra .......................... 83

3.3 Técnicas y herramientas de recopilación, análisis, procesamiento y

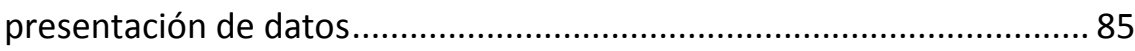

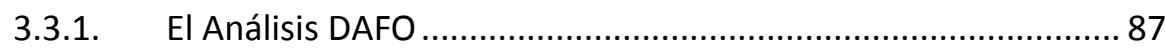

3.3.2. El Modelo de Formulación por objetivos ................................. 91

3.3.3. Evaluación por lo pares del Sistema de Gestión Propuesto ...... 96

4. EL CURSO DE GRADO EN DESIGN DE LA UNIVERSIDAD FEDERAL DE

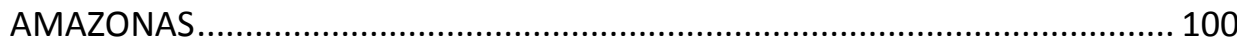

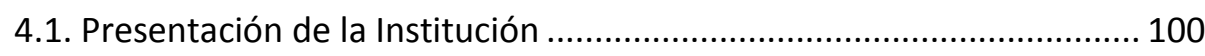

4.1.1. Estructura académica y administrativa de UFAM ........................ 101

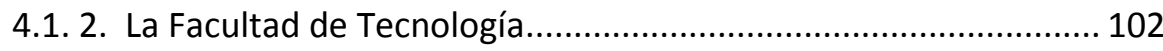

4.2. Estructura de Apoyo a la Innovación de UFAM ................................... 102

4.3 El Curso de Grado en Design UFAM ................................................... 104

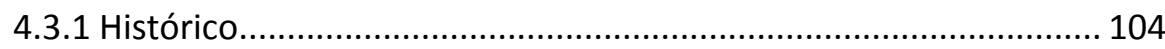

4.3.2 Objetivos del curso ................................................................. 106

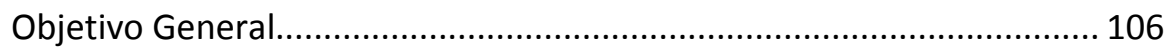


4.3.3 Estructura e Funcionamiento del Curso ........................................ 106

4.3.4 Proyecto Político-Pedagógico del Curso.......................................... 107

4.3.4.1 Formación de Personal y Mercado......................................... 107

4.3.4.2 Campos de Actuación Profesional ........................................... 108

4.3.4.3 Perfil del Profesional a ser formado ....................................... 108

4.3.5. Concepción de la Organización Curricular..................................... 110

4.3.5.1 La Matriz Curricular del curso............................................. 110

5. RESULTADOS Y DISCUSIÓN.

5.1 Resultados del instrumento de evaluación del escenario de la innovación en el curso - grupo de PROFESORES

5.1.1 Resultados de las cuestiones 01 a 06 del cuestionario PROFESORES.

5.1.2 Resultados de la Cuestión 07 de la encuesta - PROFESORES . 118

5.1.3 Resultados de la Cuestión 08 de la encuesta - PORFESORES .. 120

5.1.4 Resultados de la Cuestión 09 de la encuesta - PROFESORES .. 121

5.1.5 Resultados de la Cuestión 10 de la encuesta .......................... 121

5.1.6 Resultados de la Cuestión 11 de la encuesta - PROFESORES . 123

5.1.7 Resultados de la Cuestión 12 de la encuesta - PROFESORES . 127

5.1.8 Resultados de la Cuestión 13 de la encuesta - PROFESORES . 128

5.2 Resultados del instrumento de evaluación del escenario de la innovación en el curso - ALUMNOS .................................................................... 129

5.2.1 Resultados de las cuestiones 01 a 06 del cuestionario ALUMNOS... 129

5.2.2 Resultados de la Cuestión 07 de la encuesta - ALUMNOS ..... 130

5.2.3 Resultados de la Cuestión 08 de la encuesta - ALUMNOS ...... 132

5.2.4 Resultados de la Cuestión 09 de la encuesta - ALUMNOS ...... 132

5.2.5 Resultados de la Cuestión 10 de la encuesta - ALUMNOS ..... 133

5.2.6 Resultados de la Cuestión 11 de la encuesta - ALUMNOS ..... 135

5.2.7 Resultados de la Cuestión 12 de la encuesta - ALUMNOS ..... 139

5.2.8 Resultados de la Cuestión 13 de la encuesta - ALUMNOS ..... 140

5.2.9 Resultados de la Cuestión 14 de la encuesta - ALUMNOS ...... 141

5.3 Resultados del instrumento de evaluación del escenario de la innovación en el curso - grupo de TITULADOS 
5.3.1 Resultados de las cuestiones 01 a 11 del cuestionario TITULADOS.

5.3.2 Resultados de la Cuestión 12 de la encuesta - TITULADOS ..... 143

5.3.3 Resultados de la Cuestión 13 de la encuesta - TITULADOS ..... 143

5.3.4 Resultados de la Cuestión 14 de la encuesta - TITULADOS .... 143

5.3.5 Resultados de la Cuestión 15 de la encuesta - TITULADOS .... 144

5.3.6 Resultados de la Cuestión 16 de la encuesta - TITULADOS .... 146

5.3.7 Resultados de la Cuestión 17 de la encuesta - TITULADOS ... 149

5.3.8 Resultados de la Cuestión 18 de la encuesta - TITULADOS .... 150

5.3.8 Resultados de la Cuestión 19 de la encuesta - TITULADOS ..... 151

5.4. Descripción del sistema actual y propuesta de una estrategia para la mejorar la gestión de la innovación del curso de grado en diseño ufam:

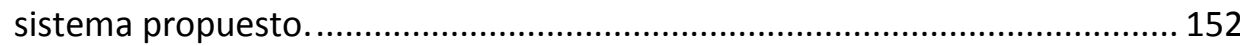

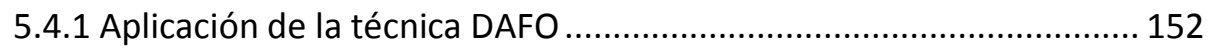

5.4.2 Aplicación del Modelo de Formulación por Objetivos para caracterización del escenario actual de la innovación e proposición de un modelo de Gestión de la innovación en el curso...................................... 159

5.4.2.1 Caracterización del Sistema en Estudio........................................ 159

5.5 Evaluación por los pares sobre el Sistema Propuesto .......................... 187

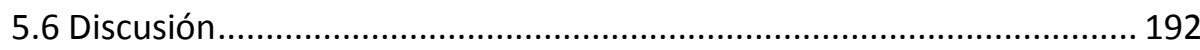

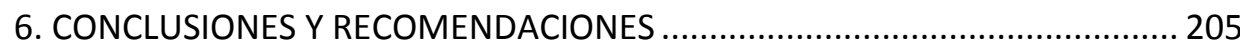

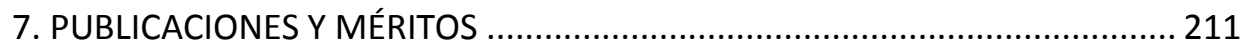

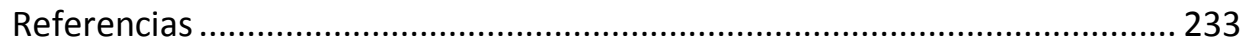

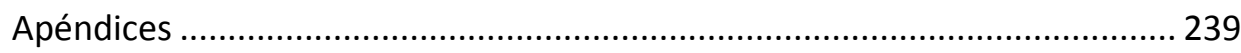

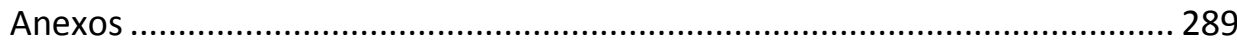




\section{LISTA DE SIGLAS Y ABREVIATURAS}

ADAM - Asociación de Designers de Amazonas

ADP - Asociación de Designers de Producto

APDesign - Asociación de Profesionales de Design

C\&T - Ciencia y Tecnología

C\&T\&I - Ciencia, Tecnología y Innovación

CDTECH - Centro de Desarrollo Empresarial y Tecnológico

CES - Cámara de Enseñanza Superior

CIDE - Centro de Incubación y Desarrollo Empresarial

CNE - Consejo Nacional de Educación

CNPq - Consejo Nacional de Desarrollo Científico y Tecnológico

CONAES - Consejo Nacional de Evaluación de la Educación Superior

CONSEPE - Consejo de Enseñanza, Investigación y Extensión

CONSUNI - Consejo Universitario

DEG - Departamento de Design e Expresión Gráfica

ENADE - Examen Nacional de Desempeño de Estudiantes

ESDI - Escuela Superior de Diseño Industrial

FAPEAM - Fundación de Amparo a la investigación del Estado de Amazonas

FORTEC - Fórum Nacional de Gestores de Innovación e Transferencia de Tecnología

FINEP - Financiadora de Estudios e Proyectos

FMF - Facultades Marta Falcão

FT - Facultad de Tecnología

FUA - Fundación Universidad de Amazonas

FUCAPI - Fundación Centro de Análisis, Investigación e Innovación en Tecnología

IAC - Instituto de Arte Contemporánea

IES - Institución de Educación Superior

INEP - Instituto Nacional de Estudios e Investigaciones Educacionales Anísio Teixeira

INPA - Instituto Nacional de Investigaciones de Amazonia

INPI - Instituto Nacional da Propiedad Industrial 
LDB - Ley de Directrices y Bases de la Educación

LPI - Ley de Propiedad Industrial

MASP - Museo de Arte de São Paulo

MCT - Ministerio da Ciencia, Tecnología e innovación

MDIC - Ministerio del Desarrollo, Industria y Comercio Exterior

MEC - Ministerio de Educación

NDE - Núcleo Docente Estructurarte

NIT - Núcleo de innovación Tecnológica

OCDE - Organización para la Cooperación y Desarrollo Económico

P\&D - Pesquisa y Desarrollo

PET - Programa de Educación Tutorial

PIBIC - Programa Institucional de Becas de Iniciación Científica

PIBITI - Programa Institucional de Becas de Iniciación en Desarrollo Tecnológico e Innovación

PIM - Pólo Industrial de Manaus

PROEG - Pró-Reitoria de Enseñanza y Grado

PROPLAN - Vice-Rectoría de planificación

PROTEC - Vice-Rectoría de Innovación Tecnológica

PSC - Proceso Selectivo Continuo

PSM - Proceso Selectivo Macro

RH - Recursos Humanos

SEBRAE - Servicio Brasileiro de Apoyo a las Micro e Pequeñas empresas

SESU - Secretaria de Educación Superior del Ministerio de Educación

SINAES - Sistema Nacional de Evaluación de la Educación Superior

SPSS - Statistical Package for the Social Sciences

SUFRAMA - Superintendencia de la Zona Franca de Manaus

DAFO - Strengh, Weakness, Opppotunities, Threats

TCC - Trabajo de Conclusión de Curso

TI - Tecnología de la Información

UFAM - Universidad Federal de Amazonas

UFPB - Universidad Federal de Paraíba

UTAM - Instituto de Tecnología do Amazonas 


\section{LISTA DE FIGURAS}

Figura 01: Matriz - Potencial para Generación de Conocimiento ...................... 34

Figura 02: Matriz - Potencial de aplicación de conocimientos tecnológicos .... 35

Figura 03: La formación de la enseñanza del Diseño en Brasil .......................... 44

Figura 04 - El espacio de la innovación ......................................................... 50

Figura 05 - Estructura del proceso de innovación............................................ 53

Figura 06: Esquema Sistémico de una Innovación Tecnológica ......................... 56

Figura 07 - Modelo de Interacción del campo de la triple hélice ........................60

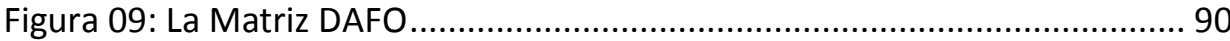

Figura 10: Modelo de Formulación por Objetivos. .......................................... 93

Figura 11: Curso de Design / Ambiente de Innovación: Sistema actual ......... 177

Figura 12: Curso de Design / Ambiente de Innovación: Sistema Propuesto... 185 



\section{LISTA DE GRÁFICOS}

Gráfico 01: Resultados de las respuestas de los pares cuanto a la Aplicabilidad

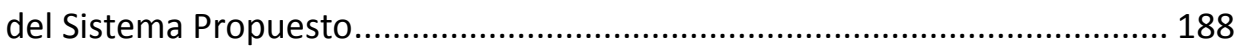

Gráfico 02: Resultados de las respuestas de los pares cuanto a la Representatividad del Sistema Propuesto 188

Gráfico 03: Resultados de las respuestas de los pares cuanto a la Amplitud del Sistema Propuesto 189

Gráfico 04: Resultados de las respuestas de los pares cuanto al acompañamiento del Sistema Propuesto

Gráfico 05: Resultados de las respuestas de los pares cuanto a la Relación Propuesta/Resultados del Sistema Propuesto. 190

Gráfico 06: Resultados de las respuestas de los pares cuanto a la Relación con los objetivos del curso del Sistema Propuesto. 



\section{LISTA DE TABLAS}

Tabla 01: Características de las definiciones de Innovación 61

Tabla 02: Resumen de las características de la base teórica del estudio 62

Tabla 03: Indicadores de organización didáctica y pedagógica 77

Tabla 04: Indicadores de los profesores, alumnado y personal técnico y administrativo 78

Tabla 05: Instalaciones Físicas 78

Tabla 06: Asignaturas Obligatorias del Curso de Design/UFAM 111

Tabla 07: Asignaturas Electivas del Curso de Design UFAM 113

Tabla 08: Perfil del grupo consultado - PROFESORES 118

Tabla 09: Compilación de las respuestas de la Cuestión 07 - PROFESORES.... 119

Tabla 10: Compilación de las respuestas de la Cuestión 08 - PROFESORES.... 120

Tabla 11: Compilación de las respuestas de la Cuestión 09 - PROFESORES.... 121

Tabla 12: Compilación de las respuestas de la Cuestión 10 - PROFESORES.... 122

Tabla 13: Orden de prioridades indicadas en la Cuestión 10 - PROFESORES.. 123

Tabla 14: Compilación de las respuestas de la Cuestión 11 - PROFESORES ... 125

Tabla 15: Orden de prioridades obtenidas en la Cuestión 11 - PROFESORES 127

Tabla 16: Orden de puntos positivos de la Cuestión 12 - PROFESORES 127

Tabla 17: Orden de las deficiencias de la Cuestión 13 - PROFESORES 128

Tabla 18: Perfil del grupo consultado - ALUMNOS. 129

Tabla 19: Compilación de las respuestas de la Cuestión 07 - ALUMNOS........ 130

Tabla 20: Compilación de las respuestas de la Cuestión 08 - ALUMNOS........ 132 
Tabla 21: Compilación de las respuestas de la Cuestión 09 - ALUMNOS 133

Tabla 22: Compilación de las respuestas de la Cuestión 10 - ALUMNOS 133

Tabla 23: Orden de prioridades de la Cuestión 10 - ALUMNOS 135

Tabla 24: Compilación de las respuestas de la Cuestión 11 - ALUMNOS 137

Tabla 25: Orden de prioridades obtenidas de la Cuestión 11 -ALUMNOS...... 139

Tabla 26: Compilación de las respuestas de la Cuestión 12- ALUMNOS. 139

Tabla 27: Orden de puntos positivosde la Cuestión 12 - ALUMNOS 140

Tabla 28: Compilación de las respuestas de la Cuestión 13 - ALUMNOS 140

Tabla 29: Orden de Deficiencias de la Cuestión 13 - ALUMNOS 141

Tabla 30: Resultados de la Cuestión 14 del cuestionario - ALUMNOS 141

Tabla 31: Perfil del grupo consultado - TITULADOS 141

Tabla 32: Resultados de la Cuestión 12 del cuestionario - TITULADOS 143

Tabla 33: Resultados de la Cuestión 13 del cuestionario - TITULADOS............ 143

Tabla 34: Resultados de la Cuestión 14 del cuestionario - TITULADOS............ 144

Tabla 35: Compilación de las respuestas de la Cuestión 15 - TITULADOS........ 144

Tabla 36: Orden de prioridades de la Cuestión 15 - TITULADOS....................... 146

Tabla 37: Compilación de las respuestas de la Cuestión 16 - TITULADOS...... 147

Tabla 38: Orden de prioridades de la Cuestión 16 - TITULADOS...................... 149

Tabla 39: Compilación de las respuestas de la Cuestión 17 - TITULADOS....... 149

Tabla 40: Orden de pontos positivosde la Cuestión 17 - TITULADOS .............. 150

Tabla 41: Compilación de las respuestas de la Cuestión 18 - TITULADOS....... 150

Tabla 42: Orden de Deficiencias encontrada en las respuestas de la Cuestión 18

- TITULADOS 
Tabla 43: Resultados de la Cuestión 19 del cuestionario - TITULADOS

Tabla 44: Lista DAFO del ambiente de innovación - Curso de Design. 152

Tabla 45: Organización en orden de importancia de los ítems de la lista DAFO Ambiente interno - puntos fuertes. 155

Tabla 46: Organización en orden de importancia de los ítems de la lista DAFO Ambiente interno - Debilidades 156

Tabla 47: Organización en orden de importancia de los ítems de la lista DAFO Ambiente externo - Oportunidades 156

Tabla 48: Organización en orden de importancia de los ítems de la lista DAFO Ambiente externo - Amenazas

Tabla 49: La Matriz DAFO - El Ambiente de la innovación en el curso de Design UFAM 158

Tabla 50: Esquema de la Evaluación por los pares del Sistema Propuesto .... 187

Tabla 51: Compilación de los resultados - evaluación del sistema propuesto por los pares 191

Tabla 52: Comparativo entre las acciones apuntadas como prioritarias en los tres grupos.

Tabla 53: Comparativo entre las prioridades apuntadas en la Cuestión sobre Calidad en los cursos de grado en los tres grupos

Tabla 54: Comparativo entre los Puntos Positivos del curso apuntados en los tres grupos.

Tabla 55: Comparativo entre las Deficiencias del curso apuntadas en los tres grupos 199

Tabla 56: Comparativos sobre las respuestas de la Cuestión en la cual eran preguntados se indicarían el curso. ALUMNOS/TITULADOS 200 



\section{Resumen}

Esta investigación tuvo como objetivo identificar y analizar, desde una perspectiva sistémica, los factores que influyen en la práctica de la innovación en el curso de Diseño de la Universidad Federal de Amazonas, con el fin de estimular su entorno para la innovación. Específicamente el estudio tuvo como objetivos: a) Identificar y analizar las dimensiones y actores que influyen y forman parte del proceso de búsqueda en el campo de la innovación b) Identificar las posibles barreras que podrían estar obstaculizando el proceso de innovación en curso c) contribuir con nuevos enfoques para minimizar el alcance de las posibles barreras identificadas, desde un enfoque sistémico, mediante la propuesta de directrices para la gestión de la innovación en el desarrollo de proyectos y en la organización del diseño del curso. La investigación se caracteriza como un estudio exploratorio descriptivo, realizado a través de un estudio de caso. La revisión de la literatura fue dirigida a áreas relacionadas con el tema, tales como: conceptos de diseño y el contexto del área en Brasil y Amazonas, las definiciones y las bases teóricas sobre innovación, Gestión Estratégica, Propiedad Industrial y Enfoque Sistémico en la evaluación de la innovación. Se estudiaron los datos relativos al actual Proyecto político-pedagógico del curso, fueron realizadas entrevistas con expertos en el campo de la innovación y diseño, y también se han aplicado a, lo largo de este estudio, cuestionarios a los profesores, alumnos e graduados con el objetivo de identificar los factores que podrían estar dañando su entorno innovador. A partir de los datos recogidos y de los resultados obtenidos en la encuesta se elaboró, a través de la técnica DAFO, una matriz en la cual se identificaron y organizaron las fortalezas y debilidades del ambiente interno y las oportunidades y amenazas del ambiente externo de la atmósfera de la Innovación en el curso. A partir de los datos de la matriz se utilizó el Método de Formulación por Objetivos para la caracterización del sistema actual y, posteriormente, para la composición de una propuesta de sistema de gestión de la innovación en el curso de Diseño. Los resultados contribuyen a una mejor comprensión del ambiente de la innovación en el curso y para expandir el interés en el tema. Es de notar, sin embargo, que ya que es un estudio de caso, los resultados obtenidos en este trabajo se limitan al campo de la investigación específica, y no deben ser generalizados al entorno de la educación superior pública en su conjunto.

Palabras clave: Innovación; Formación Profesional; Diseño. 



\section{Abstract}

This research aimed to identify and analyze, from a systemic approach, the factors that influence the practice of innovation in the undergraduate course of Design in Federal University of Amazonas, in order to stimulate the innovation environment in the course. In specific terms the study aimed to: a) Identify and analyze the dimensions and actors that influence and are part of the process of the search of innovation in the course; b) Identify possible obstacles that may be hindering the innovation process; c) contribute with new approaches to minimize the extension of possible barriers identified, by proposing guidelines for the management of innovation during the development of the projects in Design course. The research is characterized as a descriptive exploratory work through a case study. The literature review addressed areas related to the theme, such as: Design concepts and context of this area in Brazil and Amazonas, definitions and theoretical bases on innovation, strategic management, industrial property and systemic approach in evaluating innovation. Was studied data related to the current PoliticalPedagogical Project of the course, interviews with experts in the field of Innovation and Design and also questionnaires were administered to the students, graduates and teachers with the aim of identifying factors that could be harming the innovative environment. From the data collected and the results obtained in the survey was drawn a matrix, through the DAFO technique, in which were identified and organized the strengths and weaknesses of the internal environment and the opportunities and threats of the external environment of innovation on the atmosphere of the course. From the data of the DAFO matrix was applied the Formulation by Objectives Method for the construction of the current system and subsequently a proposed management system of innovation for the Design course which consists in actions and strategies to solve the problems that were identified in the research. The results contribute to a better understanding of the innovation environment in the course and to expand the interest for the subject. It is noteworthy, however, that because it is a case study, the findings obtained in this work are limited to the course that was the target of the research, and should not be generalize to the environment of public higher education as a whole.

Keywords: Innovation; Professional Formation; Design. 



\section{Resum}

Esta investigació va tindre com a objectiu identificar i analitzar, des d'una perspectiva sistèmica, els factors que influïxen en la pràctica de la innovació en el curs de Disseny de la Universitat Federal d'Amazones, a fi d'estimular el seu entorn per a la innovació. Específicament l'estudi va tindre com a objectius: a) Identificar $i$ analitzar les dimensions $i$ actors que influixen $i$ formen part del procés de busca en el camp de la innovació b) Identificar les possibles barreres que podrien estar obstaculitzant el procés d'innovació en curs c) contribuir nous enfocaments per a minimitzar l'abast de les possibles barreres identificades, des d'un enfocament sistèmic, per mitjà de la proposta de directrius per a la gestió de la innovació en el desenrotllament de projectes i en l'organització del disseny del curs. La investigació es caracteritza com un estudi explorador descriptiu, realitzat a través d'un estudi de cas. La revisió de la literatura va ser dirigida a àrees relacionades amb el tema, com ara: conceptes de disseny i el context de l'àrea a Brasil i Amazones, les definicions i les bases teòriques sobre innovació, Gestió Estratègica, Propietat Industrial i Enfocament Sistèmic en l'avaluació de la innovació. Es van estudiar les dades relatives a l'actual Projecte politicopedagògic del curs, van ser realitzades entrevistes amb experts en el camp de la innovació i disseny, i també s'han aplicat a, ho vaig d'este estudi, qüestionaris als professors, alumnes e graduats amb l'objectiu d'identificar els factors que podrien estar danyant el seu entorn innovador. A partir de les dades arreplegats i dels resultats obtinguts en l'enquesta es va elaborar, a través de la tècnica DAFO, una matriu en la qual es van identificar i van organitzar les fortaleses i debilitats de l'ambient intern i les oportunitats $i$ amenaces de l'ambient extern de l'atmosfera de la Innovació en el curs. A partir de les dades de la matriu es va utilitzar el Mètode de Formulació per Objectius per a la caracterització del sistema actual i, posteriorment, per a la composició d'una proposta de sistema de gestió de la innovació en el curs de Disseny. Els resultats contribuïxen a una millor comprensió de l'ambient de la innovació en el curs i per a expandir l'interés en el tema. És de notar, no obstant això, que ja que és un estudi de cas, els resultats obtinguts en este treball es limiten al camp de la investigació específica, i no han de ser generalitzats a l'entorn de l'educació superior pública en el seu conjunt.

\section{Paraules clau: Innovació; Formació Professional; Disseny}



Capítulo 1

\section{INTRODUCCIÓN}





\section{INTRODUCCIÓN}

Amazonia es la mayor reserva forestal e hidrológica del mundo, con más de seis millones de kilómetros cuadrados repartidos en nueve países: Brasil, Colombia, Venezuela, Ecuador, Perú, Bolivia, Guyana, Surinam y la Guayana Francesa. Alrededor del $40 \%$ de la superficie total de Amazonía se encuentra en Brasil, dato que sirve para escalar el desafío que la sociedad y el gobierno tienen ante sí: la conservación y al mismo tiempo la promoción del desarrollo de la región (REZENDE, 2007).

Este patrimonio natural ubicado en Brasil hace del país el mayor poseedor la diversidad biológica del mundo, con alrededor del $20 \%$ de las especies en el planeta (Ebole, 2007). El gran potencial de la biotecnología en la Amazonia es codiciada por los investigadores de todo el mundo. Las acciones de biopiratería, a pesar de los esfuerzos para combatirla, han sido cada vez más frecuentes, hecho que destacó la necesidad urgente del país en invertir más en la investigación y en la formación de recursos humanos en biotecnología y el desarrollo de la innovación, especialmente en la región Norte, que a pesar de haber logrado importantes avances en esta dirección se encuentra todavía en una situación de desventaja en comparación con las instalaciones más grandes en el país.

La Universidad Federal de Amazonas (UFAM) y el Curso de Diseño asumen un papel estratégico en la formación de recursos humanos calificados y por lo tanto el crecimiento económico en el estado. No obstante el Curso ya tenga 24 años de existencia y el alcance de su aportación sea indiscutible, aún es necesario fortalecer diversos aspectos relacionados a la innovación y a la interacción entre el mundo académico y la industria. Varios proyectos y monografías que se han generado tienen gran potencial para generar productos, sin embargo, no alcanzan la fase de producción, ya que no se da continuidad, hecho que ocurre, en algunas situaciones, debido al poco conocimiento de aspectos importantes involucrados en la gestión de proyectos, de la protección de la propiedad intelectual, del espíritu empresarial y de la transferencia de tecnología.

Por lo tanto, este estudio busca identificar y evaluar los aspectos que influyen en la innovación en el ambiente académico del curso de Diseño de la Universidad Federal de Amazonas, con el fin de estimular la difusión de los conocimientos generados en el mismo. Con este fin, se realizaron análisis de las dimensiones y de los actores involucrados en el su proceso de innovación.

En el entorno del curso se estudiaron los actores que generan el conocimiento, tales como: profesorado, alumnado y graduados así como su 
estructura de funcionamiento y coordinación con el fin de trazar un perfil de su producción y potencial innovador.

Además de los factores internos del Curso fueron recogidos datos para establecer su interacción con el ambiente exterior: Esferas industriales y gubernamentales, a partir del análisis de la dinámica entre la investigación desarrollada, la interacción con las empresas y las políticas públicas relacionadas con el desarrollo del país y la Innovación en la región.

Para evaluar el potencial de innovación en el Curso se reunieron datos para caracterizar su situación actual en relación a aspectos que influyen en el proceso inovativo y la necesidad de ajustes en su organización con el fin de promover un entorno favorable a la Innovación.

\subsection{Planteamiento del Problema}

A lo largo de su existencia, el Curso de Design con sede en la Universidad Federal de Amazonas (UFAM) ha capacitado personal calificado que ha producido una gran cantidad de nuevos conocimientos de gran importancia para el desarrollo y consolidación del design en Amazonía.

El curso, creado en 1988, tuvo como sus propuesta inicial formar Designers con el fin de satisfacer las demandas del Polo Industrial de Manaus (PIM), sin embargo, a lo largo de los años, este objetivo no se ha realizado porque el PIM no ha absorbido estos profesionales como se esperaba, ya que era una zona industrial mucho más centrada en la montaje de productos que en desarrollo de proyectos. Por lo tanto fue necesario que los profesionales buscasen oportunidades en el mercado de servicios, lo que ha requerido una reconfiguración de la propuesta inicial del curso a la que tenemos hoy.

Hasta el primero semestre de 2012 el curso ya tenía 223 graduados. Sin embargo, aunque el número de monografías y proyectos desarrollados en las diferentes áreas del diseño hayan dado lugar a publicaciones y otras formas de producción, existe, tanto por parte del curso como por parte de la Agencia de Evaluación de los cursos de educación superior en Brasil, el MEC (Ministerio de Educación y Cultura) una creciente preocupación sobre otro aspecto relacionado a la producción de conocimiento: la generación de nuevos procesos y productos que efectivamente puedan llegar al mercado, es decir, hay una preocupación con la cuestión de la innovación.

Johnson, Edquist y Lundvall (2003) indican que una política de Innovación debe contribuir a la capacidad de aprendizaje de las empresas e instituciones centradas en el conocimiento y de las personas. En pocas palabras, para que la innovación ocurra, el ambiente de aprendizaje debe ser objetivo en todas 
partes, incluso en las instituciones educativas. Así, algunos de los elementos básicos para el aprendizaje son: (i) el desarrollo de los recursos humanos, (ii) las nuevas formas de organización empresarial, (iii) la creación de redes, (iv) la definición de una nueva función de los servicios y el conocimiento intensivo de las universidades.

Takahashi y Amorim (2008) argumentan que dentro de estas redes, un pilar fundamental consiste en el sector de la educación y, dentro de ella, las universidades y su capacidad para crear y transferir conocimiento a la sociedad en su conjunto, especialmente en su dimensión económica.

Dentro de este contexto, el curso de Design UFAM ha revelado, desde su principio, la preocupación con la interacción entre el mundo académico y la industria. En su documento de creación, fechado en marzo de 1988, esto se llamaba Diseño Industrial, nomenclatura que se modificó en 2007, cuando el curso vino ser llamado Design y tuvo la totalidad de su Proyecto Político Pedagógico restructurado.

En el Proyecto de Curso de 2007, que entró en vigor en el mismo año, los objetivos presentados siguen mostrando la preocupación con el desarrollo de nuevos procesos y productos que pueden mejorar la vida de la sociedad:

- Promover y fomentar la investigación en Diseño en la búsqueda de nuevas soluciones a los nuevos paradigmas de la sociedad, buscando su crecimiento y mejoras en la calidad de vida.

- Promover y alentar iniciativas y proyectos que puedan representar una mejora efectiva en el desarrollo de nuevas tecnologías, productos y sistemas de comunicación, a través del diseño, en provecho del desarrollo de la sociedad.

Aún en su proyecto de 2007 se explica el perfil esperado de los titulados:

- Ser un profesional en consonancia con las necesidades de la sociedad a la que pertenece, que posee una sólida base teórica, tecnológica y humanística, comprometida con la realidad brasileña, especialmente locales, con pensamiento crítico y responsabilidad social capaces de interactuar con las transformaciones y nuevos paradigmas de la sociedad, generando innovaciones que promuevan la mejora en la calidad de vida.

De acuerdo a la información del Vice-Rectorado de Innovación Tecnológica (PROTEC), actualmente sólo hay tres procesos de solicitaciones de registro de propiedad industrial que se relacionan con el curso de Design. Dos de ellos fueron frutos de las tesinas de dos de los profesores del curso y el tercero se basó en un proyecto desarrollado por un grupo de ALUMNOS que forman parte del Programa de Educación Tutorial de Design (PET). Es de destacar que no 
hay ningún registro en UFAM de solicitudes de patentes derivadas de la realización de proyectos de grado en Diseño.

El bajo número de patentes y de generación de nuevos productos, en parte, puede ser influenciado por la actual forma de evaluación de los cursos de en el país, hay un gran reconocimiento del elemento "publicación", pero el único indicador relacionado con la generación de nuevos producto es el número de patentes. Sin embargo, es sabido, que no siempre la patente se convierte en una Innovación efectiva.

Otro aspecto que puede influir en la interacción entre el mundo académico, la industria y la generación de Innovación en el Curso es la condición profesional y el perfil de los investigadores, que en su mayoría están trabajando en régimen de dedicación exclusiva, lo que los impide, por ejemplo, de emprender. Por otro lado, aquellos que no se ven frente a este obstáculo y tienen perfil adecuado, a menudo no conocen los mecanismos necesarios para ello. También hay una gran parte de los investigadores que no tienen un perfil emprendedor y al alcanzar resultados interesantes que podrían dar lugar a un nuevo producto o proceso en el mercado, se enfrentan con las dificultades de la transferencia de tecnología a las empresas, un hecho que afecta a la relación entre estas dos esferas.

El contraste entre el gran número de monografías concluidas, un total de 223 hasta el 1er semestre de 2012 y el bajo número de solicitudes de patentes depositas (sólo 03 para el mismo período), indica la necesidad de identificar los obstáculos que pueden estar entorpeciendo la relación entre la academia y la industria y la práctica de la innovación en el Curso. Por otro lado, el número total de solicitudes de patentes de la universidad es aproximadamente sesenta, que en su mayoría han sido depositadas en los últimos cuatro años, lo que muestra una tendencia ascendente, posiblemente estimulada por la política institucional de innovación y creación de sectores responsables por al registro de propiedad industrial. Por lo tanto, la premisa del curso para fomentar la práctica de la innovación, más allá de las expresiones de MEC que indican el reconocimiento de la generación de nuevos productos y procesos en sus evaluaciones, sumado a la importancia de la formación de personal calificado en el área de Design para Amazonas configuran un entorno propicio para un estudio que podría minimizar las barreras que existen en la relación entre el mundo académico y la industria, lo que contribuye a la comprensión de las relaciones que puedan conducir a la promoción de la Innovación en el curso de Design. 


\subsection{Objetivos de investigación}

\section{General:}

Identificar y analizar, desde una perspectiva sistémica, los factores que influyen en la práctica de la innovación en el curso de Design de la Universidad Federal de Amazonas, o la falta de ellos, a fin de estimular el ambiente de la Innovación en el curso.

\section{Específicos:}

- Identificar y analizar las dimensiones y actores que influyen y forman parte del proceso de búsqueda de la innovación en el Curso de Grado en Design UFAM;

- Identificar las posibles barreras que pueden estar obstaculizando el proceso de innovación en el curso;

- Contribuir con nuevos enfoques para minimizar el alcance de las posibles barreras identificadas, desde un enfoque sistémico, mediante la propuesta de directrices para la gestión de la innovación en el desarrollo de proyectos y en la organización del curso;

\subsection{Justificación de la investigación}

Un estudio sobre la cartografía de la Innovación en Brasil llevado a cabo en 2007 muestra que el actual número de investigadores en el estado de Amazonas está muy por debajo de lo deseable en comparación con otras capitales. A través de la observación de la figura 01 podemos ver que ciudades como Florianópolis, Porto Alegre, Campinas y Niterói, son las con mayor número de investigadores, teniendo al mismo tiempo, las más altas tasas de investigadores en relación a su población económicamente activa. También se observó que Manaos no aparece en el mapa que se muestra en esta figura, asi como ninguna otra ciudad de la región norte. 
Figura 01: Matriz - Potencial para Generación de Conocimiento

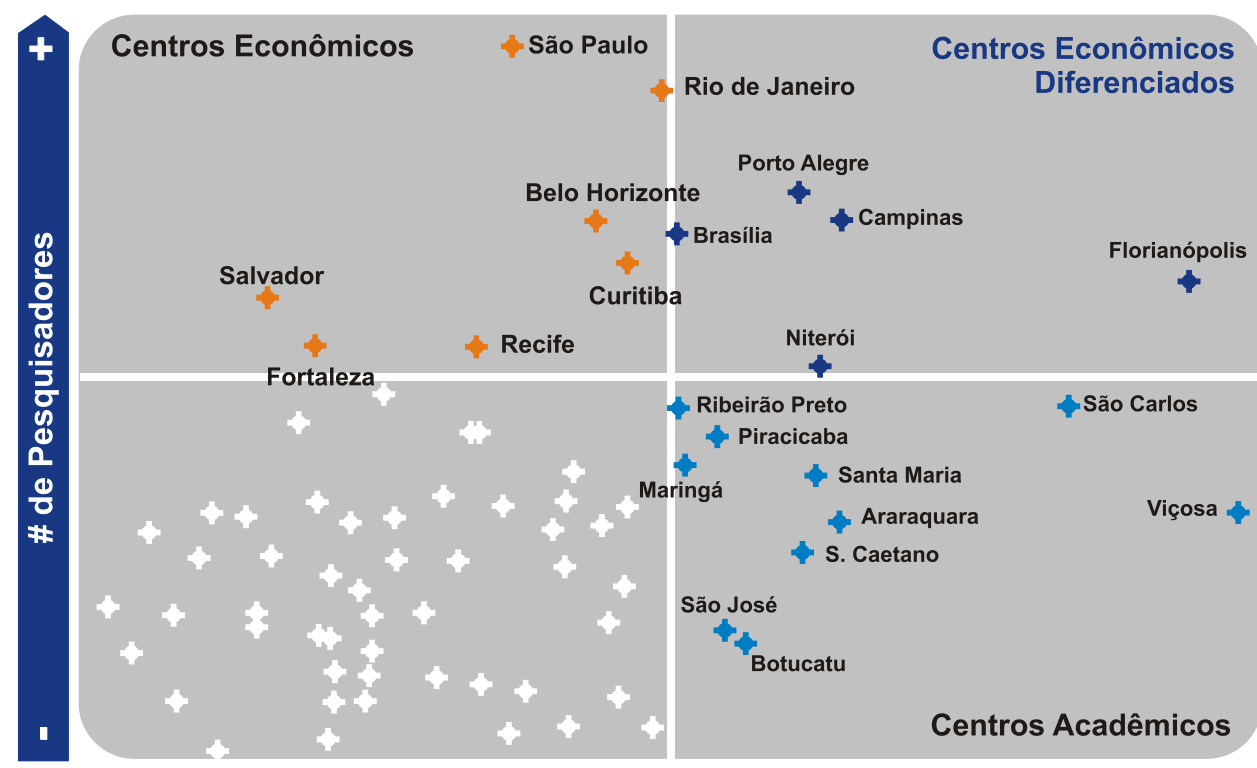

\section{\# de Pesquisadores P.E.A}

Fuente: Moreira et al. (Instituto Innovación, 2007)

Aun teniendo en cuenta la información del estudio sobre el potencial de aplicación del conocimiento tecnológico del país, hay una indicación de que las principales ciudades brasileñas en el número de patentes son responsables por agrupar a más de 60 mil solicitudes de patentes en los últimos 10 años, con un total de 140 patentes, según el Instituto Nacional de Propiedad Industrial (INPI). Como se esperaba, las ciudades más grandes del país, como Sao Paulo y Río de Janeiro, tienen el mayor número, como se muestra en la figura 02 a continuación. 
Figura 02: Matriz - Potencial de aplicación de conocimientos tecnológicos

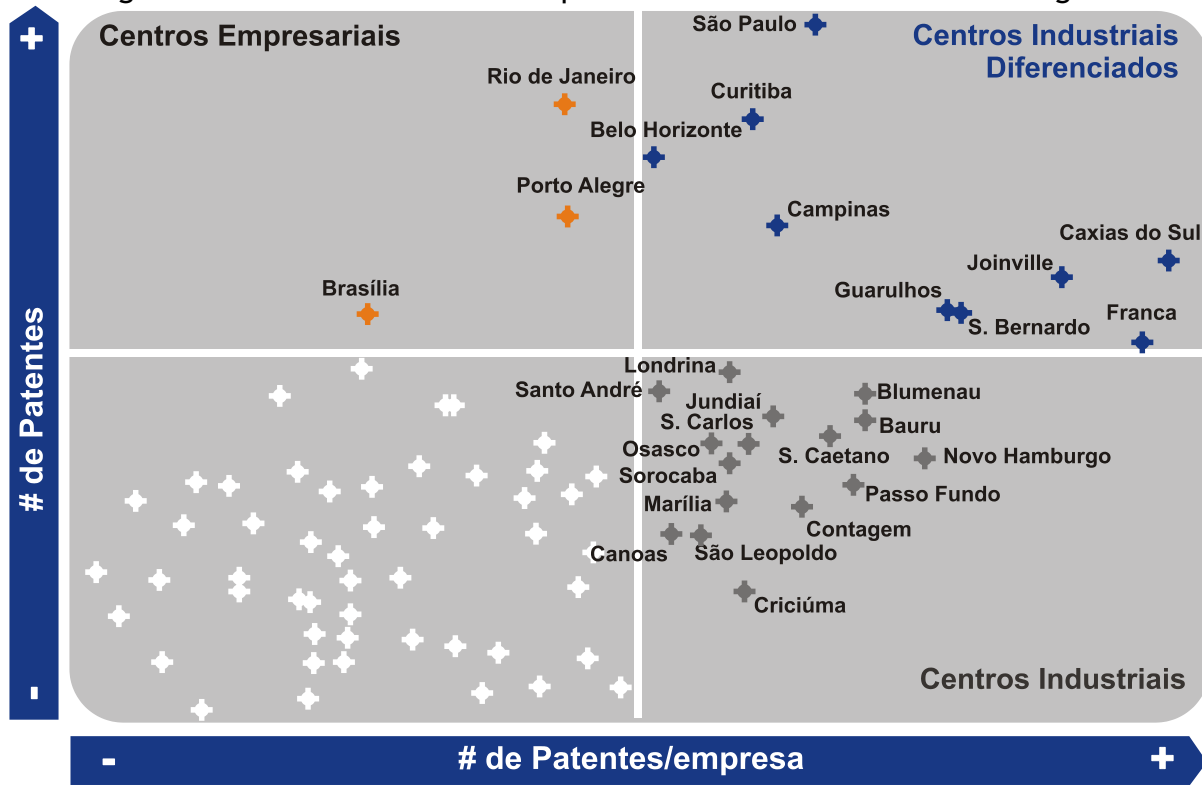

Fuente: Moreira et al. (Instituto Innovación, 2007)

En este contexto, Moreira et al (2007) demuestran que el potencial de creación de conocimientos está estrechamente relacionado con el potencial para generar innovación, y que mientras que en Brasil todavía existe una gran brecha entre la relación ideal entre estos dos aspectos, el país cuenta con calidades que son favorables para el desarrollo de innovaciones, ya que tiene grandes centros de conocimiento, y está pasando por un momento de importantes cambios estructurales en el ámbito de la innovación y el desarrollo del sector de la industria y el aumento de las inversiones públicas y privadas de base tecnológica. En el contexto actual donde el conocimiento es la base del desarrollo económico, es imprescindible fomentar la explotación de este recurso a favor de generar beneficios para la sociedad brasileña.

Por lo tanto, ha sido una premisa del Curso de Design de la Universidad Federal de Amazonas aumentar la difusión de los conocimientos sobre Innovación entre los alumnos y este escenario se suma el momento vivido por la institución, cuya Gestión Superior ha demostrado iniciativas para fomentar la Innovación en el ambiente académico.

En 2007, fue creado el NIT - Núcleo de Innovación Tecnológica, bajo la dirección del Asesor Especial para la Innovación y la Tecnología que según Coelho (2012) es dirigida a la implementación de una estructura de acuerdo con los preceptos de la ley de la Innovación (Ley $\mathrm{N}^{\circ} 10.973$, del 2 de 
diciembre de 2004) para que pueda dar autonomía y agilidad a los procedimientos relacionados con la propiedad intelectual.

En 2010, fue aprobado en el Consejo Universitario la creación del PCTIS Parque Científico Tecnológico para Inclusión Social. Financiado por el Ministerio de Ciencia y Tecnología, Secretaria de Ciencia y Tecnología para la Inclusión Social y coordinado por el Núcleo de Innovación Tecnológica (NIT/UFAM), el PCTIS está direccionado a la práctica de la innovación articulando los conocimientos científicos y técnicos al saber popular Amazonas.

También fue aprobado en CONSUNI (Consejo Universitario) en 2011 la Política Institucional de Innovación Tecnológica de la Universidad Federal de Amazonas, cuyos objetivos son:

- Estimular y potenciar, de forma continua y permanente, la actividad creativa demostrada por la producción científica, tecnológica y artística de sus profesores, estudiantes y técnicos administrativos en educación;

- Estimular y fomentar la creación intelectual a través de proyectos o actividades financiadas 0 realizadas en colaboración con otras instituciones, organizaciones de apoyo o empresas, nacionales $y$ extranjeras;

- Promover la protección de las creaciones intelectuales y tecnológicas en la institución y en las organizaciones asociadas;

- Ofrecer a UFAM mecanismos de gestión tecnológica innovadora a través de los Parques Tecnológicos e Incubadoras de todas las áreas del conocimiento;

- Fomentar la sostenibilidad institucional de las acciones de innovación y de las interfaces económica, social, cultural y ambiental. (UFAM,2011)

Aún según Coelho (2012), esta política institucional también creó el Vice Rectorado de Innovación Tecnológica (PROTEC). UFAM es la primera universidad en Brasil a tener un vice rectorado dirigido a esta área. La estructura creada por este nuevo sector está orientado a satisfacer la visión empresarial de la universidad comprometida con el desarrollo social y económico de la región amazónica. Además de PROTEC creada en 2011, la Universidad ya tenía el CDTECH - Centro de Desarrollo Empresarial y tecnológico, una de las incubadoras de la Universidad Federal de Amazonas, que en 2010 pasó a integrar el PCTIS y que junto con el nuevo Vice Rectorado también responde al carácter emprendedor de la institución.

Ante este escenario, vemos la importancia de realizar estudios que contribuyan a la construcción de un nuevo perfil de los Designers de la región, fomentando el curso de Design de la Universidad Federal de Amazonas, la formación de un profesional que conozca los mecanismos de la relación entre el mundo académico y la industria, contribuyendo así al fortalecimiento de los negocios desde los proyectos desarrollados en el curso. La relevancia de este 
estudio es, a través de la identificación y análisis de las barreras en el entorno de la innovación, y, desde un enfoque sistémico, sugerir nuevos enfoques a los problemas encontrados, y posteriormente contribuir al desarrollo científico y económico de la Región Norte a través de la innovación.

También es importante tener en cuenta que aunque los resultados de la investigación innovadora desarrollada en el ámbito académico sean asociadas generalmente a los cursos de postgrado srticto sensu, el curso de Design (aun perteneciendo al nivel de grado) tiene una característica peculiar que es inherente a la profesional: la búsqueda de nuevos paradigmas y soluciones para resolver problemas relacionados a productos. El Trabajo de Finalización de curso, consiste en el desarrollo de un proyecto práctico (producto o programación visual), y por lo tanto, cada una de estas obras tiene, potencialmente, un carácter innovador y debería ser mejor utilizado en beneficio de la sociedad.

\subsection{Limitaciones de la investigación}

El estudio es contribuir a la reflexión sobre la importancia de fortalecer la cultura de la innovación en la educación superior pública, sobre todo porque se trata de un caso relacionado con el estado de Amazonas, donde todavía hay pocas referencias sobre el tema.

Sin embargo, se destaca que la investigación tiene limitaciones porque es un estudio de caso y, por lo tanto las reflexiones y conclusiones derivadas sólo se refieren al objeto específico de estudio de esta tesis y no pueden ser extendidas a un universo más amplio que se relaciona con el problema, pues para eso son necesarias investigaciones en otras muestras, es decir, los resultados no pueden ser generalizados.

\subsection{Organización del trabajo}

Teniendo en cuenta el tema de investigación y los objetivos del estudio, el trabajo se divide en siete capítulos, lo que permite una organización secuencial de los asuntos. Para una mejor comprensión de este trabajo, se presenta, a continuación, cómo los sujetos se distribuyen en cada capítulo.

En el primer capítulo se encuentra la introducción del trabajo que presenta un panorama general sobre el tema innovación, comentando también sobre el curso que es objeto de estudio. También en este capítulo son presentados el problema, objetivos y justificación de la investigación, por lo que es posible, entender la contribución y la dimensión del trabajo. 
El segundo capítulo está dedicado a los fundamentos teóricos. Este segmento ofrece una contextualización sobre diseño en el cual son presentadas las principales definiciones y una breve historia del área en Brasil y en Amazonas, más allá de los lineamientos curriculares que direccionan los cursos de Diseño de en el país. Aun en este capítulo hay una revisión de los conceptos relacionados a la tecnología, la innovación tecnológica, la gestión de la tecnología y la tecnología de la información que serán necesarios para la comprensión del universo estudiado.

En el tercer capítulo se analiza la metodología utilizada. En esta sección se presentan los métodos para la construcción de cada etapa de la investigación, la definición del tipo, naturaleza, población y muestra de la investigación, la forma de levantamiento de datos, fuentes y métodos utilizados para el procesamiento y análisis de datos. También en este capítulo, se describen los principales aspectos de la metodología DAFO que será un punto de referencia para el análisis de las fortalezas y debilidades del entorno innovador y del Método de Formulación por Objetivos que guiará la fase de construcción de la estrategia de gestión de Innovación para el curso.

A lo largo del cuarto capítulo se presenta la institución y el curso e investigados y se muestran los aspectos principales relacionados con ellos con el fin de caracterizar los factores que serán importantes en el cumplimiento de los objetivos de la investigación.

El quinto capítulo se centra en los resultados de la investigación y el debate. Se presentan los resultados obtenidos por los instrumentos de evaluación aplicados a los tres grupos que forman el grupo: profesores, estudiantes y graduados, así como los análisis y discusiones generadas por los resultados presentados.

El sexto capítulo está dedicado a la caracterización de la situación actual y a la proposición de una estrategia para mejorar la gestión de la Innovación en el curso de Design UFAM. Con base en la metodología DAFO se enumeran en una matriz, los puntos fuertes y débiles, así como las oportunidades y amenazas para el ambiente Innovación en el curso y se sugiere, posteriormente, una nueva estrategia de gestión de la innovación basado en la metodología formulación de objetivos.

El séptimo capítulo está dedicado a la conclusión en la cual se presentan los comentarios finales sobre los resultados del trabajo y las recomendaciones para futuros estudios. 
Capítulo 2

FUNDAMENTOS TEÓRICOS 



\section{FUNDAMENTOS TEÓRICOS}

Este capítulo discuten sobre los conceptos de diseño adoptadas por los diferentes segmentos y realiza una aproximación científica e histórica del diseño en Brasil y en el estado de Amazonas. Explica aún sobre la Educación Superior en Diseño, centrándose en las directrices curriculares para programas de grado en Diseño.

\subsection{Diseño: Antecedentes}

\subsubsection{Conceptos de Diseño}

Para una mejor comprensión del tema de la investigación es importante saber lo que es la actividad de diseño. Muchas definiciones están presentes en la literatura, se presentan a continuación una selección de autores para orientar la discusión.

Según Oliveira (2005,p.4)

El diseño industrial es un proceso de transformación de una necesidad o un problema del hombre en un producto tangible, modelo, que se produce industrialmente para satisfacer esta necesidad o resolver este problema, teniendo en cuenta los aspectos técnicos, sicofisiológicos, sociológicos, psicológicos y de mercado de acuerdo con un conjunto de antecedentes socioeconómicos.

Para Jean-Pierre Vitrac (1991, citado por Schulmann, 1994, p.10) "El diseño es una actividad que consiste en crear, de acuerdo con los parámetros económicos, productos técnicos y estéticos, objetos o sistemas que son fabricados y comercializados".

Ya en el Proyecto de Ley 1.965 de 1996, que tiene la intención de reglamentar la profesión, pendiente ante la Cámara de Representantes, el diseño se define como:

El Diseñador industrial es el que realiza la actividad especializada de carácter técnico-científico, artístico y creativo, con miras al diseño y desarrollo de proyectos y mensajes visuales que equiparan sistemáticamente datos ergonómicos, tecnológicos, económicos, sociales, culturales y estéticos específicamente para satisfacer las necesidades humanas "(Designbrasil.org.br).

Esta definición ha causado cierta controversia entre las entidades, asociaciones y profesionales, pues es una definición que menciona que la actividad responde a un carácter artístico, lo que es discutible al analizar el Diseño. El diseño se basa en interacción entre el medio ambiente y el usuario, 
en información objetiva acerca de sus necesidades, direccionando el proyecto a satisfacción de las necesidades identificadas, mientras que el arte es subjetivo e intuitivo y no se subyuga a la satisfacción del usuario. El diseño utiliza, sí, el conocimiento y las teorías de la construcción de la técnica y el fundamento de los aspectos formales y estéticos de sus proyectos, sin embargo, este resultado está orientado a la producción industrial, mientras que el producto del arte es único.

Couto (2002) considera adecuado definir el diseño como una tecnología, un cuerpo organizado de conocimientos, con el estatus de disciplina que se puede enseñar a través de una estructura curricular adecuada. Se hace evidente que el diseño no descuida a utilizar los mejores principios de la estética (arte) para refinar la forma. Resulta claro también que el diseño no deja de utilizar el conocimiento científico disponible, para impartir el rendimiento funcional adecuado a los objetos y sistemas materiales que diseña, o para desarrollar y apoyar sus teorías. Por último, es evidente que los métodos de diseño utilizados para organizar su trabajo y aumentar su eficacia no se limitan a las prácticas de uso meramente intuitivas, cuya justificación no pueda defender convincentemente. El diseño implica varios enfoques metodológicos y se puede colocar en el campo de la investigación y el desarrollo tecnológico operativo.

Otra definición clásica del diseño es de Maldonado (2006, p.32)

Diseño Industrial es una actividad creativa cuyo objetivo es determinar las calidades formales de los objetos que la industria produce. Estas calidades forman son no sólo la externa, pero principalmente las relaciones estructurales y funcionales que convierten un sistema en una unidad coherente, tanto desde el punto de vista del fabricante cuanto del consumidor. El Diseño Industrial se extiende a cubrir todos los aspectos del medio ambiente humano que se ven limitados por la producción industrial.

Como se ve en la serie de definiciones presentadas, es claro que a pesar de una aparente diversidad de conceptos, los puntos en común nos permiten formular una definición general y amplia, como la adoptada en el Proyecto Político-Pedagógico del Curso de Diseño de la Universidad Federal de Paraíba:

- $\quad$ El diseño es un proceso;

- $\quad$ El diseño satisface las necesidades del hombre a través de la interface hombre objeto;

- La actividad de diseño está orientada a la producción y comercialización;

- $\quad$ El Diseño es contexto;

- $\quad$ El Diseño es tecnología; 
- $\quad$ El Diseño es interdisciplinario;

- $\quad$ El Diseño es Calidad.

Teniendo en cuenta el debate que se presenta es posible tener un conocimiento general de las diferentes concepciones de la actividad de diseño, observando su carácter tecnológico y multi/interdisciplinario en la búsqueda de soluciones a las necesidades del hombre/objeto (producto o sistema de información). Más allá de los conceptos de diseño también es necesario entender la historia de su surgimiento y establecimiento en Brasil y en el estado de Amazonas, lo que influyó directamente en la trayectoria de la creación del curso de Design de la Universidad Federal de Amazonas.

\subsubsection{Origen y contextualización histórica del diseño en Brasil y} Amazonas

Niemeyer (1997) señala que el origen del diseño en Brasil se remonta a los años 50 cuando un segmento de la reconocida elite paulista vio la necesidad de la formación de un profesional para satisfacer la demanda de diseño y comunicación visual que la reciente y creciente economía brasileña estaba generando.

Según Wollner (2003) el Instituto de Arte Contemporáneo - IAC - del MASP (Museu de Arte de São Paulo), la sociedad brasileña condujo a la idea de que era posible unir a la forma del producto cotidiano con los principios artísticos a través de diversas exposiciones celebradas en la década 50 , suscitando el interés de varios profesionales y sentando las bases para el inicio de la profesión del diseño en el país.

Niemeyer (1997) relata que la enseñanza del Diseño oficialmente llega a Brasil en 1963 con la creación de la Escuela Superior de Diseño Industrial - ESDI en Río de Janeiro, diseñado junto de las líneas de Escuela UIM y que sirvió como referencia para el desarrollo de este la actividad en el país.

Como era de esperar, la aplicabilidad de los conceptos postulados en UIm sufrió una adaptación al contexto industrial, económico, social y cultural de Brasil. La ESDI se incorporó más tarde a la Universidad Federal de Río de Janeiro. Cavalcanti (2005) señala también la importancia de la creación del Curso de Diseño de la Universidad Federal de Paraíba (UFPB) en los años 70, un hecho que también fortaleció el área en el noreste de Brasil. La secuencia cronológica de la formación y el establecimiento de la educación de Diseño en Brasil se puede ver en la figura 03, a continuación: 
Figura 03: La formación de la enseñanza del Diseño en Brasil

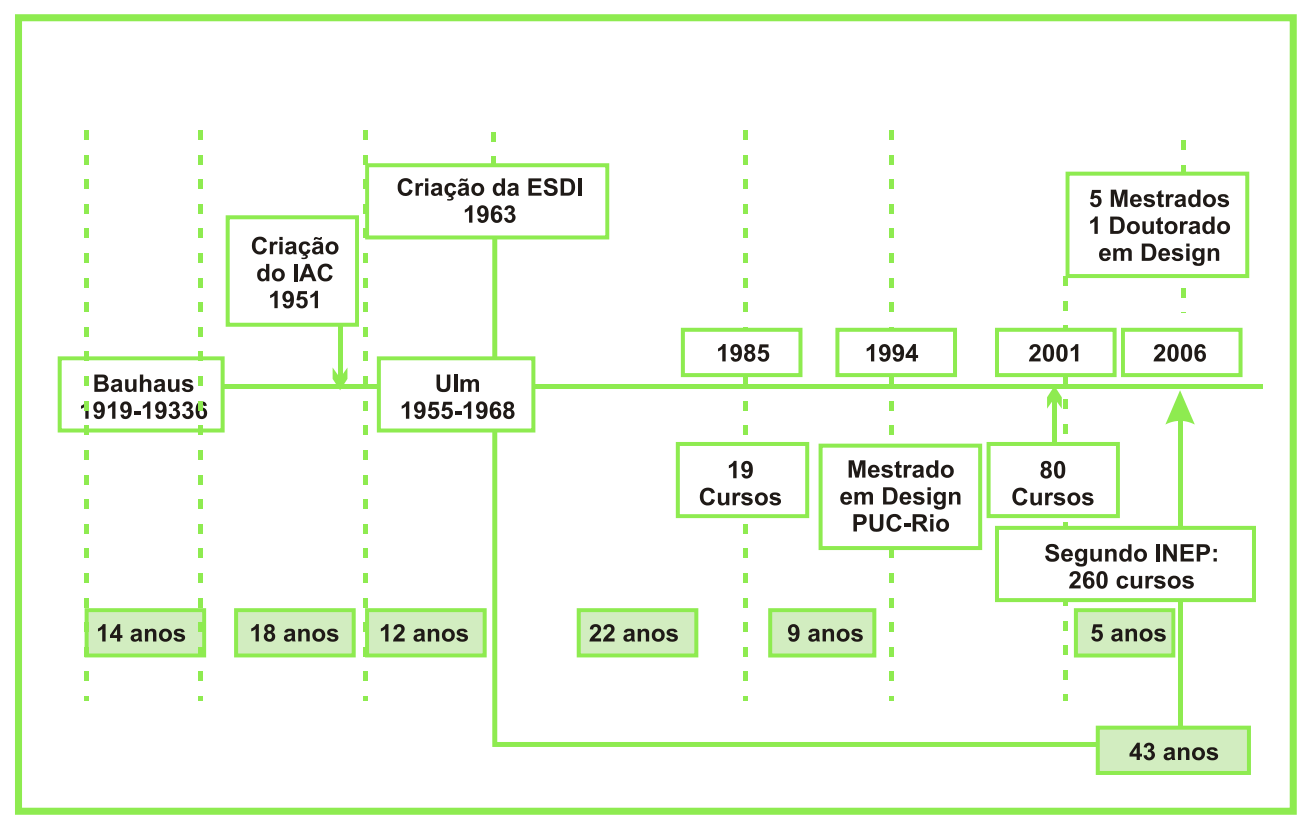

Fuente: Niemeyer (2006)

Pero el área solo empezaría a ser tratado como una especialidad distinta de la creación artística a partir de la creación de la oficina primera de diseño en el país,la FormInform por Alexandre Wollner, Geraldo de Barros, Rubem Martins y Walter Macedo, después del regreso Wollner de Europa en 1958 . Su actividad fue el punto de referencia para la profesionalización del diseño en Brasil.

La primera entidad de clase apareció en 1987 en Río Grande do Sul, la Asociación de Profesionales de Diseño de Rio Grande do Sul (APDesign), seguido por la Asociación de Diseñadores Gráficos (ADG de 1989), la Asociación de Diseñadores de Producto (ADP) y la Asociación Brasileña de Empresas de Diseño (ABEDESIGN), ambos en 2003.

En Amazonas según Cavalcanti (2005) la idea de la importancia del diseño comenzó a ser plantada en los años 80, cuando el profesor Lynaldo Cavalcanti de Albuquerque que había sido presidente del CNPq y Rector de la Universidad Federal da Paraíba fue invitado por el Superintendente de SUFRAMA en 1986 para trabajar en Manaus. En el momento, la idea era desarrollar un Plan Estratégico para la Educación, Ciencia y Tecnología para el Estado y, en virtud de la preocupación por la Zona Franca de Manaus, el desempeño de este profesional se ha centrado en la capital de Amazonas. 
Ya consciente del papel del diseño en la industria brasileña, el profesor Lynaldo Cavalcanti inicialmente invitó a un profesional, Eduardo Barroso, para liderar la discusión sobre el tema industria y universidades locales y propuso la creación de un núcleo de Diseño con el apoyo de la Fundación Centro de Análisis, Investigación e Innovación Tecnológica (FUCAPI).

Más tarde, también fue traído a la ciudad un profesional llamado Alceu Castelo Branco, quien durante su estancia en Manaus llevó a la Universidad Federal de Amazonas (UFAM) y al ya extinto Instituto de Tecnología de la Amazonía (UTAM), ambas instituciones públicas, la propuesta de creación de un curso universitario en el área. La Universidad Federal de Amazonas aceptó la idea y creó en 1988 el primer grado universitario en Diseño Industrial del estado de Amazonas.

En la actualidad, hay más de 200 cursos de diseño en el país, entre grados y cursos tecnológicos, cada uno tiene sus propias características, debido a las peculiaridades de las instituciones de educación superior y sus regiones. En carácter de posgrado existen cinco cursos de máster y tres de doctorado.

En Brasil, los cursos de grado en Diseño están actualmente dirigidos por la Resolución $n^{\circ} 5$ CNE / CES de 8 de marzo de 2004, que determina las Directrices Curriculares Nacionales para los estudios en Diseño.

\subsubsection{La Educación Superior en Diseño: Lineamientos Curriculares para los cursos de Diseño}

El Consejo Nacional de Educación (CNE) a través de su Consejo de Educación Superior (CES), a través de la Resolución $N^{\circ}$ 5, de 8 de marzo de 2004. Publicado en el Diario Oficial del 1 de abril de 2004, Sección 1, pág. 19 (anexo A), aprobó las Directrices Curriculares Nacionales para los cursos de Diseño.

En su artículo 2, el documento que establece las Directrices Curriculares indica que el organización del curso debe ser expresada a través de su proyecto pedagógico, que abarca el perfil del alumno, habilidades y destrezas, los componentes del currículo, las actividades extraescolares supervisadas, el sistema de evaluación, la monografía, el proyecto de investigación, así como la realización del trabajo de conclusión de curso - TCC (componente opcional de la institución), y el sistema de provisión académico y otros aspectos que hagan el proyecto consistente.

Observamos los elementos que deben hacer parte del proyecto político pedagógico del curso, destacando también que, además del diseño claro del curso e sus peculiaridades, su currículo y su completa operación el proyecto también debe incluir: 
I - Objetivos generales del curso, contextualizados en relación con sus inserciones institucionales, políticas, geográficas y sociales;

II - las condiciones objetivas de la oferta y la vocación del curso;

III - las cargas de trabajo de las actividades de enseñanza;

IV - formas de realización de la interdisciplinariedad;

$V$ - modos de integración entre la teoría y la práctica;

VI - las formas de evaluación de la enseñanza y el aprendizaje;

VII - modalidades de integración entre grado y postgrado, en su caso;

VIII - cursos de posgrado "lato sensu" en las modalidades integradas y/o posteriores a la graduación, de acuerdo con la aparición de las diferentes manifestaciones teóricas y prácticas y la tecnología aplicada a la zona de grado y postgrado, de acuerdo a las demandas reales del rendimiento en el trabajo ;

IX - fomento de la investigación, como la extensión necesaria de la actividad de aprendizaje y como una herramienta para la iniciación científica;

$X$ - diseño y composición de las actividades curriculares supervisadas, sus diferentes formas y condiciones, con sujeción a los reglamentos respectivos;

$X I$ - diseño y composición de las actividades complementarias;

XII - inclusión opcional de la realización del trabajo de conclusión de curso en las modalidades monografía, investigación a nivel de pregrado o proyectos universitarios de investigación en el ámbito de las actividades centradas en el área teoría-práctica o de entrenamiento en la forma establecida en sus propios reglamentos.

Cuanto a las características que se desarrollarán durante la formación de profesionales del diseño, el texto de la ley, en su artículo 4, señala las siguientes competencias y habilidades:

I - capacidad creativa para ofrecer soluciones innovadoras mediante el dominio de técnicas y el proceso creativo;

II - capacidad de poseer el dominio de la lengua que expresa conceptos y soluciones para sus proyectos, de acuerdo con las diferentes técnicas de expresión y reproducción visual;

III - capacidad de interactuar con expertos de otros campos a utilizar diferentes conocimientos y el trabajo en equipos interdisciplinares en la elaboración y ejecución de investigaciones y proyectos;

IV - visión sistémica del proyecto, mostrando capacidad de le conceptualizar por la combinación adecuada de los diversos componentes tangibles $e$ 
intangibles, procesos de fabricación, los aspectos económicos, psicológicos y sociológicos del producto;

$V$ - dominio de las diferentes etapas del desarrollo de un proyecto, a saber: el establecimiento de objetivos, las técnicas de recogida y procesamiento de datos, generación y evaluación de alternativas, configuración de la solución a y presentación de informes de resultados;

$\mathrm{VI}$ - conocimiento del sector productivo de su especialización, revelando sólida visión del sector, relacionado con el mercado, los materiales, los procesos de producción y tecnologías, incluyendo muebles, ropa, zapatos, joyas, cerámica, embalaje, artefactos de todo tipo, los rasgos culturales de la sociedad, software y otras manifestaciones regionales;

VII - dominio de la gestión de la producción, incluyendo la calidad, la productividad, la disposición física de la planta, inventario, costos $e$ inversiones, además de la gestión de los recursos humanos para la producción;

VIII - visión histórica y visión de futuro, centrándose en los aspectos socioeconómicos y culturales, mostrando conciencia de las implicaciones de la actividad económica, social, antropológica, ambiental, estética y ética.

En el artículo 5 del texto se describe que los cursos deben tener en cuenta en sus contenidos curriculares y actividades que cumplan con los siguientes ejes interconectados de formación:

I - Contenidos básicos: estudio de la historia y de las teorías de diseño en sus contextos sociológicos, antropológicos, psicológicos y artísticas, técnicas y métodos que abarcan diseños, medios de representación, comunicación y estudios de la información por parte del usuario/objeto/medio ambiente, materiales de estudio, los procesos, la gestión y otras relaciones con la producción y comercialización;

II - contenido específico: estudios relacionados con la producción artística, producción industrial, comunicación visual, la interfaz, la moda, la ropa, interiores, paisajismos, diseño y otras producciones artísticas que revelan el uso adecuado de los espacios y correspondan a los niveles de satisfacción personal;

III - contenidos teórico práctico: dominios que integran el enfoque teórico y la práctica profesional, más allá de actuaciones peculiares supervisadas, incluyendo la ejecución de las distintas actividades complementarias compatibles con el perfil deseado del alumno.. 
El plan de estudios del grado de diseño debe establecer las condiciones para la realización efectiva del currículo, de acuerdo con los regímenes académicos adoptados por las instituciones de la educación superior: sistema de régimen anual, seriado semestral, sistema de créditos con inscripción por módulos o disciplina académica, con la adopción y el requisito previo, asistiendo a las disposiciones de la Resolución.

La resolución versa, sin embargo, en los procedimientos de prácticas supervisadas (artículo 7), actividades complementarias (artículo 8) y Proyecto de Graduación. En cuanto a las prácticas supervisadas, se establece que la institución debe emitir sus propios reglamentos, aprobados por su Junta de Administración Escolar, que deben contener, de forma obligatoria, criterios, procedimientos y mecanismos de evaluación. Esta misma regla debe, sin embargo, cumplir con las características observadas en la ley.

Asimismo, se establece la obligación de cumplir con una carga de trabajo de las actividades complementares, es decir, componentes curriculares que permitan el reconocimiento, por evaluación, de las habilidades, los conocimientos y capacidades del estudiante, incluyendo los adquiridos fuera de la escuela y la práctica de los estudios y actividades independientes, opcionales, interdisciplinarias, incluidas las actividades de extensión en la comunidad.

En cuanto al Trabajar de Conclusión de Curso (TCC), la resolución establece que se trata de un componente opcional de la institución de educación superior que, si aprobado, pude desarrollarse en las modalidades monografía, proyecto de iniciación científica, o proyectos universitarios de investigación centrados en las actividades de las áreas de formación teórica y práctica y de formación relacionados, conforme a lo dispuesto en las normas específicas. Cuando la institución optar por incluir el TCC en el plan de estudios en Diseño, también debe emitir sus propios reglamentos aprobados por el Consejo Académico.

La duración del curso universitario en Diseño aparece en el Parecer CNE / CES $n{ }^{\circ}: 329 / 2004$, aprobado en: $11 / 11 / 2004$, que se ocupa de las horas mínimas del curso de grado presencial. En este dictamen se establece una carga lectiva mínima de $\mathbf{2 . 4 0 0}$ horas para los cursos de Diseño.

El dictamen CNE / CES $n{ }^{\circ}$ : 329/2004 señala también que las etapas y actividades complementarias, ya incluidos en el cálculo de la carga de trabajo total del curso, no debe exceder el $20 \%$ del total, a excepción de los cursos con requisitos legales específicos tales como del curso de la medicina. De acuerdo con los principios que definen el plan nacional de estudios de cursos de grado, su duración debe aparecer en su Proyecto Pedagógico elaborado por la institución y debe ser considerado como "carga de trabajo a realizarse en el pago del plan de estudios." 
Por lo tanto, es evidente que la duración de los cursos deberá ser establecida por la carga de trabajo total del currículo, cumplida en el conjunto de tiempo académico definidos por la Ley $N^{\circ}$ 9.394/96 - LDB (Ley de Directrices y Bases), al menos 200 días para el año académico escolar y cada institución aplicará el volumen de carga de trabajo a realizarse ofrecidas de forma semestral o por sistema de módulos académicos.

\subsection{Innovación: Conceptos y fundamentos teóricos}

Para una mejor comprensión sobre el tema de esta investigación es necesario conocer primero las principales definiciones y aspectos teóricos que orientan el enfoque sobre Innovación. Por lo tanto, se presentan, a continuación, los conceptos presentes en los principales manuales internacionales (Manual de Oslo, Manual de Bogotá y en el Manual Frascati) más allá de los enfoques que se encuentran en la literatura y que proporcionarán una base para el desarrollo de este trabajo.

\subsubsection{Los conceptos de innovación}

Con respecto a los conceptos de innovación fueron considerados dos manuales internacionales considerados referencia en este asunto: el Manual de Frascati de 2002 que presenta una definición de innovación tecnológica más usual y el Manual de Oslo de 2005 que trae una definición más amplia.

El Manual Frascati (OCDE - Organización para la Cooperación y el Desarrollo Económico) apud Sáenz e García (2002) considera Innovación Tecnológica como:

La transformación de una idea en un producto nuevo o mejorado que se introduce en el mercado, o en nuevos sistemas de producción y su distribución, comercialización y uso. También se entiende por Innovación Tecnológica, una mejora sustancial de los productos o procesos existentes (Sáenz e García, 2002, p.72).

Según el Manual de Oslo (2005) una Innovación es "la implementación de un producto (o servicio) nuevo o significativamente mejorado, o de un proceso, o de un nuevo método de comercialización, o de un nuevo método de marketing, o de un nuevo método organizativo en las prácticas comerciales, o en el lugar de trabajo, o en sus relaciones exteriores ". Esta definición de Innovación cuenta con una amplia gama de innovaciones posibles, una Innovación se puede clasificar por la aplicación de uno o más tipos de Innovación, por ejemplo, innovaciones de productos y procesos. 
El Manual de Oslo (OCDE, 2005) adopta una definición de innovación que se distingue de las presentadas en ediciones anteriores. Esta conceptualización describe cómo Innovación dos cuestiones que antes no estaban considerados en las definiciones tradicionales: Innovación Marketing e Innovación Organizacional. Este cambio tiene una importancia fundamental, ya que destaca el papel de estos dos aspectos que fueron desatendidos en otros entornos sobre el tema.

Tidd, Bessant e Pavitt (2008) en su estudio sobre innovación apuntan cuatro tipos de innovación (Figura 04):

- Innovación de productos: los cambios en las cosas (productos/servicios) que una empresa ofrece;

- Innovación de Proceso: el cambio en la forma en que los productos/ servicios son creados y entregados;

- Innovación de Posición: los cambios en el contexto en el que los productos/ servicios se introducen;

- Innovación de paradigma: cambios en los modelos mentales subyacentes que guían lo que la empresa hace.

Figura 04 - El espacio de la innovación

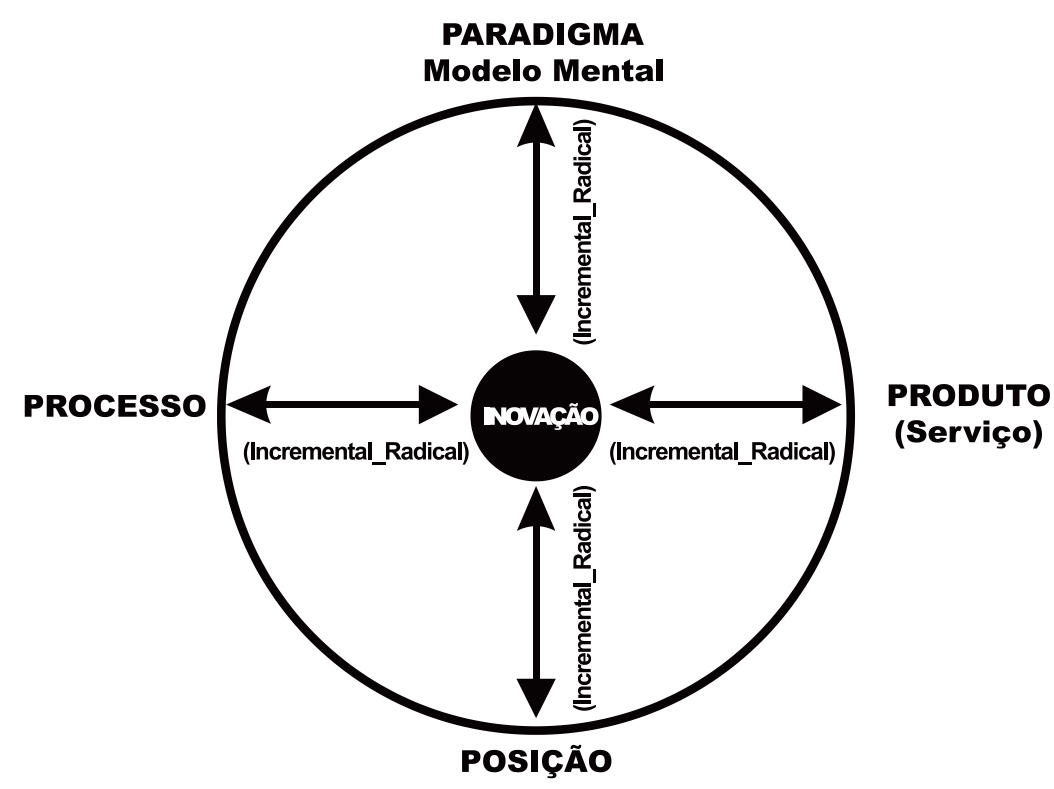

Fuente: Tidd, Bessant e Pavitt (2008) 
Aún de acuerdo con el Manual de Oslo da OCDE (2005, p.17):

\begin{abstract}
Las innovaciones organizacionales no son sólo un factor de apoyo para las innovaciones de producto y proceso, pues pueden tener un impacto importante sobre los resultados empresariales. Innovaciones organizacionales también pueden mejorar la calidad y eficiencia del trabajo, mejorar el intercambio de información, refinar la capacidad empresarial de aprender y utilizar el conocimiento y las tecnologías. [...] Y asignar grandes cantidades de recursos para la investigación de mercados y para el desarrollo de nuevas prácticas de comercialización, con objetivo en nuevos mercados o segmentos de mercado y desarrollar nuevas formas de promocionar sus productos. Las nuevas prácticas de comercialización pueden jugar un papel central en el desempeño del negocio.
\end{abstract}

El Manual también explota el contorno de cada uno de los tipos de Innovación mostrados en la definición:

- Innovación de producto - la introducción de un bien o servicio que es nuevo o significativamente mejorado con respecto a sus características o usos previstos. Esto incluye mejoras significativas en especificaciones técnicas, componentes y materiales, software incorporado, facilidad de uso u otras características funcionales.

- Innovación de proceso - la aplicación de un método de producción o distribución de nuevo o mejorado de manera significativa. Esto incluye cambios en las técnicas, equipo y / o software.

- Innovación de Marketing - la implementación de un nuevo método de comercialización con cambios significativos en el diseño del producto o en el envase, en el posicionamiento del producto y en su promoción o precio.

- Innovación Organizacional - la aplicación de un nuevo método organizativo en las prácticas comerciales de la empresa, en la organización de su lugar de trabajo o en sus relaciones exteriores.

Se observa en esta definición de innovación adoptada en el Manual de Oslo características similares a las propuestas en la definición de los tipos de Innovación de Tidd, Bessant y Pavitt (2008), donde, además de la clásica de división de Innovación en productos y procesos, también existen los conceptos de: Posición de Innovación que abarca la introducción de los productos/ procesos en el mercado (lo que salva similitud con la definición de Innovación de marketing) y el Paradigma de la Innovación, que se refiere a los modelos mentales que guían la actividad de la empresa (el concepto que se identifica con Innovación Organizacional).

Además de presentar la definición, el Manual de Oslo recomienda también diferencian aspectos de la Innovación Organizacional de otros cambios en la organización, destacando que se caracteriza por la adopción de un método de 
organización (en las prácticas comerciales, la organización del local, trabajo o las relaciones exteriores) que no ha sido aplicado con anterioridad en la organización, siendo el resultado de las decisiones estratégicas tomadas por la dirección.

Las innovaciones organizacionales en las prácticas comerciales implican en la creación de nuevas rutinas y procedimientos para la realización de los trabajos. Las innovaciones en la organización requieren la implementación de nuevas formas de responsabilidad compartida y el poder de toma de decisiones entre los empleados, la división del trabajo existente dentro de las actividades de la empresa (y unidades organizativas). Nuevos métodos de organización en las relaciones exteriores de la empresa incluyen la implementación de nuevas formas de organizar las relaciones con otras empresas o instituciones públicas, tales como el establecimiento de nuevos tipos de colaboraciones con organizaciones de investigación o consumidores.

La innovación afecta a uno o más sectores de la economía ya que, como se ha indicado en el concepto anterior, sólo se materializa en el mercado y a veces los cambios producidos por ella pueden llegar hasta a afectar a la economía como un todo, como fue el caso con el advenimiento del ordenador. La innovación combina las necesidades sociales y las exigencias del mercado como medios científicos y tecnológicos para tratar de resolverlos.

Para Sáenz y García (2002) las innovaciones se clasifican en:

1. Innovaciones radicales: originan transformación histórica en la manera de hacer las cosas, basada en un concepto totalmente nuevo en relación a lo que estaba en vigor, la apertura de nuevos mercados, campos de actividad y el comportamiento;

2. Las innovaciones incrementales o de mejoras: Son las que traen una mejora para una tecnología ya existente;

3. Innovaciones inferior: traen mejoras pequeñas en algo que ya existe, pero no traen cambios significativos en el nivel tecnológico.

Las innovaciones también pueden clasificarse de acuerdo a cómo surgieron:

- Empujadas por la ciencia (science pushed): son generalmente las radicales y surgen de los nuevos conocimientos obtenidos en investigaciones y de la identificación de nuevas soluciones a las necesidades existentes. Su carácter ofertista. Generalmente producen saltos grandes en el nivel tecnológico.

- Impulsada por la demanda (science pulled): son generalmente innovaciones incrementales, más pequeños y, en este caso, surgen de una necesidad social o productiva, explícitamente vinculada a una demanda que está presionando por una solución. 
Se enfatiza también el modelo de estructura del proceso de innovación, indicado en el Manual de Oslo (OCDE, 2005), que se muestra en la Figura 05, y que propone una integración de las visiones de diversas teorías de la innovación basada en los enfoques que asumen la Innovación como un sistema cuya principal características de su estructura son: Innovación en los negocios, las interacciones con otras empresas e instituciones de investigación, la estructura institucional en el que operan las empresas y el papel de la demanda.

Figura 05 - Estructura del proceso de innovación

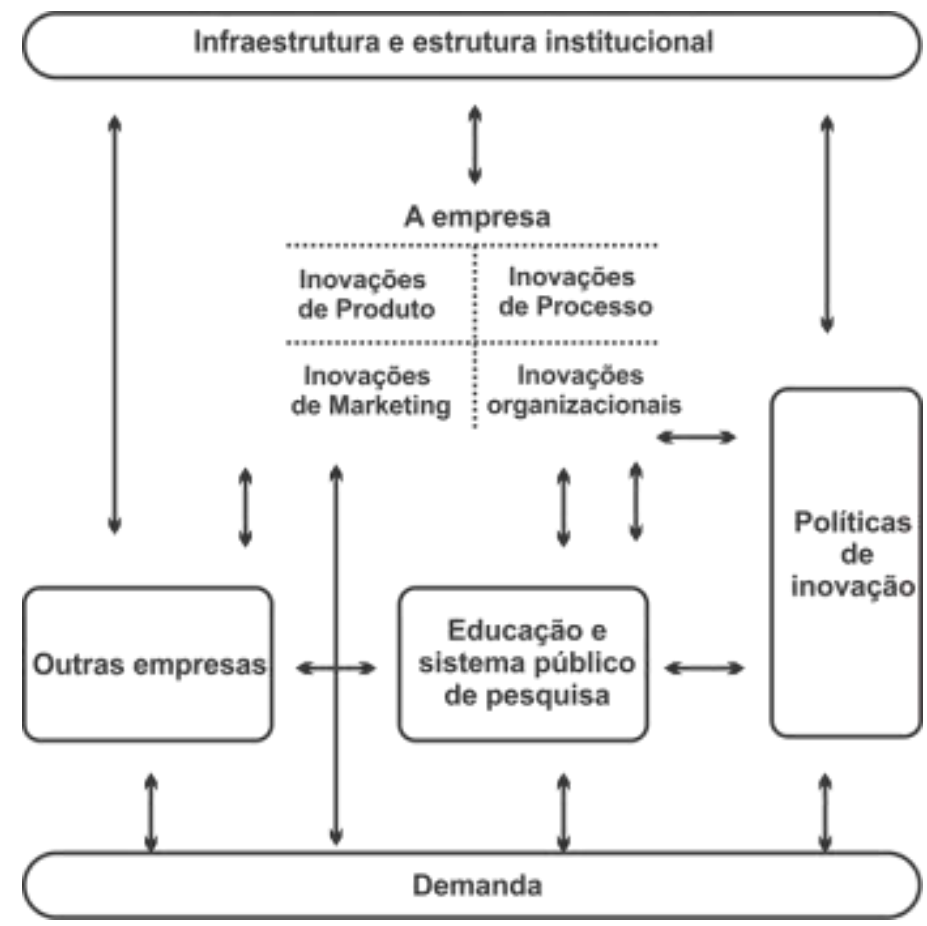

Fuente: Manual de Oslo (OCDE, 2005, p.42)

\subsubsection{Actividades innovadoras}

Otro concepto importante para el desarrollo de esta investigación es el de Actividades Innovadoras. Según el Manual de Oslo (OCDE, 2005), estas actividades son los pasos científicos, tecnológicos, organizacionales, financieros y comerciales que tratan de dirigir a la implementación de innovaciones. Algunas actividades de Innovación son en sí innovadoras, otras no son actividades nuevas pero son necesarias para la puesta en práctica de 
las innovaciones. Las actividades de innovación también están incluidas en el P\&D que no está directamente relacionado con el desarrollo de una Innovación específica.

Lasmar (2005) señala que el concepto de actividades innovadoras del Manual de Oslo se magnifica por el Manual de Bogotá (Jaramillo et al, 2001), que trata de las condiciones específicas en que se desarrollan las actividades de innovación en los países de América del Sur y el Caribe y los impactos de los mismos, cambiando el foco de análisis de la innovación en sí para el esfuerzo tecnológico y de gestión de las actividades innovadoras. El Manual de Bogotá refuerza diciendo que "por supuesto, no todas las actividades de innovación resultan en innovaciones efectivas, pero todas las innovaciones reales deben ser vistas como resultado de una serie de actividades innovadoras de la empresa". (Manual de Bogotá, 2001, p.34).

Filho, Pimenta e Lasmar (2008) reportan que los estudios sobre la práctica de la innovación en Brasil han demostrado que el país tiene la capacidad de generar alto nivel de conocimiento, pero por otro lado tiene problemas para que ello se convierta en productos o sean aprovechados en empresas, señalando que uno de los factores que influyen en esta realidad es que sólo el $23 \%$ de los investigadores en Brasil desarrolla estudios en laboratorios industriales, lo que no ocurre en otros países en desarrollo, como Corea del Sur, por ejemplo. El informe FORTEC 2012 (Foro Nacional de Gestores de Innovación y Transferencia de Tecnología), revela que el norte de Brasil creció un $33 \%$ en la creación de organismos centrados en innovación.

Filho, Pimenta e Lasmar (2008) también destacan que, a menudo, la medición de la Innovación es hecha mediante indicadores que se centran en la cantidad de patentes y otros factores relacionados con la I + D (Investigación y Desarrollo), sin embargo, la mayoría de las actividades que crean un entorno propicio para la generación de innovación no están sólo dirigidos a la I + D. Por lo tanto, debido a las especificidades de los países de América del Sur y el Caribe, es más apropiado que las análisis en esta área se dirijan a la gestión de las actividades innovadoras, incluso cuando el esfuerzo de las empresas para elevar su colección de tecnología, llamada "esfuerzo tecnológico" (Manual de Bogotá, p. 36 - Jaramillo et al, 2001).

Acerca de las articulaciones entre la innovación y las estrategias empresariales el Manual Bogotá (2001, p.34) destaca tres puntos que merecen atención:

a) las actividades innovadoras de las empresas deben ser analizados en su relación con las estrategias diseñadas para buscar mejoras en el uso de las oportunidades competitivas para incrementar la rentabilidad y el crecimiento del mercado específico en el que operan, las estrategias dependen de cómo las empresas responden a las nuevas exigencias para la apertura y la 
globalización, un hecho que está estrechamente relacionado con la acumulación de capacidades tecnológicas: una mayor capacidad para responder con más probabilidades de beneficiarse de las oportunidades.

b) Dado que los esfuerzos de restructuración la sociedad en América Latina han mostrado un fuerte énfasis en la modernización organizativa y las inversiones en el cambio técnico, el análisis de la actividad innovadora debe prestar especial atención a estos aspectos.

c) Los determinantes de las decisiones de inversión y las condiciones en que se desarrollan también debe considerarse con especial atención porque influyen decisivamente en las posibilidades de las empresas que realizan actividades de innovación.

\subsubsection{Capacidades dinámicas}

Otro concepto de relevancia para el estudio es el de Capacidades Dinámicas propuesto por Teece, Pisano y Shuen (1997) que son las "habilidades de organización para integrar, construir y reconfigurar competencias internas y externas para hacer frente rápidamente a los cambios del entorno en el que el término Dinámico se refiere a la capacidad de renovar competencias para lograr congruencia con el ambiente cambiante de los negocios. El término Capacidades destaca el papel clave de la gestión estratégica en adaptarse de forma adecuada, integrar y reconfigurar los recursos organizativos internos y externos y habilidades para cumplir con los requisitos funcionales.

Este concepto, también es tratado por Tidd, Bessant y Pavitt (2008) que presentan tres dimensiones de la estrategia innovadora: los procesos de gestión, la situación actual y los caminos disponibles para la organización. Los procesos de gestión son los medios, las formas de trabajo, la rutina de los negocios. La posición actual significa "los activos tecnológicos y propiedad intelectual de la empresa" y, finalmente, caminos disponibles significa tratan de cuales estrategias representan alternativas a la organización.

Melo y Paulilo (2005) refuerzan las bases de las capacidades dinámicas se organizan en tres bloques: a) El aprendizaje de nuevas habilidades b) las fuerzas internas y externas a la empresa que dirigen el proceso de aprendizaje y adaptación; y c) el medio ambiente de selección en el que la empresa compite por mayores recursos (políticos, constitucionales, organizativas, financieras y tecnológicas) 


\subsubsection{La Innovación como Sistema}

Como se muestra en la Figura 06, Sáenz y Capote (2002) sostienen que las tendencias modernas en innovación tecnológica indican que ella debe ser entendida como un sistema, es decir, se debe considerar todas sus interacciones y retroalimentaciones, de lo contrario puede conducir a graves errores en la planificación y gestión de procesos innovadores.

Figura 06: Esquema Sistémico de una Innovación Tecnológica

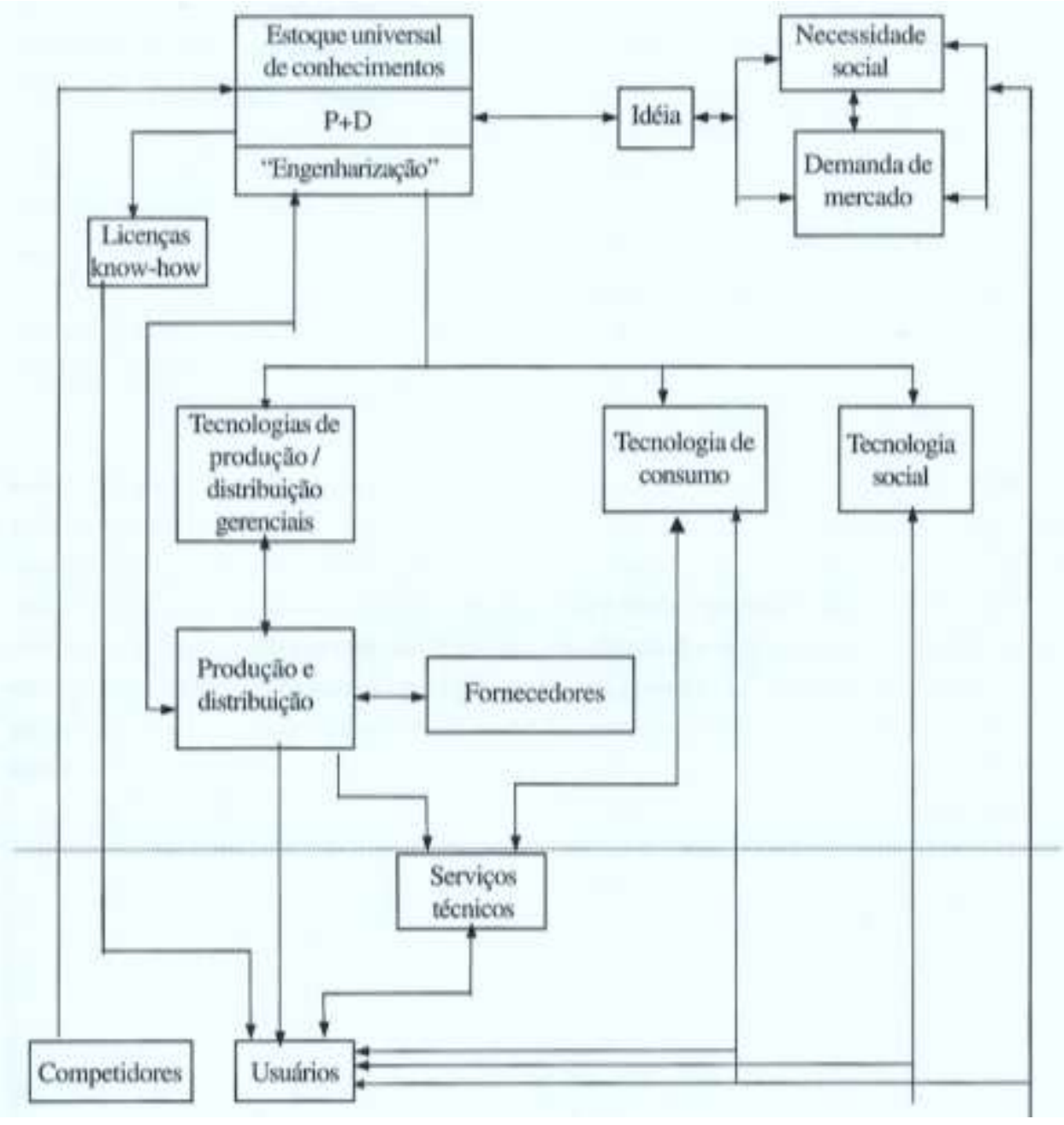

Fuente: Saénz e Capote (2002, pag. 89) 
El diagrama mostrado en la figura 06 representa un proceso de innovación sistémica simplificado, desde los tipos de tecnología que pueden ser generados a través de acciones coordinadas de I $+D$, así como funciones de su producción y distribución, hasta su llegada al usuario final a través de la comercialización.

\subsubsection{Los Sistemas de Gestión de la Innovación (SGI)}

Según Longanezi (2008) el proceso de innovación, debido a la inmensa cantidad de variables y al grado de riesgo considerable que implica, se caracteriza por ser de naturaleza compleja, incierta y desordenada. No es suficiente solo querer innovar, son necesarios elementos considerados importantes como la organización, la estrategia, el apoyo y el espíritu empresarial, entre otros y así como en otros procesos, su manejo requiere un conocimiento profundo y amplio del tema. Por lo tanto, la innovación no tiene manera de distanciarse del tema de sistemas de gestión, siguiendo el ejemplo de otras áreas.

Así, según el autor, surge la aplicación de sistemas de gestión que regulan actividades específicas, e incluyen la estructura organizacional, las actividades de planificación, las responsabilidades, las prácticas, los procedimientos, los procesos y los recursos para su desarrollo.

El objetivo de SGI es ayudar en la identificación y evaluación de las amenazas y oportunidades, la mejora continua de productos y procesos, optimizando el uso de recursos, el aumento de la productividad, el aprendizaje continuo, la estandarización, el intercambio de información, la toma de decisiones y una mejor análisis (Coutinho et al, 2006) . Estos sistemas, de manera integrada, contribuyen al logro de la visión estratégica establecida.

Para tener éxito, el diseño y la implementación de un sistema de gestión debe estar influenciado por el tipo de actividad y necesidades particulares de cada organización, como tamaño y estructura, el tipo de productos, servicios y procesos empleados.

\subsubsection{Elementos básicos de un Sistema de Gestión}

También según Longanezi (2008) para que un sistema de gestión de Innovación sea construido, así como en cualquier otro ámbito, debe ser apoyado por tres pilares - sin los cuales no tendría apoyo. Estos pilares están representados por: 
- Herramientas: desarrolladas o adaptadas para el uso en cuestión, cuyo objetivo específico es de facilitar la gestión de proyectos y gestión de la cartera de Innovación. Actualmente, la mayoría de las herramientas es presentada en forma de software.

- Procesos: establecidos mediante la aplicación de una metodología de trabajo, generalmente desarrollada o adaptada según los modelos dispuestos en la literatura, el proceso tiene la función de guiar la organización en los procedimientos y normas hacia la innovación.

- Organización: comprendida por la gente, por la cultura organizacional, por el conocimiento y las habilidades para innovar, entre otros elementos de la misma naturaleza. La organización es la parte más compleja del sistema y responsable de "hacer que las cosas sucedan" en Innovación.

Aunque las herramientas tengan un papel importante para el funcionamiento del sistema, ellas pueden adaptarse de otras áreas y por lo tanto sólo las más relevantes serán discutidas aquí. Puede citarse como ejemplo de herramientas y técnicas la análisis DAFO adoptada en este estudio.

El proceso, a su vez, es algo específico. Para que el sistema tenga éxito, el proceso debe ser establecido a través una metodología que tenga en cuenta las peculiaridades y las dimensiones críticas de la Innovación. Esta metodología debe describir claramente cada paso del proceso, los procedimientos y las actividades en las diferentes etapas, establecer interfaces entre las distintas áreas de la organización, para dictar las normas de uso de las herramientas y definir las funciones y responsabilidades.

El tercer y el más complejo de los pilares es la organización en su conjunto. Comprende las personas involucradas en el proceso, desde las más altas esferas de la planta de producción, la cultura organizacional (que puede ser favorable o resistente al proceso de innovación), la estructura organizacional que puede ser adecuada o necesitar de ajustes en el funcionamiento del sistema, el conocimiento y las habilidades necesarias para la Innovación, más allá del entorno en el que opera.

\subsubsection{Definición de empresa y organización}

Al estudiar el concepto de innovación es común encontrarse con bastante frecuencia con el uso de los términos "empresa" y "organización", es importante, por lo tanto, una definición de estos términos con el fin de posicionarnos, el objeto de estudio, el curso de Design de UFAM dentro de los contornos relacionados a innovación presentados en este documento. 
Coelho (2007, p. 17) define empresa como:

[...] un conjunto organizado de recursos para la ejecución de una actividad en particular, de economía pública o mixta, que produce y entrega de bienes y/o servicios, con el fin de responder a una necesidad humana [...]. Las empresas de propiedad del Gobierno están orientadas a la obtención de rentabilidad social. [...]

El autor señala que, independientemente del tamaño de la empresa, o bien, sea ella con o sin fines de lucro, es necesario adoptar conceptos administrativos que ayuden a su desarrollo, entre los que se destacan los principios defendidos por la Teoría Sistémica: Planificación, Organización, Coordinación y Control, por lo que el concepto de administración podrá ser dada por el acto o efecto de organizar, crear organismos que comprenden un conjunto de órganos que constituyen una empresa.

Al igual que el concepto de empresa, la definición del término "organización" ha sido objeto de mucho debate e investigación. Enfatizase el concepto de Kanaane $(1994$, p.30) que dice que la organización es "un sistema social establecido por el conjunto de valores expresados por los individuos que forman parte de ella, siendo asimilada y transmitida sucesivamente por las mismas".

Srour (1998) establece que la organización es una especie de colectividad, con objetivos bien definidos, que se especializa en la producción de un determinado tipo de bien o servicio por el cual se combinan los actores sociales y los recursos necesarios para que se conviertan en un esfuerzo donde las acciones de cooperación tienen lugar de manera ordenada.

A partir de los conceptos expuestos se puede observar que el Curso de Design, objeto de este estudio, se puede considerar dentro de los límites de las dos definiciones, empresas y organización, ya que se trata de un grupo organizado de personas y medios, con objetivos definidos, que ofrece servicios en el ámbito de la formación del personal de nivel superior en Diseño, sin fines de lucro, a través de una entidad pública, en busca de un retorno social. Por lo tanto, el curso se encaja dentro de los conceptos de empresa de Coelho (2007) y de organización propuesto por Kanaane (1994) y Srour (1998).

\subsubsection{La Relación entre Academia e Industria en Brasil}

Natividad (2001) señala que, en la actualidad, el crecimiento económico ya no depende exclusivamente de un nuevo ciclo de innovación, sino más bien una estructura que conecte de manera más profunda la investigación básica y aplicada. 
Según el autor, se observó a partir de la década de 80 un interés internacional en una mayor integración entre la comunidad académica y las empresas en las que el gobierno y las políticas públicas que actuarían como un catalizador para la integración. Natividad (2001) también describe que este proceso de acercamiento entre la empresa, la universidad y el Estado es reciente en Brasil, pero cada vez más, tanto en escala nacional y regional, se están tomando medidas para evitar el aislamiento de cada una de estos actores, pero esta relación es todavía insipiente.

Sobre la relación entre la universidad, la industria y el gobierno, los autores Etzkowitz y Leydesdorff (1997) formularon el concepto de la triple hélice.

\subsubsection{El Enfoque de la Triple Hélice}

Concepto esencial a la investigación sobre las relaciones entre las universidades, la industria y el gobierno, la Triple Hélice se desarrolló a partir de los estudios de Etzkowitz y Leydesdorff (1997) y es caracterizada a partir de la dinámica de la innovación en el contexto de la evolución, donde se establecen relaciones entre tres esferas institucionales, involucrando a tres actores diferentes: la universidad, el sector privado y el gobierno, creando tres palas distintas de una misma hélice (figura 07).

Las relaciones resultantes entre las transformaciones internas en cada hélice ejercen una influencia sobre las otras, creando nuevas redes que surgen de la interacción entre las tres hélices, generando un efecto recursivo de estas redes tanto en espirales de donde emergen y en la sociedad como un todo.

Figura 07 - Modelo de Interacción del campo de la triple hélice

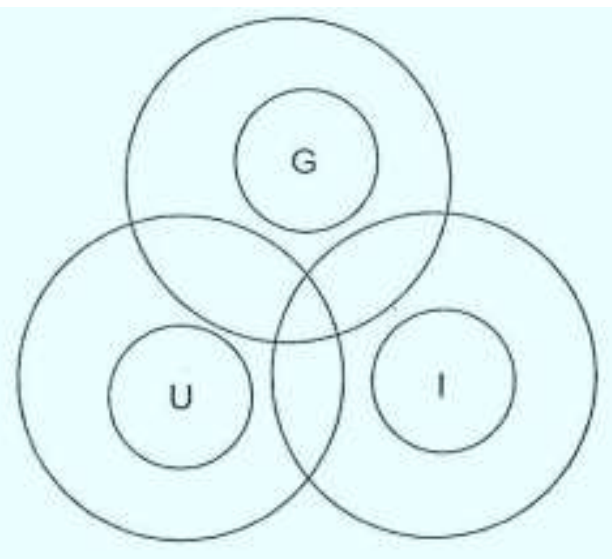

Fuente: Etzkowitz (2009) 
Etzkowitz (2009) subraya la importancia del espíritu empresarial y argumenta que el gobierno y la universidad también deben tener un papel emprendedor. Las universidades emprendedoras, representan, según el autor, un papel clave dentro de la hélice debido a sus esfuerzos para la transferencia de Innovación regional, transferencia de tecnología y la incubación de empresas, entre otros aspectos.

\subsubsection{Resumen de los fundamentos teóricos sobre innovación}

Se observa que los fundamentos teóricos sobre innovación presentados en este capítulo tienen características similares entre sí (Tabla 01):

Tabla 01: Características de las definiciones de Innovación

\begin{tabular}{|c|c|c|}
\hline Fundamentos teóricos & Características & $\begin{array}{l}\text { Puntos en común } \\
\text { entre las teorías }\end{array}$ \\
\hline $\begin{array}{l}\text { Definición de Innovación } \\
\text { (Manual Frascati, OCDE, } \\
\text { 2002) }\end{array}$ & $\begin{array}{l}\text { Innovación - producto en el } \\
\text { mercado }\end{array}$ & \\
\hline $\begin{array}{l}\text { Definición de Innovación } \\
\text { Organizacional (Manual } \\
\text { de Oslo, OCDE, 2005) }\end{array}$ & $\begin{array}{l}\text { Introducción de innovación de } \\
\text { marketing e innovación } \\
\text { organizacional. } \\
\text { Prácticas de negocios } \\
\text { Organización del local de trabajo. } \\
\text { Relaciones externas. }\end{array}$ & \multirow{3}{*}{$\begin{array}{l}\text { La preocupación } \\
\text { acerca de la } \\
\text { organización } \\
\text { institucional, las } \\
\text { prácticas y las } \\
\text { rutinas de trabajo } \\
\text { y fuerzas internas } \\
\text { que impulsan el } \\
\text { proceso de } \\
\text { innovación. }\end{array}$} \\
\hline $\begin{array}{l}\text { Definición de innovación - } \\
\text { Tidd, Bessant e Pavitt } \\
(2008)\end{array}$ & $\begin{array}{l}\text { Innovación de posición: cambios } \\
\text { en el contexto en que los } \\
\text { productos/servicios son } \\
\text { introducidos; } \\
\text { Innovación de paradigma: cambios } \\
\text { en los modelos mentales que } \\
\text { orientan lo que a empresa hace; }\end{array}$ & \\
\hline $\begin{array}{l}\text { (Modelo de proceso } \\
\text { inovativo Manual de Oslo, } \\
\text { OCDE, 2005) }\end{array}$ & $\begin{array}{l}\text { la innovación en la empresa, } \\
\text { interacciones con otras empresas e } \\
\text { instituciones de pesquisa } \\
\text { estructura institucional y el papel } \\
\text { de la demanda }\end{array}$ & \\
\hline
\end{tabular}

Fuente: revisión de literatura

En la Tabla 02 que sigue, se presenta un resumen de los principales enfoques teóricos de la innovación y de sus características más llamativas: 
Tabla 02: Resumen de las características de la base teórica del estudio

\begin{tabular}{|l|l|l|}
\hline $\begin{array}{l}\text { Fundamentos } \\
\text { teóricos }\end{array}$ & Características & $\begin{array}{l}\text { Puntos en común } \\
\text { entre las teorías }\end{array}$ \\
\hline $\begin{array}{l}\text { Las actividades } \\
\text { innovadoras }\end{array}$ & $\begin{array}{l}\text { Diversas actividades que llevan a la } \\
\text { aplicación de innovaciones (todos los } \\
\text { científicos, tecnológicos, } \\
\text { organizativos, financieros y } \\
\text { comerciales) }\end{array}$ & $\begin{array}{l}\text { La preocupación con las } \\
\text { relaciones externas: } \\
\text { relación e interacción con } \\
\text { el mercado/demanda y } \\
\text { otros actores en el proceso } \\
\text { tales como: sociedad, } \\
\text { empresas, gobierno e } \\
\text { industria. }\end{array}$ \\
\hline $\begin{array}{l}\text { Capacidades } \\
\text { Dinámicas }\end{array}$ & $\begin{array}{l}\text { habilidades empresariales para } \\
\text { integrar, construir y reconfigurar las } \\
\text { competencias internas y externas } \\
\text { para hacer frente a rápidos cambios } \\
\text { ambientales }\end{array}$ & $\begin{array}{l}\text { La preocupación por la } \\
\text { dinámica entre los } \\
\text { involucrados en el proceso } \\
\text { innovador. }\end{array}$ \\
\hline $\begin{array}{l}\text { Enfoque de la } \\
\text { triple hélice } \\
\text { (Etzkowitz e } \\
\text { Leydesdorff, } \\
\text { 1997) }\end{array}$ & $\begin{array}{l}\text { Centrarse en las relaciones } \\
\text { establecidas entre las universidades } \\
\text { la industria privada y el gobierno. }\end{array}$ & \multicolumn{2}{|c|}{} \\
\hline
\end{tabular}

Fuente: revisión de literatura

Además de conocer los fundamentos de la innovación, es necesario incrementar el conocimiento de un aspecto importante que permea el estudio sobre el tema, la gestión y sus herramientas, entre las que destaca la gestión estratégica.

\subsection{Gestión Estratégica}

La gestión estratégica busca destacar, dentro de una organización, las diferencias que ella tiene con relación a las otras empresas. La gestión estratégica busca proporcionar una dirección estratégica, es decir, fijar valores de cuestiones como objetivos de la empresa y las iniciativas y los esfuerzos que deben ser concentrados para alcanzarlos.

Según Estevão (2001,p. 34):

La gestión estratégica es, a pesar de la dificultad de encontrar una definición universalmente aceptada, un proceso global destinado a la integración efectiva de la planificación estratégica (más preocupado por la eficiencia) y otros sistemas de gestión, mientras que hace responsable a todos los gerentes de línea por el desarrollo e implementación estratégica; es un proceso continuo de decisión que determina el comportamiento de la organización, teniendo en cuenta las oportunidades y amenazas que enfrenta en su propio ambiente, sino también las fortalezas y debilidades de la organización. 
Según Tachizawa (2001) la gestión estratégica es un proceso continuo, a través del cual una organización se orienta y elabora su misión, metas y objetivos, y selecciona las mejores maneras de lograr estos objetivos en un período determinado de tiempo. Este proceso debe ser flexible y adaptarse constantemente a las necesidades que surgen a lo largo de la vida de la empresa.

También según Tachizawa (2001), la gestión estratégica proporciona un conjunto de características que la distinguen de otros procesos (tales como la planificación estratégica, que es uno de sus componentes esenciales) entre los cuales señalamos los siguientes:

- es un proceso integral que incluye la orquestación de todos los recursos de la organización para obtener ventajas competitivas;

- es continua e interactiva, es decir, consiste en una serie de etapas que se repiten cíclicamente, lo que requiere reajuste continuo;

- proporciona un marco que guía la conducta de las otras fases de la gestión (por ejemplo, la fase de evaluación de recursos, desarrollo de programas, entre otros);

- valora la flexibilidad y la creatividad, manteniendo una articulación interna más ágil de todos los componentes y procesos organizativo;

- es difícil de lograr ya que requiere que la organización, en lugar de esperar el curso de los acontecimientos o de la crisis, corra el riesgo de elegir alternativas;

- tiene la ambición de construir el futuro de la organización, trabajando en un perspectiva a largo plazo.

La gestión estratégica es por lo tanto una gestión de diversos aspectos de la organización, entre ellos, los recursos, los procesos, la planificación y el control, con el fin de contribuir a la toma de decisiones de las acciones de la compañía.

La Gestión Estratégica actúa mediante la observación del entorno interno y externo de la organización, identificando sus fortalezas y debilidades (medio interno) y las oportunidades y amenazas (ambiente externo) que pueden servir como base para la planificación. 


\subsubsection{La Gestión Estratégica del Conocimiento y de la Innovación}

La gestión estratégica de la innovación implica sobre todo en el manejo de activos intangibles como el conocimiento.

De acuerdo con Bueno et al (2004, s.n.)

La Gestión Estratégica del Conocimiento requiere un equilibrio entre los trabajadores del conocimiento y los recursos tecnológicos, definiendo la competitividad de la empresa. La Gestión Estratégica del Conocimiento tiene como objetivo maximizar la utilización de los conocimientos en conjunto con las herramientas de tecnología de la información, proporcionando una ventaja estratégica. Su proceso de implementación en las empresas requiere un cambio cultural con el fin de comprometer a toda la organización. Cuanto más información disponible para la recogida y difusión del conocimiento y su gestión, mayor el poder de toma de decisiones en la empresa, generando importantes beneficios en términos de productividad, rentabilidad y competitividad.

Aún de acuerdo con el autor la gestión del conocimiento depende en gran medida de la gestión de la infraestructura de tecnología de la información, ya que esto permite que las personas involucradas tengan acceso a los datos que proporcionan un entorno de mejora continua. Dentro de este contexto, la cultura organizacional influye en todo el proceso de innovación, la implementación de una estrategia de una institución que promueva el intercambio de información es esencial.

\subsubsection{Gestión Tecnológica}

El término gestión tecnológica surgió hace varios años en la literatura latinoamericana, sus definiciones son variadas, sin embargo, la palabra "gestión" ha sido utilizada a menudo como sinónimo de la expresión "gerencia", es decir, la acción de dirección de procesos complejos para el desarrollo eficiente de los mismos.

Para este trabajo se adoptará el siguiente concepto de Sáenz y Capote (2002, p. 120):

La Gestión Tecnológica es la gestión sistemática de todas las actividades dentro de la empresa con respecto a la generación, adquisición, inicio de la producción, procesamiento y asimilación de las tecnologías requeridas por la empresa, incluida la cooperación y las alianzas con otras instituciones, también abarca el diseño, prácticas de promoción y gestión y herramientas para la captura y la información de producción para permitir la mejora continua y sistemática Calidad y la productividad.

En resumen, la Gestión Tecnológica es el uso de técnicas de gerencia para asegurar que la variable tecnológica sea utilizada a su máximo potencial como 
un soporte para los objetivos de la organización. En su teoría y su práctica se entrelazan conocimiento de diversos campos como la economía, la ingeniería y el marketing y design, entre otros.

La gestión tecnológica comprende un conjunto de decisiones en materia de: Prospectiva Tecnológica, Gestión Estratégica, Gestión de Proyectos de I + D (Investigación y Desarrollo), estudios de mercado y viabilidad técnica y económica, Transferencia de Tecnología, Diseño Industrial, Propiedad Intelectual, calidad del desarrollo de recursos humanos, la normalización, la metrología y la seguridad, comercio y comercialización de tecnología y servicios a los clientes.

La innovación tecnológica tiene su punto fuerte dentro de la empresa, la gestión de estas innovaciones tienen factores como:

- $\quad$ Planificación de la tecnología: Análisis de fortalezas y debilidades, análisis de los competidores, acompañamiento tecnológico y del contexto y desarrollo de programas de trabajo.

- Organización e integración de equipos de personal: definición, alcance, misión y líneas de acción, la delimitación de responsabilidades, plan de negocios, plan de recursos humanos, la motivación del personal.

- $\quad$ Adquisición y transferencia de tecnologías: conocimiento y evaluación de los mercados de tecnología, negociación con proveedores.

La competitividad viene determinada en gran medida por la capacidad de Innovación de la empresa y, en consecuencia, por la calidad de la gestión que se realiza. Esta capacidad se concreta en tres elementos: la calidad de sus productos, la calidad de sus servicios de comercialización y servicios posteriores a la venta y los precios. Algunas aspectos de estos factores pueden ser mejorados a través de una gestión eficiente de la información dentro de una organización, una herramienta fundamental en este proceso es actualmente la Tecnología de la Información ( $\mathrm{TI})$.

\subsubsection{Tecnología de Información}

La sociedad ha utilizado innovaciones a gran escala, a todos los niveles, provocando cambios profundos en la comunidad. Estos cambios han, por un lado, proporcionado facilidades y progresos, especialmente en lo que se refiere a las nuevas tecnologías.

Según Baker (apud Ortolani, 1995), "Tecnología de la Información es el conjunto de recursos no humanos dedicados al almacenamiento, procesamiento y transmisión de información y la forma en que estos recursos se organizan en un sistema capaz de ejecutar un conjunto de tareas." 
La TI no se limita a los equipos (hardware), programas (software) y a la comunicación de datos. Hay tecnologías relacionadas con la planificación de informática, desarrollo de sistemas, el apoyo al software, los procesos de producción y operación y soporte al hardware.

Según Ortolani (1995, sp) "Toda organización, pública o privada, tiene un público objetivo para el que opera la producción de bienes o servicios. Para los negocios, este es el público consumidor, mientras que para la organización pública, el público objetivo, en su última instancia, es un ciudadano. El recurso usado en ambos casos es la información".

El uso de las Tl's en el sector privado tiene como objetivo lograr el máximo de beneficios de esta tecnología con el fin de obtener una ventaja competitiva sobre sus competidores. La TI se convierte, por tanto, en una herramienta que está contribuyendo en la efectividad organizacional, dentro de la empresa y en la competitividad en el entorno externo de la organización.

\subsubsection{La Transferencia de Tecnología}

En Brasil, el Instituto Nacional de Propiedad Industrial (INPI) define la Transferencia de Tecnología como "el proceso por el cual un conjunto de conocimientos, habilidades y procedimientos aplicables a los problemas de la producción se transmitirá, por una transacción económica, de una organización a otra, ampliando la capacidad de Innovación de la organización receptora.".

Según Cysne (2005), la Transferencia de Tecnología, desde una relación más estrecha entre la industria y la academia, tiene como objetivo central apoyar a las empresas para mantener la competitividad y el país y a un desarrollo tecnológico sostenible, y ha sido un tema central de debate y de una amplia investigación desde 1950.

El autor señala que esto ocurre por la necesidad de comprender de manera más vertical lo que es la Transferencia de Tecnología, lo que ella implica, qué es exactamente lo que se está se transfiriendo, cómo y lo que se requiere en términos de capacidad de transferencia (tanto en el entorno del proveedor, como del receptor), que estructura debe ser instalada para garantizar su éxito.

Para Barbosa (2009), la Transferencia de Tecnología no implica, necesariamente, el comercio, teniendo en cuenta que pueden haber situaciones de transferencia de tecnología sin la comercialización integral de ella, ya que no toda la información necesaria para utilización similar de una tecnología en la organización receptora se puede pasar por el proveedor, y a 
menudo es necesario adaptar, ajustar, mejorar y asimilar el objeto de transferencia a las condiciones locales.

Bell \& Pavitt (1992) señalan que la acumulación tecnológica implica también el conocimiento tácito, en otras palabras, un conocimiento que a veces es de difícil codificación para otras personas o instituciones, pues es adquirida con la experiencia. Por lo tanto, frente a la complejidad de la transferencia, ella no se puede reducir a una simple práctica de aplicar y implica en "reglas" que no se pueden comprar. La transferencia de conocimiento tácito no es ni rápida ni sin costo, ya que requiere la compra de esta experiencia también.

La EEN (Enterprise Europe Network, 2011) recuerda que la Transferencia de Tecnología se puede clasificar como vertical u horizontal en función de su alcance:

- La transferencia de tecnología vertical se puede definir como el proceso de transferencia de la I + D para un entorno comercial. Este es un proceso que implica a menudo la gestión de los derechos de propiedad intelectual y también puede requerir la obtención de fondos y know-how para traducir la investigación que se hace sobre los productos terminados.

- La transferencia horizontal de tecnología es el proceso de obtención de una determinada tecnología que existe en un determinado mercado y transferirlo a otro mercado, generalmente menos desarrollado. Esto puede ser ejemplificado por la transferencia de productos con algún tipo de propiedad intelectual para los mercados de exportación. Normalmente, la entidad que realiza la transferencia tiene alguna experiencia en el uso y la venta de la tecnología en su entorno de mercado y la traducción a un mercado diferente puede necesitar un cierto desarrollo o actualización del producto / proceso.

Chamas y Müller (1998) describen que así como ese proceso de desarrollo de tecnología implica una gran incertidumbre ya que la tecnología tiene un componente tácito, el proceso de transferencia de tecnología también implica la incertidumbre y es siempre parcial y limitada, y apenas se puede producir en su totalidad. Un nivel mínimo de formación es necesario para identificar, seleccionar, negociar y adquirir la tecnología. Posteriormente, las soluciones a los problemas de la tecnología y a su asimilación y reproducción no siempre pueden ser proporcionadas por los proveedores a los destinatarios.

Para que haya ajuste, asimilación, y la mejora de la tecnología es necesario entrenar de nuevo las personas para llevar a cabo las tareas. Los esfuerzos internos con el fin de adaptar la tecnología a las condiciones locales por parte del receptor son indispensables. La Transferencia de Tecnología sólo es posible si el receptor tener capacidad tecnológica, de gestión, organizacional y funcional, suficientes para su realización. 
Para la realización de la innovación en las universidades son necesarios factores como:

- Autonomía: la autonomía es la base para la cooperación entre las universidades y el sector empresarial. Se puede argumentar que es esencial y sin ella las universidades, especialmente las públicas, no puede ni siquiera pensar en asociaciones, generalmente porque están atrapados por las leyes y burocracias excesivas propias del aparato del estado. Se destaca, sin embargo, que la Universidad Federal de Amazonas (a la cual el objeto de estudio actual está vinculado) es una institución pública subordinada al Gobierno Federal de Brasil y, por lo tanto, tiene una autonomía limitada.

- Comunicación: La comunicación es un requisito fundamental para ser considerado para la asociación. Una radio integrada, televisión, prensa e Internet siempre pueden mejorar las acciones de la Universidad, especialmente cuando notifiquen su potencial humano, los resultados de investigaciones o proyectos en curso.

- Formación de Capital Intelectual: sólo un bien intangible y que es verdaderamente indispensable - el capital intelectual- y que apoya a las instituciones tiene capacidad de promover la innovación. En este caso, sólo las instituciones que invierten en los cerebros de formación pueden interactuar con éxito.

- Educación y Entrenamiento de los Líderes: La Universidad tiene que crear mecanismos de formación y capacitación de los funcionarios en el ámbito de la gestión universitaria. Los líderes deben estar preparados no sólo para satisfacer y atender las necesidades académicas, sino también para gestionar un sistema moderno y complejo de interacción con la sociedad y sus diferentes sectores, incluida las empresas.

\subsection{El Enfoque Sistémico en la evaluación de la innovación}

Se observa que a lo largo de la revisión de la literatura sobre innovación y las capacidades organizacionales vueltas a ella es común el uso de términos relacionados con los "sistemas". Por lo tanto, es necesario entender mejor el contexto de este trabajo, una discusión sobre lo que es el pensamiento sistémico. 


\subsubsection{El pensamiento sistémico}

Según Caselles (2008) el paradigma que prevaleció hasta hace poco en la sociedad científica se basaba en las ideas mecanicistas de Descartes cuya característica principal era una visión de la fragmentación de las partes de un todo para la resolución de problemas, pensamiento que llevó a la especialización y a la división del conocimiento.

El autor destaca, sin embargo, que si bien hay ciertos tipos de problemas que se resuelven mejor por los expertos, también hay otra categoría, denominada "problemas complejos" que sólo pueden ser resueltos por un profesional o un equipo con conocimientos multidisciplinarios y es a partir de este contexto que nace la lógica del pensamiento sistémico.

Para Oliveira (2002) un sistema es un conjunto de partes interdependientes que interactúan entre sí y forman un todo unitario con determinado objetivo y función. Fernández (2005) recuerda que un sistema es "un conjunto de elementos interrelacionados entre si, que existen dentro de un entorno" y que todo lo que no es parte del sistema es parte de su entorno que es separado del sistema a través de la frontera, lo que no implica que no exista una relación entre los dos espacios, Fernández observa que esto ocurre cuando el sistema se clasifica como abierto. Aún según el autor en los sistemas abiertos, caso de las empresas, existe una constante necesidad de adaptarse a los cambios que ocurren al su alrededor, y esta capacidad es la clave para su supervivencia.

Ortuño y Navarro (2000) describen que la teoría sistémica tomó fuerza a partir de los años 50. En el año 1954 se organizó la Sociedad para la Promoción de la Teoría General de Sistemas (TGS), que en 1957 cambió su nombre por "Sociedad para la Investigación General de Sistemas".

Según los autores varios nombres se han destacado en la sistémica, entre ellos se puede citar al filósofo alemán George Wilhelm Hegel Triedrich (a quien se le atribuye la idea de que "el todo es más que la suma de sus partes") y Ross Ashby, autor de "Introducción a la Cibernética", que se quedó conocido en todo el mundo por presentar a la sociedad la Ley de la Variedad Requerida que la ha logrado un gran impacto en la comunidad científica e influyó en el posterior desarrollo de los conceptos sistémicos.

Para Ortuño (2008) Ashby estableció marcos de referencia que permiten la posibilidad de simular un problema teórico y así obtener soluciones diferentes a una retroalimentación de información que periódicamente puede revisar los resultados. El modelo propuesto por Ashby sigue una serie de pasos que incluyen la definición del problema, análisis teórico, la clasificación de las variables y la detección de desviaciones y deficiencias, e influyó en el 
desarrollo de diversas metodologías dentro de la sistémica, incluso el Método de Formulación por Objetivos, adoptado en esta investigación.

\subsubsection{La sistémica y la gestión de la Innovación}

El Manual de Oslo (OCDE, 2005) define la innovación como "la implementación de un producto (o servicio) nuevo o significativamente mejorado, o un proceso, o un nuevo método de comercialización o de un nuevo método organizativo en las prácticas empresariales, o en la organización del local de trabajo o en sus relaciones exteriores". Subrayando en la definición presentada "la organización del lugar de trabajo y sus relaciones exteriores", el manual muestra la innovación como un proceso compuesto por elementos que se interrelacionan e interactúan, tanto interna como externamente.

Mytelka y Smith (2002) destacan la importancia de adoptar un enfoque sistémico para abordar la innovación y la generación de conocimiento, ya que la innovación no se produce de forma aislada, sino dentro de un contexto en el que existen relaciones estructuradas, redes, infraestructura y un entorno social y económico. Según los autores, los modelos que se ocupan de la innovación desde una perspectiva lineal han sido crecientemente remplazados por modelos que enfatizan las interacciones entre los elementos heterogéneos de la del proceso de innovación.

En cuanto a las cuestiones relacionadas con la evaluación de la Innovación Mytelka y Smith (2002) señalan que muchos de los métodos tradicionales de evaluación, incluidos los enfoques orientados a la medición del desempeño, inhiben la innovación verdadera en vez de promoverla, según los autores la innovación es, por su naturaleza, arriesgada y crucial y los fallos pueden ser una fuente importante de aprendizaje que pueden conducir a la Innovación.

Según ellos otro problema importante que enfrentan los enfoques tradicionales para la evaluación de la innovación es "la falta de reconocimiento de la naturaleza reactiva de la evaluación". Como los indicadores de desempeño en general recompensan las actividades seguras y de corto plazo, pueden no reconocer logros extraordinarios y terminan por castigar la innovación y aquellos que buscan soluciones innovadoras.

La gestión de la innovación para el desarrollo de productos y procesos en Amazonia implica una serie de cuestiones, algunas, propias de todos los procesos innovadores, como la gestión del conocimiento (aprendizaje y tecnología de la información) y creación de redes y asociaciones. Sin embargo, se hace un destaque al papel de la legislación, de las políticas públicas y de las cuestiones éticas que rodean el uso de los recursos naturales en la región, así como los conocimientos asociados a las comunidades tradicionales. Por lo tanto, el enfoque sistémico la innovación tiene una 
relevancia considerable en el desarrollo de productos generados a partir de recursos naturales, principalmente en función de las especificidades y posibilidades de este tipo de investigación.

Para la aplicación de una gestión coherente en relación con la innovación en un entorno organizacional es necesario conocer los diseños de la protección de la propiedad industrial en Brasil que promueve mecanismos que otorgan protección de la innovación generada, además de la Ley de Innovación. Por lo tanto, presentamos a continuación un resumen de la legislación brasileña.

\subsection{La Propiedad Industrial}

En Brasil, los derechos y obligaciones relativos a la propiedad industrial se rigen por la Ley $\mathrm{N}^{\circ} 9279$ del 14 de mayo de 1996. La ley trata de los siguientes puntos:

I - La concesión de patentes de invención y modelos de utilidad;

II - La concesión del registro del diseño industrial;

III - La concesión de registro de marcas;

IV - La represión de las falsas indicaciones geográficas;

$\mathrm{V}$ - La represión de la competencia desleal.

En su Título I - Las Patentes, Capítulo I - La titularidad, artículo 6, la ley dice que "al autor de una invención o modelo de utilidad se asegurará el derecho a obtener una patente que garantiza la propiedad bajo las condiciones establecidas en la Ley".

El derecho a la patente pertenece al inventor o a sus causahabientes y es transmisible por todos los medios que el derecho reconoce.

La patente es un instrumento económico que proporciona las ventajas a su inventor o cesionario debido al uso exclusivo temporal del objeto de protección de invención o modelo de utilidad. Por lo tanto, la patente puede ser concedida a una invención o modelo de utilidad.

El registro de los bienes industriales se debe exigir en el Instituto Nacional de Propiedad Industrial (INPI - agencia federal). Para un tercer explorar un bien industrial patentado o registrado (invención, modelo, diseño o marca) es necesaria el permiso de titular de derecho de la licencia.

\subsubsection{La Patente de invención}

Según la ley la invención es "una nueva solución a un problema técnico, aplicable a escala industrial y es un acto original del genio humano". En este 
sentido, enfatizamos el distinción entre invención, es decir, la creación de algo que no existía antes en la naturaleza, y el descubrimiento, algo que ya existía en la naturaleza y sólo era desconocida. No se puede hacer un registro de un mero descubrimiento sin algún tipo de creación. El descubrimiento sólo podrá ser patentable si hay alguna actividad inventiva.

La patente está sujeta a los siguientes requisitos (art. $8^{\circ}$ de la LPI):

- Novedad: debe ser desconocida por la comunidad científica, técnica o industrial, es decir, por los expertos en la materia.

- Actividad inventiva: debe ser inventiva, incluso para un técnico experto, no puede ser tomada como evidente y obvia, debe suponer un avance real. Como señala el artículo 11 de la Ley de Propiedad Industrial, la creación no puede ya estar incluida en el estado actual de la técnica. El estado de la técnica está constituido por todo lo que antes de la fecha de presentación de la solicitud de patente se ha hecho accesible al público en España o en el extranjero por una descripción escrita u oral, por una utilización o por cualquier otro medio.

- Aplicación Industrial: sólo cuando hay la explotación industrial, la posibilidad de un uso práctico, es que la invención o modelo de utilidad puede ser patentado. Se considera que una invención es susceptible de aplicación industrial cuando su objeto puede ser fabricado o utilizado en cualquier clase de industria.

- No impedimento: por motivos técnicos o de servicio al interés público, la ley prohíbe la concesión de patentes sobre invenciones o diseños determinados, como enumera el artículo 18 de la LPI, por ejemplo, aquellos que afrenta a la moral, las buenas costumbres, la seguridad pública, el orden público y la salud.

\subsubsection{La Patente de Modelo de Utilidad}

La Ley también define Modelo de utilidad como "una nueva forma o disposición que resulte en mejoría funcional en el uso del objeto o en su fabricación susceptible de aplicación industrial". No es una invención en sí, pero incrementa la utilidad de herramienta de trabajo, instrumento, o utensilio por la acción de la novedad parcial que trae. Por lo tanto, disfruta de una protección independiente de la invención cuya utilidad ha sido mejorada. Está sujeto a los siguientes requisitos (art. 9 de la LPI): novedad, actividad inventiva, la mejora en el uso o la fabricación, la aplicación industrial.

Serán protegibles como modelos de utilidad, de acuerdo con lo dispuesto en la Ley, las invenciones que, siendo nuevas e implicando una actividad inventiva, 
consisten en dar a un objeto una configuración, estructura o constitución de la que resulte alguna ventaja prácticamente apreciable para su uso o fabricación.

\subsubsection{Registro Industrial}

La Marca y el Diseño de Industrial son registrables en el INPI, a efectos de la concesión del derecho de explotación exclusiva. El registro industrial es un acto de naturaleza constituyente, por lo tanto, el derecho al uso exclusivo de anterioridad no nace de su uso, pero del registro previo.

\subsubsection{El Diseño Industrial ("Design")}

En la Ley el término Diseño Industrial se refiere a la forma de los objetos, sus especificidades que permiten la identificación inmediata con carácter meramente estético.

De conformidad con el art. 95 LPI se considera diseño industrial la forma plástica ornamental de un objeto o un conjunto de líneas ornamentales y colores que se pueden aplicar a un producto, proporcionando resultado visual nuevo y original en su configuración externa y que puede servir como un tipo de fabricación industrial. Por lo tanto, se enfatiza que el diseño industrial es de carácter funcional y ornamental, y no requiere la actividad inventiva en la patente.

\subsubsection{La Marca}

También de acuerdo con la legislación marca es "el signo que identifica los productos y servicios". En este punto, para evitar confusiones, es necesario clasificar la Propiedad Industrial en:

- Patentes: 1. Patentes, 2. Utilidad de la patente de modelo 3. Registros de Diseño Industrial 4. Secretos de la Industria.

- Signos distintivos: 1. Marcas 2. Nombres Comerciales 3. Emblemas y títulos del establecimiento 4. Las indicaciones geográficas, 5. Nombres de dominio.

- Los signos distintivos se definen como los medios de comunicación visual o fonética, en particular las palabras o imágenes que se aplican en la vida económica y social a nombre de personas físicas o jurídicas, así como los productos o servicios que ofrecen, a fin de distinguirlos y permitir que el público los reconozca. 
La marca es, específicamente, un Signo distintivo visualmente perceptible, que identifica y distingue a los productos y servicios de otros análogos de diferentes orígenes, así como certifica que cumplen con determinadas normas o especificaciones.

Podrán, especialmente, constituir marca los siguientes signos o medios:

a) Las palabras o combinaciones de palabras, incluidas las que sirven para identificar las personas.

b) Las imágenes, figuras, símbolos y gráficos.

c) Las letras, las cifras y sus combinaciones.

d) Las formas tridimensionales entre las que se incluyen los envoltorios, los envases, la forma del producto o su presentación.

e) Cualquier combinación de los signos o medios que, con carácter enunciativo, se mencionan en los apartados anteriores.

La Ley de Propiedad Industrial, art. 123, apartados II y III, introducido en la legislación brasileña, además de productos de marca y servicios, dos otras categorías de marcas:

- Marca de Certificación: certifica que un producto o servicio cumple con determinadas normas o especificaciones técnicas de calidad fijados por organismo oficial o privado.

- Colectivo Marca: informa que el proveedor del producto o servicio está afiliado a una entidad, por lo general de una asociación de productores o importadores del sector.

Por lo tanto, la marca también es un instrumento económico que otorga al titular el derecho de uso exclusivo en todo el territorio nacional de una marca particular en relación con los productos y servicios y su propiedad se adquiere por el registro válido. El Registro de una marca se otorga por diez años contados desde la fecha del depósito de la solicitud y podrá renovarse indefinidamente por periodos de diez años, siempre que se cumplan los requisitos establecidos en la Ley.

\subsubsection{Las indicaciones geográficas}

Son signos distintivos de origen o calidad utilizados en la producción o en el comercio. Se observa que no se puede utilizar las indicaciones geográficas en la marca del producto. Son especies de indicaciones geográficas:

Indicación de origen: nombre de la ubicación geográfica, país, región, ciudad, etc., que se hizo famoso por la fabricación, extracción o producción de un producto o prestación de servicios (artículo 177 de la LPI). 
Denominación de origen: nombre geográfico del lugar donde se encuentran los atributos únicos que diferencian el producto o servicio originado a partir de ahí, lo que garantiza no sólo el origen del producto, sino también asegurarse de que la función de calidad específica que se debe exclusiva o esencialmente al medio geográfico. En principio, beneficia a los productores y los consumidores, valoran el producto, estimulan y facilitan la identificación de mejoras cualitativas de productos.

\subsection{La ley de Innovación}

La Ley $\mathrm{N}^{\circ} 10.973$ de 02 diciembre de 2004, también conocida como la Ley de Innovación es una de las iniciativas del Gobierno Federal de Brasil para crear un entorno propicio a la innovación. Esta ley prevé incentivos para la innovación y la investigación científica y tecnológica en el entorno productivo, con miras a la creación de capacidades tecnológicas, autonomía y desarrollo industrial del país. Según Coelho (2012) los mecanismos presentes en esta ley permiten el fortalecimiento y la ampliación de la discusión sobre temas como modelos de organización y gestión de la innovación entre otros.

En el capítulo II, la ley trata de fomentar la participación de las instituciones de ciencia y tecnología. La ley dice que "Las ICTs (Instituciones de Ciencia y Tecnología) deben tener un núcleo de innovación tecnológica solo o en combinación con otras ICTs, con el fin de gestionar su política de innovación" (artículo 16). Para Pereira (2008), en la práctica fue necesario adaptar las ICTs para hacer cumplir la ley y por lo tanto construir entorno y potenciar los recursos humanos que puedan definir procedimientos y rutinas, mantener bases de datos, procedimientos de supervisión, realizar la transferencia de tecnología y la comercialización de todo tipo creadas en el mundo académico.

Según Coelho (2012), en Brasil la ley ha proporcionado a las ICTS la eclosión de entornos que tratan propiedad intelectual y transferencia de tecnología en sectores especializados llamados de Núcleos de Innovación Tecnológica - NITs. Estos núcleos tienen, por la prerrogativa de la ley, el papel de asegurar el mantenimiento de la política de innovación institucional, evaluar y clasificar las acciones de las iniciativas de innovación, conocer a los usuarios, incluso fuera de la institución y, esencialmente, proporcionar asistencia para el investigador y para el proceso de formalización de la exposición sus investigaciones. En la Universidad Federal de Amazonas esta discusión se inició con el establecimiento del NIT/UFAM, por la Resolución N ${ }^{\circ}$. 1.498/2007 de 27 de septiembre de 2007.

Además de la legislación en materia de protección de la propiedad industrial y la ley de la innovación, también es necesario conocer las normas de evaluación de la enseñanza universitaria en Brasil, que influyen directamente en la estructura de los cursos. 


\subsection{Evaluación de la Educación Superior en Brasil}

Maués (2008) destaca que en Brasil la evaluación ha jugado un papel importante en los últimos años, sirviendo como punto de referencia para la toma de decisiones y el consiguiente establecimiento de políticas públicas. El autor señala que la cuestión ha impregnado todas las esferas de la sociedad, con énfasis en la educación, de acuerdo con el papel privilegiado que tiene en la sociedad. La importancia está estrechamente vinculada a las funciones asignadas a la evaluación, especialmente cuando el Estado descentraliza muchas de las actividades que tradicionalmente tenían bajo su responsabilidad, en un proceso de reforma que modifica, entre otras cosas, la forma de administrar.

En Brasil, la evaluación de la educación superior ha sufrido varias transformaciones, sobre todo después de 2003, tras el cambio en el gobierno federal, cuando fue establecido por la Portaría N ${ }^{\circ} 03.11$ MEC / SESU un comité encargado de elaborar un sistema de evaluación de esta categoría de la educación. Según el documento oficial el objetivo era:

Establecer Comisión Especial con el fin de analizar, ofrecer los subsidios, hacer recomendaciones y proponer criterios y estrategias para el rediseño de procesos y de las políticas de evaluación de la educación superior y elaborar la revisión crítica de sus instrumentos, metodologías y criterios utilizados. (MAUÉS, 2008, p. 5).

La primera versión de la propuesta de la Comisión Especial de Evaluación de la Educación Superior (CEA) fue entregada al Gobierno en septiembre de 2003 y después de algunos cambios se convirtió en la Ley 10.861 de abril de 2004, que estableció el Sistema Nacional de Evaluación de la Educación Superior (SINAES).

De acuerdo a la información disponible en el sitio web oficial del MEC, el SINAES " analiza las instituciones, cursos y rendimiento de los estudiantes." Según MEC el proceso de evaluación de SINAES tiene en cuenta aspectos tales como la enseñanza, la investigación, la extensión, la responsabilidad social, la gestión de la institución y de la facultad, la recopilación de información del Examen Nacional de Rendimiento Estudiantil (ENADE) y de las evaluaciones institucionales de los cursos.

La información obtenida se utiliza para guiar las instituciones de educación superior y apoyar las políticas públicas. Además, los datos proporcionados por el sistema también pueden ser utilizados por la empresa, siendo de interés principal para los estudiantes, ya que sirve como una referencia sobre el estado de los diversos cursos e instituciones en el país. 
Maués (2008) recuerda que en el momento de su creación, el Gobierno Federal trató de mostrar que uno de los objetivos del SINAES era mejorar la calidad de la educación superior en Brasil. Para lograr esto, se evaluarían las instituciones y la actuación de grado y posgrado de los estudiantes.

Para las acciones del programa, la legislación prevé la creación de una Comisión Nacional para la Evaluación de la Educación Superior (CONAES), vinculada al MEC, que tiene como tarea principal la coordinación y el control del sistema y proponer y evaluar los procedimientos dinámicos de evaluación, así la forma de establecer las directrices para la constitución de comités para revisar las instituciones, formular propuestas de mejora de las instituciones, sobre la base de los informes recibidos, los criterios de evaluación, entre otros.

De acuerdo con el Instituto Nacional de Estudios e Investigaciones Anísio Teixeira (INEP) la estructura de revisión de programas de grado en Brasil está organizada en tres dimensiones: 1) organización didáctica y pedagógica, 2) profesores, alumnado y personal técnico y administrativo y 3) las instalaciones físicas. Cada una de estas dimensiones es analizada sobre la base de los indicadores que se describen a continuación:

Tabla 03: Indicadores de organización didáctica y pedagógica

\begin{tabular}{|l|l|}
\hline & DIMENSIÓN 1: ORGANIZACIÓN DIDÁCTICA Y PEDAGÓGICA \\
\hline 1 & $\begin{array}{l}\text { INDICADORES } \\
\text { La implementación de políticas institucionales contenidas en * PDI, dentro } \\
\text { del curso. }\end{array}$ \\
\hline 2 & $\begin{array}{l}\text { Funcionamiento de instancias de deliberación colectiva y la discusión de las } \\
\text { cuestiones inherentes al desarrollo y calificación del curso. }\end{array}$ \\
\hline 3 & $\begin{array}{l}\text { La consistencia del proyecto y currículo del curso con las directrices } \\
\text { Nacionales. }\end{array}$ \\
\hline 4 & $\begin{array}{l}\text { La adecuación y actualización de los programas y bibliografías de los } \\
\text { componentes curriculares, teniendo en cuenta el perfil de los graduados. }\end{array}$ \\
\hline 5 & $\begin{array}{l}\text { Adecuación de los recursos materiales específicos del cursos (laboratorios } \\
\text { específicos y las instalaciones, equipos y materiales) con el plan de } \\
\text { estudios. }\end{array}$ \\
\hline 7 & $\begin{array}{l}\text { La consistencia de los procedimientos de enseñanza y aprendizaje con el } \\
\text { diseño del curso. }\end{array}$ \\
\hline 8 & $\begin{array}{l}\text { Actividades articuladas con la formación académica: a) práctica } \\
\text { profesional, b) trabajo de conclusión de curso (TCC), c) actividades } \\
\text { complementarias y las estrategias de flexibilidad curricular. }\end{array}$ \\
\hline $\begin{array}{l}\text { Acciones llevadas a cabo de acuerdo con los procesos de autoevaluación y } \\
\text { evaluación externa (ENADE y otros). }\end{array}$ \\
\hline
\end{tabular}

Fuente: MEC/INEP (2012)

En la Tabla 04 que sigue, se enumeran los indicadores relativos a la $2^{a}$ Dimensión evaluada por MEC: 
Tabla 04: Indicadores de los profesores, alumnado y personal técnico y administrativo

\begin{tabular}{|l|l|}
\hline \multicolumn{2}{|l|}{ DIMENSIÓN 2: PROFESORES, ALUMNADO Y PERSONAL TECCNICO Y ADMINISTRATIVO } \\
\hline INDICADORES \\
\hline 1. & $\begin{array}{l}\text { La formación, la experiencia y la dedicación el coordinador a la } \\
\text { administración del curso. }\end{array}$ \\
\hline 2. & $\begin{array}{l}\text { Caracterización (tiempo de dedicación y permanencia sin interrupción), } \\
\text { composición y titulación del Núcleo Docente Estructurante - NDE). }\end{array}$ \\
\hline 3. & $\begin{array}{l}\text { La titulación y la experiencia de los profesores y su dedicación efectiva al } \\
\text { curso. }\end{array}$ \\
\hline 4. & Producción de material didáctico y científico de los profesores. \\
\hline 5. & $\begin{array}{l}\text { Adecuación de la formación y experiencia del personal técnico y } \\
\text { administrativo. }\end{array}$ \\
\hline
\end{tabular}

Fuente: MEC/INEP (2012)

En la Tabla 05, son enumerados los indicadores relativos a la $3^{\text {a }}$ dimensión evaluada por MEC:

Tabla 05: Instalaciones Físicas

\begin{tabular}{|l|l|}
\hline \multicolumn{2}{|l|}{ DIMENSIÓN 3: Instalaciones Físicas } \\
\hline INDICADORES \\
\hline 1. & Los espacios físicos utilizados en el desarrollo del curso. \\
\hline 2. & $\begin{array}{l}\text { Cantidad y tipo de ambientes / laboratorios de acuerdo con la propuesta del } \\
\text { curso. }\end{array}$ \\
\hline 3. & Libros - Bibliografía básica. \\
\hline 4. & Libros - Bibliografía Complementar. \\
\hline 5. & $\begin{array}{l}\text { Publicaciones periódicas, bases de datos específicas, revistas y colección } \\
\text { multimedia. }\end{array}$ \\
\hline
\end{tabular}

Fuente: MEC/INEP (2012)

Las tres dimensiones de evaluación de los cursos superiores de MEC son complementarias e inseparables para la construcción de la calidad de la educación, y, por consiguiente, que el curso tenga una producción significativa. Es de notar, sin embargo, que en el caso de las universidades federales hay una gran dependencia de los recursos públicos, que es a menudo un factor limitante para el desarrollo de un curso. 
Capítulo 3

METODOLOGÍA 



\section{METODOLOGÍA}

Este capítulo se centra en las cuestiones metodológicas adoptadas en la investigación a partir de la clasificación como cualitativa y también aborda el universo y el tamaño de la muestra de estudio, su selección, técnicas y herramientas para la recolección, análisis, procesamiento y presentación de datos. Por otra parte, se presentan también las principales características de la metodología DAFO y del Método de Formulación por Objetivos que guiarán la construcción del escenario actual y la formulación de estrategias para mejorar el entorno de la innovación en el curso.

\subsection{Clasificación de la investigación}

Cervo (2007) afirma que el método es, a su juicio más "la orden que se debe imponer a los diferentes procesos necesarios para alcanzar un determinado fin o un resultado deseado" diferenciando del concepto de técnica que en su visión se refiere a "el conjunto de procesos empleados en la investigación y en la demostración de la verdad ", según él, el método es el procedimiento sistemático en términos generales, mientras que la técnica, por su parte, es la implementación del plan metodológico y de su manera especial de ejecución. Por lo tanto, en este capítulo se presentan los aspectos relacionados con la metodología aplicada en la investigación, así como una discusión de las técnicas e instrumentos utilizados en la misma.

En relación a su naturaleza esta investigación se caracteriza por ser cualitativa, ya que tiene como objetivo examinar los aspectos que influyen de la innovación en un programa de postgrado. La clasificación como cualitativa ocure por la búsqueda de una comprensión más profunda de un fenómeno mediante el análisis de sus elementos y relaciones, además, los datos relacionados con el medio ambiente de la innovación requiere información detallada, y son difíciles de medir cuantitativamente.

Neves (1996, p.20) describe que:

La investigación cualitativa cree que hay una relación dinámica entre el mundo real y el sujeto, es decir, un vínculo inseparable entre el mundo objetivo y la subjetividad del sujeto que no se puede traducir en números. La interpretación de los fenómenos y la atribución de sentido es el proceso básico de la investigación cualitativa. No requiere el uso de métodos y técnicas estadísticas. El entorno natural es la fuente directa para la recolección de datos y el investigador es el instrumento clave. Es descriptivo. Los investigadores tienden a analizar sus datos inductivamente. El proceso y su significado son los focos principales de enfoque. 
Sobre el uso de la investigación cualitativa en los estudios de innovación del Manual de Bogotá (p. 56) señala que la investigación cualitativa "puede conducir a la investigación académica significativa e incluso orientar a los responsables políticos en la toma de decisiones", que apenas hace a través de enfoques meramente cuantitativos, especialmente en la innovación, y también en el sector privado en las iniciativas promovidas y financiadas por organizaciones gubernamentales.

Neves (1996) afirma que la mayoría de los estudios cualitativos se realizan en el lugar de origen de los datos y tiene un estudio descriptivo y crítico, porque es a través de él que se recogerán los datos. El estudio se inscribe, por lo tanto, en la investigación del tipo descriptiva que según Cervo (2007) es un tipo de investigación que busca entender las diferentes situaciones y relaciones que se producen en la vida social, política y económica en un entorno dado, según él, este tipo de investigación, registra, analiza y correlaciona los hechos sin manipularlos.

Según Gil (2008), así como la clasificación cualitativa y / o cuantitativa de la investigación también se pueden clasificarla mediante la observación de su objetivo general como criterio en tres grupos: investigación exploratoria, investigación descriptiva e investigación explicativa.

Para el autor el objetivo de una investigación exploratoria es familiarizarse con un tema aún poco conocido, poco explorado. Al final de la investigación, se podrá conocer más acerca de este tema, y ser capaz de construir hipótesis. Según él en los estudios descriptivos se busca describir las características de una población o fenómeno o de una experiencia. Al final de un estudio descriptivo, tendremos recopiladas y analizadas una gran cantidad de información sobre el tema investigado.

La gran contribución de la investigación descriptiva es proporcionar nuevos conocimientos sobre una realidad ya conocida.

Aún según Gil (2008) en el tercer grupo, la investigación explicativa hay el objetivo de identificar los factores principales que determinan o contribuyen a la ocurrencia de los fenómenos.

Así, en relación con sus objetivos, este estudio se clasifica como Exploratorio.

En este trabajo, para lograr los objetivos propuestos, las actividades fueron pertinentes a un solo curso de la Universidad Federal de Amazonas, y se caracteriza por lo tanto como un estudio de caso.

Según Yin (apud Bressan, 2004) "El estudio de caso es una investigación empírica que investiga un fenómeno contemporáneo dentro de un contexto de la vida real, cuando los límites entre el fenómeno y el contexto no son 
claramente evidentes y en el que múltiples fuentes de evidencias son utilizadas".

Tull apud Bressan (2004) afirma que "un estudio de caso se refiere a un análisis intensivo de una situación particular" y Bonoma (apud Bressan, 2004) señala que el "estudio de caso es una descripción de una situación de gestión" Por lo tanto, el estudio de caso se revela una técnica compatible con los objetivos del presente estudio. En este trabajo, la institución elegida es la Universidad Federal de Amazonas, y el análisis de la situación especial se centrará en el curso de Diseño de esta institución.

\subsection{Universo de estudio, selección y tamaño de la muestra}

Según lo explicado por Lakatos (2008, p. 27) el universo de la investigación, también llamado de la población es el conjunto de los seres animados e inanimados que tienen características en común. Dado que la muestra según el autor, es una parte debidamente seleccionados del universo.

En este estudio serán consultados dos grupos distintos:

1) Expertos en el ámbito de la innovación y Expertos en el ámbito de Diseño para aplicación de entrevistas en profundidad de carácter semi-estructurado, el número de diez entrevistados.

Los componentes de este grupo fueron seleccionados por muestreo no probabilístico basado en su experiencia en el diseño y la innovación. Este grupo fue consultado por entrevistas durante la primera fase investigación.

2) Los componentes del curso en estudio, profesores, alumnos y titulados (aplicación de cuestionarios para llevar a cabo la evaluación propuesta).

Con respecto al grupo 2, según datos proporcionados por la Secretaría y Coordinación del Curso de Diseño en el primer semestre de 2012, el curso era formado por 181 alumnos, 17 profesores y 223 graduados formando un total de 421 personas.

Los componentes de este grupo también fueron seleccionados por muestreo no probabilístico.

Número de participantes de la encuesta: 15 profesores, 86 Alumnos y 54 titulados.

Según Oliveira (2001) existen varios tipos de muestras y planes de muestreo, debe ser diferenciada la definición de muestreo probabilístico y no probabilístico.

- Muestreo probabilístico es aquel en el que cada elemento de la población tiene una probabilidad conocida y distinta de cero de ser seleccionados para 
componer la muestra. Las muestras generar muestras probabilísticas de probabilidad. (Mattar, 1996, p. 132).

- El muestreo no probabilístico es aquel en el que la selección de elementos para componer la población de la muestra depende al menos en parte el juicio del investigador o entrevistador en el campo. (Mattar, 1996, p. 132).

Schiffman y Kanuk, L. (2000, p.27) explican las principales características de cada tipo de muestreo.

\section{No probabilística:}

- Muestra por conveniencia: El investigador selecciona a miembros de la población más accesible.

- Muestra Intencional: El investigador utiliza su criterio para seleccionar a los miembros de la población que son buenas fuentes de información precisa.

- Muestra por cuotas: El investigador entrevista un determinado número de personas en cada una de las varias categorías.

\section{Probabilística:}

- Muestra aleatoria simple: cada miembro de la población tiene una probabilidad conocida e igual de ser escogido.

- Muestra aleatoria por estratos: La población se divide en grupos proporcionales a la composición de la población.

- Muestra por conglomerados: La población se divide en grupos mutuamente excluyentes y el investigador extrae una muestra de los grupos a ser entrevistados.

Así, por las características del estudio fue adoptado el muestreo no probabilístico para la determinación del tamaño de la muestra de las poblaciones en las diferentes etapas de investigación. Esta elección se justifica por las siguientes razones:

- Estudio de la naturaleza predominantemente cualitativa;

- Población muy pequeña (en el caso de la aplicación del muestreo probabilístico el tamaño de la muestra fue muy cerca de la población total y esta no estaba disponible en su totalidad ;

- Limitaciones de diversas órdenes - Factor practicidad necesario (dificultades relacionadas con el tiempo disponible, los recursos y el acceso a ciertos miembros de la población). 


\subsection{Técnicas y herramientas de recopilación, análisis, procesamiento y presentación de datos}

La técnica aplicada para el desarrollo de este estudio será, inicialmente, la obtención de información existente sobre el tema propuesto y, además, actividades de campo a través de visitas y entrevistas en el curso en estudio, para recoger los datos específicos de la institución. Este material va a proporcionar una mayor comprensión sobre la realidad del análisis del ambiente.

En esta etapa las fuentes de datos serán primarias y secundarias:

Las fuentes primarias: se describen como fuentes más cercanas a la fuente de información o idea en estudio. Se recogieron los datos históricos, archivos y registros oficiales y realizaron entrevistas semi-estructuradas para obtener datos que no aparecen en el material proporcionado por el curso.

Fuentes secundarias: se refieren o analizan información originalmente presentadas otros lugares e implican generalización, análisis, síntesis, interpretación o evaluación de la información original. Aquí se consultó bibliografía y otros materiales.

La recolección de datos para la investigación se llevó a cabo, en primer lugar, a través de un estudio de la literatura. Esta fase fueron consultados los temas relacionados para una adecuada fundamentación teórica. El estudio de la literatura se justifica por la necesidad de profundizar los conceptos de los investigadores y otros aspectos del tema a través de estudios previos de otros autores. Además de la biblioteca, también fueron consultados sitios (internet) relacionados al tema tales como: MEC, CAPES (Coordinación de Apoyo al Personal de Enseñanza Superior) y UFAM.

Después de realizar la búsqueda bibliográfica se llevará a cabo un estudio de campo, que según Lakatos (2008, p. 69) "es la observación de los hechos y fenómenos que se producen de forma espontánea y en la recogida de datos sobre ellos y registro de las variables que se supone pertinentes para su análisis. "

Por lo tanto, se realizaron visitas a la sede del curso, entre agosto de 2011 y abril de 2012, durante las cuales se hicieron observaciones sobre el curso y su estructura, registros fotográficos, entrevistas y aplicaciones de cuestionarios.

Como se mencionó anteriormente, los principales instrumentos adoptados para la recolección de datos en esta fase fueron:

- Investigación documental. 
- Las entrevistas, que de acuerdo con Cervo (2007), son aplicadas para obtener datos que no están registrados en las fuentes documentales, pero que pueden ser prestados por algunas personas que tienen el conocimiento. Las entrevistas tuvieron carácter semi-estructurado, (Guía - Apéndice A).

- Encuestas: Compuestas por preguntas abiertas y cerradas. (Modelos aplicados a los grupos de docentes, alumnos y titulados - Apéndices A, B e C).

Por lo tanto, la técnica de recolección de datos considerada apropiada para esta investigación, apoyada por la literatura, fue el método mixto, por la combinación de varios métodos para recogida de datos (1) investigación documental, (2) entrevistas en profundidad y (3) Encuestas.

Las entrevistas con expertos en el campo del Diseño y con expertos en el campo de la Innovación se llevaron a cabo en la primera etapa de la investigación y tuvieron como objetivo conocer su opinión sobre el ambiente de la innovación en diseño y los factores que impiden su desarrollo, más allá de las formas de evaluación de estos factores, las posibilidades de cooperación con el sector privado y la formación de los investigadores.

La entrevista en profundidad es un recurso metodológico que busca, basada en las teorías y presupuestos establecidos por el investigador, recoger las respuestas de la experiencia subjetiva de una fuente, seleccionada por tener información sobre lo que se desea saber. En este camino la exploración de las preguntas permiten una profundizar el tema, describir los procesos y flujos, entender el pasado, analizar, discutir y hacer prospectivas. Las preguntas permiten identificar posibles problemas, patrones y detalles, obtener juicios e interpretaciones, caracterizar la riqueza de un tema y explicar los fenómenos de alcance limitado.

Basado en la opinión de los expertos y, siguiendo la lógica de los métodos adoptados para guiar la construcción del escenario del curso (técnica DAFO y Método de Formulación por Objetivos), se construyó la primera versión de la herramienta de evaluación (encuesta) que se aplicaría a los grupos de interés que conforman el panorama de la Innovación: profesores, alumnos y titulados. Las preguntas fueron elaboradas a partir de las observaciones realizadas por los expertos y organizadas con el fin de proporcionar información acerca de las fortalezas y debilidades del ambiente interno y de las amenazas y oportunidades presentes en el entorno externo del curso.

Antes de ser aplicado, los formularios de las encuestas se sometieron a una revisión por los pares (06 profesores) con el fin de identificar posibles fallos y contribuir a la mejora del instrumento. Este grupo de evaluadores se 
componía de dos (02) profesores de la Universidad Politécnica de Valencia y cuatro (04) profesores de la Universidad Federal de Amazonas. A partir de los problemas identificados por ellos se hicieron cambios que permitieron llegar a la versión final del Cuestionario

Después de aplicar las encuestas a los grupos de profesores, alumnos y titulado del curso, los datos fueron ingresados en un software específico para datos estadísticos - el SPSS (Statistical Package for the Social Sciences), etapa a partir de la que se puede extraer salidas del software relacionadas con diversas cuestiones que formaban parte de la herramienta de evaluación (presentados en el Capítulo 5 - Resultados y Discusión).

Es importante destacar que, aunque la determinación de tamaño de la muestra no haya adoptado métodos probabilísticos, esto no impide el uso de herramientas estadísticas para realizar análisis de datos, en particular la correlación entre los resultados de varios grupos. Los datos se presentan a través de tablas y gráficos de sectores y son analizados desde la observación de estas salidas.

Con los resultados obtenidos se utilizó la técnica DAFO para construir una matriz acerca de los ambientes interno y externo del curso, A partir de la que se formuló una estrategia para la gestión de la innovación en el ámbito del objeto de estudio. A continuación se muestran las principales características de la técnica DAFO para permitir una mejor comprensión de esta etapa de la investigación.

\subsubsection{El Análisis DAFO}

El análisis DAFO es una metodología utilizada en la formulación de la estrategia competitiva de las empresas, donde se identifican, el suministro de información para su posterior análisis, los siguientes elementos (Porter, 1989):

D - Debilidades: Las deficiencias o limitaciones que pueden restringir los resultados de la organización, identificadas en el ambiente interno.

A - Amenazas: Situaciones del entorno externo, con potencial de impedir el éxito de la organización.

F - Fortalezas: hechos, los recursos, y otros factores del entorno interno, que pueden significar a la organización una ventaja sobre sus competidores y / o una diferencia en el cumplimiento de su misión.

0 - Oportunidades: hechos o circunstancias en el entorno externo que la organización puede llegar a explorar con éxito.

Según Tarapanoff (2001), la técnica DAFO es parte del análisis de los ambientes organizacionales. Este análisis de las fortalezas y debilidades se 
refieren al ambiente interno de la empresa, mientras que las oportunidades y enfrentar las amenazas con el ambiente externo de la misma. En el ambiente interno se busca identificar los aspectos positivos como los recursos o capacidades que la organización puede utilizar con eficacia para lograr sus objetivos, las competencias distintivas, se investiga si las situaciones negativas que pueden inhibir el correcto desempeño de la empresa, tales como la falta de habilidad de los empleados y equipos obsoletos. Al analizar el entorno externo se analizan los aspectos positivos y negativos que pueden influir en el desarrollo de la organización, tales como las tendencias del mercado, la legislación restrictiva, las nuevas tecnologías o competidores.

\begin{abstract}
El Análisis DAFO [...] es de uso general en los procesos de planificación estratégica, para evaluar el posicionamiento de la organización y su capacidad de competir. Contribuye a la estrategia competitiva de la organización. Técnicas de monitoreo y verificación de los ambientes internos y externos son esenciales para el análisis y la planificación empresarial, contribuyendo a la diversificación de las oportunidades de mejora a estudiar, así como la toma de decisiones acerca de los productos y servicios. (TARAPANOFF, 2001, p.209)
\end{abstract}

El método DAFO tiene como objetivo la búsqueda de estrategias innovadoras de acción, para generar subsidios que aproveche debidamente las oportunidades y minimizar las amenazas a través del uso de los puntos fuertes de la organización y la corrección de las deficiencias existentes. La matriz DAFO es usada para identificar la ventaja competitiva de las organizaciones, proporcionando la información necesaria para permitir una evaluación coherente de los impactos ambientales del entorno interno y externo, en consonancia con los recursos disponibles.

El análisis ambiental sirve también para ayudar a uniformar la comprensión de las cuestiones clave para la organización - una estandarización de los diferentes modos de percibir y comprender las variables ambientales. Este tipo de técnica puede considerarse como una especie de filtro, por lo que la información ambiental debe llegar al proceso de decisión de la organización. El Análisis DAFO si aplicada adecuadamente, proporciona la información necesaria y permite una evaluación constante de los impactos ambientales del entorno interno y externo, en consonancia con los recursos disponibles.

Según Tarapanoff (2001), el análisis DAFO se aplica en las etapas preliminares del proceso de decisión, por lo general como una etapa - análisis del entorno en la planificación estratégica de la organización (como se muestra en la figura 08). Por lo tanto, se recomienda utilizar la técnica DAFO después de establecer la misión de la organización, el análisis DAFO puede ser hecha por individuos o equipos. 
Figura 08: Formulación de estrategias - DAFO

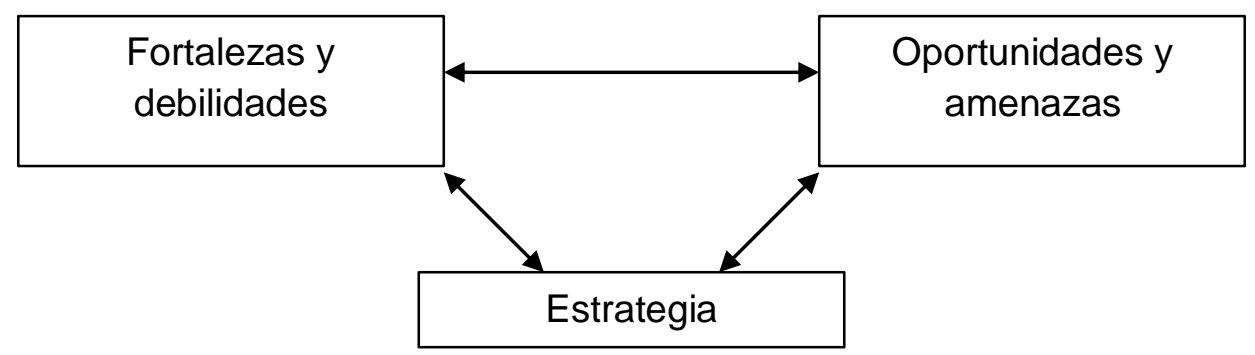

Fuente: adaptado de Silveira apud Tarapanoff, 2001.

Tarapanoff (2001) establece que el análisis DAFO se compone básicamente de tres etapas, que se obtienen a través de tres productos. El primer paso consiste en relacionar en una lista, los puntos fuertes y debilidades relativas al ambiente interno de la organización y las oportunidades y amenazas del entorno externo de la misma, la composición de esta lista, el primer producto del análisis, se puede realizar utilizando técnicas como la lluvia de ideas, cuestionarios y entrevistas.

La segunda fase de la técnica DAFO consiste en clasificar la lista obtenida en el paso anterior, ordenando a los factores establecidos, desde el más importante al menos importante, esta clasificación se debe hacer teniendo en cuenta el logro los objetivos organizacionales. Como resultado de esta segunda fase, se puede obtener una visión clara de los aspectos que causan el mayor impacto en el potencial de acción de la empresa, e identificar cuáles son los factores del ambiente externo que ejercen mayor presión

El tercer paso es la construcción de una matriz (Figura 09), enumerando los varios factores levantados, para identificar temas críticos y situaciones que requieren una atención especial. 
Figura 09: La Matriz DAFO

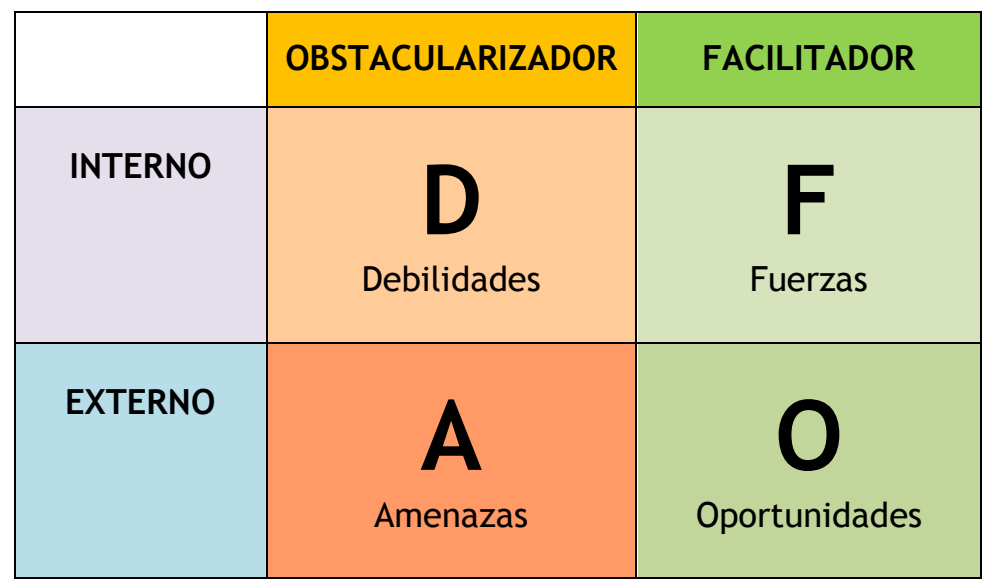

Fuente: adaptado de Silveira apud Tarapanoff, 2001.

Una vez construida, la matriz DAFO se utiliza para fijar la estrategia de la organización, que deberá tener en cuenta no sólo la situación actual de los factores, pero el cambio esperado, de los esfuerzos de la organización o escenarios alternativos aplicados al medio ambiente.

Las estrategias que se definan deben considerar el establecimiento de los parámetros que guían el desarrollo de la acción de la organización. Así, los resultados del análisis, DAFO, junto con la misión y visión de la empresa, deben contribuir al desarrollo de una estrategia capaz de percibir los cambios en el entorno interno y externo de la organización, que pueden comprometer la institución en su objetivo de cumplir su misión.

Está claro, pues, que un punto importante a tener en cuenta es que el análisis no debe hacerse sin tener en cuenta la misión de la institución. Además, todos los sectores de la compañía deben trazar sus objetivos en línea con esta misión.

A partir de la recopilación de datos, de la construcción de la matriz DAFO y de la formulación de un plan de acción para mejorar el entorno para apoyar la innovación en el curso de Design fue utilizado un método sistémico llamado "Modelo de Formulación objetivos" de Ortuño (2003) para el desarrollo de una propuesta de la gestión de la innovación en el curso. 


\subsubsection{El Modelo de Formulación por objetivos}

De acuerdo a los diseños presentados en el capítulo sobre el marco teórico en el que se observan los procesos de innovación y su evaluación sistémica, se empleó el método seleccionado con este enfoque con el fin de describir el sistema actual y proponer mejoras en el entorno de la Innovación.

Existen numerosos modelos y metodologías basadas en los conceptos de sistémica. Esparducer, Ortuño y Marco (1994, p. 165) describen que "la estructura determina el comportamiento de los sistemas, por lo que su análisis y configuración resulta decisivo para determinar el origen de las respuestas del sistemas". Fueran estos autores que, basados en las propuestas teóricas de Ashby de los años 50 y 60 han propuesto el diseño de un modelo de representación de los objetivos de un sistema a través del estudio “Representación reticular de los objetivos de un sistema” (1994).

Para el análisis de los datos para la generación de una estrategia de gestión de la innovación en el curso de Design/UFAM, objeto de este estudio, fue adoptado el "Modelo de Formulación por Objetivos", elaborado por Ortuño (2003) y desarrollado en el ámbito de la Escuela de Investigación Operativa de Valencia (España).

Como describe Ortuño (2008) este método se refiere al estudio de modelos organizacionales por la descripción de sus características y la determinación de los elementos del sistema en estudio y la interrelación entre ellos. La formulación del modelo puede ser descrito por el siguiente gráfico: 


\section{SISTEMA EXTERIOR}

$\begin{array}{ll}\text { Variáveis de Entrada } & \text { VE } \\ \text { Varíavis de Saída } & \text { Sistema em Estudo }\end{array}$

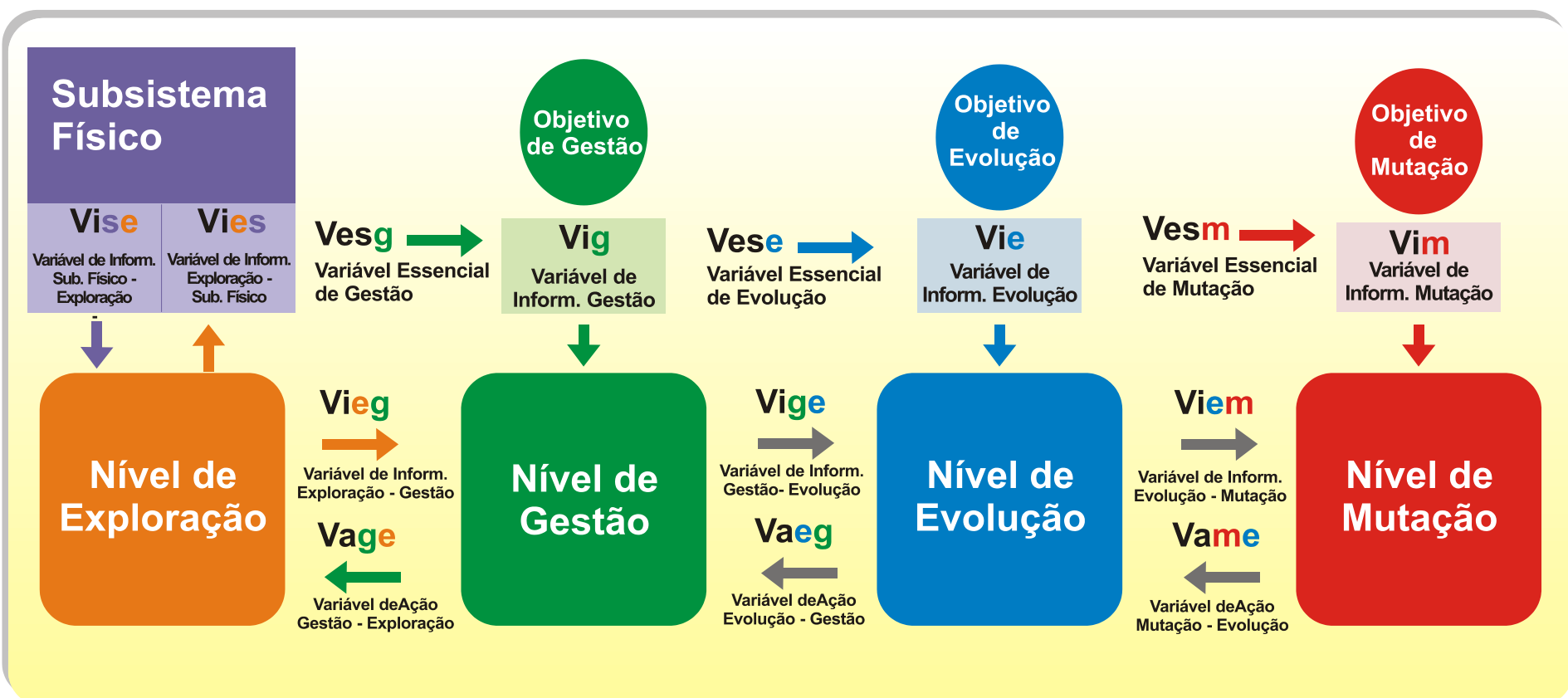

Fuente: Ortuño (2008) 

El autor señala que el primer paso en la aplicación del modelo es definir los límites del sistema y analizar ambos elementos integrados a él, tales como los que influyen y no puede ser controlado por él. Por motivos de organización de análisis del sistema bajo estudio se divide en varios sistemas, subsistemas y niveles de la siguiente manera:

- Sistema Exterior: Se compone de varios subsistemas en el entorno con el que se refieren el sistema en estudio, por ejemplo: los compradores, los proveedores, los clientes, los bancos, la política, la legislación y el público.

- Sistema Física: consiste en elementos que llevan a cabo las actividades contempladas en el sistema, tales como recursos humanos, recursos materiales, equipos y laboratorios.

Todavía con el objetivo de delimitar mejor el análisis del sistema bajo estudio Ortuño también le subdivide en:

- Nivel de Explotación (operativo): Nivel correspondiente a la ejecución de las actividades diarias y procedimientos. El nivel de explotación debe adaptarse inmediatamente a corregir las desviaciones y retrasos, las decisiones relacionadas con el clima en este nivel varían entre semanas y quincenas.

- Nivel de Gestión: Su misión es establecer metas que serán transmitidas al nivel de explotación y controlar su ejecución. En caso de perturbaciones afectaren el nivel operativo y siendo incapaz de volver a un estado de equilibrio solo, el nivel de Gestión hace el cambio de los programas para alcanzar las metas. Su discurso es más lento que el nivel de exploración y se puede hablar de una actuación que circula alrededor de un mes y medio.

- Nivel de Evolución: Este nivel está diseñado para garantizar el desarrollo de los niveles más bajos y representa la función por excelencia de "dirección". Establece objetivos a medio y largo plazo, ajusta la estructura, las decisiones de inversión y la búsqueda de nuevos mercados. Este nivel también es responsable de la organización de las funciones, métodos, medios y procedimientos. El nivel de Evolución tiene una tasa de intervención más espaciada que los niveles anteriores y opera sobre una base anual: la planificación anual de recursos materiales y humanos es una de sus principales actividades.

- Nivel de Mutación: se conecta a la organización con el universo en el que se inserta. Es en este nivel donde se decide su propia existencia y los cambios fundamentales como fusiones y adquisiciones, este nivel es responsable de proteger a la organización contra las crisis económicas y los cambios violentos del entorno. Es en este nivel donde se producen las políticas de alianza con otras empresas, la concentración de estudio, estrategia multinacional y desempeño profesional. 
Una vez identificados los subsistemas que conforman estudio son definidos los objetivos de cada nivel. Estas metas deben estar en consonancia con el objetivo principal de la organización, por ejemplo, si el objetivo es fomentar el desarrollo de nuevos productos, es necesario caracterizar los objetivos de cada nivel con respecto a este objetivo e identificar el nivel de cumplimiento de estos objetivos para identificar los obstáculos y ayudar a establecer prioridades. El análisis del sistema y de los niveles de éxito se consiguen mediante el estudio de las siguientes variables:

Variables de entrada (VE): Vienen de fuera del sistema u otros sistemas. Puede ser la demanda de producción, el precio de los materiales o la demanda de servicios.

Variables de salida (VS): son aquellas que salen del sistema en estudio para el sistema exterior en la forma de información o materiales. Pueden ser productos terminados, pacientes, clientes que disfrutaron de un servicio.

Variables de acción (VA): Son las acciones que regulan las transformaciones: reglas de prioridad, de admisión, de programación.

Variable de Información (VI): Es el flujo de noticias sobre el funcionamiento del sistema, puede ser el número de visitas, consultas, intervenciones, entre otros.

Variables Esenciales (VES): Describen el funcionamiento del sistema y cuantifican el grado de cumplimiento de los objetivos.

Después de la formulación de un modelo de la situación actual del sistema en estudio los análisis se realizan en función de las deficiencias encontradas, a a partir de lo que, se parte a la construcción de que el autor denomina "sistema propuesto", que es la propuesta de un nuevo flujo organizacional que permita corregir los fallos en el sistema actual. El contraste entre los dos modelo del sistema en estudio, el actual y el propuesto las debilidades posibilita ver sus debilidades e proponer soluciones para el correcto funcionamiento del sistema.

\subsubsection{Evaluación por lo pares del Sistema de Gestión de la Innovación}

\section{Propuesto}

Después de la construcción de una propuesta de Sistema Gestión de la Innovación, basado en la aplicación del Método de Formulación por Objetivos, el modelado fue llevado para evaluación en un grupo de siete (07) personas pertenecientes a la Coordinación general, a la coordinación de TCC e de Prácticas profesionales y al NDE del curso. 
La Coordinación del Curso y NDE son los sectores responsables por la realización de cambios en el proyecto político pedagógico del curso, hecho que motivó la elección de su participación en la evaluación del modelado propuesto.

Es importante destacar que este no es un procedimiento para validar el sistema, sino más bien una forma de llevar el sistema a la atención de pares, que pueden ser responsables por una posible implementación de la propuesta, con el fin de detectar fallos y realizar mejoras en el sistema propuesto.

La técnica utilizada para conducir la apreciación por los pares fue el Grupo Focal que para Caplan (1990) son "pequeños grupos de personas reunidas para evaluar conceptos o identificar problemas", convirtiéndose así en una herramienta común usada en investigaciones cualitativas.

En la visión de Vaughn et al. (1996), que utilizaran esta técnica en la investigación en la educación, el objetivo central del grupo focal es identificar las percepciones, sentimientos, actitudes e ideas de los participantes sobre un determinado tema, producto o actividad.

La reunión del grupo focal se inicia con seis (06) a diez (10) personas seleccionadas en función de sus características, homogéneas o heterogéneas, en relación con el tema que se discute. Algunos autores citan grupos con siete, ocho o incluso 12 personas. El número de personas debe ser tal que se fomente la participación y la interacción de todos, de manera ordenada. Por experiencia práctica con dinámicas de grupo, se puede considerar que 6 personas son suficientes para promover una buena discusión.

Durante la sesión se presentaron los resultados originados en las aplicaciones de las entrevistas y encuestas, la matriz DAFO con las fortalezas y debilidades del ambiente interno y las oportunidades y amenazas del ambiente externo del curso, además del modelo sistémico propuesto para la gestión de la innovación.

Después de la presentación se ha iniciado un debate en el que los participantes intercambiaron sus opiniones con respecto a las acciones propuestas y sus debilidades. Tras el cierre de esto debate los participantes les pidió que rellenaran un formulario que contenía una evaluación realizada por la indicación del grado de concordancia con los aspectos relacionados al sistema propuesto, cuyos resultados se presentan en el capítulo 5 de esta tesis. Esta etapa utiliza, por lo tanto, más una técnica cualitativa, basada en una pequeña muestra pero de gran importancia para los intereses de los resultados de la investigación, ya que la percepción de estos participantes sobre el contexto del problema es fundamental para su comprensión. 

Capítulo 4

\section{EL CURSO DE GRADO EN DESIGN DE LA UNIVERSIDAD FEDERAL DE AMAZONAS}




\section{EL CURSO DE GRADO EN DESIGN DE LA UNIVERSIDAD FEDERAL DE AMAZONAS}

En el cuarto capítulo se presenta la Institución y el curso investigado, además de enumerarse los principales factores relacionados con ellos con el fin de caracterizar los aspectos fundamentales que son importantes en el cumplimiento de los objetivos de la investigación.

\subsection{Presentación de la Institución}

De acuerdo con Brito (2009) la Universidad Federal de Amazonas (UFAM), la historia de esta institución educativa se inicia el 17 de enero de 1909, cuando se fundó la primera universidad brasileña, la Escuela Universitaria Libre de Manaos, más tarde llamada Universidad de Manaos.

La Universidad Libre de Manaos concebida por Eulalio Chaves, era formada por las Facultades de Derecho, Ciencias Sociales, Medicina, Ingeniería, Ciencias y Letras, y por medio del voto directo del personal educativo de estas unidades, Prof. Astrolabio Passos fue elegido como su primer director general. La Universidad de Manaos pasó por grandes dificultades $y$, después de algún tiempo, fue desintegrada en cursos aislados.

Debido a la crisis en la economía de Amazonas, que se centraba en la extracción del caucho, los cursos fueron extinguiéndose hasta el cierre oficial de la institución en 1926. La única unidad restante fue la Facultad de Ciencias Jurídicas y Sociales, más tarde llamada sólo de Facultad de Derecho, que permaneció de forma autónoma hasta que se fusionó con la Universidad de Amazonas.

La Universidad de Amazonas, con ese nombre, fue fundada el 12 de junio de 1962, bajo la ley federal 4.069-A, escrito por su fundador, el senador Arthur Virgilio Filho, siendo posteriormente rebautizada con el nombre de Fundación Universidad de Amazonas (FUA) pero que se quedó popularmente conocida apenas como Universidad de Amazonas (UA), y consistió en la reintegración de las instituciones de educación superior que trabajaron aisladas en nuestro estado. Con la Ley Federal 10.468, de junio de 2002, la institución pasó a llamarse Universidad Federal de Amazonas.

En los años 60, la universidad tenía aproximadamente 700 alumnos repartidos en cinco cursos; La UFAM ofrece en la actualidad 51 cursos de grado, 19 Masters, siendo 13 de ellos ya acreditados por la CAPES, 02 cursos a nivel de doctorado y sobre 30 en la modalidad lato sensu. De los 766 docentes que trabajan en las 11 unidades académicas, 218 son doctores, 344 son maestros, 
119 son especialistas y 85 licenciados. En 2003, la Universidad tenía inscritos regularmente, 20.500 alumnos en los cursos de grado y postgrado.

Además del Campus en la ciudad de Manaus, UFAM también tiene unidades en otras ciudades del estado de Amazonas como Benjamin Constant, Coari, Itacoatiara, Parintins, Humaitá y São Gabriel da Cachoeira, entre otros.

El campus en Manaus tiene una superficie de 6,7 millones de metros cuadrados, convirtiéndola en la mayor floresta urbana del país. En ella se encuentran muchas especies de fauna y flora. El área de construcción es de aproximadamente el 35\% del diseño arquitectónico original (con exclusión de la Facultad de Ciencias Sociales, en construcción), por el arquitecto Mario Severiano Porto, que le valió una mención de honor en el año 1987, del Instituto de Arquitectos de Brasil (IAB / RJ). En 2005 se inició la construcción de dos bloques ubicados en la Facultad de Tecnología.

\subsubsection{Estructura académica y administrativa de UFAM}

También de acuerdo a la información disponible en el sitio UFAM, la estructura administrativa de esta Universidad está compuesta por el órgano superior, que es la Rectoría, seguido de Pro-Rectorías e sectores complementarios. Cada uno de estos segmentos tiene varias secciones, como sigue:

Rectoría: Se hace por el Gabinete, la Dirección Ejecutiva, la Secretaría General de los Consejos Superiores, Representación en Brasilia, Departamento de Comunicación, Departamento Jurídico, Auditoría Interna y el Comité de Gestión.

Pro-Rectorías: Se dividen en Enseñanza de Grado, Investigación y Estudios de Posgrado, Extensión e internalización, Planificación, Administración y Asuntos Comunitarios.

Sectores complementarios: Biblioteca Central, Centro de Artes, Centro de Ciencias Medioambientales, Centro de Procesamiento de Datos, Comisión Permanente de Selección, Editor de UFAM, Granja Experimental, Prensa Universitaria, Hospital Universitario Getúlio Vargas, Museo Amazónico, Ayuntamiento del Campus, Centro de I \& D (Investigación y Desarrollo) en Tecnología Electrónica y de la Información, Editora, Centro de Desarrollo de Energías, Centro de Investigación y Producción de Drogas.

La estructura académica de UFAM se divide entre institutos, facultades y escuelas, distribuidos de acuerdo a su área.

Institutos: Instituto de Ciencias Biológicas, Instituto de Ciencias Matemáticas, Instituto de Humanidades y Letras. 
Faculdades: Faculdad de Ciencias Agrícolas, Faculdad de Ciencias de la Salud, Faculdad de Derecho, Faculdad de Educación, Faculdad de Ciencias Sociales, Facultad de Educación Física y Facultad de Tecnología.

Escuela: Escuela de Enfermería.

\subsection{La Facultad de Tecnología}

El curso de Diseño de Pregrado, objeto de este estudio, se asigna en la Facultad de Tecnología. Esta unidad alberga 04 cursos de grado: Ingeniería Civil, Ingeniería Eléctrica, Ingeniería de Producción y Diseño Industrial.

La Facultad de Tecnología y sus cursos se distribuyen en los siguientes departamentos académicos: Construcción, Design y Expresión Gráfica, Electricidad, Electrónica y Telecomunicaciones, Plomería y Saneamiento, Transporte e Ingeniería Geotécnica. Esta unidad también ofrece varios cursos de postgrado, en los niveles de especialización, máster y doctorado, en las siguientes áreas:

- Cursos de especialización: Ingeniería de Producción, Design, Publicidad y Marketing, Ergonomía, Design de Interiores, Tv Digital, Dinámica y Control de sistemas robóticos.

- Cursos de máster: Ingeniería de Producción; Microelectrónica.

- Cursos de Doctorado: Ingeniería de Transporte.

\subsection{Estructura de Apoyo a la Innovación de UFAM}

La Universidad Federal de Amazonas, a través de su dirección superior ha demostrado iniciativas para fomentar el entorno de la innovación dentro de la institución. En 2007, fue creado el NIT - Núcleo de Innovación Tecnológica, bajo la dirección del Asesor Especial para la Innovación y la Tecnología que, según la información de la página web oficial de UFAM, tenía como objetivo establecer una estructura de acuerdo con los preceptos de la Ley de Innovación y dar agilidad a los procedimientos administrativos relacionados con la propiedad intelectual. 
También se aprobó en 2011 por CONSUNI (Consejo Universitario) La Política Institucional de Innovación Tecnológica de la Universidad Federal de Amazonas, cuyos objetivos son:

- Estimular y potenciar, de manera continua y permanente la actividad creativa demostrada por la producción científica, tecnológica y artística de sus profesores, estudiantes y técnicos administrativos en educación;

- Estimular y fomentar la creación intelectual a través de proyectos o actividades financiadas o realizadas en colaboración con otras instituciones, organizaciones de apoyo o empresas, nacionales $y$ extranjeras;

- Promover la protección de las creaciones intelectuales y tecnológicas en la institución y en las organizaciones asociadas;

- Proporcionar a UFAM los mecanismos de gestión tecnológica innovadora a través de los Parques Tecnológicos e Incubadoras de todas las áreas del conocimiento;

- Fomentar la sostenibilidad institucional de las acciones de innovación y de las interfaces económico, social, cultural y ambiental.

Además del NIT se creó en 2010 el PCTIS (Parque Científico y Tecnológico para la Inclusión Social). De acuerdo con Silva y Scherer (2010) el PCTIS es una estructura institucional orientada a la organización de una Red de Investigación, Extensión e Innovación centrada en la inclusión social, con el firme propósito de velar por la política de sostenibilidad socioeconómico. El parque permite crear oportunidades de acceso para el disfrute de los bienes y servicios sociales y la adopción de prácticas sostenibles de generación de ingresos a través de la Investigación, Desarrollo e Innovación. 


\subsection{El Curso de Grado en Design UFAM}

\subsubsection{Histórico}

Creado el 16 de enero de 1988, mediante la Resolución No. 02/87 en proceso de reconocimiento, el curso de Diseño Industrial de la Universidad Federal de Amazonas era destinado a formar las calificaciones de Diseñadores Industriales de Productos y Programadores Visuales. El curso inicialmente tenía una duración de 10 períodos ( 5 años) y funcionaba en turnos de mañana y tarde, posteriormente alocado sólo en el turno de la mañana.

Pionero de la enseñanza del Diseño en Amazonas, la llegada del curso confundiese con la llegada del propio diseño en el estado. El Curso de Diseño Industrial UFAM, que a lo largo de los años ha estado cada vez más fuerte, fue, por más de una década, el único curso en el área del estado, donde existen hoy cuatro grados en diseño, ofrecidos por instituciones privadas.

El curso pasó por su última evaluación del MEC en abril de 2004, y de acuerdo a las recomendaciones de la evaluación y de una la planificación estratégica para el curso propuesta por los profesores, alumnos y personal, guiados por PROPLAN (Pro-Rectoría de Planificación), en octubre 2004 comenzó un proceso de reformulación con el fin de satisfacer a las nuevas orientaciones curriculares para la educación de los cursos de grado en diseño y otros aspectos destacados en la evaluación de MEC y la evaluación en el autoevaluación hecha entre profesores, estudiantes y coordinación del curso.

Algunos de los aspectos en los que las necesidades de mejora fueron identificadas fueron: la falta de actualización de la estructura pedagógica y curricular, la necesidad de concursos para contratación de más profesores en el ámbito de la programación visual, evaluación y formulación de un plan de capacitación docente y la mejora de la estructura física del curso.

Durante el rediseño del proyecto de curso fueron hechos ajustes para de inserir en su realidad el contexto actual de la actividad, pues así como la actividad de diseño ha evolucionado y adquirido nuevas dimensiones, también era de gran importancia que el curso tuviera un carácter actualizado y flexible con el fin de tener una evolución constante.

En junio de 2007 se concluyó la reformulación nuevo proyecto políticopedagógico del Curso, fruto del esfuerzo conjunto de profesores, técnicos, y representantes de los estudiantes. El proyecto tiene como características principales la extinción de las cualificaciones y la implementación de un plan de estudios más completo que permite a los estudiantes a adaptarse mejor al 
mercado de trabajo actual y a la característica dinámica que la actividad adquirió en los últimos años.

Otro cambio fue que la duración del curso pasó a ser de 08 semestres (4 años) con la carga de trabajo total correspondiente a 3.105 horas, con una visión más actualizada que proporciona a los alumnos, la formación de un nuevo perfil de los egresados y del mercado laboral. También se evaluó y restructuró los procesos de trabajo de Conclusión de Curso y de Prácticas Supervisadas, además de mecanismos más eficientes para estimular la investigación y la extensión.

La nueva estructura del curso de Design UFAM fue desarrollada en la base de las Directrices Curriculares Nacionales de los Cursos de Diseño (Resolución $\mathrm{N}^{\circ}$ 5, de 8 de marzo de 2004 - CNE / CES) y da al estudiante una formación más completa, basada en una reflexión teórica actualizado en el campo de las distintas áreas de conocimiento y del Design. El diseño del curso tiene que ver con el estímulo metodológico para aplicar la potencialidad y la libertad creativa, la promoción de la conciencia social, la valoración y el reconocimiento de nuestra historia, y siempre con la preocupación de la consolidación de la ética profesional.

Además de los cambios estructurales, en el nuevo proyecto políticopedagógico del curso, se decidió cambiar el nombre del curso para Design, en sustitución del término Diseño Industrial para su divulgación y su proceso de selección (PSM- Proceso Selectivo Macro / PSC- Proceso Selectivo continuo).

El término Diseño Industrial para describir el curso, aunque esté correcto, ha traído muchas dificultades en la comprensión de su actividad, tanto en la búsqueda de alumnos por el curso (que en general desconocen el contenido de los cursos de grado) pues expresaba una asociación de nomenclatura con actividades centradas en la ingeniería de procesos industriales, como en la inserción de los egresados en el mercado laboral que está más familiarizado con el término Design.

La popularización del término Design en el Estado de Amazonas fue reforzado especialmente después de la llegada de más cuatro cursos de grado en el área que adoptan este nombre, pertenecientes a instituciones privadas, después de lo cual se hizo común la percepción errónea de los laicos que Design y Diseño Industrial se trataban de actividades distintas.

En ámbito nacional se observa que el término Design es adoptado también en la Resolución $\mathrm{n}^{\circ} 5$ CNE / CES 8 de marzo de 2004, que trata de las Directrices Nacionales para los cursos de Design. Esta denominación ha presentado asimilación nacional notable, en especial, desde el lanzamiento en noviembre de 1996, del Programa Brasileño de Design. Oficialmente, por lo tanto, el 
término Design ha sido asimilado por el Gobierno Federal y ha sido objeto de una amplia cobertura mediática en la prensa y la televisión.

\subsubsection{Objetivos del curso}

\section{Objetivo General}

Formar profesionales de nivel superior, capacitados para ejecutar proyectos industriales, que actúen en las fases de definición de necesidades, concepción y desarrollo de los proyectos, con miras a la idoneidad de estas necesidades de los usuarios y las posibilidades de producción, ejerciendo sus actividades con actitud profesional y competencia para trabajar como un agente de transformación social.

\section{Objetivos Específicos}

- Promover y fomentar la investigación en Diseño en la búsqueda de nuevas soluciones a los nuevos paradigmas de la sociedad, buscando su crecimiento y mejoras en la vida Calidad.

- Promover y alentar iniciativas y proyectos que puedan representar una mejora efectiva en el desarrollo de nuevas tecnologías, productos y sistemas de comunicación, a través del diseño, en provecho del desarrollo de la sociedad.

- Generar conocimiento y actuar como difusor de estos, fomentando las relaciones entre profesores, alumnos, la sociedad y el mercado laboral.

\subsubsection{Estructura e Funcionamiento del Curso}

\section{Titulación}

El alumno del Curso de Design de UFAM al Graduarse recibe el título de Licenciado en Design.

\section{Modalidades}

El curso no tiene énfasis en su nuevo diseño y plan de estudios. 


\section{Número de plazas ofertadas por el curso}

Se ofrecen anualmente 42 plazas para el Curso de Design UFAM, 30 a través del Vestibular (Proceso Selectivo Macro- PSM) y 12 a través del PSC (Proceso Selectivo Continuo).

\subsubsection{Proyecto Político-Pedagógico del Curso}

La concepción que guía la formación de personal en el Proyecto PolíticoPedagógico del Curso se basa en los cambio de las características del mercado de trabajo para el profesional de Design que se produjo durante casi 20 años de existencia del curso en UFAM.

\subsubsection{Formación de Personal y Mercado}

En el momento de la creación del curso, en 1988, la expectativa que se generó fue la de formar profesionales para satisfacer las demandas del Polo Industrial de Manaus, esta expectativa no se ha materializado pues el Polo, en su mayoría, es compuesto por fabricantes que no tienen la autonomía necesaria para desarrollar productos.

Teniendo en cuenta la baja absorción de los profesionales por el Polo Industrial, los egresados del área de desarrollo de proyectos empezaron a buscar alternativas de productos de trabajo con el crecimiento de otros sectores del mercado como la industria de muebles y consultoría y desarrollo de proyectos en centros de investigación, estas alternativas, sin embargo, han demostrado ser insuficientes para absorber en el mercado la mayor parte de los titulados en el área de producto.

Junto a este escenario, desde mediados de los años 90 hubo un crecimiento considerable en el sector de la comunicación en el Estado de Amazonas, con el surgimiento y consolidación de empresas de publicidad, diseño y marketing, y el desarrollo de una gran industria gráfica impresa y digital, que ahora absorbe casi por completo los graduados de Design que tienen la calificación en Programación Visual y a menudo también los profesionales de diseño de producto. 


\subsubsection{Campos de Actuación Profesional}

La formación del profesional de Design en el curso permite su actuación en un rol de proyectos que circulan en diferentes áreas del diseño, no separando el conocimiento, como se hizo anteriormente, entre diferentes calificaciones. Diferentes destrezas y habilidades que se desarrollan en las disciplinas de proyecto, tecnológicas y de herramientas, también son dirigidas a capacidades perceptivas de los usuarios.

El campo del profesional de diseño se encuentra principalmente en los sectores de la actividad industrial y gráfica. El Designer puede trabajar en empresas privadas o de forma autónoma. Incluso puede dedicarse a la investigación y a la práctica docente en las escuelas técnicas y universidades.

En la actualidad, el diseño ya está siendo reconocido como un importante diferenciador estratégico y competitivo para las empresas, lo que lleva a la absorción de los profesionales en el mercado laboral.

A pesar de la baja penetración de los Designers en el Polo Industrial de Manaus - PIM, se observó que en los últimos años se ha producido un cambio en la dinámica de las empresas de este sector, causada por el establecimiento de algunos equipos de desarrollo dentro de las empresas en Manaus, mismo tímidamente, ya se observa la admisión de algunos Designers en la mano de obra del PIM.

Otro campo para los Designer que está en fuerte crecimiento es el desarrollo de aplicaciones para medios digitales, tales como sitios web, software e interfaces para juegos electrónicos, viñetas y animaciones.

\subsubsection{Perfil del Profesional a ser formado}

El perfil de los graduados del curso de design UFAM debe ser de un profesional con una formación completa para trabajar en distintas áreas del diseño, que posee una visión global, sin perder el dominio sobre los detalles específicos de los conocimientos de estas áreas, y con tránsito en los dos campos básicos de trabajo: Diseño de Producto y Diseño Gráfico.

El profesional formado también debe poseer conocimientos acerca de los diversos sectores productivos y sus posibilidades de desarrollo, principalmente en el contexto regional. También debe preocuparse por la sostenibilidad de la región amazónica, poseer la competencia técnica para interactuar con el 
medio ambiente y el conocimiento para conceptualizar y ejecutar proyectos que cumplan con las necesidades ambientales y sociales, sin perder, sin embargo, la visión del mercado global.

El egreso debe estar en consonancia con la diversidad de nichos de actuación, tener una formación teórica, crítica e innovadora para realizar también la investigación y producción de conocimiento en un área desprovista de bibliografía, documentación y análisis de proyectos. El Curso de Diseño UFAM debe ofrecer la información para que el profesional pueda construir una actitud empresarial con el desarrollo de habilidades en las áreas de gestión de productos y proyectos, así como la capacidad de trabajar en equipos multidisciplinarios.

Ser un profesional en consonancia con las necesidades de la sociedad a la que pertenece, que posee una sólida base teórica, tecnológica y humanística, comprometida con la realidad brasileña, especialmente locales, con pensamiento crítico y responsabilidad social capaces de interactuar con las transformaciones y nuevos paradigmas de la sociedad, generando innovaciones que promuevan la mejora en la calidad de vida.

El alumno del cursos de Design debe dejará ser capaz de detectar la percepción del consumidor, con respecto a cuestiones funcionales, estructurales, semánticas, pragmáticas y estéticas, y por lo tanto capaz de actuar como un diferencial competitivo en la industria con respecto a la Calidad y al costo / beneficio de bienes y servicios. 


\subsubsection{Concepción de la Organización Curricular}

El currículo del curso de Design se organiza en ocho (08) semestres, teniendo la carga de trabajo total de 3.105 horas, respetando el mínimo de horas requeridas por la ley (2.400 horas). Así, los sujetos fueron clasificados en las áreas de formación básica y específica y teórica/práctica.

La filosofía y planificación del currículo del curso de Design fueron desarrolladas de acuerdo con la concepción y los objetivos de la institución y por supuesto, respetando las directrices nacionales establecidas por el MEC para la graduación en el área.

El programa del curso actual se ha adoptado para remplazar el del su creación en el ano de 1988, que fue eliminado frente a las necesidades actuales de la profesión. El currículo antiguo adoptaba la división convencional entre las cualificaciones de diseño de producto y programación Visual y tenía una duración de 10 períodos ( 5 años).

El plan de estudios actual funciona con líneas modernas de grado de la educación en diseño, en el que la división entre las cualificaciones ya no se produce, los contenidos están unificados, la estructura tiene un enfoque interdisciplinario, que ofrece al estudiante más allá del contenido específico del curso, formación en diversas disciplinas de conocimiento general que circulan entre las áreas de humanidades y tecnologías.

La unificación de las cualificaciones proporciona una mayor eficiencia en la relación profesor / número de cursos que se imparten. La estructura en ocho períodos optimiza la cuestión de la evasión, detectada debido a la larga duración del plan de estudios anterior. El diseño del nuevo plan de estudios también corrige los defectos detectados en la estructura anterior, al igual que la repetición de contenidos, y aporta más flexibilidad a la actualización e inclusión de contenidos adecuados a la realidad regional.

\subsubsection{La Matriz Curricular del curso}

Se presenta en este tópico el currículo vigente en el curso de Design , formado por un grupo de asignaturas obligatorias (Tabla 06) y un grupo de asignaturas electivas (Tabla 07). 


\section{Asignaturas Obligatorias}

Tabla 06: Estructura Curricular de asignaturas Obligatorias del Curso de Design/UFAM

\begin{tabular}{|c|c|c|c|c|c|}
\hline PER. & CÓDIG & Asignaturas Obligatorias & CRÉDITOS & C.H. & Requisitos \\
\hline $1^{\circ}$ & & $\begin{array}{l}\text { História e Conceitos gerais de } \\
\text { Design }\end{array}$ & 4.4 .0 & $60 \mathrm{~h}$ & \\
\hline $1^{\circ}$ & & Matemática aplicada ao Design & 4.4 .0 & $60 \mathrm{~h}$ & \\
\hline $1^{\circ}$ & & Desenho Básico & 4.4 .0 & $60 \mathrm{~h}$ & \\
\hline $1^{\circ}$ & & Teoria da cor & 2.2 .0 & $30 \mathrm{~h}$ & \\
\hline $1^{\circ}$ & FTD008 & Metodologia Visual & 4.4 .0 & $60 \mathrm{~h}$ & \\
\hline $1^{\circ}$ & & $\begin{array}{l}\text { Metodologia do trabalho } \\
\text { Científico }\end{array}$ & 3.3 .0 & $45 \mathrm{~h}$ & \\
\hline \multirow[t]{2}{*}{$1^{\circ}$} & $\mathrm{IHI006}$ & História da Arte I & 4.4 .0 & $60 \mathrm{~h}$ & \\
\hline & & Subtotal & 25.25 .0 & $375 \mathrm{~h}$ & \\
\hline $2^{\circ}$ & & Computação Gráfica I & 3.2 .1 & $60 \mathrm{~h}$ & \\
\hline $2^{\circ}$ & & Análise Mecânica & 4.4 .0 & $60 \mathrm{~h}$ & $\begin{array}{l}\text { Matemática } \\
\text { aplicada ao } \\
\text { Design }\end{array}$ \\
\hline $2^{\circ}$ & & Perspectiva e Sombra & 4.4 .0 & $60 \mathrm{~h}$ & $\begin{array}{l}\text { Desenho } \\
\text { Básico }\end{array}$ \\
\hline $2^{\circ}$ & & Técnicas Analíticas & 4.4 .0 & $60 \mathrm{~h}$ & \\
\hline $2^{\circ}$ & & $\begin{array}{l}\text { Metodologia do projeto em } \\
\text { Design }\end{array}$ & 3.3 .0 & $45 \mathrm{~h}$ & \\
\hline $2^{\circ}$ & & Representação bidimensional & 4.4 .0 & $60 \mathrm{~h}$ & \\
\hline \multirow[t]{2}{*}{$2^{\circ}$} & IHI016 & História da Arte II & 4.4 .0 & $60 \mathrm{~h}$ & $\begin{array}{l}\text { História da } \\
\text { Arte I (IHI006) }\end{array}$ \\
\hline & & Subtotal & 26.25 .1 & $405 \mathrm{~h}$ & \\
\hline $3^{\circ}$ & & Computação Gráfica II & 3.2 .1 & $60 \mathrm{~h}$ & \\
\hline $3^{\circ}$ & & Design de Produtos de madeira & 3.2 .1 & $60 \mathrm{~h}$ & \\
\hline $3^{\circ}$ & & Geometria Descritiva & 4.3 .1 & $75 \mathrm{~h}$ & $\begin{array}{l}\text { Perspectiva e } \\
\text { Sombra }\end{array}$ \\
\hline $3^{\circ}$ & & Projeto I & 3.2 .1 & $60 \mathrm{~h}$ & $\begin{array}{l}\text { Técnicas } \\
\text { Analíticas } \\
\text { Metodologia } \\
\text { do projeto em } \\
\text { Design }\end{array}$ \\
\hline $3^{\circ}$ & FTD022 & Ergonomia I & 4.3 .1 & $75 \mathrm{~h}$ & \\
\hline $3^{\circ}$ & & Representação Tridimensional I & 3.2 .1 & $60 \mathrm{~h}$ & \\
\hline $3^{\circ}$ & & Tipografia & 2.2 .0 & $30 \mathrm{~h}$ & \\
\hline & & Subtotal & 22.16 .6 & $420 \mathrm{~h}$ & \\
\hline $4^{\circ}$ & & Computação Gráfica III & 3.2 .1 & $60 \mathrm{~h}$ & \\
\hline $4^{\circ}$ & FTD031 & Materiais industriais & 3.2 .1 & $60 \mathrm{~h}$ & \\
\hline $4^{\circ}$ & & Desenho Técnico para Design & 3.2 .1 & $60 \mathrm{~h}$ & $\begin{array}{l}\text { Desenho } \\
\text { Básico }\end{array}$ \\
\hline $4^{\circ}$ & & Projeto II & 3.2 .1 & $60 \mathrm{~h}$ & Projeto I \\
\hline $4^{\circ}$ & FTD023 & Ergonomia II & 4.4 .0 & $60 \mathrm{~h}$ & Ergonomia I \\
\hline
\end{tabular}




\begin{tabular}{|c|c|c|c|c|c|}
\hline PER. & CÓDIG & Asignaturas Obligatorias & CRÉDITOS & C.H. & Requisitos \\
\hline & & & & & (FTD022) \\
\hline $4^{\circ}$ & & Representação Tridimensional II & 3.2 .1 & $60 \mathrm{~h}$ & $\begin{array}{l}\text { Representação } \\
\text { Tridimens. I }\end{array}$ \\
\hline \multirow[t]{2}{*}{$4^{\circ}$} & & $\begin{array}{l}\text { Teoria semiótica e Percepção } \\
\text { em Design }\end{array}$ & 4.4 .0 & $60 \mathrm{~h}$ & \\
\hline & & Subtotal & 23.18 .5 & $420 \mathrm{~h}$ & \\
\hline $5^{\circ}$ & & Tecnologia Gráfica & 4.4 .0 & $60 \mathrm{~h}$ & \\
\hline $5^{\circ}$ & & $\begin{array}{l}\text { Tecnologia e Processos de } \\
\text { Fabricação I }\end{array}$ & 4.4 .0 & $60 \mathrm{~h}$ & $\begin{array}{l}\text { Materiais } \\
\text { industriais } \\
\text { (FTD031) }\end{array}$ \\
\hline $5^{\circ}$ & & Estudo da Embalagem & 3.2 .1 & $60 \mathrm{~h}$ & \\
\hline $5^{\circ}$ & & Projeto III & 3.2 .1 & $60 \mathrm{~h}$ & Projeto I \\
\hline \multirow[t]{2}{*}{$5^{\circ}$} & & Fotografia & 3.2 .1 & $60 \mathrm{~h}$ & \\
\hline & & Subtotal & 19.16 .3 & $330 \mathrm{~h}$ & \\
\hline $6^{\circ}$ & IHSO08 & $\begin{array}{l}\text { Introdução à Antropologia } \\
\text { Cultural }\end{array}$ & 4.4 .0 & $60 \mathrm{~h}$ & \\
\hline $6^{\circ}$ & & $\begin{array}{l}\text { Tecnol. e Processos de } \\
\text { Fabricação II }\end{array}$ & 4.4 .0 & $60 \mathrm{~h}$ & $\begin{array}{l}\text { Tecnologia e } \\
\text { Processos de } \\
\text { Fab. I }\end{array}$ \\
\hline $6^{\circ}$ & & Produção e análise gráfica & 3.2 .1 & $60 \mathrm{~h}$ & \\
\hline $6^{\circ}$ & & Projeto IV & 3.2 .1 & $60 \mathrm{~h}$ & Projeto I \\
\hline \multirow[t]{2}{*}{$6^{\circ}$} & & EcoDesign & 4.4 .0 & $60 \mathrm{~h}$ & \\
\hline & & Subtotal & 18.16 .2 & $300 \mathrm{~h}$ & \\
\hline $7^{\circ}$ & & Design de Superfície & 3.2 .1 & $60 \mathrm{~h}$ & \\
\hline $7^{\circ}$ & & Gestão econômica & 4.4 .0 & $60 \mathrm{~h}$ & \\
\hline \multirow[t]{2}{*}{$7^{\circ}$} & & Projeto Final de Graduação I & 3.2 .1 & $60 \mathrm{~h}$ & $\begin{array}{l}\text { Projeto I } \\
\text { Projeto II } \\
\text { Projeto III } \\
\text { Projeto IV }\end{array}$ \\
\hline & & Subtotal & 10.8 .2 & $150 \mathrm{~h}$ & \\
\hline $8^{\circ}$ & & $\begin{array}{l}\text { Legislação e ética aplicadas ao } \\
\text { Design }\end{array}$ & 3.3 .0 & $45 \mathrm{~h}$ & \\
\hline $8^{\circ}$ & & $\begin{array}{l}\text { Estágio Supervisionado em } \\
\text { Design }\end{array}$ & 5.0 .5 & $150 \mathrm{~h}$ & \\
\hline \multirow[t]{3}{*}{$8^{\circ}$} & & Projeto Final de Graduação II & 3.2 .1 & $60 \mathrm{~h}$ & $\begin{array}{l}\text { Proj. Final de } \\
\text { Graduação I }\end{array}$ \\
\hline & & & 11.5 .6 & $255 \mathrm{~h}$ & \\
\hline & & TOTAIS OBRIGATÓRIAS & 151.126 .25 & $2.655 \mathrm{~h}$ & \\
\hline
\end{tabular}




\section{Asignaturas Electivas - 20 créditos - mínimo de 300 horas}

Tabla 07: Estructura Curricular de asignaturas Electivas del Curso de Design UFAM

\begin{tabular}{|c|c|c|c|c|c|}
\hline & CÓDIG & ASIGNATURAS ELECTIVAS & CRÉDITOS & C.H. & Requisitos \\
\hline 01 & & Propaganda e Marketing* & 4.4 .0 & $60 \mathrm{~h}$ & \\
\hline 02 & & Web Design* & 4.4 .0 & $60 \mathrm{~h}$ & \\
\hline 03 & & Design de interiores* & 3.2 .1 & $60 \mathrm{~h}$ & $\begin{array}{l}\text { Desenho } \\
\text { Básico; } \\
\text { Perspectiva e } \\
\text { Sombra; } \\
\text { Representação } \\
\text { bidimensional; } \\
\text { Representa-ção } \\
\text { Tridimensional; } \\
\text { Desenho } \\
\text { Téc.p/ Design. }\end{array}$ \\
\hline 04 & & Tópicos Especiais em Design I* & 4.4 .0 & $60 \mathrm{~h}$ & \\
\hline 05 & & Tópicos Especiais em Design II* & 2.2 .0 & $30 \mathrm{~h}$ & \\
\hline 06 & & Tópicos Especiais em Design III* & 4.4 .0 & $60 \mathrm{~h}$ & \\
\hline 07 & & Tópicos Especiais em Design IV* & 2.2 .0 & $30 \mathrm{~h}$ & \\
\hline 08 & & Fashion Design * & 4.4 .0 & $60 \mathrm{~h}$ & \\
\hline 09 & & Arquitetura e urbanismo* & 6.6 .0 & $90 \mathrm{~h}$ & \\
\hline 10 & & Inglês instrumental I & 4.4 .0 & $60 \mathrm{~h}$ & \\
\hline 11 & & Português instrumental I & 4.4 .0 & $60 \mathrm{~h}$ & \\
\hline
\end{tabular}

La planificación de la metodología del diseño del curso se conduce a través de una serie de situaciones relacionadas con la Coordinación de Curso, el Colegiado de Profesores y la Pro-Rectoría de enseñanza de grado.

Dadas las realidades percibidas por todos los profesionales, profesores, alumnos, y la sociedad, los requisitos y los criterios para la organización curricular, tienen en cuenta, en el caso, algunos aspectos importantes de la cultura local y de la estructura de los campos de conocimiento del diseño, considerando las peculiaridades de la región del Amazonas, tales como materias primas, iconografía, condiciones climáticas y la mano de obra local. 

Capítulo 5

\section{RESULTADOS Y DISCUSIÓN}





\section{RESULTADOS Y DISCUSIÓN}

A lo largo de este capítulo se presentan los resultados obtenidos en la aplicación del instrumento de evaluación (Encuestas) entre los tres grupos que componen el curso: profesores, estudiantes y titulados. Los resultados se presentan en un primero momento, a partir de una división por grupos y, en una segunda etapa, son contrastados los resultados globales y realizado un análisis comparativo y la discusión acerca de las respuestas.

\subsection{Resultados del instrumento de evaluación del escenario de la innovación en el curso - grupo de PROFESORES}

La encuesta destinada a los profesores del curso de Design / UFAM fue compuesto de 13 preguntas (Apéndice B). Actualmente, el curso está compuesto por 18 profesores, el Cuestionario se aplicó a un total de 15 profesores (01 docente no tenía formación o experiencia en el área de diseño, 01 se encontraba lejos para asistir a doctorado y 01 en proceso del jubilación).

\subsubsection{Resultados de las cuestiones 01 a 06 del cuestionario (datos de identificación) - PROFESORES}

En Tabla 08, a continuación, se presenta una recopilación de los resultados de las preguntas 01 hasta 06 de la encuesta cuyo objetivo era reunir información para caracterizar el perfil de los participantes. 
Tabla 08: Perfil del grupo consultado - PROFESORES

\begin{tabular}{|c|c|c|c|}
\hline \multicolumn{2}{|c|}{ CARACTERÍSTICA } & \multirow{2}{*}{$\begin{array}{l}\text { FRECUÊNCIA } \\
06\end{array}$} & \multirow{2}{*}{$\begin{array}{l}\text { PORCENTAGE } \\
40 \%\end{array}$} \\
\hline$G \hat{E} N E P O$ & Hombre & & \\
\hline GETVETU & Mujer & 09 & $60 \%$ \\
\hline \multirow{5}{*}{ EDAD } & de 17 a 25 años & & \\
\hline & de 26 a 35 años & 03 & $20 \%$ \\
\hline & de 36 a 45 años & 09 & $60 \%$ \\
\hline & de 46 a 55 años & 02 & $13,3 \%$ \\
\hline & Más de 55 años & 01 & $6,7 \%$ \\
\hline \multirow{5}{*}{ ESTADO CIVIL } & Soltero & 03 & $20 \%$ \\
\hline & Casado & 09 & $60 \%$ \\
\hline & Viudo & 01 & $6,7 \%$ \\
\hline & Separado & - & - \\
\hline & Unión Estable & 02 & $13,3 \%$ \\
\hline \multirow{3}{*}{$\begin{array}{l}\text { ÁREA DEL } \\
\text { DESIGN EN QUE } \\
\text { ATUA }\end{array}$} & $\begin{array}{l}\text { Proyecto de } \\
\text { Productos }\end{array}$ & 11 & $73,3 \%$ \\
\hline & Programación Visual & 03 & $20 \%$ \\
\hline & $\begin{array}{l}\text { Interfaces Gráficas } \\
\text { Digitales } \\
\text { (Web/juegos/aplicati } \\
\text { vos electrónicos en } \\
\text { general) }\end{array}$ & 01 & $6,7 \%$ \\
\hline \multirow{5}{*}{ TITULAÇÃO } & Post-Doctor & - & - \\
\hline & Doctor & 02 & $13,3 \%$ \\
\hline & Maestro & 09 & $60 \%$ \\
\hline & Especialista & 04 & $26,7 \%$ \\
\hline & Licenciado & - & - \\
\hline
\end{tabular}

Fuente: El Autor

\subsubsection{Resultados de la Cuestión 07 de la encuesta (Grado de}

\section{Concordancia) - PROFESORES}

En la cuestión 07 de la encuesta de los profesores se presentó una lista de afirmaciones relacionadas con la Innovación para las cuales deberían responder entre las alternativas: Totalmente de acuerdo, Parcialmente de acuerdo, Parcialmente y Totalmente en desacuerdo. A continuación los resultados para cada uno de los ítems y la salida del SPSS para la cuestión: 
Para una mejor comprensión de las respuestas se presenta la consolidación de los datos en una única tabla con el fin de facilitar la visualización de las tendencias en las respuestas:

Tabla 09: Compilación de las respuestas de la Cuestión 07 - PROFESORES

\begin{tabular}{|c|c|c|c|c|c|c|c|c|c|}
\hline \multirow{2}{*}{\multicolumn{2}{|c|}{ İtem }} & \multicolumn{8}{|c|}{ Frecuencia/Porcentaje } \\
\hline & & \multicolumn{2}{|c|}{$\begin{array}{l}\text { Concordo } \\
\text { Totalmente }\end{array}$} & \multicolumn{2}{|c|}{$\begin{array}{l}\text { Concordo } \\
\text { Parcialmente }\end{array}$} & \multicolumn{2}{|c|}{$\begin{array}{l}\text { Discordo } \\
\text { Parcialmente }\end{array}$} & \multicolumn{2}{|c|}{$\begin{array}{l}\text { Discordo } \\
\text { Totalmente }\end{array}$} \\
\hline$a$ & $\begin{array}{l}\text { Estoy familiarizado } \\
\text { con el concepto de } \\
\text { innovación. }\end{array}$ & 09 & $60 \%$ & 06 & $40 \%$ & - & - & - & - \\
\hline b & $\begin{array}{l}\text { Estoy familiarizado } \\
\text { con el concepto } \\
\text { Emprendedor. }\end{array}$ & 09 & $60 \%$ & 06 & $40 \%$ & - & - & - & - \\
\hline c & $\begin{array}{l}\text { Estoy familiarizado } \\
\text { con el concepto de } \\
\text { transferencia de } \\
\text { tecnología. }\end{array}$ & 04 & $26,7 \%$ & 09 & $60 \%$ & 02 & $13,3 \%$ & - & - \\
\hline d & $\begin{array}{l}\text { Estoy familiarizado } \\
\text { con las reglas y otros } \\
\text { procedimientos } \\
\text { relacionados con la } \\
\text { Protección de la } \\
\text { Propiedad Intelectual } \\
\text { / Industrial. }\end{array}$ & 05 & $33,3 \%$ & 08 & 53,3 & 01 & $6,7 \%$ & 01 & $6,7 \%$ \\
\hline $\mathrm{e}$ & $\begin{array}{l}\text { Conozco los objetivos } \\
\text { del curso en relación } \\
\text { a la innovación. }\end{array}$ & 08 & 53,3 & 06 & $40 \%$ & - & - & 01 & $6,7 \%$ \\
\hline$f$ & $\begin{array}{l}\text { Conozco la } \\
\text { investigación y los } \\
\text { proyectos que se } \\
\text { desarrollan en el } \\
\text { curso }\end{array}$ & 05 & $33,3 \%$ & 08 & $53,3 \%$ & 02 & $13,3 \%$ & - & - \\
\hline $\mathrm{g}$ & $\begin{array}{l}\text { El curso fomenta la } \\
\text { práctica de la } \\
\text { innovación entre los } \\
\text { alumnos y los } \\
\text { profesores. }\end{array}$ & 05 & $33,3 \%$ & 07 & $46,7 \%$ & 03 & $20 \%$ & - & - \\
\hline $\mathrm{h}$ & $\begin{array}{l}\text { La infraestructura de } \\
\text { laboratorios } \\
\text { disponible en el Curso } \\
\text { es suficiente para } \\
\text { estimular el } \\
\text { desarrollo de nuevos } \\
\text { productos y procesos. }\end{array}$ & - & - & 06 & $40 \%$ & 05 & $33,3 \%$ & 04 & $26,7 \%$ \\
\hline $\mathrm{i}$ & $\begin{array}{l}\text { Tengo acceso fácil a } \\
\text { la producción de } \\
\text { conocimientos } \\
\text { generados en el curso } \\
\text { (monografías, } \\
\text { artículos publicados, } \\
\text { los resultados de los } \\
\text { proyectos, etc.) }\end{array}$ & Est & cuestiór & no & plicó a & $\mathrm{s}$ pr & sores. & & \\
\hline
\end{tabular}




\begin{tabular}{|c|l|l|l|l|l|l|l|l|l|}
\hline $\mathrm{j}$ & $\begin{array}{l}\text { Creo que el acceso a } \\
\text { la información y la } \\
\text { formación dirigida a } \\
\text { la protección de la } \\
\text { propiedad intelectual } \\
\text { es esencial. }\end{array}$ & 12 & $80 \%$ & 03 & $20 \%$ & - & - & - & - \\
\hline $\mathrm{I}$ & $\begin{array}{l}\text { Creo que es esencial } \\
\text { fomentar el espíritu } \\
\text { emprendedor entre } \\
\text { los estudiantes y } \\
\text { profesores del Curso. }\end{array}$ & 12 & $80 \%$ & 03 & $20 \%$ & - & - & - & - \\
\hline $\mathrm{m}$ & $\begin{array}{l}\text { Creo que es esencial } \\
\text { la existencia de } \\
\text { proyectos } \\
\text { desarrollados en } \\
\text { cooperación con el } \\
\text { sector privado. }\end{array}$ & 14 & $93,3 \%$ & 01 & $6,7 \%$ & - & - & - & - \\
\hline $\mathrm{n}$ & $\begin{array}{l}\text { Creo que es esencial } \\
\text { la existencia de } \\
\text { proyectos } \\
\text { desarrollados en } \\
\text { cooperación con otras } \\
\text { instituciones de } \\
\text { educación e } \\
\text { investigación. }\end{array}$ & 12 & $80 \%$ & 03 & $20 \%$ & - & - & - & - \\
\hline
\end{tabular}

Fuente: El autor

\subsubsection{Resultados de la Cuestión 08 de la encuesta (Respuesta SI o NO) -}

\section{PORFESORES}

En esta pregunta se les pidió respuestas dicotómicas (sí o no) sobre los factores que influyen en el ambiente de Innovación del curso, cuyos resultados se muestran en la Tabla 22 a continuación:

Tabla 10: Compilación de las respuestas de la Cuestión 08 - PROFESORES

\begin{tabular}{|l|l|l|l|l|l|}
\hline & PREGUNTA & \multicolumn{3}{|l|}{ FRECÜÊNCIA/PORCENTAJE } \\
\hline & \multicolumn{3}{|l|}{ SI } & NO & \\
\hline a & $\begin{array}{l}\text { ¿Ya ha oído hablar del NIT } \\
\text { (Núcleo de Innovación } \\
\text { Tecnológica) de UFAM? }\end{array}$ & 13 & $86,7 \%$ & 02 & $13,3 \%$ \\
\hline b & $\begin{array}{l}\text { ¿En caso positivo, conoce el } \\
\text { alcance de sus actividades? }\end{array}$ & 08 & $53,3 \%$ & 07 & $46,7 \%$ \\
\hline c & $\begin{array}{l}\text { ¿Ya ha oído hablar de la PROTEC } \\
\text { (Pro-Rectoría de Innovación } \\
\text { Tecnológica) de UFAM? }\end{array}$ & 12 & $80,0 \%$ & 03 & $20,0 \%$ \\
\hline d & $\begin{array}{l}\text { ¿Ya ha oído hablar del CDTECH } \\
\text { (Centro de Desarrollo } \\
\text { Tecnológico y empresarial) de } \\
\text { UFAM? }\end{array}$ & 08 & $53,3 \%$ & 07 & $46,7 \%$ \\
\hline
\end{tabular}




\begin{tabular}{|c|l|l|l|l|l|}
\hline e & $\begin{array}{l}\text { ¿Conoce alguna incubadora de } \\
\text { empresas que opere en } \\
\text { Amazonas? }\end{array}$ & 09 & $60 \%$ & 06 & $40 \%$ \\
\hline $\mathrm{f}$ & $\begin{array}{l}\text { Ya he participado en proyectos } \\
\text { desarrollados con el apoyo del } \\
\text { sector privado. }\end{array}$ & 10 & $66,7 \%$ & 05 & $33,3 \%$ \\
\hline $\mathrm{g}$ & $\begin{array}{l}\text { Estoy interesado en participar en } \\
\text { proyectos desarrollados en } \\
\text { cooperación con el sector } \\
\text { privado. }\end{array}$ & 15 & $100 \%$ & - & - \\
\hline
\end{tabular}

Fuente: El autor

\subsubsection{Resultados de la Cuestión 09 de la encuesta - PROFESORES}

La cuestión 09 de la encuesta de los profesores estaba vinculada al ítem "e" de la cuestión anterior. Si la respuesta de los encuestados fuera "sí" a la pregunta: "¿Conoces alguna incubadora de empresas que opere en Amazonas?" Deberían citar las incubadoras que conocían. Las respuestas están en la tabla a continuación:

Tabla 11: Compilación de las respuestas de la Cuestión 09 - PROFESORES

\begin{tabular}{|l|l|l|}
\hline \multirow{2}{*}{ NOMBRE DE LA INCUBADORA } & \multicolumn{2}{l|}{ FRECÜÊNCIA/PORCENTAJE } \\
\hline Incubadora SEBRAE & 1 & 6,7 \\
\hline Incubadora FUCAPI & 2 & 13,3 \\
\hline Incubadora o CIDI & 4 & 26,7 \\
\hline Incubadora INPA & 1 & 6,7 \\
\hline Incubadora FMF & 1 & 6,7 \\
\hline No conozco ninguna incubadora & 6 & 40,0 \\
\hline Total & 15 & 100,0 \\
\hline
\end{tabular}

Fuente: El autor

\subsubsection{Resultados de la Cuestión 10 de la encuesta (Acciones Inovativas)}

En la cuestión 10 de la encuesta de los profesores se les consultó sobre las acciones que podrían contribuir a la mejora del proceso de innovación en el curso de Design. Se presentó al grupo una lista de 11 sugerencias de medidas entre las que deberían elegir cuatro (4) en orden de importancia. ( 1 para el más importante / 4 para el menos importante). A continuación se muestra el Output del SPSS para la cuestión:

A continuación son presentados dos datos consolidados de la Cuestión 10: 
Tabla 12: Compilación de las respuestas de la Cuestión 10 - PROFESORES

\begin{tabular}{|c|c|c|c|c|c|c|c|c|c|c|c|c|c|}
\hline \multirow{2}{*}{\multicolumn{2}{|c|}{ İtem }} & \multicolumn{10}{|c|}{ Frecuencia/Porcentaje (\%) } & \multirow{2}{*}{\multicolumn{2}{|c|}{ TOTAL }} \\
\hline & & \multicolumn{2}{|c|}{$\begin{array}{l}1^{\circ} \text { más } \\
\text { importan } \\
\text { te }\end{array}$} & \multicolumn{2}{|c|}{$\begin{array}{l}2^{\circ} \text { más } \\
\text { importan } \\
\text { te }\end{array}$} & \multicolumn{2}{|c|}{$\begin{array}{l}3^{\circ} \text { más } \\
\text { importan } \\
\text { te }\end{array}$} & \multicolumn{2}{|c|}{$\begin{array}{l}4^{\circ} \text { más } \\
\text { importante }\end{array}$} & \multicolumn{2}{|c|}{$\begin{array}{l}\text { No se citó } \\
\text { entre las } 04 \\
\text { opciones }\end{array}$} & & \\
\hline a & $\begin{array}{l}\text { Mejorar el } \\
\text { conocimiento de la } \\
\text { parte del curso } \\
\text { sobre las } \\
\text { demandas del } \\
\text { sector privado en } \\
\text { el área de Design. }\end{array}$ & 7 & 46,7 & 3 & 20,0 & - & - & 1 & 6,7 & 4 & 26,7 & 15 & $\begin{array}{l}100 \\
\%\end{array}$ \\
\hline $\mathrm{b}$ & $\begin{array}{l}\text { Mejorar la } \\
\text { infraestructura y } \\
\text { laboratorios que } \\
\text { puedan apoyar el } \\
\text { desarrollo de } \\
\text { nuevos procesos y } \\
\text { productos. }\end{array}$ & 4 & 26,7 & 5 & 33,3 & 3 & 20 & 2 & 13,3 & 1 & 6,7 & 15 & $\begin{array}{l}100 \\
\%\end{array}$ \\
\hline c & $\begin{array}{l}\text { Formación en } \\
\text { materia de } \\
\text { protección de la } \\
\text { propiedad } \\
\text { industrial (registro } \\
\text { de marcas, } \\
\text { patentes, etc) }\end{array}$ & - & - & - & - & 1 & 6,7 & 1 & 6,7 & 13 & 86,7 & 15 & $\begin{array}{l}100 \\
\%\end{array}$ \\
\hline $\mathrm{d}$ & $\begin{array}{l}\text { Mejorar el } \\
\text { acompañamiento } \\
\text { de la destinación } \\
\text { de los titulados } \\
\text { con el fin de } \\
\text { establecer una red } \\
\text { de cooperación. }\end{array}$ & 1 & 6,7 & - & - & 2 & $\begin{array}{l}13, \\
3\end{array}$ & 1 & 6,7 & 11 & 73,3 & 15 & $\begin{array}{l}100 \\
\%\end{array}$ \\
\hline $\mathrm{e}$ & $\begin{array}{l}\text { Apoyo técnico /de } \\
\text { gestión } \\
\text { implantación de } \\
\text { negocios. }\end{array}$ & - & - & 2 & 13,3 & 1 & 6,7 & 1 & 6,7 & 11 & 73,3 & 15 & $\begin{array}{l}100 \\
\%\end{array}$ \\
\hline$f$ & $\begin{array}{l}\text { Apoyo a la } \\
\text { Transferencia de } \\
\text { Tecnología. }\end{array}$ & - & - & - & - & - & - & 1 & 6,7 & 14 & 93,3 & 15 & $\begin{array}{l}100 \\
\%\end{array}$ \\
\hline $\mathrm{g}$ & $\begin{array}{l}\text { Mayor cooperación } \\
\text { con las } \\
\text { incubadoras. }\end{array}$ & - & - & - & - & - & - & - & - & 15 & 100,0 & 15 & $\begin{array}{l}100 \\
\%\end{array}$ \\
\hline $\mathrm{h}$ & $\begin{array}{l}\text { Foros para reunir } \\
\text { los investigadores } \\
\text { a las empresas. }\end{array}$ & & & - & - & 1 & 6,7 & & - & 14 & 93,3 & 15 & $\begin{array}{l}100 \\
\%\end{array}$ \\
\hline $\mathrm{i}$ & $\begin{array}{l}\text { Construcción, por } \\
\text { el curso de la } \\
\text { agenda de } \\
\text { investigación } \\
\text { definida en } \\
\text { conjunto con el } \\
\text { sector productivo. }\end{array}$ & & - & 3 & 20,0 & 4 & $\begin{array}{l}26, \\
7\end{array}$ & & - & 8 & 53,3 & 15 & $\begin{array}{l}100 \\
\%\end{array}$ \\
\hline$j$ & $\begin{array}{l}\text { Participación de la } \\
\text { PROTEC en } \\
\text { proyectos e } \\
\text { Investigaciones. }\end{array}$ & - & - & - & - & 1 & 6,7 & 3 & 20,0 & 11 & 73,3 & 15 & $\begin{array}{l}100 \\
\%\end{array}$ \\
\hline
\end{tabular}




\begin{tabular}{|c|c|c|c|c|c|c|c|c|c|c|c|c|c|}
\hline \multicolumn{2}{|c|}{ İtem } & \multicolumn{10}{|c|}{ Frecuencia/Porcentaje (\%) } & \multirow{2}{*}{\multicolumn{2}{|c|}{ TOTAL }} \\
\hline & & \multicolumn{2}{|c|}{$\begin{array}{l}1^{\circ} \text { más } \\
\text { importan } \\
\text { te }\end{array}$} & \multicolumn{2}{|c|}{$\begin{array}{l}2^{\circ} \text { más } \\
\text { importan } \\
\text { te }\end{array}$} & \multicolumn{2}{|c|}{$\begin{array}{l}3^{\circ} \text { más } \\
\text { importan } \\
\text { te }\end{array}$} & \multicolumn{2}{|c|}{$\begin{array}{l}4^{\circ} \text { más } \\
\text { importante }\end{array}$} & \multicolumn{2}{|c|}{$\begin{array}{l}\text { No se citó } \\
\text { entre las } 04 \\
\text { opciones }\end{array}$} & & \\
\hline \multirow[t]{2}{*}{ l } & $\begin{array}{l}\text { Desarrollo de } \\
\text { proyectos de } \\
\text { investigación y de } \\
\text { extensión capaces } \\
\text { de generar } \\
\text { negocios. }\end{array}$ & 3 & 20,0 & 2 & 13,3 & 2 & $\begin{array}{l}13, \\
3\end{array}$ & 5 & 33,3 & 3 & 20,0 & 15 & $\begin{array}{l}100 \\
\%\end{array}$ \\
\hline & TOTAL & $\begin{array}{l}1 \\
5\end{array}$ & $100 \%$ & $\begin{array}{l}1 \\
5\end{array}$ & $100 \%$ & 15 & $\begin{array}{l}100 \\
\%\end{array}$ & 15 & $100 \%$ & & & & \\
\hline
\end{tabular}

Fuente: El autor

La tabla siguiente muestra el orden de prioridades en las acciones indicadas por los profesores.

Tabla 13: Orden de prioridades en las acciones indicadas en la Cuestión 10 PROFESORES.

\begin{tabular}{|l|l|}
\hline $\begin{array}{l}\text { Grado de } \\
\text { Importancia }\end{array}$ & PROFESORES \\
\hline 1 & $\begin{array}{l}\text { Ítem más citado } \\
\text { demandas del sector privado en el área de Design. }\end{array}$ \\
\hline 2 & $\begin{array}{l}\text { Mejorar la infraestructura y laboratorios que puedan } \\
\text { apoyar el desarrollo de nuevos procesos y productos. }\end{array}$ \\
\hline 3 & $\begin{array}{l}\text { Construcción, por el curso de la agenda de } \\
\text { investigación definida en conjunto con el sector } \\
\text { productivo. }\end{array}$ \\
\hline 4 & $\begin{array}{l}\text { Desarrollo de proyectos de investigación y de extensión } \\
\text { capaces de generar negocios. }\end{array}$ \\
\hline
\end{tabular}

Fuente: El autor

Destacamos que no se mencionó ni una sola vez entre los 4 grados de importancia el ítem "g" Mayor cooperación con las incubadoras.

\subsubsection{Resultados de la Cuestión 11 de la encuesta (Calidad de un curso de grado) - PROFESORES}

En la cuestión 11 de la encuesta de los profesores se les pidió que clasificasen en orden de importancia, de una lista de 10 elementos, los que se consideran más relevantes para la Calidad de un curso de grado. (1 para el más importante - 10 para el menos importante). A continuación se presentan los resultados. 
En la Tabla 47, que se muestra a continuación, se puede ver que las frecuencias generales mencionadas por los docentes como prioridad en la Calidad de un curso. 
A partir de esta orden de prioridades será posible establecer un criterio para la interpretación de las preguntas 12 y 13, en las que los encuestados deben señalar las fortalezas y debilidades del curso de Design.

\begin{tabular}{|c|c|c|c|c|c|c|c|c|c|c|c|c|c|c|c|c|c|c|c|c|c|c|c|}
\hline & \multirow{2}{*}{$\begin{array}{l}\text { CONCEPTO DE } \\
\text { CALIDAD - PROFESORES } \\
\text { ITEM }\end{array}$} & \multicolumn{20}{|c|}{ PRIORIDADES } & \multirow{2}{*}{\multicolumn{2}{|c|}{ TOTAL }} \\
\hline & & \multicolumn{2}{|l|}{01} & \multicolumn{2}{|c|}{02} & \multicolumn{2}{|l|}{03} & \multicolumn{2}{|c|}{04} & \multicolumn{2}{|l|}{05} & \multicolumn{2}{|l|}{06} & \multicolumn{2}{|l|}{07} & \multicolumn{2}{|l|}{08} & \multicolumn{2}{|l|}{09} & \multicolumn{2}{|l|}{10} & & \\
\hline $\mathrm{a}$ & $\begin{array}{l}\text { Estructura del Currículo / } \\
\text { Contenido de las asignaturas }\end{array}$ & 10 & 66,7 & 1 & 6,7 & 1 & 6,7 & - & - & 1 & 6,7 & - & - & 2 & 13,3 & - & - & - & - & - & - & 15 & $100 \%$ \\
\hline $\mathrm{b}$ & Didáctica de los profesores & 1 & 6,7 & 3 & 20,0 & 6 & 40,0 & 3 & 20,0 & - & - & 1 & 6,7 & 1 & 6,7 & - & - & - & - & - & - & 15 & $100 \%$ \\
\hline C & $\begin{array}{l}\text { Puntualidad y asiduidad de } \\
\text { los profesores }\end{array}$ & - & - & - & - & 1 & 6,7 & 4 & 26,7 & 3 & 20,0 & 2 & 13,3 & 2 & 13,3 & 1 & 6,7 & 1 & 6,7 & 1 & 6,7 & 15 & $100 \%$ \\
\hline $\mathrm{d}$ & Titulación de los profesores & 1 & 6,7 & 3 & 20,0 & - & - & - & - & 3 & 20,0 & 4 & 26,7 & 1 & 6,7 & 2 & 13,3 & 1 & 6,7 & - & - & 15 & $100 \%$ \\
\hline e & $\begin{array}{l}\text { Envolvimiento de los } \\
\text { profesores con el curso }\end{array}$ & 3 & 20,0 & 5 & 33,3 & 5 & 33,3 & 1 & 6,7 & 1 & 6,7 & - & - & - & - & - & - & - & - & - & - & 15 & $100 \%$ \\
\hline$f$ & $\begin{array}{l}\text { Conforto e adecuación de } \\
\text { las aulas }\end{array}$ & - & - & - & - & 1 & 6,7 & 1 & 6,7 & 2 & 13,3 & 1 & 6,7 & 5 & 33,3 & 2 & 13,3 & 1 & 6,7 & 2 & 13,3 & 15 & $100 \%$ \\
\hline $\mathrm{g}$ & $\begin{array}{l}\text { Calidad de los laboratorios y } \\
\text { espacios específicos }\end{array}$ & 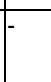 & - & 3 & 20,0 & 2 & 13,3 & 3 & 20,0 & - & - & 1 & 6,7 & - & - & - & - & 5 & 33,3 & 1 & 6,7 & 15 & $100 \%$ \\
\hline $\mathrm{h}$ & $\begin{array}{l}\text { Apoyo de personal técnico } \\
\text { (ex.: técnicos de } \\
\text { laboratorios y oficinas) }\end{array}$ & - & - & - & - & 1 & 6,7 & 2 & 13,3 & 5 & 33,3 & 1 & 6,7 & 2 & 13,3 & - & - & 2 & 13,3 & 2 & 13,3 & 15 & $100 \%$ \\
\hline$i$ & $\begin{array}{l}\text { Apoyo de la Coordinación } \\
\text { del Curso }\end{array}$ & - & - & - & - & - & - & 1 & 6,7 & 1 & 6,7 & 1 & 6,7 & 2 & 13,3 & 8 & 53,3 & 1 & 6,7 & 1 & 6,7 & 15 & $100 \%$ \\
\hline$j$ & $\begin{array}{l}\text { Apoyo de la Secretaria del } \\
\text { Curso }\end{array}$ & - & - & - & - & - & - & - & - & - & - & 1 & 6,7 & 1 & 6,7 & 2 & 13,3 & 4 & 26,7 & 7 & 46,7 & 15 & $100 \%$ \\
\hline & TOTAL & 15 & $100 \%$ & 15 & $100 \%$ & 15 & $100 \%$ & 15 & $100 \%$ & 15 & $100 \%$ & 15 & $100 \%$ & 15 & $100 \%$ & 15 & $100 \%$ & 15 & $100 \%$ & 15 & $100 \%$ & & \\
\hline
\end{tabular}

Tabla 14: Compilación de las respuestas de la Cuestión 11 - PROFESORES/ Fuente: El autor 

A partir de la observación de la Tabla 48, se presenta la siguiente prioridad en los factores que son más importantes para Calidad de un curso de grado en la opinión de los profesores.

Tabla 15: Orden de prioridades obtenidas en las respuestas de la Cuestión 11 PROFESORES

\begin{tabular}{|l|l|}
\hline PRIORIDADES & ITEM \\
\hline PRIORIDAD 01 & Estructura del Currículo / Contenido de las asignaturas \\
\hline PRIORIDAD 02 & Envolvimiento de los profesores con el curso \\
\hline PRIORIDAD 03 & Didáctica de los profesores \\
\hline PRIORIDAD 04 & Puntualidad y asiduidad de los profesores \\
\hline PRIORIDAD 05 & Apoyo de personal técnico (ex.: técnicos de laboratorios) \\
\hline PRIORIDAD 06 & Titulación de los profesores \\
\hline PRIORIDAD 07 & Conforto e adecuación de las aulas \\
\hline PRIORIDAD 08 & Apoyo de la Coordinación del Curso \\
\hline PRIORIDAD 09 & Calidad de los laboratorios y espacios específicos \\
\hline PRIORIDAD 10 & Apoyo de la Secretaria del Curso \\
\hline
\end{tabular}

Fuente: El autor

\subsubsection{Resultados de la Cuestión 12 de la encuesta (Puntos positivos del curso de Design) - PROFESORES}

En la Cuestión 12 fue solicitado a los participantes que indicasen 3 puntos positivos del curso de Design con base en la lista de 10 ítems de la Cuestión 11. A seguir los resultados obtenidos:

Tabla 16: Orden de puntos positivos obtenidos en las respuestas de la Cuestión 12 PROFESORES

\begin{tabular}{|l|l|l|l|l|l|l|l|l|l|}
\hline PUNTOS POSITIVOS & \multicolumn{2}{|l|}{ PRIORIDAD 1 } & \multicolumn{2}{|l|}{ PRIORIDAD 2 } & \multicolumn{2}{l|}{ PRIORIDAD 3 } & \multicolumn{2}{l|}{ NO CITADO } \\
\hline $\begin{array}{l}\text { Estructura del Currículo } \\
\text { / Contenido de las } \\
\text { asignaturas }\end{array}$ & 5 & 33,3 & 3 & 20,0 & 1 & 6,7 & 6 & 40,0 \\
\hline $\begin{array}{l}\text { Didáctica de los } \\
\text { profesores }\end{array}$ & 1 & 6,7 & 2 & 13,3 & 3 & 20,0 & 9 & 60,0 \\
\hline $\begin{array}{l}\text { Puntualidad y asiduidad } \\
\text { de los profesores }\end{array}$ & - & - & 3 & 20,0 & - & - & 12 & 80,0 \\
\hline $\begin{array}{l}\text { Titulación de los } \\
\text { profesores }\end{array}$ & 3 & 20,0 & 5 & 33,3 & 2 & 13,3 & 5 & 33,3 \\
\hline $\begin{array}{l}\text { Envolvimiento de los } \\
\text { profesores con el curso }\end{array}$ & 4 & 26,7 & 1 & 6,7 & 3 & 20,0 & 7 & 46,7 \\
\hline Conforto e adecuación & 1 & 6,7 & - & - & - & - & 14 & 93,3 \\
\hline
\end{tabular}




\begin{tabular}{|l|l|l|l|l|l|l|l|l|}
\hline PUNTOS POSITIVOS & \multicolumn{2}{|l|}{ PRIORIDAD 1 } & \multicolumn{2}{|l|}{ PRIORIDAD 2 } & \multicolumn{2}{l|}{ PRIORIDAD 3 } & NO CITADO \\
\hline de las aulas & & & & & & & & \\
\hline $\begin{array}{l}\text { Calidad de los } \\
\text { laboratorios y espacios } \\
\text { específicos }\end{array}$ & - & - & 1 & 6,7 & 1 & 6,7 & 13 & 86,7 \\
\hline $\begin{array}{l}\text { Apoyo de personal } \\
\text { técnico (ex.: técnicos } \\
\text { de laboratorios y } \\
\text { oficinas) }\end{array}$ & 1 & 6,7 & - & - & 1 & 6,7 & 13 & 86,7 \\
\hline $\begin{array}{l}\text { Apoyo de la } \\
\text { Coordinación del Curso }\end{array}$ & - & - & 1 & 6,7 & 4 & 26,7 & 10 & 66,7 \\
\hline $\begin{array}{l}\text { Apoyo de la Secretaria } \\
\text { del Curso }\end{array}$ & 2 & 13,3 & - & - & 1 & 6,7 & 12 & 80,0 \\
\hline TOTAL & 15 & 15 & 15 & & 15 & \\
\hline
\end{tabular}

5.1.8 Resultados de la Cuestión 13 de la encuesta (Deficiencias del curso de Design) - PROFESORES

En la Cuestión 13 fue solicitado a los participantes que indicasen 3 Deficiencias del curso de Design con base en la lista de 10 ítems de la Cuestión 11. A seguir los resultados obtenidos:

Tabla 17: Cuestión 13 - Orden de las deficiencias obtenidas en las respuestas de la Cuestión 13 - PROFESORES

\begin{tabular}{|l|l|l|l|l|l|l|l|l|}
\hline DEFICIENCIAS & \multicolumn{2}{|l|}{ PRIORIDAD 1 } & \multicolumn{2}{|l|}{ PRIORIDAD 2 } & \multicolumn{2}{l|}{ PRIORIDAD 3 } & \multicolumn{2}{|l|}{ NO CITADO } \\
\hline $\begin{array}{l}\text { Estructura del Currículo / } \\
\text { Contenido de las } \\
\text { asignaturas }\end{array}$ & 1 & 6,7 & - & - & - & - & 14 & 93,3 \\
\hline $\begin{array}{l}\text { Didáctica de los } \\
\text { profesores }\end{array}$ & 1 & 6,7 & - & - & 2 & 13,3 & 12 & 80,0 \\
\hline $\begin{array}{l}\text { Puntualidad y asiduidad } \\
\text { de los profesores }\end{array}$ & - & - & 2 & 13,3 & - & - & 13 & 86,7 \\
\hline $\begin{array}{l}\text { Titulación de los } \\
\text { profesores }\end{array}$ & 1 & 6,7 & 1 & 6,7 & - & - & 13 & 86,7 \\
\hline $\begin{array}{l}\text { Envolvimiento de los } \\
\text { profesores con el curso }\end{array}$ & 1 & 6,7 & - & - & 1 & 6,7 & 13 & 86,7 \\
\hline $\begin{array}{l}\text { Conforto e adecuación de } \\
\text { las aulas }\end{array}$ & 4 & 26,7 & 2 & 13,3 & 6 & 40,0 & 3 & 20,0 \\
\hline $\begin{array}{l}\text { Calidad de los } \\
\text { laboratorios y espacios }\end{array}$ & 3 & 20,0 & 8 & 53,3 & - & - & 4 & 26,7 \\
\hline
\end{tabular}




\begin{tabular}{|l|l|l|l|l|l|l|l|l|}
\hline DEFICIENCIAS & \multicolumn{2}{|l|}{ PRIORIDAD 1 } & \multicolumn{2}{l|l|}{ PRIORIDAD 2 } & \multicolumn{2}{l|}{ PRIORIDAD 3 } & NO CITADO \\
\hline específicos & & & & & & & & \\
\hline $\begin{array}{l}\text { Apoyo de personal } \\
\text { técnico (ex.: técnicos de } \\
\text { laboratorios y oficinas) }\end{array}$ & 3 & 20,0 & 1 & 6,7 & 3 & 20,0 & 8 & 53,3 \\
\hline $\begin{array}{l}\text { Apoyo de la Coordinación } \\
\text { del Curso }\end{array}$ & - & - & - & - & - & - & 15 & 100,0 \\
\hline $\begin{array}{l}\text { Apoyo de la Secretaria } \\
\text { del Curso }\end{array}$ & - & - & 1 & 6,7 & 3 & 20,0 & 11 & 73,3 \\
\hline TOTAL & $\mathbf{1 5}$ & & $\mathbf{1 5}$ & & $\mathbf{1 5}$ & & & \\
\hline
\end{tabular}

Fuente: El autor

5.2 Resultados del instrumento de evaluación del escenario de la innovación en el curso - ALUMNOS

La encuesta destinada a los ALUMNOS del curso de Design/UFAM fue compuesto de 14 preguntas (Apéndice $C$ ). Actualmente, el curso es compuesto por 181 alumnos. La encuesta se aplicó a un total de 86 alumnos pertenecientes a diferentes períodos del curso.

\subsubsection{Resultados de las cuestiones 01 a 06 del cuestionario (datos de identificación) - ALUMNOS}

En Tabla 18, a continuación, se presenta una recopilación de los resultados de las preguntas 01 A 06 de la encuesta cuyo objetivo era reunir información para caracterizar el perfil de los participantes (ALUMNOS).

Tabla 18: Perfil del grupo consultado - ALUMNOS

\begin{tabular}{|l|l|l|l|}
\hline CARACTERÍSTICA & FRECÜÊNCIA & PORCENTAJE \\
\hline GÊNERO & Hombre & 37 & $43,0 \%$ \\
\cline { 2 - 4 } & Mujer & 49 & $57,0 \%$ \\
\hline \multirow{4}{*}{ EDAD } & de 17 a 25 años & 81 & $94,2 \%$ \\
\cline { 2 - 4 } & de 26 a 35 años & 4 & $4,7 \%$ \\
\cline { 2 - 4 } & de 36 a 45 años & 1 & $1,2 \%$ \\
\cline { 2 - 4 } & de 46 a 55 años & 0 & $0 \%$ \\
\cline { 2 - 4 } & Más de 55 años & 0 & $0 \%$ \\
\hline \multirow{4}{*}{ CSTADO } & Soltero & 84 & $97,7 \%$ \\
\cline { 2 - 4 } & Casado & 1 & $1,2 \%$ \\
\cline { 2 - 4 } & Viudo & 0 & $0 \%$ \\
\cline { 2 - 4 } & Separado & 1 & $1,2 \%$ \\
\cline { 2 - 4 } & Unión Estable & 0 & $0 \%$ \\
\hline
\end{tabular}




\begin{tabular}{|l|l|l|l|}
\hline \multicolumn{2}{|l|}{ CARACTERISTICA } & FRECÚÊNCIA & PORCENTAJE \\
\hline \multirow{4}{*}{$\begin{array}{l}\text { ÁREA DE } \\
\text { INTERES }\end{array}$} & Proyecto de Productos & 34 & $39,5 \%$ \\
\cline { 2 - 4 } & Programación Visual & 33 & $38,4 \%$ \\
\cline { 2 - 4 } & $\begin{array}{l}\text { Interfaces Gráficas } \\
\text { Digitales } \\
\text { (Web/juegos/aplicativos } \\
\text { electrónicos en general) }\end{array}$ & 19 & $22,1 \%$ \\
\hline PERIOODO \\
$\begin{array}{l}\text { QUE ESTÁ } \\
\text { CURSANDO }\end{array}$ & Segundo & 29 & \\
\cline { 2 - 4 } & Cuarto & 25 & $33,7 \%$ \\
\cline { 2 - 4 } & Sexto & 21 & $29,1 \%$ \\
\cline { 2 - 4 } & Octavo & 11 & $12,8 \%$ \\
\hline
\end{tabular}

Fuente: El Autor

\subsubsection{Resultados de la Cuestión 07 de la encuesta (Grado de}

\section{Concordancia) - ALUMNOS}

En la cuestión 07 de la encuesta de los Alumnos se presentó una lista de afirmaciones relacionadas con la Innovación para las que deberían responder entre las alternativas: Totalmente de acuerdo, Parcialmente de acuerdo, Parcialmente y Totalmente en desacuerdo. A continuación los resultados para cada uno de los ítems y el Output del SPSS para la cuestión:

Para una mejor comprensión de las respuestas se presenta la consolidación de los datos en una única tabla con el fin de facilitar la visualización de las tendencias en las respuestas:

Tabla 19: Compilación de las respuestas de la Cuestión 07 - ALUMNOS

\begin{tabular}{|c|l|l|l|l|l|l|l|l|l|}
\hline \multicolumn{2}{|l|}{ İtem } & \multicolumn{2}{|l|}{ Frecuencia/Porcentaje } \\
\hline \multicolumn{2}{|c|}{$\begin{array}{l}\text { Concordo } \\
\text { Totalmente }\end{array}$} & \multicolumn{2}{l|}{$\begin{array}{l}\text { Concordo } \\
\text { Parcialmente }\end{array}$} & \multicolumn{2}{l|}{$\begin{array}{l}\text { Discordo } \\
\text { Parcialmente }\end{array}$} & \multicolumn{2}{l|}{$\begin{array}{l}\text { Discordo } \\
\text { Totalmente }\end{array}$} \\
\hline a & $\begin{array}{l}\text { Estoy familiarizado con } \\
\text { el concepto de } \\
\text { innovación. }\end{array}$ & 33 & 38,4 & 49 & 57,0 & 2 & 2,3 & 2 & 2,3 \\
\hline b & $\begin{array}{l}\text { Estoy familiarizado con } \\
\text { el concepto } \\
\text { Emprendedor. }\end{array}$ & 25 & 29,1 & 30 & 34,9 & 26 & 30,2 & 5 & 5,8 \\
\hline C & $\begin{array}{l}\text { Estoy familiarizado con } \\
\text { el concepto de } \\
\text { transferencia de } \\
\text { tecnología. }\end{array}$ & 9 & 10,5 & 31 & 36,0 & 33 & 38,4 & 13 & 15,1 \\
\hline d & $\begin{array}{l}\text { Estoy familiarizado con } \\
\text { las reglas y otros } \\
\text { procedimientos } \\
\text { relacionados con la } \\
\text { Protección de la } \\
\text { Propiedad Intelectual / } \\
\text { Industrial. }\end{array}$ & 8 & 9,3 & 32 & 37,2 & 26 & 30,2 & 20 & 23,3 \\
\hline
\end{tabular}




\begin{tabular}{|c|c|c|c|c|c|c|c|c|c|}
\hline \multirow{2}{*}{\multicolumn{2}{|c|}{ Ítem }} & \multicolumn{8}{|c|}{ Frecuencia/Porcentaje } \\
\hline & & \multicolumn{2}{|c|}{$\begin{array}{l}\text { Concordo } \\
\text { Totalmente }\end{array}$} & \multicolumn{2}{|c|}{$\begin{array}{l}\text { Concordo } \\
\text { Parcialmente }\end{array}$} & \multicolumn{2}{|c|}{$\begin{array}{l}\text { Discordo } \\
\text { Parcialmente }\end{array}$} & \multicolumn{2}{|c|}{$\begin{array}{l}\text { Discordo } \\
\text { Totalmente }\end{array}$} \\
\hline $\mathrm{e}$ & $\begin{array}{l}\text { Conozco los objetivos } \\
\text { del curso en relación a } \\
\text { la innovación. }\end{array}$ & 27 & 31,4 & 44 & 51,2 & 14 & 16,3 & 1 & 1,2 \\
\hline$f$ & $\begin{array}{l}\text { Conozco la investigación } \\
\text { y los proyectos que se } \\
\text { desarrollan en el curso }\end{array}$ & 9 & 10,5 & 53 & 61,6 & 20 & 23,3 & 4 & 4,7 \\
\hline $\mathrm{g}$ & $\begin{array}{l}\text { El curso fomenta la } \\
\text { práctica de la } \\
\text { innovación entre los } \\
\text { alumnos y los } \\
\text { profesores. }\end{array}$ & 22 & 25,6 & 48 & 55,8 & 15 & 17,4 & 1 & 1,2 \\
\hline $\mathrm{h}$ & $\begin{array}{l}\text { La infraestructura de } \\
\text { laboratorios disponible } \\
\text { en el Curso es suficiente } \\
\text { para estimular el } \\
\text { desarrollo de nuevos } \\
\text { productos y procesos. }\end{array}$ & 6 & 7,0 & 29 & 33,7 & 35 & 40,7 & 16 & 18,6 \\
\hline$i$ & $\begin{array}{l}\text { Tengo acceso fácil a la } \\
\text { producción de } \\
\text { conocimientos } \\
\text { generados en el curso } \\
\text { (monografías, artículos } \\
\text { publicados, los } \\
\text { resultados de los } \\
\text { proyectos, etc.) }\end{array}$ & 11 & 12,8 & 33 & 38,4 & 37 & 43,0 & 5 & 5,8 \\
\hline $\mathrm{j}$ & $\begin{array}{l}\text { Creo que el acceso a la } \\
\text { información y la } \\
\text { formación dirigida a la } \\
\text { protección de la } \\
\text { propiedad intelectual es } \\
\text { esencial. }\end{array}$ & 62 & 72,1 & 22 & 25,6 & 2 & 2,3 & 0 & 0 \\
\hline l & $\begin{array}{l}\text { Creo que es esencial } \\
\text { fomentar el espíritu } \\
\text { emprendedor entre los } \\
\text { estudiantes y profesores } \\
\text { del Curso. }\end{array}$ & 69 & 80,2 & 14 & 16,3 & 3 & 3,5 & 0 & 0 \\
\hline $\mathrm{m}$ & $\begin{array}{l}\text { Creo que es esencial la } \\
\text { existencia de proyectos } \\
\text { desarrollados en } \\
\text { cooperación con el } \\
\text { sector privado. }\end{array}$ & 50 & 58,1 & 30 & 34,9 & 6 & 7,0 & 0 & 0 \\
\hline$n$ & $\begin{array}{l}\text { Creo que es esencial la } \\
\text { existencia de proyectos } \\
\text { desarrollados en } \\
\text { cooperación con otras } \\
\text { instituciones de } \\
\text { educación e } \\
\text { investigación. }\end{array}$ & 59 & 68,6 & 27 & 31,4 & 0 & 0 & 0 & 0 \\
\hline
\end{tabular}

Fuente: El autor 


\subsubsection{Resultados de la Cuestión 08 de la encuesta (Respuesta SI o NO) -}

\section{ALUMNOS}

En esta pregunta se les pidió respuestas dicotómicas (sí o no) sobre los factores que influyen en el ambiente de Innovación del curso, cuyos resultados se muestran en la Tabla 66 a continuación:

Tabla 20: Compilación de las respuestas de la Cuestión 08 - ALUMNOS

\begin{tabular}{|c|c|c|c|c|c|}
\hline & PREGUNTA & \multicolumn{4}{|c|}{ FRECÜÊNCIA/PORCENTAJE } \\
\hline & & \multicolumn{2}{|l|}{ SI } & \multicolumn{2}{|l|}{ NO } \\
\hline $\mathrm{a}$ & $\begin{array}{l}\text { ¿Ya ha oído hablar del NIT } \\
\text { (Núcleo de Innovación } \\
\text { Tecnológica) de UFAM? }\end{array}$ & 42 & 48,8 & 44 & 51,2 \\
\hline $\mathrm{b}$ & $\begin{array}{l}\text { ¿En caso positivo, conoce el } \\
\text { alcance de sus actividades? }\end{array}$ & 12 & 14,0 & 74 & 86,0 \\
\hline c & $\begin{array}{l}\text { ¿Ya ha oído hablar de la PROTEC } \\
\text { (Pro-Rectoría de Innovación } \\
\text { Tecnológica) de UFAM? }\end{array}$ & 15 & 17,4 & 71 & 82,6 \\
\hline $\mathrm{d}$ & $\begin{array}{l}\text { ¿Ya ha oído hablar del CDTECH } \\
\text { (Centro de Desarrollo } \\
\text { Tecnológico y empresarial) de } \\
\text { UFAM? }\end{array}$ & 21 & 24,4 & 65 & 75,6 \\
\hline e & $\begin{array}{l}\text { ¿Conoce alguna incubadora de } \\
\text { empresas que opere en } \\
\text { Amazonas? }\end{array}$ & 44 & 51,2 & 42 & 48,8 \\
\hline$f$ & $\begin{array}{l}\text { Ya he participado en proyectos } \\
\text { desarrollados con el apoyo del } \\
\text { sector privado. }\end{array}$ & 15 & 17,4 & 71 & 82,6 \\
\hline g & $\begin{array}{l}\text { Estoy interesado en participar en } \\
\text { proyectos desarrollados en } \\
\text { cooperación con el sector } \\
\text { privado. }\end{array}$ & 78 & 90,7 & 8 & 9,3 \\
\hline
\end{tabular}

Fuente: El autor

\subsubsection{Resultados de la Cuestión 09 de la encuesta - ALUMNOS}

La cuestión 09 de la encuesta de los profesores estaba vinculada al ítem "e" de la cuestión anterior. Si la respuesta de los encuestados fuera "sí a la pregunta: "¿Conoces alguna incubadora de empresas que opere en Amazonas?" Deberían citar las incubadoras que conocían. Las respuestas están en la tabla a continuación: 
Tabla 21: Compilación de las respuestas de la Cuestión 09 - ALUMNOS

\begin{tabular}{|l|l|l|}
\hline & \multicolumn{2}{|l|}{ FRECUENCIA/PORCENTAJE } \\
\hline Incubadora SEBRAE & 2 & 2,3 \\
\hline Incubadora FUCAPI & 5 & 5,8 \\
\hline Incubadora o CIDI & 1 & 1,2 \\
\hline Incubadora INPA & 1 & 1,2 \\
\hline Incubadora FMF & 1 & 1,2 \\
\hline Incubadora CDTECH & 1 & 1,2 \\
\hline No conozco ninguna incubadora & 77 & 89,5 \\
\hline Total & & \\
\hline
\end{tabular}

Fuente: El autor

\subsubsection{Resultados de la Cuestión 10 de la encuesta (Acciones Inovativas) -}

\section{ALUMNOS}

En la cuestión 10 de la encuesta de los alumnos se les consultó sobre las acciones que podrían contribuir a la mejora del proceso de innovación en el curso de Design. Se presentó al grupo una lista de 11 sugerencias de medidas entre las que deberían elegir cuatro (4) en orden de importancia. ( 1 para el más importante / 4 para el menos importante). A continuación se muestra el

A continuación son presentados dos datos consolidados de la Cuestión 10 aplicada a los Alumnos:

Tabla 22: Compilación de las respuestas de la Cuestión 10 - ALUMNOS

\begin{tabular}{|c|c|c|c|c|c|c|c|c|c|c|c|}
\hline \multirow{2}{*}{\multicolumn{2}{|c|}{ Item }} & \multicolumn{10}{|c|}{ Frecuencia/Porcentaje $(\%)$} \\
\hline & & \multicolumn{2}{|c|}{$\begin{array}{l}1^{\circ} \text { más } \\
\text { important } \\
\text { e }\end{array}$} & \multicolumn{2}{|c|}{$\begin{array}{l}2^{\circ} \text { más } \\
\text { important } \\
\text { e }\end{array}$} & \multicolumn{2}{|c|}{$\begin{array}{l}3^{\circ} \text { más } \\
\text { importan } \\
\text { te }\end{array}$} & \multicolumn{2}{|c|}{$\begin{array}{l}4^{\circ} \text { más } \\
\text { important } \\
\text { e }\end{array}$} & \multicolumn{2}{|c|}{$\begin{array}{l}\text { No se citó } \\
\text { entre las } \\
04 \\
\text { opciones }\end{array}$} \\
\hline a & $\begin{array}{l}\text { Mejorar el } \\
\text { conocimiento de } \\
\text { la parte del curso } \\
\text { sobre las } \\
\text { demandas del } \\
\text { sector privado en } \\
\text { el área de Design. }\end{array}$ & 43 & 50,0 & 10 & 11,6 & 6 & 7,0 & 4 & 4,7 & 23 & 26,7 \\
\hline b & $\begin{array}{l}\text { Mejorar la } \\
\text { infraestructura y } \\
\text { laboratorios que } \\
\text { puedan apoyar el } \\
\text { desarrollo de } \\
\text { nuevos procesos y } \\
\text { productos. }\end{array}$ & 26 & 30,2 & 34 & 39,5 & 5 & 5,8 & 4 & 4,7 & 17 & 19,8 \\
\hline
\end{tabular}




\begin{tabular}{|c|c|c|c|c|c|c|c|c|c|c|c|}
\hline \multirow{2}{*}{\multicolumn{2}{|c|}{ Item }} & \multicolumn{10}{|c|}{ Frecuencia/Porcentaje (\%) } \\
\hline & & \multicolumn{2}{|c|}{$\begin{array}{l}1^{\circ} \text { más } \\
\text { important } \\
\text { e }\end{array}$} & \multicolumn{2}{|c|}{$\begin{array}{l}2^{\circ} \text { más } \\
\text { important } \\
\text { e }\end{array}$} & \multicolumn{2}{|c|}{$\begin{array}{l}3^{\circ} \text { más } \\
\text { importan } \\
\text { te }\end{array}$} & \multicolumn{2}{|c|}{$\begin{array}{l}4^{\circ} \text { más } \\
\text { important } \\
\text { e }\end{array}$} & \multicolumn{2}{|c|}{$\begin{array}{l}\text { No se citó } \\
\text { entre las } \\
04 \\
\text { opciones }\end{array}$} \\
\hline c & $\begin{array}{l}\text { Formación en } \\
\text { materia de } \\
\text { protección de la } \\
\text { propiedad } \\
\text { industrial (registro } \\
\text { de marcas, } \\
\text { patentes, etc) }\end{array}$ & 1 & 1,2 & 10 & 11,6 & 11 & $\begin{array}{l}12 \\
8\end{array}$ & 10 & $\begin{array}{l}11, \\
6\end{array}$ & 54 & 62,8 \\
\hline$d$ & $\begin{array}{l}\text { Mejorar el } \\
\text { acompañamiento } \\
\text { de la destinación } \\
\text { de los titulados } \\
\text { con el fin de } \\
\text { establecer una red } \\
\text { de cooperación. }\end{array}$ & 5 & 5,8 & 2 & 2,3 & 10 & $\begin{array}{l}11, \\
6\end{array}$ & 8 & 9,3 & 61 & 70,9 \\
\hline $\mathrm{e}$ & $\begin{array}{l}\text { Apoyo técnico /de } \\
\text { gestión } \\
\text { implantación de } \\
\text { negocios. }\end{array}$ & 0 & 0 & 5 & 5,8 & 4 & 4,7 & 5 & 5,8 & 72 & 83,7 \\
\hline$f$ & $\begin{array}{l}\text { Apoyo a la } \\
\text { Transferencia de } \\
\text { Tecnología. }\end{array}$ & 0 & 0 & 2 & 2,3 & 6 & 7,0 & 5 & 5,8 & 73 & 84,9 \\
\hline $\mathrm{g}$ & $\begin{array}{l}\text { Mayor cooperación } \\
\text { con las } \\
\text { incubadoras. }\end{array}$ & 1 & 1,2 & 0 & 0 & 7 & 8,1 & 4 & 4,7 & 74 & 86,0 \\
\hline $\mathrm{h}$ & $\begin{array}{l}\text { Foros para reunir } \\
\text { los investigadores } \\
\text { a las empresas. }\end{array}$ & 0 & 0 & 1 & 1,2 & 2 & 2,3 & 20 & $\begin{array}{l}23 \\
3\end{array}$ & 63 & 73,3 \\
\hline $\bar{i}$ & $\begin{array}{l}\text { Construcción, por } \\
\text { el curso de la } \\
\text { agenda de } \\
\text { investigación } \\
\text { definida en } \\
\text { conjunto con el } \\
\text { sector productivo. }\end{array}$ & 4 & 4,7 & 7 & 8,1 & 2 & 2,3 & 5 & 5,8 & 68 & 79,1 \\
\hline$j$ & $\begin{array}{l}\text { Participación de la } \\
\text { PROTEC en } \\
\text { proyectos e } \\
\text { Investigaciones. }\end{array}$ & 2 & 2,3 & 4 & 4,7 & 6 & 7,0 & 4 & 4,7 & 70 & 81,4 \\
\hline l & $\begin{array}{l}\text { Desarrollo de } \\
\text { proyectos de } \\
\text { investigación y de } \\
\text { extensión capaces } \\
\text { de generar } \\
\text { negocios. }\end{array}$ & 8 & 9,3 & 10 & 11,6 & 23 & $\begin{array}{l}26 \\
7\end{array}$ & 16 & $\begin{array}{l}18 \\
6\end{array}$ & 29 & 33,7 \\
\hline
\end{tabular}

Fuente: El autor

La tabla siguiente muestra el orden de prioridades en las acciones indicadas por los Alumnos. 
Tabla 23: Orden de prioridades en las acciones de la Cuestión 10 - ALUMNOS

\begin{tabular}{|l|l|}
\hline $\begin{array}{l}\text { Grado de } \\
\text { Importancia }\end{array}$ & ALUMNOS \\
\hline 1 & $\begin{array}{l}\text { Mejom más citado el conocimiento de la parte del curso sobre las } \\
\text { demandas del sector privado en el área de Design. }\end{array}$ \\
\hline 2 & $\begin{array}{l}\text { Mejorar la infraestructura y laboratorios que puedan apoyar } \\
\text { el desarrollo de nuevos procesos y productos. }\end{array}$ \\
\hline 3 & $\begin{array}{l}\text { Desarrollo de proyectos de investigación y de extensión } \\
\text { capaces de generar negocios. }\end{array}$ \\
\hline 4 & Foros para reunir los investigadores a las empresas. \\
\hline
\end{tabular}

Fuente: El autor

\subsubsection{Resultados de la Cuestión 11 de la encuesta (Calidad de un curso de grado) - ALUMNOS}

En la cuestión 11 de la encuesta de los Alumnos se les pidió que clasificasen en orden de importancia, de una lista de 10 elementos, los que se consideran más relevantes para la Calidad de un curso de grado. (1 para el más importante - 10 para el menos importante). A continuación se presentan los resultados.

En la Tabla 91, que se muestra a continuación, se puede ver que las frecuencias generales mencionadas por los Alumnos como prioridad en la Calidad de un curso de grado.

A partir de esta orden de prioridades será posible establecer un criterio para la interpretación de las preguntas 12 y 13, en las que los encuestados deben señalar las fortalezas y debilidades del curso de Design. 



\begin{tabular}{|c|c|c|c|c|c|c|c|c|c|c|c|c|c|c|c|c|c|c|c|c|c|}
\hline \multirow{3}{*}{$\mathrm{a}$} & \multirow{3}{*}{\begin{tabular}{|l|} 
CONCEPTO DE \\
CALIDAD - ALUMNOS \\
ITEM \\
$\begin{array}{l}\text { Estructura del Currículo / } \\
\text { Contenido de las asignaturas }\end{array}$
\end{tabular}} & \multicolumn{20}{|c|}{ PRIORIDADES } \\
\hline & & \multicolumn{2}{|l|}{01} & \multicolumn{2}{|c|}{02} & \multicolumn{2}{|l|}{03} & \multicolumn{2}{|l|}{04} & \multicolumn{2}{|l|}{05} & \multicolumn{2}{|l|}{06} & \multicolumn{2}{|l|}{07} & \multicolumn{2}{|l|}{08} & \multicolumn{2}{|l|}{09} & \multicolumn{2}{|l|}{10} \\
\hline & & 49 & 57,0 & 10 & 11,6 & 8 & 9,3 & 6 & 7,0 & 5 & 5,8 & - & & 2 & 2,3 & 2 & 2,3 & 1 & 1,2 & 3 & 3,5 \\
\hline $\mathrm{b}$ & Didáctica de los profesores & 16 & 18,6 & 43 & 50,0 & 6 & 7,0 & 8 & 9,3 & 6 & 7,0 & 1 & 1,2 & 3 & 3,5 & - & & 2 & 2,3 & 1 & 1,2 \\
\hline $\mathrm{C}$ & $\begin{array}{l}\text { Puntualidad y asiduidad de los } \\
\text { profesores }\end{array}$ & 2 & 2,3 & 5 & 5,8 & 4 & 4,7 & 10 & 11,6 & 14 & 16,3 & 12 & 14,0 & 10 & 11,6 & 12 & 14,0 & 13 & 15,1 & 7 & 8,1 \\
\hline $\mathrm{d}$ & Titulación de los profesores & - & - & 4 & 4,7 & 15 & 17,4 & 4 & 4,7 & 10 & 11,6 & 5 & 5,8 & 4 & 4,7 & 17 & 19,8 & 11 & 12,8 & 16 & 18,6 \\
\hline $\mathrm{e}$ & $\begin{array}{l}\text { Envolvimiento de los } \\
\text { profesores con el curso }\end{array}$ & 11 & 12,8 & 9 & 10,5 & 24 & 27,9 & 12 & 14,0 & 9 & 10,5 & 11 & 12,8 & 5 & 5,8 & 3 & 3,5 & 2 & 2,3 & - & - \\
\hline$f$ & $\begin{array}{l}\text { Conforto e adecuación de las } \\
\text { aulas }\end{array}$ & 2 & 2,3 & 3 & 3,5 & 4 & 4,7 & 7 & 8,1 & 11 & 12,8 & 6 & 7,0 & 12 & 14,0 & 13 & 15,1 & 8 & 9,3 & 20 & 23,3 \\
\hline$g$ & $\begin{array}{l}\text { Calidad de los laboratorios y } \\
\text { espacios específicos }\end{array}$ & 3 & 3,5 & 6 & 7,0 & 15 & 17,4 & 21 & 24,4 & 10 & 11,6 & 14 & 16,3 & 8 & 9,3 & 1 & 1,2 & 5 & 5,8 & 3 & 3,5 \\
\hline $\mathrm{h}$ & $\begin{array}{l}\text { Apoyo de personal técnico } \\
\text { (ex.: técnicos de laboratorios } \\
\text { y oficinas) }\end{array}$ & 1 & 1,2 & 3 & 3,5 & 1 & 1,2 & 5 & 5,8 & 6 & 7,0 & 13 & 15,1 & 19 & 22,1 & 16 & 18,6 & 7 & 8,1 & 15 & 17,4 \\
\hline$i$ & $\begin{array}{l}\text { Apoyo de la Coordinación del } \\
\text { Curso }\end{array}$ & 2 & 2,3 & 3 & 3,5 & 4 & 4,7 & 11 & 12,8 & 12 & 14,0 & 20 & 23,3 & 9 & 10,5 & 11 & 12,8 & 9 & 10,5 & 5 & 5,8 \\
\hline$j$ & $\begin{array}{l}\text { Apoyo de la Secretaria del } \\
\text { Curso }\end{array}$ & 2 & 2,3 & 3 & 3,5 & 2 & 2,3 & 2 & 2,3 & 2 & 2,3 & 6 & 7,0 & 14 & 16,3 & 11 & 12,8 & 28 & 32,6 & 16 & 18,6 \\
\hline
\end{tabular}

Tabla 24: Compilación de las respuestas de la Cuestión 11 - ALUMNOS/ Fuente: El autor 

A partir de la observación de la Tabla 92, se presenta la siguiente prioridad en los factores que son más importantes para la Calidad de un curso de grado en la opinión de los Alumnos.

Tabla 25: Orden de prioridades obtenidas en las respuestas de la Cuestión 11 ALUMNOS

\begin{tabular}{|l|l|}
\hline PRIORIDADES & ITEM \\
\hline PRIORIDAD 01 & Estructura del Currículo / Contenido de las asignaturas \\
\hline PRIORIDAD 02 & Didáctica de los profesores \\
\hline PRIORIDAD 03 & Envolvimiento de los profesores con el curso \\
\hline PRIORIDAD 04 & Calidad de los laboratorios y espacios específicos \\
\hline PRIORIDAD 05 & Puntualidad y asiduidad de los profesores \\
\hline PRIORIDAD 06 & Apoyo de la Coordinación del Curso \\
\hline PRIORIDAD 07 & Apoyo de personal técnico (ex.: técnicos de laboratorios) \\
\hline PRIORIDAD 08 & Titulación de los profesores \\
\hline PRIORIDAD 09 & Apoyo de la Secretaria del Curso \\
\hline PRIORIDAD 10 & Conforto e adecuación de las aulas \\
\hline
\end{tabular}

Fuente: El autor

\subsubsection{Resultados de la Cuestión 12 de la encuesta (Puntos positivos del curso de Design) - ALUMNOS}

En la Cuestión 12 fue solicitado a los participantes que indicasen 3 puntos positivos del curso de Design con base en la lista de 10 ítems de la Cuestión 11. A seguir los resultados obtenidos:

Tabla 26: Compilación de las respuestas de la Cuestión 12- ALUMNOS

\begin{tabular}{|c|c|c|c|c|c|c|c|c|}
\hline \multirow{2}{*}{$\begin{array}{l}\text { PUNTOS POSITIVOS } \\
\text { Estructura del Currículo / } \\
\text { Contenido de las } \\
\text { asignaturas }\end{array}$} & \multicolumn{2}{|c|}{ PRIORIDAD 1} & \multicolumn{2}{|c|}{ PRIORIDAD 2} & \multicolumn{2}{|c|}{ PRIORIDAD 3} & \multicolumn{2}{|c|}{$\begin{array}{l}\text { NO } \\
\text { CITADO }\end{array}$} \\
\hline & 34 & 39,5 & 12 & 14,0 & 6 & 7,0 & 34 & 39,5 \\
\hline Didáctica de los profesores & 10 & 11,6 & 25 & 29,1 & 8 & 9,3 & 43 & 50,0 \\
\hline $\begin{array}{l}\text { Puntualidad y asiduidad de } \\
\text { los profesores }\end{array}$ & 4 & 4,7 & 8 & 9,3 & 7 & 8,1 & 67 & 77,9 \\
\hline Titulación de los profesores & 4 & 4,7 & 14 & 16,3 & 24 & 27,9 & 44 & 51,2 \\
\hline $\begin{array}{l}\text { Envolvimiento de los } \\
\text { profesores con el curso }\end{array}$ & 22 & 25,6 & 11 & 12,8 & 8 & 9,3 & 45 & 52,3 \\
\hline $\begin{array}{l}\text { Conforto e adecuación de } \\
\text { las aulas }\end{array}$ & 2 & 2,3 & 1 & 1,2 & 4 & 4,7 & 79 & 91,9 \\
\hline $\begin{array}{l}\text { Calidad de los laboratorios } \\
\text { y espacios específicos }\end{array}$ & 1 & 1,2 & 6 & 7,0 & 6 & 7,0 & 73 & 84,9 \\
\hline Apoyo de personal técnico & 4 & 4,7 & 6 & 7,0 & 5 & 5,8 & 71 & 82,6 \\
\hline
\end{tabular}




\begin{tabular}{|l|l|l|l|l|l|l|l|l|l|}
\hline & \multicolumn{2}{l|}{ PRIORIDAD 1 } & \multicolumn{2}{l|}{ PRIORIDAD 2 } & \multicolumn{2}{l|}{ PRIORIDAD 3 } & \multicolumn{2}{l|}{$\begin{array}{l}\text { NO } \\
\text { CITADO }\end{array}$} \\
\hline $\begin{array}{l}\text { PUNTOS POSITIVOS } \\
\begin{array}{l}\text { (ex.: técnicos de } \\
\text { laboratorios y oficinas) }\end{array}\end{array}$ & & & & & & & \\
\hline $\begin{array}{l}\text { Apoyo de la Coordinación } \\
\text { del Curso }\end{array}$ & 5 & 5,8 & 2 & 2,3 & 14 & 16,3 & 65 & 75,6 \\
\hline $\begin{array}{l}\text { Apoyo de la Secretaria del } \\
\text { Curso }\end{array}$ & - & - & 1 & 1,2 & 3 & 3,5 & 82 & 95,3 \\
\hline
\end{tabular}

Fuente: El autor

Tabla 27: Orden de puntos positivos encontrada en las respuestas de la Cuestión 12 ALUMNOS

\begin{tabular}{|l|l|}
\hline $\begin{array}{l}\text { PUNTOS POSITIVOS - } \\
\text { ALUMNOS }\end{array}$ & ITEM \\
\hline PRIORIDAD 01 & Estructura del Currículo / Contenido de las asignaturas \\
\hline PRIORIDAD 02 & Didáctica de los profesores \\
\hline PRIORIDAD 03 & Titulación de los profesores \\
\hline & Fuente: El autor \\
\hline
\end{tabular}

\subsubsection{Resultados de la Cuestión 13 de la encuesta (Deficiencias del curso de Design) - ALUMNOS}

En la Cuestión 13 fue solicitado a los participantes que indicasen 3 Deficiencias del curso de Design con base en la lista de 10 ítems de la Cuestión 11. A seguir los resultados obtenidos:

Tabla 28: Compilación de las respuestas de la Cuestión 13 - ALUMNOS

\begin{tabular}{|l|l|l|l|l|l|l|l|l|}
\hline DEFICIENCIAS & \multicolumn{2}{|l|}{ PRIORIDAD 1 } & \multicolumn{2}{l|}{ PRIORIDAD 2 } & \multicolumn{2}{l|}{ PRIORIDAD 3 } & \multicolumn{2}{l|}{ NO CITADO } \\
\hline $\begin{array}{l}\text { Estructura del Currículo I } \\
\text { Contenido de las asignaturas }\end{array}$ & 9 & 10,5 & 7 & 8,1 & 2 & 2,3 & 68 & 79,1 \\
\hline Didáctica de los profesores & 6 & 7,0 & 7 & 8,1 & 9 & 10,5 & 64 & 74,4 \\
\hline $\begin{array}{l}\text { Puntualidad y asiduidad de } \\
\text { los profesores }\end{array}$ & 10 & 11,6 & 6 & 7,0 & 7 & 8,1 & 63 & 73,3 \\
\hline Titulación de los profesores & - & - & - & - & 4 & 4,7 & 82 & 95,3 \\
\hline $\begin{array}{l}\text { Envolvimiento de los } \\
\text { profesores con el curso }\end{array}$ & 1 & 1,2 & 3 & 3,5 & 6 & 7,0 & 76 & 88,4 \\
\hline $\begin{array}{l}\text { Conforto e adecuación de las } \\
\text { aulas }\end{array}$ & 29 & 33,7 & 19 & 22,1 & 6 & 7,0 & 32 & 37,2 \\
\hline $\begin{array}{l}\text { Calidad de los laboratorios y } \\
\text { espacios específicos }\end{array}$ & 19 & 22,1 & 23 & 26,7 & 13 & 15,1 & 31 & 36,0 \\
\hline $\begin{array}{l}\text { Apoyo de personal técnico } \\
\text { (ex.: técnicos de laboratorios } \\
\text { y oficinas) }\end{array}$ & 4 & 4,7 & 4 & 4,7 & 24 & 27,9 & 54 & 62,8 \\
\hline $\begin{array}{l}\text { Apoyo de la Coordinación del } \\
\text { Curso }\end{array}$ & 6 & 7,0 & 11 & 12,8 & 4 & 4,7 & 65 & 75,6 \\
\hline $\begin{array}{l}\text { Apoyo de la Secretaria del } \\
\text { Curso }\end{array}$ & 2 & 2,3 & 6 & 7,0 & 11 & 12,8 & 67 & 77,9 \\
\hline
\end{tabular}

Fuente: El autor 
Tabla 29: Orden de Deficiencias encontrada en las respuestas de la Cuestión 13 ALUMNOS

\begin{tabular}{|l|l|}
\hline $\begin{array}{l}\text { DEFICIÊNCIAS - } \\
\text { PROFESORES }\end{array}$ & ITEM \\
\hline PRIORIDAD 01 & Conforto e adecuación de las aulas \\
\hline PRIORIDAD 02 & Calidad de los laboratorios y espacios específicos \\
\hline PRIORIDAD 03 & Apoyo de personal técnico \\
\hline
\end{tabular}

Fuente: El autor

\subsubsection{Resultados de la Cuestión 14 de la encuesta - ALUMNOS}

En la encuesta de dos ALUMNOS fue inserida la pregunta:

Usted recomendaría a un amigo que hiciera el curso de Design UFAM?

Tabla 30: Resultados de la Cuestión 14 del cuestionario - ALUMNOS

\begin{tabular}{|l|l|l|}
\hline & Frecuencia & Porcentaje (\%) \\
\hline SI & 78 & $90,7 \%$ \\
\hline NO & 8 & $9,3 \%$ \\
\hline
\end{tabular}

Fuente: El autor

\subsection{Resultados del instrumento de evaluación del escenario de la innovación en el curso - grupo de TITULADOS}

La encuesta destinada a los Titulados del curso de Design/UFAM fue compuesto de 19 preguntas (Apéndice C). Actualmente, el curso está compuesto por 18 Titulados, el Cuestionario se aplicó a un total de 54 Titulados.

\subsubsection{Resultados de las cuestiones 01 a 11 del cuestionario (datos de identificación) - TITULADOS}

En Tabla 98, a continuación, se presenta una recopilación de los resultados de las preguntas 01 a 11 de la encuesta cuyo objetivo era reunir información para caracterizar el perfil de los participantes.

Número total de participantes: 54

Tabla 31: Perfil del grupo consultado - TITULADOS 


\begin{tabular}{|c|c|c|c|}
\hline \multicolumn{2}{|c|}{ CARACTERÍSTICA } & FRECUÊNCIA & PORCENTAGE \\
\hline \multirow{2}{*}{ 1) GENERO } & Hombre & 26 & 48,1 \\
\hline & Mujer & 28 & 51,9 \\
\hline \multirow{5}{*}{ 2) EDAD } & de 17 a 25 años & 18 & 33,3 \\
\hline & de 26 a 35 años & 28 & 51,9 \\
\hline & de 36 a 45 años & 8 & 14,8 \\
\hline & de 46 a 55 años & 0 & 0 \\
\hline & Más de 55 años & 0 & 0 \\
\hline \multirow{5}{*}{ 3) ESTADO CIVIL } & Soltero & 43 & 79,6 \\
\hline & Casado & 7 & 13,0 \\
\hline & Viudo & 0 & 0 \\
\hline & Separado & 3 & 5,6 \\
\hline & Unión Estable & 1 & 1,9 \\
\hline \multirow{12}{*}{$\begin{array}{l}\text { 5) AÑO DE } \\
\text { CONCLUSIÓN }\end{array}$} & 1998 & 2 & 3,7 \\
\hline & 2000 & 1 & 1,9 \\
\hline & 2001 & 1 & 1,9 \\
\hline & 2003 & 1 & 1,9 \\
\hline & 2004 & 2 & 3,7 \\
\hline & 2005 & 4 & 7,4 \\
\hline & 2006 & 2 & 3,7 \\
\hline & 2007 & 3 & 5,6 \\
\hline & 2008 & 3 & 5,6 \\
\hline & 2009 & 6 & 11,1 \\
\hline & 2010 & 19 & 35,2 \\
\hline & 2011 & 10 & 18,5 \\
\hline \multirow{2}{*}{$\begin{array}{l}\text { 6) ACTUA EM EL ÁREA } \\
\text { DE DESIGN? }\end{array}$} & SI & 47 & 87,0 \\
\hline & NO & 7 & 13,0 \\
\hline \multirow{5}{*}{$\begin{array}{l}\text { 7) SITUACIÓN EN EL } \\
\text { MERCADO DE } \\
\text { TRABAJO }\end{array}$} & Autónomo & 18 & 33,3 \\
\hline & $\begin{array}{l}\text { Empleado en empresa } \\
\text { privada }\end{array}$ & 29 & 53,7 \\
\hline & Funcionario Público & 4 & 7,4 \\
\hline & $\begin{array}{l}\text { Profesor/Investigador en } \\
\text { Institución Pública. }\end{array}$ & 0 & 0 \\
\hline & $\begin{array}{l}\text { Profesor/Investigador en } \\
\text { Institución Privada }\end{array}$ & 3 & 5,6 \\
\hline \multirow[t]{3}{*}{ 8) HABILITACIÓN } & Programación Visual & 23 & 42,6 \\
\hline & Proyecto de Producto & 12 & 22,2 \\
\hline & $\begin{array}{l}\text { No tengo habilitación - } \\
\text { Graduado en la nova } \\
\text { estructura curricular }\end{array}$ & 19 & 35,2 \\
\hline \multirow{3}{*}{$\begin{array}{l}\text { 9) SI USTED TIENE } \\
\text { HABILITACIÓN, ACTÚA } \\
\text { SÓLO EN SU ÁREA? }\end{array}$} & SI & 17 & 38,9 \\
\hline & NO & 18 & 33,3 \\
\hline & No tengo habilitación & 19 & 27,8 \\
\hline \multirow{3}{*}{$\begin{array}{l}\text { 10) ÁREA DEL DESIGN } \\
\text { EN QUE MÁS ATUA }\end{array}$} & Proyecto de Producto & 13 & 24,1 \\
\hline & Programación Visual & 32 & 59,3 \\
\hline & $\begin{array}{l}\text { Interfaces Gráficas } \\
\text { Digitales }\end{array}$ & 9 & 16,7 \\
\hline
\end{tabular}




\begin{tabular}{|l|l|l|l|}
\hline & $\begin{array}{l}\text { (Web/juegos/aplicativos } \\
\text { electrónicos en general) }\end{array}$ & & \\
\hline \multirow{4}{*}{ 11) TITULACIÓN } & Post-Doctor & 0 & 0 \\
\cline { 2 - 4 } & Doctor & 0 & 0 \\
\cline { 2 - 4 } & Maestro & 1 & 1,9 \\
\cline { 2 - 4 } & Especialista & 21 & 38,9 \\
\cline { 2 - 4 } & Licenciado & 32 & 59,3 \\
\hline
\end{tabular}

Fuente: El autor

\subsubsection{Resultados de la Cuestión 12 de la encuesta - TITULADOS}

En la encuesta de dos TITULADOS fue inserida la pregunta:

¿Está satisfecho con la profesión de Designer?

En la tabla que sigue las respuestas obtenidas:

Tabla 32: Resultados de la Cuestión 12 del cuestionario - TITULADOS

\begin{tabular}{|l|l|l|}
\hline & Frecuencia & Porcentaje (\%) \\
\hline SI & 37 & 68,5 \\
\hline NO & 17 & 31,5 \\
\hline
\end{tabular}

Fuente: El autor

\subsubsection{Resultados de la Cuestión 13 de la encuesta - TITULADOS}

En esta Cuestión fue hecha a los TITULADOS la siguiente pregunta:

¿Tiene alguna patente?

En la tabla que sigue las respuestas obtenidas:

Tabla 33: Resultados de la Cuestión 13 del cuestionario - TITULADOS

\begin{tabular}{|l|l|l|}
\hline & Frecuencia & Porcentaje (\%) \\
\hline SI & 1 & 1,9 \\
\hline NO & 53 & 98,1 \\
\hline
\end{tabular}

Fuente: El autor

\subsubsection{Resultados de la Cuestión 14 de la encuesta - TITULADOS}

En esta Cuestión fue hecha a los TITULADOS la siguiente pregunta:

Ya ha producido, por su propia iniciativa o por medio de transferencia de Tecnología algún producto o proceso que ha desarrollado?

En la tabla que sigue las respuestas obtenidas: 
Tabla 34: Resultados de la Cuestión 14 del cuestionario - TITULADOS

\begin{tabular}{|l|l|l|}
\hline & Frecuencia & Porcentaje (\%) \\
\hline SI & 15 & 27,8 \\
\hline NO & 39 & 72,2 \\
\hline
\end{tabular}

Fuente: El autor

\subsubsection{Resultados de la Cuestión 15 de la encuesta - TITULADOS}

En la cuestión 15 de la encuesta de los TITULADOS se les consultó sobre las acciones que podrían contribuir a la mejora del proceso de innovación en el curso de Design. Se presentó al grupo una lista de 11 sugerencias de medidas entre las que deberían elegir cuatro (4) en orden de importancia. (1 para el más importante / 4 para el menos importante).

A continuación son presentados dos datos consolidados de la Cuestión 15:

Tabla 35: Compilación de las respuestas de la Cuestión 15 - TITULADOS

\begin{tabular}{|c|c|c|c|c|c|c|c|c|c|c|c|}
\hline \multirow{2}{*}{\multicolumn{2}{|c|}{ İtem }} & \multicolumn{10}{|c|}{ Frecuencia/Porcentaje (\%) } \\
\hline & & \multicolumn{2}{|c|}{$\begin{array}{l}1^{\circ} \text { más } \\
\text { importa } \\
\text { nte }\end{array}$} & \multicolumn{2}{|c|}{$\begin{array}{l}2^{\circ} \text { más } \\
\text { importan } \\
\text { te }\end{array}$} & \multicolumn{2}{|c|}{$\begin{array}{l}3^{\circ} \text { más } \\
\text { important } \\
\text { e }\end{array}$} & \multicolumn{2}{|c|}{$\begin{array}{l}4^{\circ} \text { más } \\
\text { important } \\
\text { e }\end{array}$} & \multicolumn{2}{|c|}{$\begin{array}{l}\text { No se citó } \\
\text { entre las } \\
04 \\
\text { opciones }\end{array}$} \\
\hline a & $\begin{array}{l}\text { Mejorar el } \\
\text { conocimiento de la } \\
\text { parte del curso } \\
\text { sobre las demandas } \\
\text { del sector privado } \\
\text { en el área de } \\
\text { Design. }\end{array}$ & 30 & $\begin{array}{l}55 \\
, 6\end{array}$ & 7 & $\begin{array}{l}13 \\
, 0\end{array}$ & 4 & 7,4 & 2 & 3,7 & 11 & 20,4 \\
\hline b & $\begin{array}{l}\text { Mejorar la } \\
\text { infraestructura y } \\
\text { laboratorios que } \\
\text { puedan apoyar el } \\
\text { desarrollo de } \\
\text { nuevos procesos y } \\
\text { productos. }\end{array}$ & 2 & $\begin{array}{l}3, \\
7\end{array}$ & 13 & $\begin{array}{c}24 \\
, 1\end{array}$ & 9 & $\begin{array}{l}16, \\
7\end{array}$ & 6 & $\begin{array}{l}11, \\
1\end{array}$ & 24 & 44,4 \\
\hline C & $\begin{array}{l}\text { Formación en } \\
\text { materia de } \\
\text { protección de la } \\
\text { propiedad } \\
\text { industrial (registro } \\
\text { de marcas, } \\
\text { patentes, etc) }\end{array}$ & 1 & $\begin{array}{l}1, \\
9\end{array}$ & 2 & $\begin{array}{l}3, \\
7\end{array}$ & 1 & 1,9 & 2 & 3,7 & 48 & 88,9 \\
\hline$d$ & $\begin{array}{l}\text { Mejorar el } \\
\text { acompañamiento } \\
\text { de la destinación } \\
\text { de los titulados con } \\
\text { el fin de establecer } \\
\text { una red de } \\
\text { cooperación. }\end{array}$ & 3 & $\begin{array}{l}5, \\
6\end{array}$ & 5 & $\begin{array}{l}9, \\
3\end{array}$ & 8 & $\begin{array}{l}14, \\
8\end{array}$ & 3 & 5,6 & 35 & 64,8 \\
\hline
\end{tabular}




\begin{tabular}{|c|c|c|c|c|c|c|c|c|c|c|c|}
\hline \multirow{2}{*}{\multicolumn{2}{|c|}{ Ítem }} & \multicolumn{10}{|c|}{ Frecuencia/Porcentaje (\%) } \\
\hline & & \multicolumn{2}{|c|}{$\begin{array}{l}1^{\circ} \text { más } \\
\text { importa } \\
\text { nte }\end{array}$} & \multicolumn{2}{|c|}{$\begin{array}{l}2^{\circ} \text { más } \\
\text { importan } \\
\text { te }\end{array}$} & \multicolumn{2}{|c|}{$\begin{array}{l}3^{\circ} \text { más } \\
\text { important } \\
\text { e }\end{array}$} & \multicolumn{2}{|c|}{$\begin{array}{l}4^{\circ} \text { más } \\
\text { important } \\
\text { e }\end{array}$} & \multicolumn{2}{|c|}{$\begin{array}{l}\text { No se citó } \\
\text { entre las } \\
04 \\
\text { opciones }\end{array}$} \\
\hline $\mathrm{e}$ & $\begin{array}{l}\text { Apoyo técnico /de } \\
\text { gestión } \\
\text { implantación de } \\
\text { negocios. }\end{array}$ & 2 & $\begin{array}{l}3, \\
7\end{array}$ & 2 & $\begin{array}{l}3, \\
7\end{array}$ & 3 & 5,6 & 4 & 7,4 & 43 & 79,6 \\
\hline$f$ & $\begin{array}{l}\text { Apoyo a la } \\
\text { Transferencia de } \\
\text { Tecnología. }\end{array}$ & 2 & $\begin{array}{l}3, \\
7\end{array}$ & 5 & $\begin{array}{l}9 \\
3\end{array}$ & 2 & 3,7 & - & - & 45 & 83,3 \\
\hline $\mathrm{g}$ & $\begin{array}{l}\text { Mayor cooperación } \\
\text { con las } \\
\text { incubadoras. }\end{array}$ & 1 & $\begin{array}{l}\text { 1, } \\
9\end{array}$ & 2 & $\begin{array}{l}3, \\
7\end{array}$ & 4 & 7,4 & 10 & $\begin{array}{l}18, \\
5\end{array}$ & 37 & 68,5 \\
\hline $\mathrm{h}$ & $\begin{array}{l}\text { Foros para reunir } \\
\text { los investigadores a } \\
\text { las empresas. }\end{array}$ & 3 & $\begin{array}{l}5, \\
6\end{array}$ & 3 & $\begin{array}{l}5, \\
6\end{array}$ & 4 & 7,4 & 5 & 9,3 & 39 & 72,2 \\
\hline i & $\begin{array}{l}\text { Construcción, por } \\
\text { el curso de la } \\
\text { agenda de } \\
\text { investigación } \\
\text { definida en } \\
\text { conjunto con el } \\
\text { sector productivo. }\end{array}$ & 5 & $\begin{array}{l}9, \\
3\end{array}$ & 5 & $\begin{array}{l}9 \\
3\end{array}$ & 5 & 9,3 & 8 & $\begin{array}{l}14, \\
8\end{array}$ & 31 & 57,4 \\
\hline j & $\begin{array}{l}\text { Participación de la } \\
\text { PROTEC en } \\
\text { proyectos e } \\
\text { Investigaciones. }\end{array}$ & - & - & 1 & $\begin{array}{l}1, \\
9\end{array}$ & 4 & 7,4 & 2 & 3,7 & 47 & 87,0 \\
\hline l & $\begin{array}{l}\text { Desarrollo de } \\
\text { proyectos de } \\
\text { investigación y de } \\
\text { extensión capaces } \\
\text { de generar } \\
\text { negocios. }\end{array}$ & 5 & $\begin{array}{l}9, \\
3\end{array}$ & 9 & $\begin{array}{l}16 \\
, 7\end{array}$ & 10 & $\begin{array}{l}18, \\
5\end{array}$ & 12 & $\begin{array}{l}22 \\
2\end{array}$ & 18 & 33,3 \\
\hline
\end{tabular}

Fuente: El autor

La tabla siguiente muestra el orden de prioridades en las acciones indicadas por los Titulados. 
Tabla 36: Orden de prioridades obtenidas en las respuestas de la Cuestión 15 TITULADOS.

\begin{tabular}{|l|l|}
\hline $\begin{array}{l}\text { Grado de } \\
\text { Importancia }\end{array}$ & TITULADOS \\
\hline 1 & $\begin{array}{l}\text { Mejem más citado } \\
\text { demandas del sector privado en el área de Design. }\end{array}$ \\
\hline 2 & $\begin{array}{l}\text { Mejorar la infraestructura y laboratorios que puedan } \\
\text { apoyar el desarrollo de nuevos procesos y productos. }\end{array}$ \\
\hline 3 & $\begin{array}{l}\text { Desarrollo de proyectos de investigación y de extensión } \\
\text { capaces de generar negocios. }\end{array}$ \\
\hline 4 & Mayor cooperación con las incubadoras. \\
\hline
\end{tabular}

Fuente: El autor

Destacamos que la acción “Formación en materia de protección de la propiedad industrial (registro de marcas, patentes, etc.)" fue la menos citada entre los 4 grados de importancia por los titulados.

\subsubsection{Resultados de la Cuestión 16 de la encuesta (Calidad de un curso de grado) - TITULADOS}

En la cuestión 16 de la encuesta de los Titulados se les pidió que clasificasen en orden de importancia, a partir de una lista de 10 elementos, los que se consideran más relevantes para la Calidad de un curso de grado. (1 para el más importante - 10 para el menos importante).

En la Tabla 125, que se muestra a continuación, se puede ver que las frecuencias generales mencionadas por los docentes como prioridad en la Calidad de un curso.

A partir de esta orden de prioridades será posible establecer un criterio para la interpretación de las preguntas 17 y 18, en las que los encuestados deben señalar las fortalezas y debilidades del curso de Design. 


\begin{tabular}{|c|c|c|c|c|c|c|c|c|c|c|c|c|c|c|c|c|c|c|c|c|c|}
\hline \multirow[b]{3}{*}{ a } & \multirow{3}{*}{$\begin{array}{l}\text { CONCEPTO DE } \\
\text { CALIDAD - TITULADOS } \\
\text { ITEM } \\
\text { Estructura del Currículo / } \\
\text { Contenido de las asignaturas }\end{array}$} & \multicolumn{20}{|c|}{ PRIORIDADES } \\
\hline & & \multicolumn{2}{|l|}{01} & \multicolumn{2}{|l|}{02} & \multicolumn{2}{|l|}{03} & \multicolumn{2}{|l|}{04} & \multicolumn{2}{|l|}{05} & \multicolumn{2}{|l|}{06} & \multicolumn{2}{|l|}{07} & \multicolumn{2}{|l|}{08} & \multicolumn{2}{|l|}{09} & \multicolumn{2}{|l|}{10} \\
\hline & & 35 & 64,8 & 10 & 18,5 & 5 & 9,3 & 2 & 3,7 & - & - & - & - & 1 & 1,9 & - & - & - & - & 1 & 1,9 \\
\hline $\mathrm{b}$ & Didáctica de los profesores & 7 & 13,0 & 20 & 37,0 & 15 & 27,8 & 4 & 7,4 & 2 & 3,7 & 1 & 1,9 & 3 & 5,6 & - & - & 2 & 3,7 & - & - \\
\hline $\mathrm{C}$ & $\begin{array}{l}\text { Puntualidad y asiduidad de los } \\
\text { profesores }\end{array}$ & - & - & - & - & 2 & 3,7 & 2 & 3,7 & 4 & 7,4 & 8 & 14,8 & 4 & 7,4 & 6 & 11,1 & 9 & 16,7 & 19 & 35,2 \\
\hline $\mathrm{d}$ & Titulación de los profesores & - & - & 3 & 5,6 & 4 & 7,4 & 6 & 11,1 & 7 & 13,0 & 7 & 13,0 & 13 & 24,1 & 6 & 11,1 & 4 & 7,4 & 4 & 7,4 \\
\hline $\mathrm{e}$ & $\begin{array}{l}\text { Envolvimiento de los profesores } \\
\text { con el curso }\end{array}$ & 10 & 18,5 & 13 & 24,1 & 17 & 31,5 & 5 & 9,3 & 4 & 7,4 & 3 & 5,6 & 1 & 1,9 & - & - & - & - & 1 & 1,9 \\
\hline$f$ & $\begin{array}{l}\text { Conforto e adecuación de las } \\
\text { aulas }\end{array}$ & 1 & 1,9 & 1 & 1,9 & - & - & 6 & 11,1 & 2 & 3,7 & 4 & 7,4 & 6 & 11,1 & 6 & 11,1 & 13 & 24,1 & 15 & 27,8 \\
\hline $\mathrm{g}$ & $\begin{array}{l}\text { Calidad de los laboratorios y } \\
\text { espacios específicos }\end{array}$ & - & - & 2 & 3,7 & 5 & 9,3 & 17 & 31,5 & 12 & 22,2 & 5 & 9,3 & 4 & 7,4 & 7 & 13,0 & 1 & 1,9 & 1 & 1,9 \\
\hline $\mathrm{h}$ & $\begin{array}{l}\text { Apoyo de personal técnico (ex.: } \\
\text { técnicos de laboratorios y } \\
\text { oficinas) }\end{array}$ & - & - & - & - & 2 & 3,7 & 1 & 1,9 & 5 & 9,3 & 12 & 22,2 & 10 & 18,5 & 10 & 18,5 & 10 & 18,5 & 4 & 7,4 \\
\hline $\mathrm{i}$ & $\begin{array}{l}\text { Apoyo de la Coordinación del } \\
\text { Curso }\end{array}$ & 3 & 5,6 & 1 & 1,9 & 3 & 5,6 & 3 & 5,6 & 14 & 25,9 & 11 & 20,4 & 8 & 14,8 & 8 & 14,8 & 2 & 3,7 & 1 & 1,9 \\
\hline$j$ & Apoyo de la Secretaria del Curso & 3 & 5,6 & 4 & 7,4 & 2 & 3,7 & 3 & 5,6 & 3 & 5,6 & 3 & 5,6 & 4 & 7,4 & 16 & 29,6 & 10 & 18,5 & 6 & 11,1 \\
\hline & TOTAL & 54 & & 54 & & 54 & & 54 & & 54 & & 54 & & 54 & & 54 & & 54 & & 54 & \\
\hline
\end{tabular}

Tabla 37: Compilación de las respuestas de la Cuestión 16 - TITULADOS/ Fuente: El autor 

A partir de la observación de la Tabla 126, se presenta la siguiente prioridad en los factores que son más importantes para Calidad de un curso de grado en la opinión de los Titulados.

Tabla 38: Orden de prioridades obtenidas en las respuestas de la Cuestión 16 TITULADOS

\begin{tabular}{|l|l|}
\hline PRIORIDADES & ITEM \\
\hline PRIORIDAD 01 & Estructura del Currículo / Contenido de las asignaturas \\
\hline PRIORIDAD 02 & Didáctica de los profesores \\
\hline PRIORIDAD 03 & Envolvimiento de los profesores con el curso \\
\hline PRIORIDAD 04 & Calidad de los laboratorios y espacios específicos \\
\hline PRIORIDAD 05 & Apoyo de la Coordinación del Curso \\
\hline PRIORIDAD 06 & Apoyo de personal técnico (ex.: técnicos de laboratorios) \\
\hline PRIORIDAD 07 & Titulación de los profesores \\
\hline PRIORIDAD 08 & Apoyo de la Secretaria del Curso \\
\hline PRIORIDAD 09 & Conforto e adecuación de las aulas \\
\hline PRIORIDAD 10 & Puntualidad y asiduidad de los profesores \\
\hline
\end{tabular}

Fuente: El autor

\subsubsection{Resultados de la Cuestión 17 de la encuesta (Puntos positivos del curso de Design) - TITULADOS}

En la Cuestión 17 fue solicitado a los participantes que indicasen 3 puntos positivos del curso de Design con base en la lista de 10 ítems de la Cuestión 16. A seguir los resultados obtenidos:

Tabla 39: Compilación de las respuestas de la Cuestión 17 - TITULADOS

\begin{tabular}{|l|l|l|l|l|l|l|l|l|}
\hline $\begin{array}{c}\text { PUNTOS POSITIVOS } \\
\text { TITULADOS }\end{array}$ & \multicolumn{2}{|l|}{ PRIORIDAD 1 } & \multicolumn{2}{|c|}{ PRIORIDAD 2 } & \multicolumn{2}{l|}{ PRIORIDAD 3 } & \multicolumn{2}{c|}{$\begin{array}{l}\text { NO } \\
\text { CITADO }\end{array}$} \\
\hline $\begin{array}{l}\text { Estructura del Currículo I } \\
\text { Contenido de las asignaturas }\end{array}$ & 14 & 25,9 & 3 & 5,6 & 5 & 9,3 & 32 & 59,3 \\
\hline Didáctica de los profesores & 7 & 13,0 & 10 & 18,5 & 5 & 9,3 & 32 & 59,3 \\
\hline $\begin{array}{l}\text { Puntualidad y asiduidad de los } \\
\text { profesores }\end{array}$ & 1 & 1,9 & 2 & 3,7 & 4 & 7,4 & 47 & 87,0 \\
\hline Titulación de los profesores & 8 & 14,8 & 9 & 16,7 & 7 & 13,0 & 30 & 55,6 \\
\hline $\begin{array}{l}\text { Envolvimiento de los } \\
\text { profesores con el curso }\end{array}$ & 7 & 13,0 & 6 & 11,1 & 5 & 9,3 & 36 & 66,7 \\
\hline $\begin{array}{l}\text { Conforto e adecuación de las } \\
\text { aulas }\end{array}$ & & - & 2 & 3,7 & 3 & 5,6 & 49 & 90,7 \\
\hline $\begin{array}{l}\text { Calidad de los laboratorios y } \\
\text { espacios específicos }\end{array}$ & 3 & 5,6 & 7 & 13,0 & 7 & 13,0 & 37 & 68,5 \\
\hline $\begin{array}{l}\text { Apoyo de personal técnico } \\
\text { (ex.: técnicos de laboratorios } \\
\text { y oficinas) }\end{array}$ & 7 & 13,0 & 7 & 13,0 & 5 & 9,3 & 35 & 64,8 \\
\hline
\end{tabular}




\begin{tabular}{|l|l|l|l|l|l|l|l|l|}
\hline $\begin{array}{c}\text { PUNTOS POSITIVOS } \\
\text { TITULADOS }\end{array}$ & \multicolumn{2}{|c|}{ PRIORIDAD 1 } & \multicolumn{3}{c|}{ PRIORIDAD 2 } & \multicolumn{2}{l|}{ PRIORIDAD 3 } & \multicolumn{2}{c|}{ NO } \\
CITADO \\
\hline $\begin{array}{l}\text { Apoyo de la Coordinación del } \\
\text { Curso }\end{array}$ & 7 & 13,0 & 8 & 14,8 & 12 & 22,2 & 27 & 50,0 \\
\hline $\begin{array}{l}\text { Apoyo de la Secretaria del } \\
\text { Curso }\end{array}$ & - & - & - & - & 1 & 1,9 & 53 & 98,1 \\
\hline TOTAL & & & & & & & & \\
\hline
\end{tabular}

Fuente: El autor

A partir de la observación de la Tabla 128, son presentados los tres puntos considerados como los más positivos en la opinión de los titulados:

Tabla 40: Orden de pontos positivos encontrada en las respuestas da Cuestión 17 -

TITULADOS

\begin{tabular}{|l|l|}
\hline $\begin{array}{l}\text { PUNTOS POSITIVOS } \\
\text { TITULADOS }\end{array}$ & ITEM \\
\hline PRIORIDAD 01 & Estructura del Currículo / Contenido de las asignaturas \\
\hline PRIORIDAD 02 & Didáctica de los profesores \\
\hline PRIORIDAD 03 & Apoyo de la Coordinación del Curso \\
\hline
\end{tabular}

Fuente: El autor

\subsubsection{Resultados de la Cuestión 18 de la encuesta (Deficiencias del curso} de Design) - TITULADOS

En la Cuestión 18 fue solicitado a los participantes que indicasen 3 Deficiencias del curso de Design con base en la lista de 10 ítems de la Cuestión 11. A seguir los resultados obtenidos:

Tabla 41: Compilación de las respuestas de la Cuestión 18 - TITULADOS

\begin{tabular}{|l|l|l|l|l|l|l|l|l|}
\hline DEFICIENCIAS & \multicolumn{2}{l|}{ PRIORIDAD 1 } & \multicolumn{2}{l|}{ PRIORIDAD 2 } & \multicolumn{2}{l|}{ PRIORIDAD 3 } & \multicolumn{2}{|l|}{ NO CITADO } \\
\hline $\begin{array}{l}\text { Estructura del Currículo / } \\
\text { Contenido de las } \\
\text { asignaturas }\end{array}$ & 8 & 14,8 & 5 & 9,3 & 2 & 3,7 & 39 & 72,2 \\
\hline Didáctica de los profesores 8 & 14,8 & 6 & 11,1 & 3 & 5,6 & 37 & 68,5 \\
\hline $\begin{array}{l}\text { Puntualidad y asiduidad } \\
\text { de los profesores }\end{array}$ & 6 & 11,1 & 9 & 16,7 & 6 & 11,1 & 33 & 61,1 \\
\hline $\begin{array}{l}\text { Titulación de los } \\
\text { profesores }\end{array}$ & 1 & 1,9 & - & - & 4 & 7,4 & 49 & 90,7 \\
\hline $\begin{array}{l}\text { Envolvimiento de los } \\
\text { profesores con el curso }\end{array}$ & 9 & 16,7 & 9 & 16,7 & 4 & 7,4 & 32 & 59,3 \\
\hline $\begin{array}{l}\text { Conforto e adecuación de } \\
\text { las aulas }\end{array}$ & 6 & 11,1 & 4 & 7,4 & 13 & 24,1 & 31 & 57,4 \\
\hline $\begin{array}{l}\text { Calidad de los laboratorios } \\
\text { y espacios específicos }\end{array}$ & 8 & 14,8 & 12 & 22,2 & 11 & 20,4 & 23 & 42,6 \\
\hline $\begin{array}{l}\text { Apoyo de personal técnico } \\
\text { (ex.: técnicos de } \\
\text { laboratorios y oficinas) }\end{array}$ & 3 & 5,6 & 5 & 9,3 & 6 & 11,1 & 40 & 74,1 \\
\hline
\end{tabular}




\begin{tabular}{|c|c|c|c|c|c|c|c|}
\hline DEFICIENCIAS & PRIORIDAD 1 & & DAD 2 & & IDAD 3 & NO & TADO \\
\hline $\begin{array}{l}\text { Apoyo de la Coordinación } \\
\text { del Curso }\end{array}$ & 3,7 & 1 & 1,9 & ] & - & 51 & 94,4 \\
\hline $\begin{array}{l}\text { Apoyo de la Secretaria del } \\
\text { Curso }\end{array}$ & 5,6 & 3 & 5,6 & 5 & 9,3 & 43 & 79,6 \\
\hline TOTAL & & & & & & & \\
\hline
\end{tabular}

Fuente: El autor

A partir de la observación de la Tabla 130, son presentados los tres ítems considerados como los más deficiencias en la opinión de los titulados:

Tabla 42: Orden de Deficiencias encontrada en las respuestas de la Cuestión 18 TITULADOS

\begin{tabular}{|l|l|}
\hline DEFICIENCIAS - TITULADOS & ITEM \\
\hline PRIORIDAD 01 & Envolvimiento de los profesores con el curso \\
\hline PRIORIDAD 02 & Calidad de los laboratorios y espacios específicos \\
\hline PRIORIDAD 03 & Conforto e adecuación de las aulas \\
\hline
\end{tabular}

Fuente: El autor

\subsubsection{Resultados de la Cuestión 19 de la encuesta - TITULADOS}

En la encuesta de dos TITULADOS fue inserida la pregunta:

Usted recomendaría a un amigo que hiciera el curso de Design UFAM?

En la tabla que sigue las respuestas obtenidas:

Tabla 43: Resultados de la Cuestión 19 del cuestionario - TITULADOS

\begin{tabular}{|l|l|l|}
\hline & Frecuencia & Porcentaje (\%) \\
\hline SI & 51 & 94,4 \\
\hline NO & 3 & 5,6 \\
\hline
\end{tabular}




\subsection{Descripción del sistema actual y propuesta de una estrategia para la mejorar la gestión de la innovación del curso de grado en Diseño UFAM: sistema propuesto.}

El sexto capítulo está dedicado a la caracterización de la situación actual y proposición de una estrategia para mejorar la gestión de la Innovación en Design UFAM curso. Basado en la técnica DAFO se relacionan en una matriz, las fortalezas y debilidades, así como las oportunidades y amenazas relacionadas con el ambiente de la innovación del curso y posteriormente es sugerida un nuevo sistema de gestión de la innovación en el curso basado en el Método de Formulación por Objetivos.

\subsubsection{Aplicación de la técnica DAFO}

La técnica adoptada para el análisis inicial de este entorno de estudio, la metodología DAFO, identifica tres etapas básicas (Tarapanoff, 2001) que se presentan a continuación junto con los resultados de la investigación para cada una de ellas:

Etapa 01: Consiste en relacionar en una lista, los puntos fuertes y débiles en relación con el ambiente interno de la organización y las oportunidades y amenazas del entorno externo de la misma, la composición de esta lista, el primer producto del análisis, se puede realizar utilizando técnicas tales como entrevistas , cuestionarios y lluvia de ideas (Tarapanoff, 2001).

En esta fase fueron relacionados factores que se encuentran en las respuestas de los cuestionarios aplicados junto con grupos de profesores, alumnos y titulados del curso de Design. Se construyó la lista que se refiere al paso 01 de la técnica de la siguiente manera:

Tabla 44: Lista DAFO del ambiente de apoyo a la innovación en el curso de Design.

Ambiente interno - Puntos fuertes:

- Familiaridad de los docentes con los conceptos sobre Innovación (Innovación, espíritu empresarial, transferencia de tecnología);

- Acceso a la información y formación dirigidas a la protección de la propiedad intelectual se considera esencial por la mayoría de los profesores y estudiantes;

- El profesorado está familiarizado con los mecanismos y políticas para 
apoyar la innovación UFAM.

- La difusión del espíritu emprendedor entre los estudiantes y los profesores del curso se considera esencial por la mayoría de los profesores y alumnos;

- La existencia de proyectos desarrollados en cooperación con el sector privado y otras instituciones de enseñanza e investigación se considera esencial por la mayoría de los profesores y alumnos;

- Los profesores y los alumnos tienen interés en participar en los proyectos desarrollados en cooperación con el sector privado;

- Momento de valoración del apoyo a la Innovación vivido en UFAM (Aprobación de la política de Innovación y creación de la PROTEC);

Ambiente Interno - Debilidades:

- $\quad$ No existe una estrategia definida para fomentar la innovación en el curso;

- Desconocimiento parcial de profesores y estudiantes sobre los objetivos de Innovación del curso;

- Desconocimiento parcial de los profesores y estudiantes sobre los proyectos que están siendo desarrollados por otros docentes en el curso;

- La infraestructura de laboratorio se considera insuficiente por profesores y alumnos;

- Sólo el 33,3\% de los profesores creen que el curso fomenta la práctica de la innovación entre los profesores y Alumnos;

- Los profesores no consideran importante un vínculo con las incubadoras y el apoyo a la transferencia de tecnología.

- Poca familiaridad de los alumnos con los conceptos relativos a la innovación.

- Poca familiaridad de los alumnos con los procedimientos de la ley relacionadas con la Protección de la Propiedad Intelectual / Industrial.

- La mayoría de los estudiantes piensan que no tienen fácil acceso a la producción de conocimiento generado en el curso (monografías, artículos publicados, los resultados de los proyectos, etc.).

- Una parte significativa de los alumnos no conocen la función del NIT y nunca habían oído hablar de la PROTEC.

Ambiente Externo - Oportunidades 
- Los intereses de algunas empresas en desarrollar proyectos en conjunto con la Universidad (por ejemplo, la Natura);

- Las convocatorias de financiamiento para el asociación específica entre la universidad y la industria (por ejemplo FAPEAM/IEL);

- Se observó que la mayoría de los titulados actúa en el sector privado, echo que puede ser una oportunidad para acercarse el curso de este sector.

- Fortalecimiento de políticas de apoyo a la Innovación del Gobierno Federal (Ley de Innovación, etc.).

\section{Ambiente Externo - Amenazas}

- El riesgo de la iniciativa privada conducir sus inversiones a otras instituciones;

- Imagen del curso se puede proyectar como de poca producción innovadora;

- La gran mayoría de los titulados $(98 \%)$ nunca ha patentado producto o producido (sea por sí mismo o por medio de transferencia de tecnología) cualquier producto o proceso que desarrollaron $(72,2 \%)$, mostrando que la baja producción de Innovación entre los designers también se refleja en el sistema exterior;

- $\quad$ No existe un monitoreo sistemático de los titulados, lo que dificulta el establecimiento de una red de cooperación entre ellos y la universidad.

Fuente: El autor

Paso 02: La segunda fase de la técnica DAFO es clasificar la lista obtenida en el paso anterior, ordenando a los factores establecidos, lo más importante al menos importante, esta clasificación se debe hacer teniendo en cuenta el logro de los objetivos organizacionales. (Tarapanoff, 2001)

Así, siguiendo la secuencia de la metodología adoptada para este estudio, la lista de factores generada en el paso 01 fue organizada en orden de importancia basada en la observación de los objetivos de Innovación del curso. 


\section{Objetivos de innovación del Curso:}

- Promover y fomentar la investigación en Diseño en la búsqueda de nuevas soluciones a los nuevos paradigmas de la sociedad, buscando su crecimiento y mejoras en la vida Calidad.

- Promover y alentar iniciativas y proyectos que puedan representar una mejora efectiva en el desarrollo de nuevas tecnologías, productos y sistemas de comunicación, a través del diseño, en provecho del desarrollo de la sociedad.

Tabla 45: Organización en orden de importancia de los ítems de la lista DAFO Ambiente interno - puntos fuertes

\begin{tabular}{|c|l|}
\hline $\begin{array}{c}\text { Orden de } \\
\text { Importancia }\end{array}$ & Ambiente interno - Puntos fuertes: \\
\hline 1 & $\begin{array}{l}\text { Momento de valoración del apoyo a la Innovación vivido en UFAM } \\
\text { (Aprobación de la política de Innovación y creación de la PROTEC); }\end{array}$ \\
\hline 2 & $\begin{array}{l}\text { Familiaridad de los docentes con los conceptos sobre Innovación } \\
\text { (Innovación, espíritu empresarial, transferencia de tecnología); }\end{array}$ \\
\hline 3 & $\begin{array}{l}\text { El profesorado está familiarizado con los mecanismos y políticas } \\
\text { para apoyar la innovación UFAM. }\end{array}$ \\
\hline 4 & $\begin{array}{l}\text { La difusión del espíritu emprendedor entre los estudiantes y los } \\
\text { profesores del curso se considera esencial por la mayoría de los } \\
\text { profesores y alumnos; }\end{array}$ \\
\hline 5 & $\begin{array}{l}\text { La existencia de proyectos desarrollados en cooperación con el } \\
\text { sector privado y otras instituciones de enseñanza e investigación se } \\
\text { considera esencial por la mayoría de los profesores y alumnos; }\end{array}$ \\
\hline 6 & $\begin{array}{l}\text { El Acceso a la información y formación dirigidas a la protección de la } \\
\text { propiedad intelectual se considera esencial por la mayoría de los } \\
\text { profesores y estudiantes; }\end{array}$ \\
\hline 7 & $\begin{array}{l}\text { Los profesores y los alumnos tienen interés en participar en los } \\
\text { proyectos desarrollados en cooperación con el sector privado; }\end{array}$ \\
\hline
\end{tabular}

Fuente: El autor 
Tabla 46: Organización en orden de importancia de los ítems de la lista DAFO Ambiente interno - Debilidades

\begin{tabular}{|c|c|}
\hline $\begin{array}{l}\text { Orden de } \\
\text { Importancia }\end{array}$ & Ambiente interno - Debilidades: \\
\hline 1 & $\begin{array}{l}\text { No existe una estrategia definida para fomentar la innovación en el } \\
\text { curso; }\end{array}$ \\
\hline 2 & $\begin{array}{l}\text { Desconocimiento parcial de profesores y estudiantes sobre los } \\
\text { objetivos de Innovación del curso; }\end{array}$ \\
\hline 3 & $\begin{array}{l}\text { Una parte significativa de los alumnos no conocen la función del NIT } \\
\text { y nunca habían oído hablar de la PROTEC. }\end{array}$ \\
\hline 4 & $\begin{array}{l}\text { Desconocimiento parcial de los profesores y estudiantes sobre los } \\
\text { proyectos que están siendo desarrollados por otros docentes en el } \\
\text { curso; }\end{array}$ \\
\hline 5 & $\begin{array}{l}\text { Sólo el } 33,3 \% \text { de los profesores creen que el curso fomenta la } \\
\text { práctica de la innovación entre los profesores y Alumnos; }\end{array}$ \\
\hline 6 & $\begin{array}{l}\text { Los profesores no consideran importante el vínculo con las } \\
\text { incubadoras y el apoyo a la transferencia de tecnología. }\end{array}$ \\
\hline 7 & $\begin{array}{l}\text { La infraestructura de laboratorio se considera insuficiente por } \\
\text { profesores y alumnos; }\end{array}$ \\
\hline 8 & $\begin{array}{l}\text { Poca familiaridad de los alumnos con los conceptos relativos a la } \\
\text { innovación. }\end{array}$ \\
\hline 9 & $\begin{array}{l}\text { Poca familiaridad de los alumnos con los procedimientos de la ley } \\
\text { relacionadas con la Protección de la Propiedad Intelectual / } \\
\text { Industrial. }\end{array}$ \\
\hline 10 & $\begin{array}{l}\text { La mayoría de los estudiantes piensan que no tienen fácil acceso a la } \\
\text { producción de conocimiento generado en el curso (monografías, } \\
\text { artículos publicados, los resultados de los proyectos, etc.). }\end{array}$ \\
\hline
\end{tabular}

Fuente: El autor

Tabla 47: Organización en orden de importancia de los ítems de la lista DAFO Ambiente externo - Oportunidades

\begin{tabular}{|c|l|}
\hline $\begin{array}{c}\text { Orden de } \\
\text { Importancia }\end{array}$ & \multicolumn{1}{c|}{ Ambiente Externo - Oportunidades } \\
\hline 1 & $\begin{array}{l}\text { Fortalecimiento de políticas de apoyo a la Innovación del Gobierno } \\
\text { Federal (Ley de Innovación, etc.). }\end{array}$ \\
\hline 2 & $\begin{array}{l}\text { Las convocatorias de financiamiento para el asociación específica } \\
\text { entre la universidad y la industria (por ejemplo FAPEAM/IEL); }\end{array}$ \\
\hline 3 & $\begin{array}{l}\text { El interés de algunas empresas en desarrollar proyectos en conjunto } \\
\text { con la Universidad (por ejemplo, la Natura); }\end{array}$ \\
\hline 4 & $\begin{array}{l}\text { Se observó que la mayoría de los titulados actúa en el sector } \\
\text { privado, echo que puede ser una oportunidad para acercarse el } \\
\text { curso de este sector. }\end{array}$ \\
\hline
\end{tabular}

Fuente: El autor 
Tabla 48: Organización en orden de importancia de los ítems de la lista DAFO Ambiente externo - Amenazas

\begin{tabular}{|c|l|}
\hline $\begin{array}{c}\text { Orden de } \\
\text { Importancia }\end{array}$ & \multicolumn{1}{|c|}{ Ambiente Externo - Amenazas } \\
\hline 1 & $\begin{array}{l}\text { La gran mayoría de los titulados (98\%) nunca ha patentado producto } \\
\text { o producido (sea por sí mismo o por medio de transferencia de } \\
\text { tecnología) cualquier producto o proceso que desarrollaron (72,2\%), } \\
\text { mostrando que la baja producción de Innovación entre los designers } \\
\text { también se refleja en el sistema exterior; }\end{array}$ \\
\hline 2 & $\begin{array}{l}\text { Imagen del curso se puede proyectar como de poca producción } \\
\text { innovadora; }\end{array}$ \\
\hline 3 & $\begin{array}{l}\text { El riesgo de la iniciativa privada conducir sus inversiones a otras } \\
\text { instituciones; }\end{array}$ \\
\hline 4 & $\begin{array}{l}\text { No existe un monitoreo sistemático de los titulados, lo que dificulta } \\
\text { el establecimiento de una red de cooperación entre ellos y la } \\
\text { universidad. }\end{array}$ \\
\hline
\end{tabular}

Fuente: El autor

Paso 03: El tercer paso es la construcción de una matriz, una lista de los diversos factores planteados, para identificar los temas críticos y situaciones que requieren una atención especial.

Partir de la construcción de la Matriz DAFO con las fortalezas y debilidades, amenazas y oportunidades identificadas, fue posible formular una estrategia de los aspectos clave que pueden contribuir al entorno de la innovación en el curso. 
Tabla 49: La Matriz DAFO - El Ambiente de la innovación en el curso de Design UFAM

\begin{tabular}{|c|c|c|}
\hline & AJUDA & ATRAPALHA \\
\hline \multirow[b]{2}{*}{ 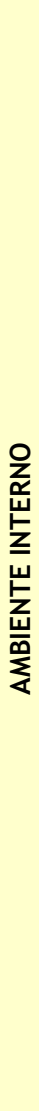 } & FORÇAS & FRAQUEZAS \\
\hline & 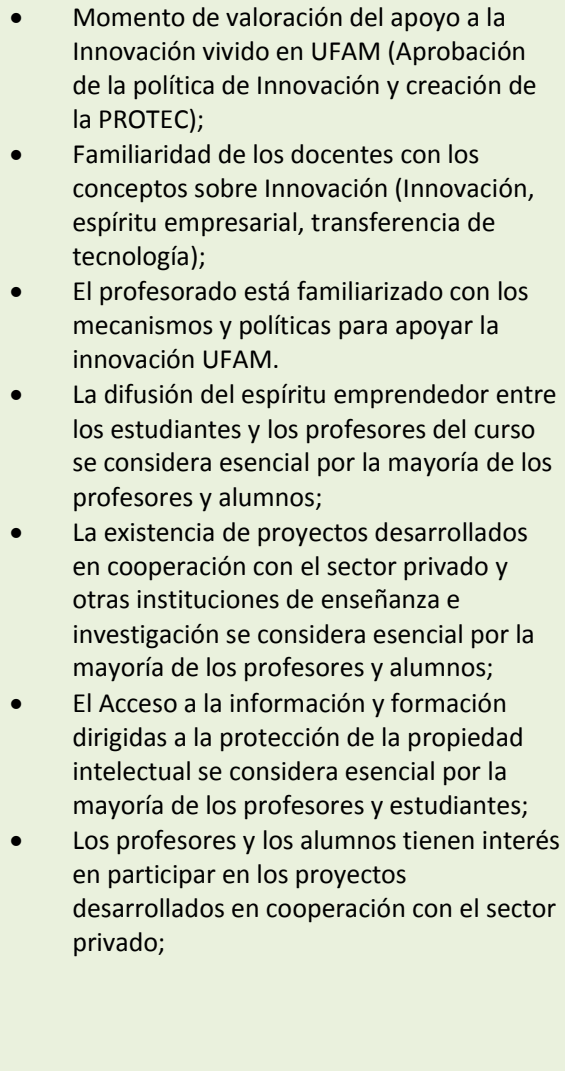 & $\begin{array}{l}\text { - } \quad \text { No existe una estrategia definida para } \\
\text { fomentar la innovación en el curso; } \\
\text { Desconocimiento parcial de profesores y } \\
\text { estudiantes sobre los objetivos de Innovación } \\
\text { del curso; } \\
\text { Una parte significativa de los alumnos no } \\
\text { conocen la función del NIT y nunca habían } \\
\text { oído hablar de la PROTEC. } \\
\text { Desconocimiento parcial de los profesores y } \\
\text { estudiantes sobre los proyectos que están } \\
\text { siendo desarrollados por otros docentes en el } \\
\text { curso; } \\
\text { - Sólo el 33,3\% de los profesores creen que el } \\
\text { curso fomenta la práctica de la innovación } \\
\text { entre los profesores y Alumnos; } \\
\text { - Los profesores no consideran importante el } \\
\text { vínculo con las incubadoras y el apoyo a la } \\
\text { transferencia de tecnología. } \\
\text { La infraestructura de laboratorio se considera } \\
\text { insuficiente por profesores y alumnos; } \\
\text { Poca familiaridad de los alumnos con los } \\
\text { conceptos relativos a la innovación. } \\
\text { Poca familiaridad de los alumnos con los } \\
\text { procedimientos de la ley relacionadas con la } \\
\text { Protección de la Propiedad Intelectual / } \\
\text { Industrial. } \\
\text { ta mayonen fáa de los estudiantes piensan que no } \\
\text { conocimiento generado en el curso } \\
\text { (monografías, artículos publicados, los } \\
\text { resultados de los proyectos, etc.). }\end{array}$ \\
\hline \multirow{5}{*}{ 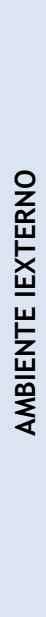 } & OPORTUNIDADES & AMEAÇAS \\
\hline & $\begin{array}{l}\text { Fortalecimiento de políticas de apoyo a la } \\
\text { Innovación del Gobierno Federal (Ley de } \\
\text { Innovación, etc.). }\end{array}$ & $\begin{array}{l}\text { La gran mayoría de los titulados (98\%) nunca ha } \\
\text { patentado producto o producido (sea por sí mismo } \\
\text { o por medio de transferencia de tecnología) } \\
\text { cualquier producto o proceso que desarrollaron } \\
\text { ( } 72,2 \%) \text {, mostrando que la baja producción de } \\
\text { Innovación entre los designers también se refleja } \\
\text { en el sistema exterior; }\end{array}$ \\
\hline & $\begin{array}{l}\text { Las convocatorias de financiamiento para el } \\
\text { asociación específica entre la universidad y la } \\
\text { industria (por ejemplo FAPEAM/IEL); }\end{array}$ & $\begin{array}{l}\text { Imagen del curso se puede proyectar como de } \\
\text { poca producción innovadora; }\end{array}$ \\
\hline & $\begin{array}{l}\text { El interés de algunas empresas en desarrollar } \\
\text { proyectos en conjunto con la Universidad (por } \\
\text { ejemplo, la Natura); }\end{array}$ & $\begin{array}{l}\text { El riesgo de la iniciativa privada conducir sus } \\
\text { inversiones a otras instituciones; }\end{array}$ \\
\hline & $\begin{array}{l}\text { Se observó que la mayoría de los titulados actúa } \\
\text { en el sector privado, echo que puede ser una } \\
\text { oportunidad para acercarse el curso de este } \\
\text { sector. }\end{array}$ & $\begin{array}{l}\text { No existe un monitoreo sistemático de los } \\
\text { titulados, lo que dificulta el establecimiento de una } \\
\text { red de cooperación entre ellos y la universidad. }\end{array}$ \\
\hline
\end{tabular}

Fuente: El autor/Adaptado de Tarapanoff, 2001. 
Los datos obtenidos en la investigación (entrevistas y cuestionarios) y los análisis realizados a partir de la Matriz DAFO servirán de base para la aplicación del Método de Formulación por Objetivos, donde se presentará la caracterización del sistema actual y se propondrá una nueva organización del curso de Design centrada en sus objetivos de innovación.

\subsubsection{Aplicación del Modelo de Formulación por Objetivos para caracterización del escenario actual de la innovación e proposición de un modelo de Gestión de la innovación en el curso.}

\subsubsection{Caracterización del Sistema en Estudio}

\section{a) Sistema Exterior}

\section{a.1 Análisis Geográfico}

El grado en Design está vinculado a la Universidad Federal Amazonas (UFAM) y está situado en el Campus Universitario de Manaus, estado de Amazonas, ciudad en la que se instaló el Polo Industrial de Manaus (PIM) parque que acoge aproximadamente 600 industrias de varios segmentos, en función de los incentivos fiscales ofrecidos por el Gobierno Federal.

El curso de grado en Design fue creado en los años 80 con la idea de servir a un mercado de trabajo procedente del PIM, sin embargo, el Polo no absorbió esta demanda de profesionales, ya que la mayoría de las industrias actuó únicamente como de montadoras de productos.

Por lo tanto, los egresados del curso han quedado absorbidos, principalmente por el mercado de programación visual, y los que tenían experiencia en el ámbito del diseño de producto han migrado hacia el área de Design de muebles, interiores y productos de la diversidad amazónica.

El Estado de Amazonas es conocido mundialmente por ser el poseedor de zonas forestales que albergan una rica y codiciada diversidad biológica y el crecimiento del estado en la actualidad está relacionado con la búsqueda de la sostenibilidad en la región, es dentro de este contexto que el curso se ajusta al objetivo de ser un agente de desarrollo regional. 


\section{a.2 Titulación}

El curso ofrece el grado de Design sin división en cualificaciones. Hasta marzo de 2012, el curso había formado un total de 223 graduados en Design.

\section{a.3 I imagen ofrecida y la percepción de los clientes (alumnado)}

El UFAM goza de una buena imagen tanto a nivel nacional como regional. En general las universidades federales aún son consideradas por la población como mejores instituciones que ofrecen mayor calidad de educación en comparación con las instituciones privadas.

Subrayando el resultado de la investigación realizada como parte de este estudio junto con alumnos y titulados del curso, cuando preguntados se indicarían el curso de diseño a un amigo el resultado fue UFAM: Sí (alumnos: 90,7\% / Titulados: 94,4\%).

A través de las respuestas obtenidas en la encuesta, señalase que el curso tiene una buena imagen con sus clientes, los Alumnos, ya que la gran mayoría de los encuestados declaró que indicarían el curso para los demás.

Además, el curso cuenta con concepto cuatro (4) en la evaluación del MEC, que es un concepto que lo pone entre las mejores universidades del país en Design.

\section{a.4 Histórico}

La historia de la Universidad Federal se funde con la historia de la educación superior en Brasil. Fue la primera universidad en el país y cuenta con 103 años de existencia. Los 100 años del establecimiento de la educación superior en la región amazónica fue celebrado el 17 de enero, 2009. Fue en esta fecha en 1909, que surgió la primera institución de educación superior en el país, la Escuela Universitaria Libre de Manaos.

El curso de Diseño fue creado en 1988 y su historia se puede ver en más detalle en el capítulo 4.

\section{a.5 Legislación}

Según el sitio web oficial de UFAM, la Universidad de Amazonas es una Institución Federal de Educación Superior, creada por la Ley $n^{\circ}$ 4069-A, 12 de junio de 1962, el Decreto no. 53699 de 13 de marzo de 1964. La UFAM es mantenida por la Unión como entidad de dominación indirecta en la forma de la legislación y goza de autonomía didáctica, científica, administrativa y de 
gestión financiera y patrimonial, siguiendo el principio de la indivisibilidad entre enseñanza, investigación y extensión.

Institucionalmente el curso se rige por las Resoluciones $N^{\circ}$ 015/2007CONSEPE/CEG que modifica la nomenclatura del Curso de Diseño Industrial para Design, $N^{\circ}$ 016/2007- CONSEPE/CEG que aprueba el proyecto pedagógico del Curso de Grado en Design, modalidad Bachillerato y $N^{\circ}$ 017/2007CONSEPE/CEG que regula el Proyecto Pedagógico del curso.

A nivel nacional, el curso está guiado por la Resolución $N^{\circ} 5$, de 8 de marzo de 2004 del Consejo Nacional de Educación/Cámara de Educación Superior que establece las Directrices Curriculares Nacionales para los Cursos de Design, estableciendo la carga de trabajo mínima y materiales que deben se ver en el plan de estudios de los cursos.

\section{a.6 Aspectos Económicos}

Debido a que es una institución pública federal el curso se ofrece de forma gratuita a los ALUMNOS.

Las becas disponibles para profesores y alumnos tienen como objetivo la investigación y la extensión y cuentan con financiamiento principalmente de las tres agencias que apoyan la investigación en Brasil:

- CNPq: Consejo Nacional de Desarrollo Científico y Tecnológico, un organismo del Ministerio de Ciencia y Tecnología (MCT) para la promoción de la investigación científica y tecnológica y la formación de recursos humanos para la investigación en el país.

- FAPEAM: Fundación para la Investigación del Estado de Amazonas, un organismo de la Secretaría de Estado de Ciencia y Tecnología, es una fundación destinada al apoyo a la investigación básica y aplicada, el desarrollo científico y tecnológico y experimental, en el Estado Amazonas.

Otros recursos:

- A nivel institucional hay también un destino de sus propios recursos para ofrecer becas en diferentes niveles:

- Becas de investigación;

Programa Institucional de Becas de Iniciación Científica (PIBIC)

Programa institucional de Becas de Iniciación en Desarrollo

Tecnológico e Innovación (PIBIT)

- Becas de Extensión;

- Becas Trabajo; 
- Los fondos de proyectos, acuerdos y convenios que utilizan los recursos humanos y materiales disponibles en el curso y los contratos de servicios a la comunidad, también originan recursos para la asignación de subvenciones a los alumnos.

\section{a.7 Competencia del curso (General)}

El curso tiene sus competencias definidas por el Proyecto Político Pedagógico constitutivo de sus objetivos, perfil de estudiante, currículo y normas generales de funcionamiento del TCC y Prácticas.

El curso debe proporcionar las condiciones para que sus estudiantes puedan, en primer lugar, interactuar bien con la tecnología y sus constantes cambios, explorando con la creatividad inherente en el desempeño de sus actividades profesionales dentro de la sociedad.

El curso, en sintonía con el perfil deseado para su egreso debe ser tal que pueda, entre otras habilidades, actitudes y habilidades, tener:

- Habilidades creativas - debe ser capaz de proponer soluciones innovadoras para el campo de los procesos técnicos y creativos.

- Dominio de Lenguaje - debe ser capaz de expresar conceptos y soluciones para sus proyectos, tanto a mano alzada y por el uso de instrumentos, el dominio de las técnicas de expresión y bi y tri dimensionales, así como las capacidades de la tecnología de información.

- Transito Interdisciplinario - debe ser capaz de hablar con expertos de otros campos a utilizar diferentes conocimientos y el trabajar en equipos multidisciplinares en el desarrollo e implementación de investigaciones y proyectos.

- Capacidad para conceptualizar el proyecto - debe tener una visión sistémica del proyecto, la combinación adecuada de los diferentes componentes, reconociendo las características de los diferentes materiales y procesos de fabricación, teniendo en cuenta los aspectos ergonómicos, psicológicos y sociológicos de productos.

- Conocimiento de los aspectos de la metodología de diseño - debe dominar las etapas de desarrollo del proyecto, a saber: el establecimiento de objetivos, la recopilación técnica, procesamiento y análisis de datos, generación y evaluación de conceptos, configuración de soluciones y presentación de informes.

- Conocimiento de aspectos administrativos - debe tener nociones de gestión de la producción, incluida la comercialización, calidad, productividad, 
disposición física de la fábrica (diseño de producción), el inventario, los costos y las inversiones, además de la gestión de los recursos humanos para la producción.

- Conocimiento de los aspectos socio-económicos - debe tener la visión histórica y prospectiva, así como la conciencia de las implicaciones de la actividad económica, social, antropológica, ético ambiental.

\section{a.8 Perfil del Cliente}

Según una investigación realizada con el alumnado del curso (ya presentada en el capítulo sobre los resultados) los alumnos son los jóvenes cuyo grupo de edad predominante es entre 17 y 25 años de edad, en su mayoría solteros, cuya área de interés en el diseño se divide uniformemente entre las tres áreas básicas: Diseño de Producto, Programación Visual e interfaces gráficas digitales (Web / juegos / aplicaciones de la electrónica en general). Según los datos proporcionados por el registro, por supuesto, la mayoría asistió a los estudios secundarios en escuelas privadas.

\section{b. SISTEMA ACTUAL}

El escenario actual del sistema en estudio se analizó desde el punto de vista de los objetivos presentes en el Proyecto Pedagógico del curso y los principales resultados sobre la percepción de las partes interesadas en las cuestiones relacionadas con el ambiente de la Innovación que se presentaron en el capítulo 5, sobre los resultados de las encuestas y al comienzo del capítulo 6 con el aplicación de la técnica DAFO.

A continuación son presentadas más informaciones que ayudarán a establecer el escenario del curso para atender la aplicación del Método de Formulación por Objetivos.

\section{b.2 Subsistema Físico}

El subsistema físico consta de varios elementos tales como los recursos humanos, materiales, equipos, laboratorios y estructuras físicas. A continuación se describe la infraestructura humana y física disponible en el curso. 


\section{Recursos Humanos}

\section{Compuesto por la siguiente estructura:}

Coordinación del curso: 02 personas

01 Coordinador y 01 Coordinador Adjunto

Dirección del Departamento: 02 personas

01 Jefe e 01 subjefe

Personal docente: 20 profesores

Secretaria: 03 personas

01 secretario y 02 becarios

Núcleo Docente estructurante del Curso (NDE): 08 personas

08 profesores que forman parte del profesorado del curso

Colegiado del Curso

El Coordinador del curso de Design, 01 representante del curso y 01 representante de cada departamento que ofrece asignaturas para el curso

Centro Académico - Representación de los estudiantes: 05 Personas

Infraestructura Física

Para su funcionamiento el curso de Design cuenta con su propio espacio, un bloque (Río Japurá) desde el año 2007 ubicado en la Facultad de Tecnología, de uso exclusivo del curso. Este espacio alberga estructuras administrativas, laboratorios, núcleos y talleres:

\section{Estructura administrativa:}

Sala de la Dirección del Departamento y de la Coordinación de Curso

Actividades emprendidas en el lugar: Atendimiento a los a alumnos y profesores del curso

Espacio: $15 \mathrm{~m}^{2}$

Equipos / materiales permanentes / otros:

01 aire acondicionado split, 02 ordenadores con monitor, 01 impresora color HP Deskjet, 02 mesas, 04 sillas, 01 armario metálico. 
Secretaria del cursol sala de reuniones:

Actividades emprendidas en el lugar: Atendimiento a los a alumnos y profesores del curso/ reuniones del Departamento.

Espacio: $25 \mathrm{~m}^{2}$

Equipos / materiales permanentes / otros:

01 aire acondicionado split, 02 ordenadores con monitor, 01 impresora color HP Deskjet A3, 02 mesas, 15 sillas, 01 armario metálico, 02 mesas para reuniones.

Recursos audiovisuales:

El curso cuenta con el siguiente equipo para su uso exclusivo:

5 (Cinco) Proyectores Multimedia, 3 (tres) Notebooks; 3 (tres) Retroproyectores, 1 (A) Proyector de diapositivas

Centro Académico de Design (Sala de Representación de estudiantes)

Actividades emprendidas en el lugar:

Reuniones entre los discentes del centro académico/ Atendimiento a los a alumnos.

Espacio: $12,5 \mathrm{~m}^{2}$

Equipos / materiales permanentes / otros:

01 ordenador con monitor, 01 impresora HP laser, 01 mesa de, 04 sillas.

\section{Laboratorios y talleres:}

\section{LIFT II - Laboratorio Informático II}

Actividades emprendidas en el lugar: Espacio donde se imparten las clases que necesitan el uso de herramientas computacionales.

Espacio: $50 \mathrm{~m}^{2}$

Equipos / materiales permanentes / otros:

30 ordenadores con monitor, bancos para 30 ordenadores; 35 sillas; Teléfono.

\section{COMVIdeo - Laboratorio de Comunicación Visual y Diseño de Vídeo}

Actividades emprendidas en el lugar: Desarrollo de diseños gráficos, recogida, tratamiento y edición de imágenes, creación de viñetas y animaciones.

Espacio: $50 \mathrm{~m}^{2}$

Equipos / materiales permanentes / otros:

01 TV 21 ", 01 DVD, 01 Isla de Edition Analog (Monitor de 19", teclado, ratón, altavoces, disco duro externo, tarjeta de captura), 01 Isla Digital de Edition, 02 Ordenadores (Monitor, CPU, ratón, teclado y 
caja de sonido), 02 impresoras láser (imprime sólo en negro), 01 paquete de iluminación, 01 aparatos VHS, videocámaras JVC 02 Semiprofissonal, 01 Ministros, 05 mesas, 10 sillas, 03 bancos, 07 monitores , 01 Teleprompter (de madera banco + monitor y CPU adaptado) , 01 y Escenario Chroma para programa de televisión, 01 escáner plano

\section{Laboratorio de Testes y Pruebas de embalajes}

Actividades emprendidas en el lugar: testes y desarrollo de proyectos de embalajes

Espacio: $30 \mathrm{~m}^{2}$

Equipos / materiales permanentes / otros:

02 ordenadores con monitor; 01 impresora HP 1200; 01 impresora HP 860; 01 Scanner HP; Área de producción con Drop Test (Equipo para testes de caída de embalajes) modelo LAB Profesional con capacidad para 905 Kg por producto; Mesa de corte; Camera Digital Minolta.

\section{Taller de Serigrafía}

Actividades emprendidas en el lugar: Clases prácticas de serigrafía y actividades de extensión

Espacio: $80 \mathrm{~m}^{2}$

Equipos / materiales permanentes / otros:

01 Ordenador con monitor; cuarto oscuro para revelación de pantallas con fregadero; Mesa de luz convencional; Mesa de luz y toques de diapositivas, una mesa, un banco, una mesa fotoincisora, dos sillas, doce bancos, dos aerógrafos, un compresor, un secador, una pluma térmica para hacer serigrafía en relieve; un carrusel de impresión con tres literas, una estantería, un armario.

\section{Taller de madera y metal}

Actividades emprendidas en el lugar: Sesiones prácticas sobre el diseño de productos de madera y metales.

Espacio: $58 \mathrm{~m}^{2}$.

Equipos / materiales permanentes / otros:

Madera: Maquinaria pesada para trabajar la madera (de acceso restringido); Sierras, lijadora angular; dos Lijadoras común, uno pulidora de ángulo, herramientas varias, un taladro manual, dos tablas de herramientas, equipo de protección personal.

Metales: Un banco, dos morsas, Tijeras de banco, taladro, lijadora, un panel con herramientas diversas, dos estanterías, un armario. 


\section{Taller de Cerámica}

Actividades emprendidas en el lugar: Clases prácticas de cerámica y actividades de extensión

Espacio: $20 \mathrm{~m} 2$

Equipos / materiales permanentes / otros:

05 tornos eléctricos, un horno tostador, un horno de barro a leña, juegos de herramientas para el modelado, 04 contenedores para esmalte, 02 estantes01 Banco, recipientes de plástico, cubos para el agua, 06 planchas de espuma; Conos pirométricos y cepillos.

\section{Núcleos de investigación:}

\section{Núcleo INOVE (Modelos tridimensionales / Fashion Design)}

Actividades emprendidas en el lugar: Construcción de modelos mediante diversas técnicas.

Espacio: $42 \mathrm{~m}^{2}$

Equipos / materiales permanentes / otros:

01 ordenador con monitor, 02 mesas, 04 sillas, 02 bancos para artesanías, 02 sumideros; Drill / lijadora, herramientas varias.

\section{TRANSPORTAR}

Actividades emprendidas en el lugar: Proyectos de investigación relacionados con la logística en el Amazonas.

Espacio: $55 \mathrm{~m}^{2}$

Equipos / materiales permanentes / otros:

10 ordenadores, 5 computadoras portátiles, 4 impresoras, un router para el control de la red; 8 GPS, 4 máquinas fotográficas digitales, dos cámaras, dos grabadoras digitales, 1 TV 42 ", un grabador de DVD para TV, 1 Plotter 42 ", 1 lux metros, 1 medidor de decibelios, 1 globo termómetro; 1 Trena laser, 1 Trena de rueda, 1 nevera, 1 Máquina de Fax.

NUPED (Núcleo de investigación y desarrollo de proyectos en ergonomía) Actividades emprendidas en el lugar: Desarrollo de actividades de investigación e intervenciones en ergonomía, prestación de servicios en el área.

Espacio: $42 \mathrm{~m}^{2}$

Equipos / materiales permanentes / otros: 
03 Ordenadores con monitor y accesorios, 01 impresora láser, 01 impresora colores, tres mesas, una mesa de reuniones, 10 sillas.

\section{NIDE (Núcleo de Innovación y Design de Embalajes)}

Actividades emprendidas en el lugar: Coordinación de proyectos de consultoría de embalaje integrada a la Micro y Pequeña Empresa. Desarrollo de investigaciones sobre las tendencias, materiales, procesos e innovaciones tecnológicas sobre embalaje.

Espacio: $25 \mathrm{~m}^{2}$

Equipos / materiales permanentes / otros:

1 impresora HP 9800, 1 impresora HP Laserjet 1015, 1 Benq Scanner 4300, 1 nobreak, 1 estabilizador, 1 PC con CPU Multicom, grabador de CD, Monitor Proview 17 ", cajas de sonido, una cámara digital Kodak 4,0 Megapixel. un servidor de intranet, 1 Gabinete para archivos; Gabinete Pandim 1/2 puertas, 1 armario de madera, 1 mesa redonda, 2 mesas de oficina / 2 cajones

1 mesa rectangular con 6 sillas, 4 sillas giratorias

\section{ERGODESIGN}

Actividades emprendidas en el lugar: Intervenciones en ergonomía en los diferentes sectores del sistema hospitalario de UFAM (Facultad de Medicina y PROANDE). El servicio debe detectar y priorizar las necesidades y dificultades en el desarrollo de las actividades de los usuarios del hospital y proponer procedimientos o sistemas que faciliten dichas actividades.

Espacio: $30 \mathrm{~m}^{2}$

Equipos / materiales permanentes / otros:

01 ordenador con monitor; Dos mesas; cuatro sillas.

\section{b.3 NIVELES}

Obedeciendo al indicado por la metodología de análisis (Método de formulación por objetivos) ya detallado en el capítulo sobre materiales y métodos se establece la existencia de cuatro niveles en el curso y su configuración actual es la siguiente:

\section{b.3.1 Nivel de Explotación}

Agentes que forman parte del nivel y sus funciones: 
- Técnico administrativo y Becario

Funciones:

- Ejecución de la demanda diaria de los docentes y alumnos en servicios de secretaría.

- Técnico de Laboratorio

Funciones:

- Ejecución de la demanda diaria del laboratorio al cual pertenece.

- Profesores

\section{Funciones:}

- Realización de planes de estudio y otras actividades diarias con el fin de alcanzar los objetivos de estudio del curso.

- Cumplimiento de los planes de estudio de las asignaturas.

- Representación discente

Funciones:

- Planificación y realización de actividades académicas y culturales destinadas a alumnos.

- Coordinadores de laboratorios, talleres y núcleos (en su función de ejecución de las tareas diarias)

\section{Funciones:}

- Realización de los trabajos diarios y de la dinámica de los equipos de cada núcleo, taller o laboratorio;

Nota: Con respecto a los objetivos de la innovación no se detectaron funciones específicas o sistematizadas en este nivel.

\section{b.3.2 Nivel de Gestión}

Agentes que forman parte del nivel y sus funciones: 
- Jefe de departamento

\section{Funciones:}

- Supervisar la observancia del régimen académico, el cumplimiento de los programas y la aplicación de los planes de actividades;

- Gestión Administrativa y de recursos humanos del curso;

- Proporcionar la verificación de asiduidad de los profesores y personal técnico y administrativo del Departamento;

- Adoptar medidas para el desarrollo del plan de actividades a desarrollar en cada semestre, incluyendo la propuesta de lista de asignaturas ofrecidas;

- Solicitar al Director los recursos humanos y materiales que requieran el Departamento;

\section{- Coordinación General del Curso}

\section{Funciones:}

- Promover la coordinación didáctica de curso;

Aprobar el calendario académico y la lista de asignatura ofrecidas por el curso;

- Decidir sobre el cierre o transferencia de matrícula y júbilo;

- Decidir sobre reconocimiento de los estudios de con fines de dispensa, oídos los departamentos;

\section{Núcleo docente estructurante}

- Acompañamiento del Proyecto Político-Pedagógico del curso;

- Contribuir a la consolidación del perfil del curso de grado;

- Proponer formas de fomentar el desarrollo de la investigación y de la extensión articulado a las necesidades del curso;

Nota: Con respecto a los objetivos de la innovación no se detectaron funciones específicas o sistematizadas en este nivel.

\section{b.3.3 Nivel de Evolución}

Agentes que forman parte del nivel y sus funciones: 
- Consejo Departamental de la Unidad a la que está vinculado el curso (Facultad de Tecnología)

\section{Funciones:}

- Aprobar el Proyecto Político-Pedagógico del curso;

- Supervisar las actividades de los departamentos y promover su articulación;

- Decidir sobre el uso de equipos e instalaciones confiados a la Unidad

- Colegiado de curso

Funciones:

- Aprovar o Projeto Político-Pedagógico do Curso;

- Sugerir, planejar e aprovar eventuais alterações no funcionamento do curso;

- Núcleo docente estruturante

Funciones:

- Contínua atualização do Projeto Político-Pedagógico do Curso;

- Coordenação Geral do curso

Funciones:

- Elaboração do Projeto Político-Pedagógico do Curso;

- Estabelecimento de metas e estratégias para a correta aplicação do Projeto Político-Pedagógico do curso;

- Estabelecimento do plano de estudos do Curso;

- Planejamento geral das atividades didáticas do curso.

- Jefe de departamento

Funciones:

- Planejamento geral da utilização de recursos humanos e físicos para a execução do curso.

- Organizar Interação da infraestrutura com o projeto pedagógico.

- Estabelecer objetivos para os laboratórios, núcleos e oficinas, além de acompanhar suas atividades. 
Nota: Con respecto a los objetivos de la innovación no se detectaron funciones específicas o sistematizadas en este nivel.

\section{b.3.4 Nivel de Mutación}

Agentes que forman parte del nivel y sus funciones:

- Ministerio de Educación y Cultura (Gobierno Federal);

Funciones:

- Implementar políticas y estrategias en el área de diseño definidas por el Gobierno Federal;

- Establecer lineamientos curriculares de los cursos de grado en Diseño en el País.

- Consejo Universitario - CONSUNI

Funciones:

- Elaborar y reformar el Reglamento General de la Universidad;

- Aprobar, en vista de los planes aprobados por CONSEPE, la creación o supresión de los cursos de grado;

- Aprobar la creación o supresión de departamentos en vista de los planes presentados por CONSEPE.

- Consejo de Enseñanza, Investigación y Extensión - CONSEPE

Funciones:

- Homologar los proyectos político-pedagógicos de los cursos.

- Decidir y aprobar la creación, ampliación, modificación y extinción cursos de grado en la Universidad;

- $\quad$ PROEG - Vice Rectorado de enseñanza de Grado UFAM;

Funciones:

- Definir y aplicar las políticas y normas internas para cursos de grado;

Nota: Con respecto a los objetivos de la innovación no se detectaron funciones específicas o sistematizadas en este nivel. 


\section{b.4 Variables del Sistema Actual}

De acuerdo con la metodología adoptada varias variables fueron analizadas en cada nivel, así como su relación:

\section{b.4.1 Variables de Acción (VA)}

Variables de Acción (VAme): Mutación a Evolución

Definición de la política nacional para la educación superior (MEC);

Aprobación de la creación o extinción de cursos de grado (CONSUNI/CONSEPE);

Definición de las políticas internas para estudios de grado (PROEG/UFAM);

Homologación del Proyecto Político de los cursos y expedición de la autorización para el funcionamiento; (CONSEPE)

Planificación de las actividades relacionadas con el Proyecto de Curso.

\section{Variables de Acción (VAeg): Evolución a Gestión}

Nombramiento de los Responsables por los Departamentos, Núcleos y Laboratorios;

Establecimiento y comunicación de las prioridades;

Formación de los equipos de los departamentos y laboratorios;

Formulación de objetivos que se deben cumplir;

Desarrollo e Implantación de proyectos de investigación y extensión;

Preparación de informes de los proyectos.

\section{Variables de Acción (VAge): Gestión a Explotación}

Planificación y el seguimiento del trabajo mensual del departamento y del curso.

\section{Variables de Acción (VAef): Explotación a Sistema Físico}

Distribución de las tareas diarias de personal disponible (profesores, secretaria, técnicos);

Definición de procedimientos para la aplicación y seguimiento de las tareas;

Definición de la distribución y uso de los recursos materiales necesarios. 


\section{b.4.2 Variables de Entrada y de Salida}

Variables de Entrada (VE)

- Documentos legales para la operación: Reconocimiento del MEC, orientaciones curriculares, UFAM Resoluciones, Normas PROEG;

- La información sobre el Sector de diseño (Escenario regional y nacional);

- La demanda por el curso

- La demanda por servicios de laboratorio

- Políticas y estrategias para el desarrollo de la Innovación (Gobierno Federal)

\section{Variables de Salida (VA)}

- Capital humano: alumnos titulados

- Innovación: Productos y procesos generados (resultados de investigaciones)

- Producción de Conocimiento: Monografías y artículos publicados

- Consultoría y colaboraciones externas

\section{b.4.3 Variables Esenciales (VES)}

Variables Esenciales del Nivel de Gestión (VESg):

El control del desarrollo de los proyectos en curso:

- Evaluaciones, análisis y acciones de replanificación;

- Control de los equipos (frecuencia, etc);

- Control de la Calidad de las actividades.

Variables Esenciales del Nivel de Evolución (VESe):

Evaluación del trabajo realizado:

- Número de proyectos llevados a cabo anualmente;

- Balance de las inversiones en los proyectos; 
- Resultados de las evaluaciones internas - estudiantes / profesores.

\section{Variables Esenciales del Nivel de Mutación (VESm):}

La medición del grado de consecución de los objetivos:

- Número de alumnos titulados en relación a lo previsto;

- Monitoreo de la producción docente / alumno curso de acuerdo con los objetivos de la institución;

- ejecución de rendición de cuentas de los proyectos.

\section{b.4.4 Variables de Información (VI)}

\section{Variables de Información al Nivel de Gestión (Vlg):}

- Plan de trabajo de los técnicos (administrativos y de laboratorio)

- Plan Individual de Trabajo de los Profesores (PIT) - a cada semestre;

- Informe Individual de Trabajo de los Profesores (RIT) - a cada semestre;

- Planes de enseñanza de las asignaturas elaboradas por los docentes;

- Informe de notas y frecuencias de las asignaturas - a cada semestre

- Listado de necesidades de adquisición de bienes de consumo;

- Hoja de monitoreo mensual de frecuencia de los profesores.

Variables de Información al Nivel de Evolución (Vle):

- Planificación de la salida para cualificación en nivel de posgrado de los docentes del curso;

- Informes semestrales y finales sobre el período de prueba de los profesores;

- Informes para solicitar la promoción profesional del personal docente (a cada dos años);

- Informes anual de ejecución de los proyectos;

- $\quad$ Evaluación de los docentes por los alumnos (Semestral);

- $\quad$ Auto evaluación de los docentes (Semestral). 
Variables de Información al Nivel de Mutación (VIm):

- Proyecto Político-Pedagógico del curso (Al CONSEPE, CONSUNI y MEC);

- Informes anuales a PROEG;

- Informes requeridos para la renovación del reconocimiento del curso (MEC);

- Informes de cumplimiento de los proyectos sujetos a las agencias de desarrollo y el MEC.

Nota: no se han detectado variables de información relacionadas con el seguimiento de los objetivos del Innovación. 


\begin{tabular}{lll|}
\hline & - Análise Geográfica (Amazonas) & - Imagem institucional e do Curso \\
SISTEMA & - Legistaçắo que influencia o curso & - Percepçấo dos clientes (Alunado) \\
EXTERIOR & - Histórico Institucional e do curso & - Perfil do Cliente \\
& - Titulaçáo Oferecida (Graduaçăo) & - Demanda pelo curso e seus serviços
\end{tabular}

Objetivo de inovaç̧o do curso:

pomover e essimular inciativas e projettos que

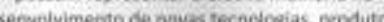

Mistemas de cominicachio, mraves do Design, ave possam alavarka o desemotvinemto da sociedase.

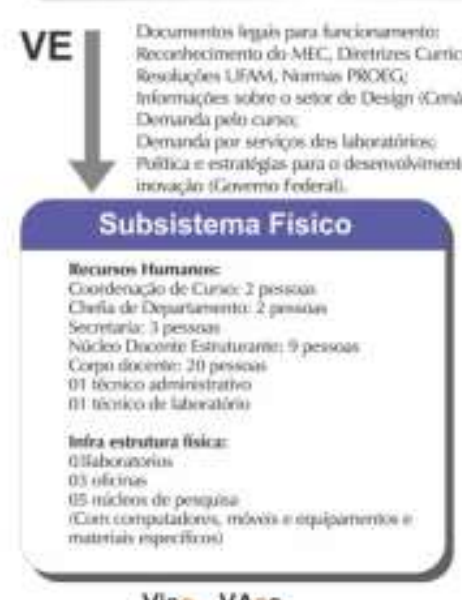

Vise VAes

\section{Nivel de Exploraçāo}

Técnice aduiniotration

Jérnike de labextatiris

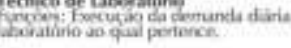

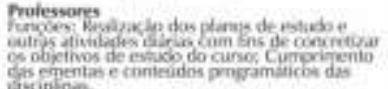

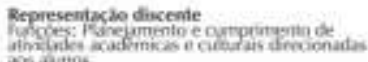

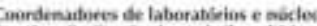

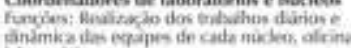

êtrimkation:
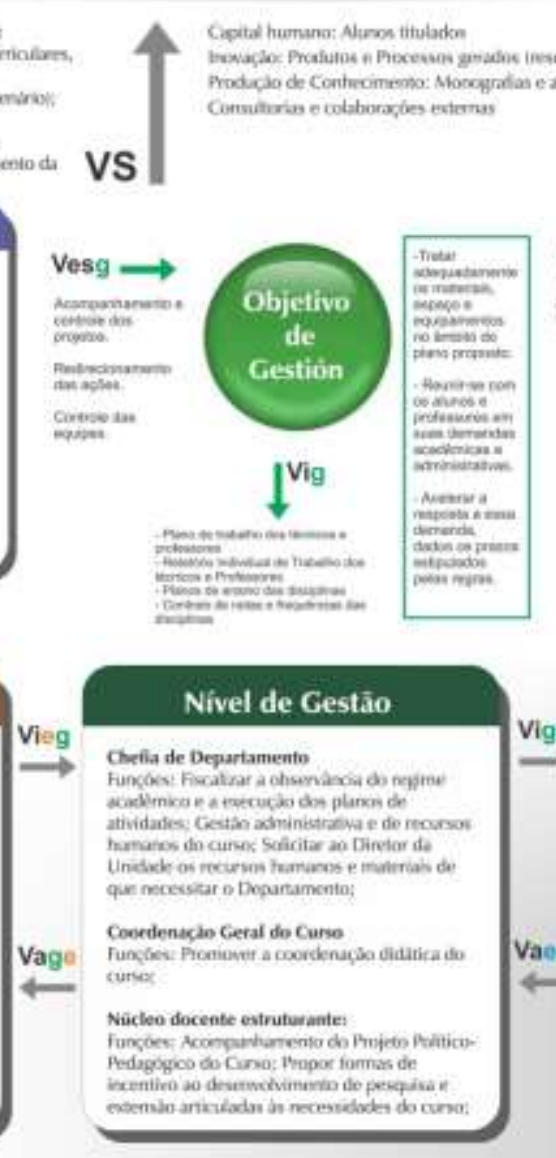

\section{Curso de Graduação em Design da UFAM}

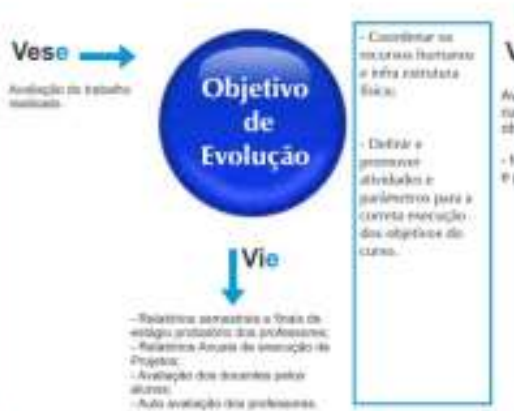

Nivel de Evoluçẫo

Vige

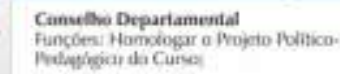

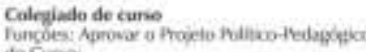

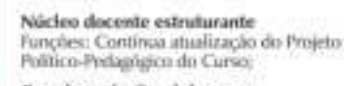

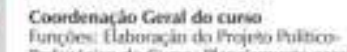

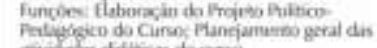

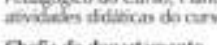

Chefiu de departarmente

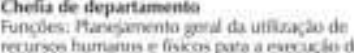

ons

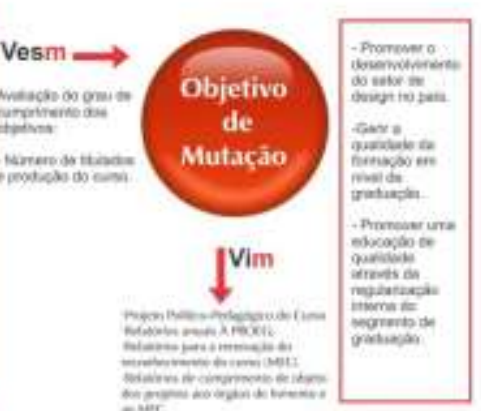

Nivel de Mutaçào

Vien

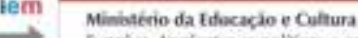

where a drea de Desien definidas peto coseres

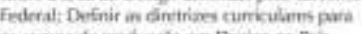

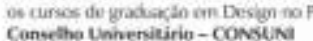

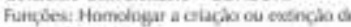

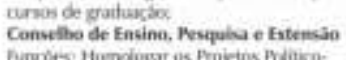

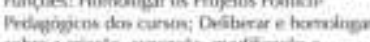

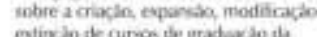

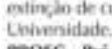

nofC - Pros-Meitoria de Grubacio da UAM

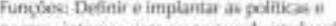





\subsubsection{SISTEMA PROPUESTO}

\subsubsection{Estrategia para la gestión del entorno de la Innovación en el curso de Design UFAM}

Objetivo de la estrategia: La mejora del entorno de la Innovación en curso de Design UFAM, desde un enfoque sistémico, con el objetivo de elevar el desarrollo de nuevos productos y procesos generados a partir de monografías y otros proyectos de investigación desarrollados en el curso.

Partiendo del modelado del sistema actual hecho desde la aplicación del Método de Formulación por Objetivos objetivos, en el que se han destacado los principales problemas encontrados en el ambiente de innovación del curso se propusieron estrategias de acciones de intervención.

Las sugerencias fueron divididas en temas específicos en los que las propuestas fueron agrupadas por afinidad (teniendo en cuenta la solución de las debilidades y amenazas y el aprovechamiento de las fortalezas y oportunidades que se encuentran en el estudio).

\subsection{Proyecto Político Pedagógico e y organización interna del Curso:}

\section{Estrategias sugeridas:}

- Reformulación de los objetivos de Innovación contemplados en el actual proyecto político pedagógico del curso;

- Insertar contenido sobre Innovación en una de las asignaturas obligatorias del curso;

- Inserción de un curso electivo de 30 horas con un enfoque más profundo sobre la "Gestión de la Innovación Tecnológica";

- Una mayor divulgación Proyecto Pedagógico del curso junto a los estudiantes y profesores:

- Proporcionar la versión actualizada del PPP en el sitio web del curso.

- Desarrollo del cuaderno de Curso (resumen del PPP) para ponerse a disposición de la comunidad académica. 
- Establecer la planificación de metas con los coordinadores de laboratorios, a fin de integrarlos en la búsqueda de la realización de los objetivos del curso;

\subsection{Organización del Trabajo de Conclusión de Curso}

\section{Estrategias sugeridas:}

- Al principio del TCC, cuando es definido el tema y objeto de estudio, debe haber, por parte de los supervisores, un incentivo para trabajos que puedan generar nuevos productos y procesos (aquí también se incluyen productos gráficos) que puedan generar registros de la propiedad industrial (por ejemplo: registro de marcas y patentes).

- Incluir el "carácter innovador del producto" entre los criterios para evaluar los resultados del TCC.

- Creación de un comité encargado de elegir los trabajos con mayor potencial de innovación y reenviarlos para análisis de la PROTEC para orientación sobre el registro de la propiedad industrial y la verificación de oportunidades de financiación.

\subsection{Difusión y Divulgación del conocimiento generado en el Curso}

\section{Estrategias sugeridas:}

- Creación de una base de datos digital de las monografías del curso;

- Creación de la cartera de proyectos del curso, dividido po profesor / núcleo, que contenga un resumen de los proyectos que han sido o están siendo desarrollados y los resultados obtenidos o esperados;

- Actualizar y activar el sitio web del curso, creando mecanismos para su mantenimiento continuo;

\subsection{Aproximación del Curso a los Mecanismos de Apoyo a la} Innovación existentes en la institución y en otras esferas:

\section{Estrategias sugeridas:}

- Realización de conferencias de presentación de la PROTEC en la semana de recepción de los estudiantes de primer año; 
- Divulgar la política de Innovación de UFAM entre los profesores y estudiantes a través del sitio web y de redes sociales relacionadas con el curso;

- Introducción del tema "Innovación" que debe abordarse bajo diferentes enfoques en el transcurso de las semanas académicas de curso;

- Fomentar la participación de los alumnos en la convocatoria PIBITI/ UFAM;

- Acercamiento entre los alumnos del curso e incubadoras presentes en el estado mediante la realización de talleres sobre el espíritu empresarial (también establecer asociación con SEBRAE);

- Visita de los miembros del curso a las empresas con potencial para el desarrollo de productos con el fin de responder mejor a las demandas del sector productivo y establecer posibles asociaciones entre la universidad y el sector privado en el desarrollo de proyectos;

- Una mayor participación en las convocatorias, a través de la creación de un grupo encargado de investigar los avisos existentes y difundirlos entre los profesores y los estudiantes;

\subsubsection{5 mejorías del subsistema físico:}

\section{Estrategias sugeridas:}

- Envío de documento a la administración superior que contenga la demanda para la contratación de técnicos de laboratorios especializados para mejorar los procesos de apoyo al desarrollo y prueba de productos.

- Reestructuración del equipo de laboratorio con el objetivo de apoyar el desarrollo de prototipos (incluyendo el área de programación visual, por ejemplo, pruebas de usabilidad, etc.)

Las estrategias sugeridas implican la inclusión o cambio en la organización de los niveles y de las variables en el sistema propuesto. A continuación son presentados estos cambios: 
Modificaciones que se sugieren en la organización de los niveles

\section{Nivel de Explotación}

Los coordinadores de laboratorios, talleres y núcleos ya no serían parte de este nivel con el fin de poder dedicar más eficazmente a la función de coordinación.

\section{Nivel de Gestión}

Los coordinadores de laboratorios, talleres y núcleos tomarían parte de este nivel, para promover el logro de los objetivos de Innovación del curso junto con los otros actores en el nivel. (Función: control y evaluación de las acciones)

También pasarían a figurar en este nivel los coordinadores de TCC y Practicas Supervisadas. (Función: Direccionar las normas de acuerdo con la estrategia definida)

\section{Nivel de Evolución}

Los coordinadores de laboratorios, talleres y núcleos también tomarían parte de este nivel, para promover el logro de los objetivos de Innovación del curso junto con los otros actores en el nivel. (Función: planificación de las acciones de implementación del Proyecto Política Pedagógica del curso y el cumplimiento de sus objetivos)

\section{Nivel de Mutación}

En este nivel también figuraría la PROTEC (Decano de la Innovación Tecnológica). Función: Diseñar e implementar su propia estrategia para la implementación y seguimiento de la política de innovación de la institución (creada en 2011).

\section{Cambios sugeridos en la organización de las Variables}

Se presentan a continuación las adiciones y cambios en las variables de acción de acuerdo a las brechas del sistema actual curso identificadas en el estudio. Las variables de acción tienen un impacto directo en la organización de las variables de información de cada nivel. 


\section{Variables de Acción (VAme): Mutación a Evolución}

Planificación y ejecución de acciones relacionadas con la implementación de la Política de Innovación UFAM (PROTEC);

\section{Variables de Información (Vlem): Evolución a Mutación}

Formularios de solicitud para el registro de patentes, modelos de utilidad, etc.

\section{Variables de Acción (VAeg): Evolución a Gestión}

- Reformulación del proyecto político pedagógico del curso (inclusión de contenido / asignaturas sobre innovación, actualización de los objetivos y otros elementos del proyecto);

- Formulación de una estrategia orientada al cumplimiento de los objetivos del curso Innovación (Coordinación de Curso /NDE/ Colegiado);

- Formulación de planes y metas de los laboratorios con el fin de optimizar la generación de Innovación a través de sus proyectos y mejor apoyo a los alumnos. (Coordinación de Curso/ Coordinadores de laboratorios).

\section{Variables de Información (Vlge): Gestión a Evolución}

- Planeamiento estratégico de cada laboratorio (metas para cada uno de los sectores que componen el curso);

- Informe de la consecución de las metas del curso.

- Informe de la consecución de las metas de los laboratorios.

- Documento resultante de la evaluación interna de cada sector del curso.

- Cartera de Proyectos de cada sector del curso.

\section{Variables de Información (VAge): Gestión a Explotación}

- Planificación y seguimiento del trabajo diario / mensual del departamento y del curso centrado en el logro de metas (coordinación de curso/ jefe de departamento). 
- Planificación y seguimiento de las acciones de Divulgación del Proyecto pedagógico y del conocimiento generado en el curso;

- Actualización de los criterios de evaluación para el TCC.

Variables de Información (Vleg): Explotación a Gestión

- Hojas con los resultados de las evaluaciones del TCC y su potencial innovador (para la comunicación con PROTEC).

- Informes mensuales de progreso de los proyectos desarrollados por los profesores.

- Listado de los avisos de financiamiento vigentes.

- Sitio oficial del curso actualizado y activado.

- Cuaderno de curso.

Variables de Acción (VAef): Explotación a sistema físico

- Distribución de las tareas diarias al personal disponible, de conformidad con la planificación estratégica del curso.

- Definición de procedimientos para la ejecución y supervisión de las tareas.

- Definición, distribución y uso de los recursos materiales 
Sistema PROPOSTO

\begin{tabular}{lll}
\hline & - Análise Geográfica (Amazonas) & - Imagem institucional e do Curso \\
SISTEMA & - Legislaçāo que influencia o curso & - Percepçăo dos clientes (Alunado) \\
EXTERIOR & - Histórico Institucional e do curso & - Perfil do Cliente \\
& - Titulaçăo Oferecida (Graduaçào) & - Demanda pelo curso e seus serviços
\end{tabular}

\begin{tabular}{|c|}
\hline 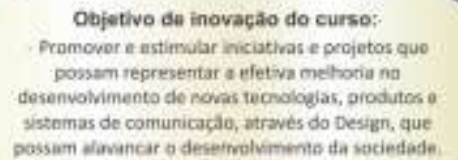 \\
\hline
\end{tabular}

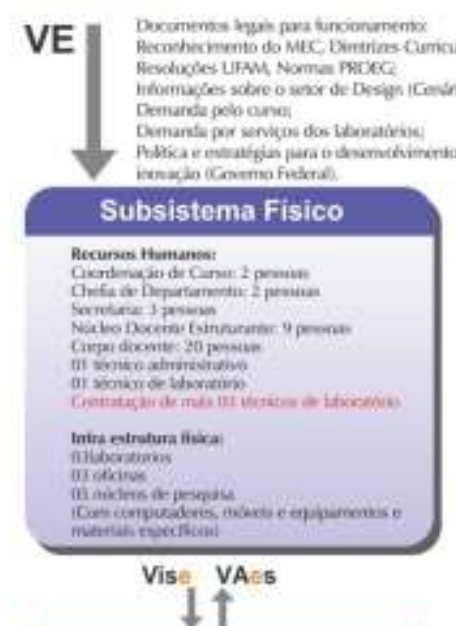

$$
\text { VS }
$$

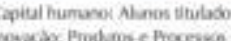

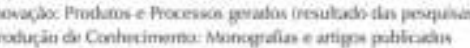

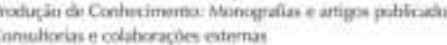

Sistema en estudo

Curso de Graduação em Design da UFAM

Nivel de Exploraçầo

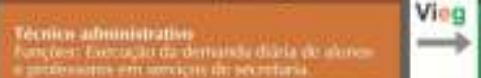

Vesg $\longrightarrow$

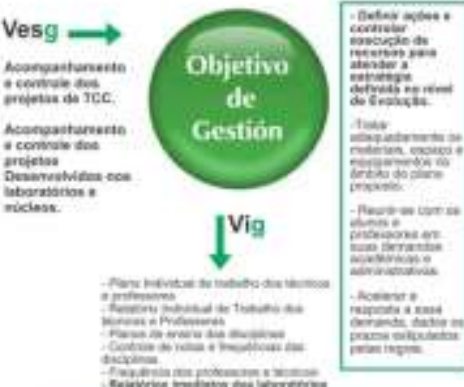

Vese $\longrightarrow$

$+5$

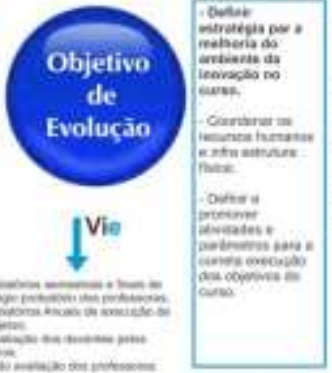

Vesm $\longrightarrow$

Objetivo

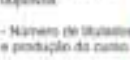

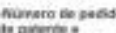

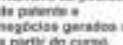

Mutacio
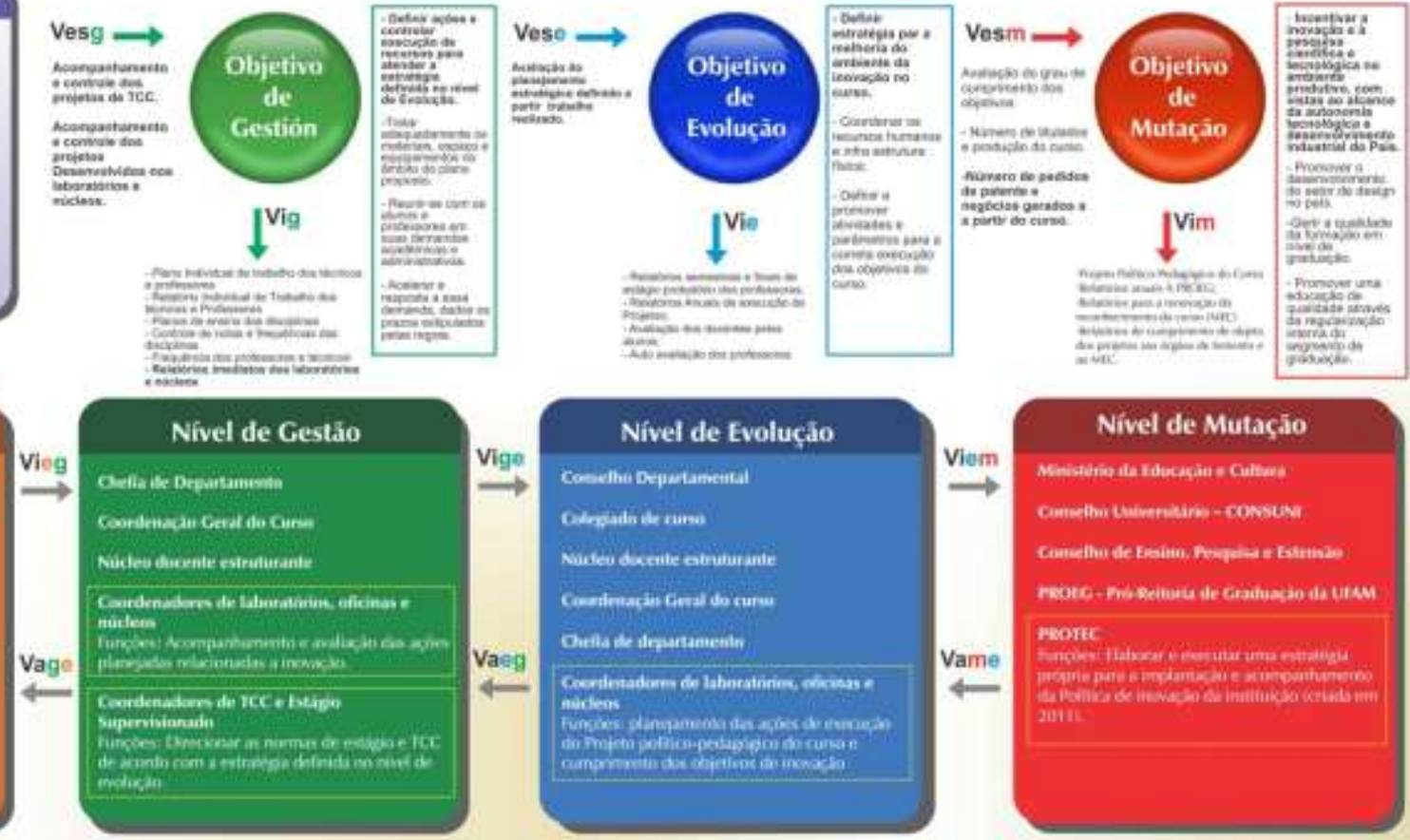

Fuente: El autor - Adaptado de Ortuño (2010) 



\subsection{Evaluación por los pares sobre el Sistema Propuesto}

Como se explica en el capítulo sobre la metodología, a partir de los resultados obtenidos en las diferentes formas de recolección de datos (investigación documental, entrevistas y encuestas) fue construida una estrategia de gestión de la innovación del para el curso de Design (Sistema Propuesto).

Esta propuesta fue presentada a un grupo de especialistas en Design que hacen parte del NDE (Núcleo Docente de Estructuración) para una evaluación a través de la técnica de grupo focal. El sistema propuesto es presentado en más detalle, en el Capítulo 6.

El Modelo de Sistema de Gestión de la Innovación (SGI) para el curso fue presentado a un grupo de siete personas que realizaron una evaluación a través del esquema que se presenta a continuación:

Tabla 50: Esquema de la Evaluación por los pares del Sistema Propuesto

\begin{tabular}{|l|l|l|}
\hline Categorías & Variables & Ítems \\
\hline \multirow{3}{*}{ Construcción } & $\begin{array}{l}\text { Viabilidad de la } \\
\text { estrategia }\end{array}$ & $\begin{array}{l}\text { El sistema presentado puede ser } \\
\text { implementado en el curso (Viabilidad: los } \\
\text { recursos humanos, la infraestructura } \\
\text { física). }\end{array}$ \\
\hline \multirow{3}{*}{ Registro } & $\begin{array}{l}\text { Representatividad del } \\
\text { contenido }\end{array}$ & $\begin{array}{l}\text { El contenido del diagnóstico es una } \\
\text { muestra representativa del universo del } \\
\text { curso. }\end{array}$ \\
\cline { 2 - 3 } & Alcance del contenido & $\begin{array}{l}\text { La estrategia propuesta abarca los } \\
\text { principales aspectos del curso que } \\
\text { pueden contribuir a la innovación. }\end{array}$ \\
\hline \multirow{3}{*}{ Resultados } & $\begin{array}{l}\text { Relación Estrategia / } \\
\text { Resultados }\end{array}$ & $\begin{array}{l}\text { El sistema presentado puede ser } \\
\text { acompañado por documentación } \\
\text { específica. }\end{array}$ \\
\cline { 2 - 3 } & $\begin{array}{l}\text { El sistema presentado puede promover } \\
\text { una mejora en el entorno de la } \\
\text { Innovación del curso. }\end{array}$ \\
\cline { 2 - 3 } & Conexión con los & $\begin{array}{l}\text { El sistema presentado es coherente con } \\
\text { los objetivos de Innovación del curso. }\end{array}$ \\
\hline
\end{tabular}

Cada participante debería responder entre las alternativas: Totalmente de acuerdo, Parcialmente de acuerdo, Totalmente en desacuerdo, Parcialmente en desacuerdo. A continuación se presentan los resultados obtenidos: 
1) El sistema presentado puede ser implementado en el curso (Viabilidad: los recursos humanos, la infraestructura física).

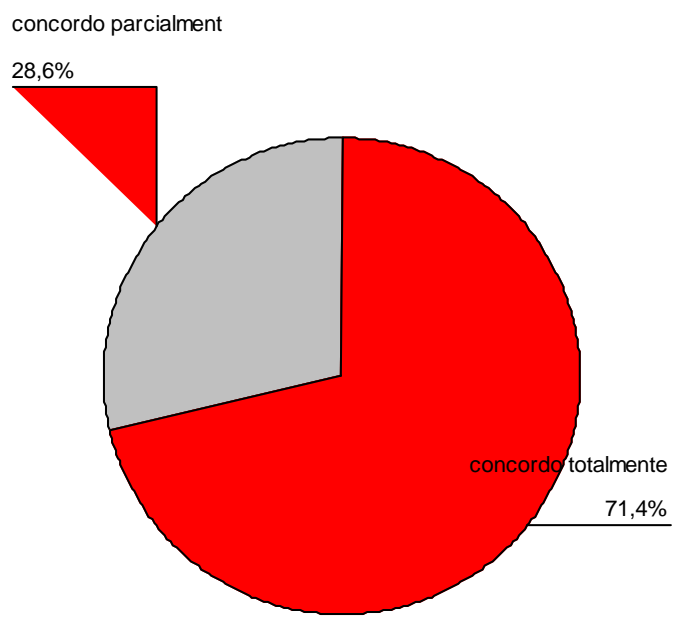

Gráfico 01: Resultados de las respuestas de los pares cuanto a la Aplicabilidad del Sistema Propuesto

2) El contenido del diagnóstico es una muestra representativa del universo del curso.

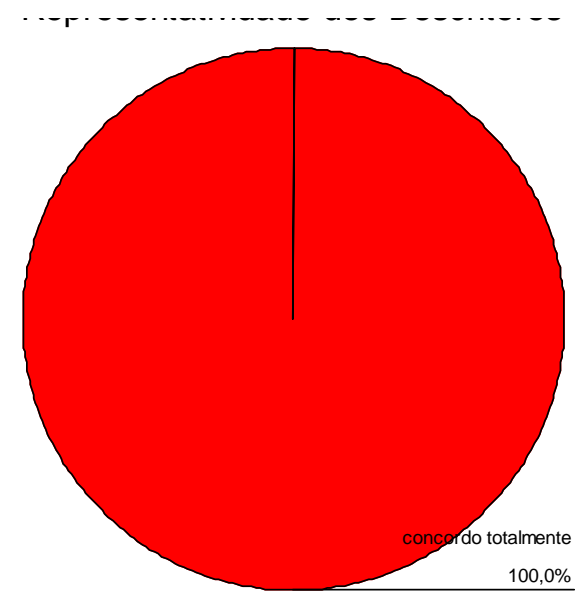

Gráfico 02: Resultados de las respuestas de los pares cuanto a la Representatividad del Sistema Propuesto 
3) La estrategia propuesta abarca los principales aspectos del curso que pueden contribuir a la innovación.

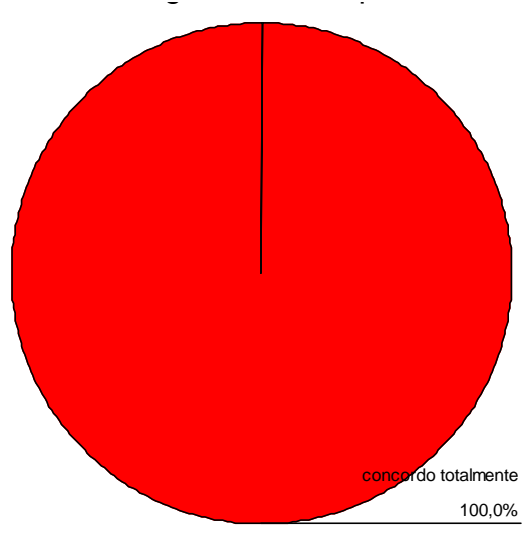

Gráfico 03: Resultados de las respuestas de los pares cuanto a la Amplitud del Sistema Propuesto

4) El sistema presentado puede ser acompañado por documentación específica.

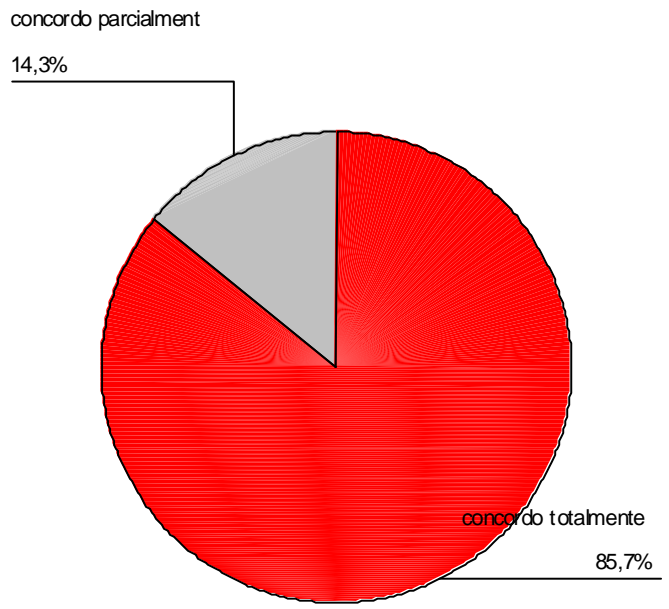

Gráfico 04: Resultados de las respuestas de los pares cuanto al acompañamiento del Sistema Propuesto 
5) El sistema presentado puede promover una mejora en el entorno de la Innovación del curso.

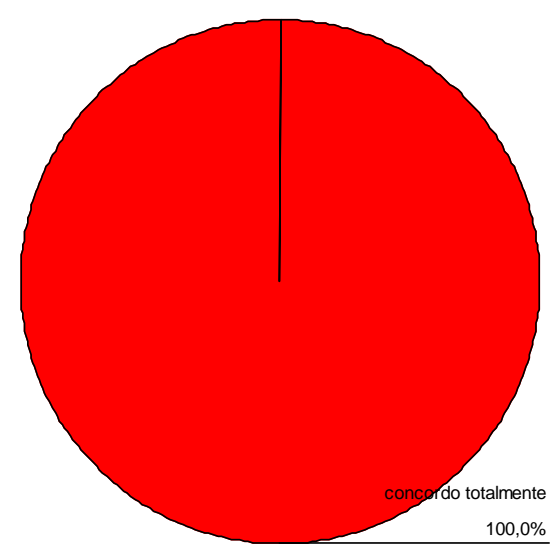

Gráfico 05: Resultados de las respuestas de los pares cuanto a la Relación Propuesta/Resultados del Sistema Propuesto.

6) El sistema presentado es coherente con los objetivos de Innovación del curso.

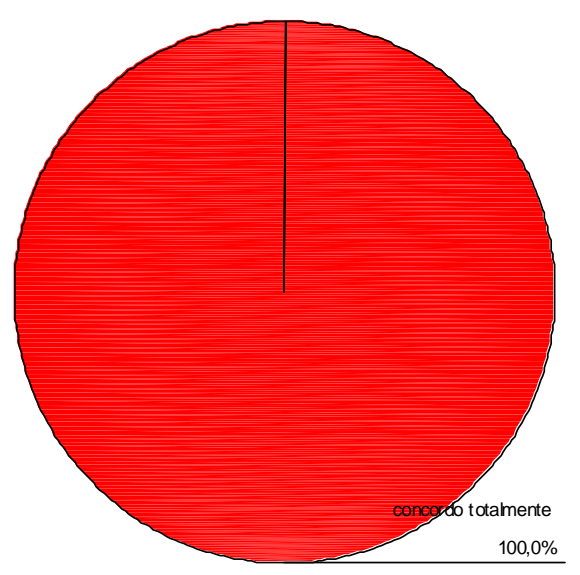

Gráfico 06: Resultados de las respuestas de los pares cuanto a la Relación con los objetivos del curso del Sistema Propuesto.

A continuación, la recopilación de los resultados de la evaluación sobre el sistema propuesto por los expertos: 
Tabla 51: Compilación de los resultados sobre la evaluación del sistema propuesto por los pares

\begin{tabular}{|c|c|c|c|c|c|c|c|c|}
\hline Ítem & \multicolumn{8}{|c|}{ Frecuencia/Porcentaje } \\
\hline & \multicolumn{2}{|c|}{$\begin{array}{l}\text { Totalmente } \\
\text { de acuerdo }\end{array}$} & \multicolumn{2}{|c|}{$\begin{array}{l}\text { Parcialmente } \\
\text { de acuerdo }\end{array}$} & \multicolumn{2}{|c|}{$\begin{array}{l}\text { Parcialmente } \\
\text { en desacuerdo }\end{array}$} & \multicolumn{2}{|c|}{$\begin{array}{l}\text { Totalmente } \\
\text { en desacuerdo }\end{array}$} \\
\hline $\begin{array}{l}\text { El sistema } \\
\text { presentado puede } \\
\text { ser implementado } \\
\text { en el curso } \\
\text { (Viabilidad: los } \\
\text { recursos humanos, } \\
\text { la infraestructura } \\
\text { física). }\end{array}$ & 5 & 71,4 & 2 & 28,6 & - & - & - & - \\
\hline $\begin{array}{l}\text { El contenido del } \\
\text { diagnóstico es una } \\
\text { muestra } \\
\text { representativa del } \\
\text { universo del } \\
\text { curso. }\end{array}$ & 7 & 100,0 & - & - & - & - & - & - \\
\hline $\begin{array}{l}\text { La estrategia } \\
\text { propuesta abarca } \\
\text { los principales } \\
\text { aspectos del curso } \\
\text { que pueden } \\
\text { contribuir a la } \\
\text { innovación. }\end{array}$ & 7 & 100,0 & - & - & - & - & - & - \\
\hline $\begin{array}{l}\text { El sistema } \\
\text { presentado puede } \\
\text { ser acompañado } \\
\text { por } \\
\text { documentación } \\
\text { específica. }\end{array}$ & 6 & 85,7 & 1 & 14,3 & - & - & - & - \\
\hline $\begin{array}{l}\text { El sistema } \\
\text { presentado puede } \\
\text { promover una } \\
\text { mejora en el } \\
\text { entorno de la } \\
\text { Innovación del } \\
\text { curso. }\end{array}$ & 7 & 100,0 & - & - & - & - & - & - \\
\hline $\begin{array}{l}\text { El sistema } \\
\text { presentado es } \\
\text { coherente con los } \\
\text { objetivos de } \\
\text { Innovación del } \\
\text { curso. }\end{array}$ & 7 & 100,0 & - & - & - & - & - & - \\
\hline
\end{tabular}

Fuente: El autor 


\subsection{Discusión}

A partir de los resultados obtenidos mediante la aplicación de encuestas a los grupos de profesores, alumnos y titulados del curso, fue posible realizar análisis y conclusiones sobre el panorama de la innovación en este entorno. Lo que sigue es una discusión sobre los resultados obtenidos en la investigación.

Cuanto al perfil del grupo de 15 profesores consultados (cuestiones 01-06 de la encuesta de los profesores) se identificó un número superior de mujeres $(60 \%)$ al número de hombres (40\%). La edad predominante entre los profesores está entre 36 y 45 años (60\%), revelando un grupo relativamente joven. $60 \%$ de los profesores están casados y el 73,3\% tienen actuación en el área de diseño de productos. $60 \%$ de los profesores son maestros y el $13,3 \%$ son doctores.

Datos adicionales obtenidos a partir de investigación documental en la secretaría mostraron que de los nueve (09) profesores del curso con titulación actual de Maestro, cinco (05) ya están inscritos en cursos de doctorado, entre los cuales tres (03) se han programado para concluir sus tesis hasta finales de 2012. Los 04 maestros que poseen el título de especializados ya están matriculados en cursos de Máster, de los cuales dos (02) tienen prevista su finalización en el 2012.

Estos datos demuestran una buena evolución de la titulación del profesorado, un elemento que es esencial para impulsar la innovación en el curso, porque la mayoría de las convocatorias de financiación de investigación se limitan a los investigadores que tienen el título de doctor.

En el grupo de 86 Alumnos consultados el género es mayoritariamente femenino (57\%), la edad más frecuente es entre 17 y 25 años $(94,2 \%)$, siendo la mayoría soltera $(97,7 \%)$. A medida que el curso no tiene más calificaciones, al grupo se le pidió también que indicasen el área de interés en el Design, en la cuestión se presentaron 03 alternativas cuya distribución se encontró como sigue: Diseño de producto - 39,5\%, Programación Visual - 38, 4\%, Interfaces Gráficas Digitales - 22,1\%. Entre los 86 encuestados se encontró el 33,7\% que asistían al segundo período del curso, $29,1 \%$ al cuarto, $24,4 \%$ al sexto y $12,8 \%$ al octavo.

En el grupo de 54 titulados el $51,9 \%$ eran mujeres y el $48,1 \%$ eran hombres, el grupo de edad predominante fue entre 26 a 35 años $(51,9 \%)$. En el grupo había un predominio de solteros $(79,6 \%)$. Entre los egresados que respondieron a la encuesta hubo ocurrencia de titulados entre los años de 1998 a 2011, lo que muestra una buena representación de las diferentes clases. $87 \%$ del grupo de titulados trabaja en el área de Diseño, en cuanto a su situación en el mercado laboral, el $33,3 \%$ trabaja por cuenta propia, el $53,7 \%$ son empleados de 
empresas privadas, $7,4 \%$ son empleados públicos y $5,6 \%$ son investigadores/ profesores en instituciones privadas.

En el grupo de titulados hubo una mayor incidencia de formación en el área de Programación Visual, un área que también fue dominante en el actuación profesional de los graduados $(59,3 \%)$. Con respecto a la titulación la mayoría del grupo $(59,3 \%)$ sólo tiene el grado, el $38,9 \%$ son especialistas y sólo el $1,9 \%$ tiene un título de maestría.

En cuanto a la Cuestión número 07 de la encuesta de los profesores y alumnos (Cuestión esto que no se aplicó a los titulados) sobre el nivel de familiaridad con los conceptos, aspectos jurídicos y mecanismos de apoyo disponibles en la institución sobre Innovación, fue posible observar que la mayoría de los profesores y los estudiantes están muy familiarizados con el concepto de Innovación y Emprendimiento. Lo mismo no es verdadero con respecto al concepto de transferencia de tecnología y de los aspectos de la legislación sobre propiedad industrial, donde aún queda necesidad de fortalecer, ya que sólo el $26,7 \%$ de los profesores y el 33,3\% de los estudiantes dijeron que estaban completamente familiarizados con estos conceptos Se observa que entre los alumnos estos conceptos son aún más desconocido que entre los profesores.

Al enfrentarse con la afirmación "Conozco los objetivos de Innovación del curso", el 53,3\% de los docentes han marcado la opción "totalmente de acuerdo", mientras que sólo el $31,4 \%$ de los alumnos marcaron esta opción, lo que indica la necesidad de una mayor difusión de este aspecto del proyecto pedagógico entre los dos grupos.

También sobre esta cuestión se observó que la existencia de proyectos desarrollados en cooperación con el sector privado y otras instituciones educativas y de investigación es considerada esencial por la mayoría de los profesores y alumnos además, ambos grupos afirman tener interés en participar en proyectos desarrollados en cooperación con el sector privado. El acceso a la información y formación dirigidas a la protección de la propiedad intelectual y la difusión del espíritu emprendedor entre los estudiantes y los profesores del curso también es considerado esencial por la mayoría de los profesores y estudiantes.

En la Cuestión 08, también común a los profesores y alumnos (esta cuestión tampoco se aplicó a los titulados), los encuestados deberían responder sí o no a una serie de preguntas sobre el entorno de la innovación en el curso, en la institución y en el escenario local.

La primera de ellas era si los encuestados ya habían oído hablar del NIT (Núcleo de Innovación Tecnológica de UFAM que en 2011 se transformó en PROTEC) y si conocían el alcance de sus actividades. Entre los profesores el 
$86,7 \%$ dijeron que "SI" y el 53,3\% dijeron que conocían sus acciones. Entre los alumnos $48,8 \%$ dijeron que habían oído hablar de este sector, pero sólo el $14 \%$ dijo conocer el tipo de actividades desarrolladas. También se les preguntó si los dos grupos habían oído hablar de la PROTEC. Entre los profesores el $80 \%$ respondió que Sí y entre los alumnos sólo el 17,4\% respondió afirmativamente.

Todavía en la cuestión 08 de la encuesta de los profesores y alumnos se les hicieron preguntas relacionadas con el tema "Incubadoras". A ambos grupos se les preguntó si habían oído hablar del CDTECH (Centro de Desarrollo Tecnológico y de negocios) de UFAM que es una incubadora que viene acogiendo varias spin-offs de la institución. En este ítem 53,3\% de los profesores dijo que Sí, mientras que sólo el $24,4 \%$ de los alumnos afirmó conocer la incubadora.

También se preguntó a los grupos si conocían a empresas incubadoras que operan en el Amazonas, las respuestas fueron las siguientes: $60 \%$ de los docentes respondieron que sí, entre los alumnos $51,2 \%$ dijo conocer alguna incubadora. Este ítem cuestión de la 08 se complementa con la cuestión 09 del cuestionario, en el que los encuestados que respondieron "sí" a la pregunta sobre las incubadoras deberían indicar los nombres de las incubadoras que conocían. Entre el grupo de profesores se encontró que las dos incubadoras más conocidos fueron el CIDI (1er lugar) y el FUCAPI ( $2^{\circ}$ lugar), mientras que entre los alumnos surgieron las incubadoras de FUCAPI (1er lugar) y SEBRAE ( $2^{\circ}$ lugar).

Los últimos dos puntos de la cuestión número 08 giró en torno a la realización de proyectos en asociación con el sector privado. En primer lugar se les preguntó a los grupos si ya habían desarrollado algún proyecto en conjunto con el sector privado, el $66,7 \%$ de los docentes ya habían tenido esta experiencia, sin embargo, entre el grupo alumnos sólo el 17,4\% informó haber participado en actividades de esta naturaleza. En el último ítem de la 08 se les preguntó si tenían interés en este tipo de proyecto, la respuesta fue del $100 \%$ "Sí" en el grupo de profesores y 90,7\% "Sí" en el grupo de alumnos.

En general, los datos encontrados en la cuestión 08 revelaron una debilidad en el entorno actual de la innovación que es el desconocimiento de una gran parte de los actores sobre los mecanismos que pueden ayudar en el proceso de un producto innovador.

La información obtenida de las encuestas indican la necesidad de dar a conocer mejor la existencia y las actividades de la PROTEC, ya que es el órgano competente de la universidad para apoyar los procesos relacionados con la innovación y promover la interacción constante entre los investigadores, el sector privado y los agentes de financiamiento. Además de estrechar los lazos con incubadoras locales. 
En cuanto a la cuestión sobre las acciones que podrían contribuir a la mejora del proceso de innovación en el curso de Design UFAM, común a las encuestas aplicadas a los tres grupos (cuestión 10 del cuestionario de los profesores y alumnos, y cuestión de número 15 en el cuestionario de los titulados) fue señalado el siguiente orden de prioridades entre los tres grupos:

Tabla 52: Comparativo entre las acciones apuntadas como prioritarias en los tres grupos

\begin{tabular}{|c|c|c|c|}
\hline & PROFESORES & ALUMNOS & TITULADOS \\
\hline $\begin{array}{l}\text { Grado de } \\
\text { Importancia }\end{array}$ & \multicolumn{3}{|c|}{ ÍTEMS MÁS CITADO } \\
\hline 01 & $\begin{array}{l}\text { Mejorar el } \\
\text { conocimiento de la } \\
\text { parte del curso } \\
\text { sobre las demandas } \\
\text { del sector privado } \\
\text { en el área de Design. }\end{array}$ & $\begin{array}{l}\text { Mejorar el } \\
\text { conocimiento de la } \\
\text { parte del curso } \\
\text { sobre las } \\
\text { demandas del } \\
\text { sector privado en } \\
\text { el área de Design. }\end{array}$ & $\begin{array}{l}\text { Mejorar el } \\
\text { conocimiento de } \\
\text { la parte del curso } \\
\text { sobre las } \\
\text { demandas del } \\
\text { sector privado en } \\
\text { el área de Design. }\end{array}$ \\
\hline 02 & $\begin{array}{l}\text { Mejorar la } \\
\text { infraestructura y } \\
\text { laboratorios que } \\
\text { puedan apoyar el } \\
\text { desarrollo de nuevos } \\
\text { procesos y } \\
\text { productos. }\end{array}$ & $\begin{array}{l}\text { Mejorar la } \\
\text { infraestructura y } \\
\text { laboratorios que } \\
\text { puedan apoyar el } \\
\text { desarrollo de } \\
\text { nuevos procesos y } \\
\text { productos. }\end{array}$ & $\begin{array}{l}\text { Mejorar la } \\
\text { infraestructura y } \\
\text { laboratorios que } \\
\text { puedan apoyar el } \\
\text { desarrollo de } \\
\text { nuevos procesos y } \\
\text { productos. }\end{array}$ \\
\hline 03 & $\begin{array}{l}\text { Construcción, por el } \\
\text { curso de la agenda } \\
\text { de investigación } \\
\text { definida en conjunto } \\
\text { con el sector } \\
\text { productivo. }\end{array}$ & $\begin{array}{l}\text { Desarrollo de } \\
\text { proyectos de } \\
\text { investigación y de } \\
\text { extensión capaces } \\
\text { de generar } \\
\text { negocios. }\end{array}$ & $\begin{array}{l}\text { Desarrollo de } \\
\text { proyectos de } \\
\text { investigación y de } \\
\text { extensión capaces } \\
\text { de generar } \\
\text { negocios. }\end{array}$ \\
\hline 04 & $\begin{array}{l}\text { Desarrollo de } \\
\text { proyectos de } \\
\text { investigación y de } \\
\text { extensión capaces } \\
\text { de generar negocios. }\end{array}$ & $\begin{array}{l}\text { Foros para reunir los } \\
\text { investigadores a las } \\
\text { empresas. }\end{array}$ & $\begin{array}{l}\text { Mayor cooperación } \\
\text { con las incubadoras. }\end{array}$ \\
\hline
\end{tabular}

Fuente: El autor

Se observa que hubo un acuerdo sobre las acciones descritas en los grados de importancia 01 y 02 entre los tres grupos, "Mejorar el conocimiento de la parte del curso sobre las demandas del sector privado en el área de Design" y " Mejorar la infraestructura y laboratorios que puedan apoyar el desarrollo de nuevos procesos y productos", fueron las acciones más importantes para los profesores, alumnos y titulados.

Ya en los grados de importancia 3 y 4 hubo divergencia de opinión entre los grupos. Para los profesores, en el grado de importancia 03 se indicó la acción " Construcción, por el curso de la agenda de investigación definida en 
conjunto con el sector productivo", ya en el grupo de alumnos y titulados fue nominado una acción coincidente: " Desarrollo de proyectos de investigación y de extensión capaces de generar negocios". Se observa que el grupo de profesores considera más importante la aproximación del sector privado a través de iniciativas emprendidas en el curso para el desarrollo de actividades en colaboración con este sector. La respuesta de los estudiantes y titulados a este apartado revela una preocupación más directa con el desarrollo de proyectos que pueden resultar en la innovación o en negocios.

Esta misma acción " Desarrollo de proyectos de investigación y de extensión capaces de generar negocios " es identificada como el $4^{\circ}$ grado de importancia entre los profesos. En este nivel de prioridad los alumnos indicaran la acción "Foros para reunir los investigadores a las empresas", y los titulados " Mayor cooperación con las incubadoras", por lo tanto, en este grado no hubo concordancia entre los grupos.

La indicación de los titulados sobre sobre incubadoras muestra preocupación por la necesidad de fortalecer mecanismos que permitan iniciar una empresa, algo muy difícil de lograr sin financiamiento y otros tipos de apoyo.

Un aspecto que vale mayor destaque en esta cuestión son las acciones que fueran menos citadas entre los cuatro grados de prioridad propuestos. Entre los profesores y los estudiantes "Mayor coordinación con incubadoras" tuvo el $100 \%$ y el $86 \%$ de rechazo, respectivamente, como una estrategia que podría contribuir a la mejora del proceso de innovación en el curso.

Esto es preocupante porque las incubadoras desempeñan un papel fundamental en el sistema local de innovación, ya que permiten la generación de negocio a través de fuertes incentivos para la creación de empresas y han sido citados por los graduados como una de las prioridades.

Los resultados muestran la necesidad de crear conciencia entre los grupos de profesores y alumnos sobre el papel de las incubadoras. Entre los titulados acción menos citada fue "Capacitación en materia de protección de la propiedad industrial."

En la encuesta de los tres grupos se les pidió que indicasen en orden de importancia, basados en una lista de 10 elementos, los aspectos considerados más importantes para la calidad de un curso universitario. Sigue un análisis comparativo de los resultados: 
Tabla 53: Comparativo entre las prioridades apuntadas en la Cuestión sobre Calidad en los cursos de grado en los tres grupos

\begin{tabular}{|c|c|c|c|}
\hline & \multicolumn{3}{|c|}{ ITENS MAIS APONTADOS } \\
\hline PRIORIDADES & PROFESORES & ALUMNOS & TITULADOS \\
\hline PRIORIDAD 01 & $\begin{array}{l}\text { Estructura del } \\
\text { Currículo / } \\
\text { Contenido de las } \\
\text { asignaturas }\end{array}$ & $\begin{array}{c}\text { Estructura del } \\
\text { Currículo / } \\
\text { Contenido de las } \\
\text { asignaturas }\end{array}$ & $\begin{array}{c}\text { Estructura del } \\
\text { Currículo / } \\
\text { Contenido de las } \\
\text { asignaturas }\end{array}$ \\
\hline PRIORIDAD 02 & $\begin{array}{l}\text { Envolvimiento de } \\
\text { los profesores con } \\
\text { el curso }\end{array}$ & $\begin{array}{c}\text { Didáctica de los } \\
\text { profesores }\end{array}$ & $\begin{array}{c}\text { Didáctica de los } \\
\text { profesores }\end{array}$ \\
\hline PRIORIDAD 03 & $\begin{array}{c}\text { Didáctica de los } \\
\text { profesores }\end{array}$ & $\begin{array}{l}\text { Envolvimiento de } \\
\text { los profesores con } \\
\text { el curso }\end{array}$ & $\begin{array}{l}\text { Envolvimiento de } \\
\text { los profesores con } \\
\text { el curso }\end{array}$ \\
\hline PRIORIDAD 04 & $\begin{array}{l}\text { Puntualidad y } \\
\text { asiduidad de los } \\
\text { profesores }\end{array}$ & $\begin{array}{l}\text { Calidad de los } \\
\text { laboratorios y } \\
\text { espacios } \\
\text { específicos }\end{array}$ & $\begin{array}{l}\text { Calidad de los } \\
\text { laboratorios y } \\
\text { espacios } \\
\text { específicos }\end{array}$ \\
\hline PRIORIDAD 05 & $\begin{array}{c}\text { Apoyo de } \\
\text { personal técnico } \\
\text { (ex.: técnicos de } \\
\text { laboratorios) }\end{array}$ & $\begin{array}{c}\text { Puntualidad y } \\
\text { asiduidad de los } \\
\text { profesores }\end{array}$ & $\begin{array}{c}\text { Apoyo de la } \\
\text { Coordinación del } \\
\text { Curso }\end{array}$ \\
\hline PRIORIDAD 06 & $\begin{array}{l}\text { Titulación de los } \\
\text { profesores }\end{array}$ & $\begin{array}{c}\text { Apoyo de la } \\
\text { Coordinación del } \\
\text { Curso }\end{array}$ & $\begin{array}{l}\text { Apoyo de personal } \\
\text { técnico (ex.: } \\
\text { técnicos de } \\
\text { laboratorios) }\end{array}$ \\
\hline PRIORIDAD 07 & $\begin{array}{c}\text { Conforto e } \\
\text { adecuación de las } \\
\text { aulas }\end{array}$ & $\begin{array}{c}\text { Apoyo de personal } \\
\text { técnico (ex.: } \\
\text { técnicos de } \\
\text { laboratorios) }\end{array}$ & $\begin{array}{l}\text { Titulación de los } \\
\text { profesores }\end{array}$ \\
\hline PRIORIDAD 08 & $\begin{array}{c}\text { Apoyo de la } \\
\text { Coordinación del } \\
\text { Curso }\end{array}$ & $\begin{array}{c}\text { Titulación de los } \\
\text { profesores }\end{array}$ & $\begin{array}{c}\text { Apoyo de la } \\
\text { Secretaria del } \\
\text { Curso }\end{array}$ \\
\hline PRIORIDAD 09 & $\begin{array}{l}\text { Calidad de los } \\
\text { laboratorios y } \\
\text { espacios } \\
\text { específicos }\end{array}$ & $\begin{array}{c}\text { Apoyo de la } \\
\text { Secretaria del } \\
\text { Curso }\end{array}$ & $\begin{array}{c}\text { Conforto e } \\
\text { adecuación de las } \\
\text { aulas }\end{array}$ \\
\hline PRIORIDAD 10 & $\begin{array}{c}\text { Apoyo de la } \\
\text { Secretaria del } \\
\text { Curso }\end{array}$ & $\begin{array}{c}\text { Conforto e } \\
\text { adecuación de las } \\
\text { aulas }\end{array}$ & $\begin{array}{c}\text { Puntualidad y } \\
\text { asiduidad de los } \\
\text { profesores }\end{array}$ \\
\hline
\end{tabular}

Fuente: El autor

En el grado 01 de importancia hubo una coincidencia en las respuestas de los grupos que indicaron " Estructura del Currículo/Contenido de las asignaturas" como el elemento más importante para la calidad de un curso universitario. En el grado de importancia 02 surge el tema " Didáctica de los profesores" en las respuestas de los alumnos y titulados y " Envolvimiento de los profesores con el curso " en la respuesta de los profesores", lo que es una diferencia 
natural porque los alumnos son los más directamente afectados por la forma de enseñar de los profesores.

A excepción del ítem "titulación", todos los demás relacionados con los docentes figuran entre los 05 principales en las prioridades de los tres grupos, destacando la importancia de la enseñanza para la Calidad de la enseñanza. El ítem "Comodidad y adecuación de las aulas" surge en el $7^{\circ}$ lugar entre los profesores, en el $10^{\circ}$ lugar entre los alumnos y en el $9^{\circ}$ lugar entre los graduados, hecho curioso, porque se imaginaba que los alumnos serían los que más se preocuparían por la adecuación de las clases y del espacio.

El análisis de la percepción de los participantes en el curso de Design sobre cuáles son los factores que son más importantes para un curso de grado establece parámetros para poder analizar las respuestas de las preguntas siguientes.

De la lista de 10 artículos presentados a los encuestados en la cuestión anterior sobre calidad en un curso universitario, a los participantes se les pidió que nombrasen los 03 puntos más positivo del curso de Design UFAM. El resultado obtenido fue el siguiente:

Tabla 54: Comparativo entre los Puntos Positivos del curso apuntados en los tres grupos

\begin{tabular}{|c|c|c|c|}
\hline \multirow[b]{2}{*}{ PRIORIDADES } & \multicolumn{3}{|c|}{ PUNTOS POSITIVOS DEL CURSO } \\
\hline & PROFESORES & ALUMNOS & TITULADOS \\
\hline PRIORIDAD 1 & $\begin{array}{l}\text { Estructura del Currículo / } \\
\text { Contenido de las } \\
\text { asignaturas }\end{array}$ & $\begin{array}{l}\text { Estructura del Currículo } \\
\text { / Contenido de las } \\
\text { asignaturas }\end{array}$ & $\begin{array}{l}\text { Estructura del Currículo } \\
\text { / Contenido de las } \\
\text { asignaturas }\end{array}$ \\
\hline PRIORIDAD 2 & $\begin{array}{l}\text { Titulación de los } \\
\text { profesores }\end{array}$ & $\begin{array}{l}\text { Didáctica de los } \\
\text { profesores }\end{array}$ & $\begin{array}{l}\text { Didáctica de los } \\
\text { profesores }\end{array}$ \\
\hline PRIORIDAD 3 & $\begin{array}{l}\text { Envolvimiento de los } \\
\text { profesores con el curso }\end{array}$ & $\begin{array}{l}\text { Titulación de los } \\
\text { profesores }\end{array}$ & $\begin{array}{l}\text { Apoyo de la } \\
\text { Coordinación del Curso }\end{array}$ \\
\hline
\end{tabular}

Fuente: El autor

Un resultado muy positivo en relación con la percepción de los participantes sobre el curso de Design es que el elemento identificado como los más importantes para la calidad un curso universitario también fue nominado como el punto más positivo del curso por los tres grupos.

En el grado de importancia 2 hay coincidencia entre las respuestas de los alumnos y de los titulados sobre que indicaron " Didáctica de los profesores", como el segundo ítem más positivo, hecho que, por supuesto, también es muy positivo ya que este tema se señaló en el 2 do lugar en la visión de calidad de un curso universitario en ambos grupos. 
En el grado de importancia 3, no hay ninguna coincidencia entre las respuestas de los grupos. Los profesores consideran su envolvimiento con el curso como lo tercero elemento más positivo, pero este elemento no aparece en las respuestas de los alumnos y graduados que consideran "La titulación de los profesores" y " Apoyo de la Coordinación del Curso" como el tercero más positivo, respectivamente.

También se le pidió a los participantes que indicasen, también en orden de importancia, las tres principales deficiencias del curso de Design, los resultados obtenidos fueron los siguientes:

Tabla 55: Comparativo entre las Deficiencias del curso apuntadas en los tres grupos

\begin{tabular}{|c|c|c|c|}
\hline PRIORIDADES & \multicolumn{3}{|c|}{ DEFICIÊNCIAS DEL CURSO } \\
\hline & PROFESORES & ALUMNOS & TITULADOS \\
\hline PRIORIDAD 1 & $\begin{array}{l}\text { Conforto e adecuación } \\
\text { de las aulas }\end{array}$ & $\begin{array}{l}\text { Conforto e adecuación } \\
\text { de las aulas }\end{array}$ & $\begin{array}{l}\text { Envolvimiento de los } \\
\text { profesores con el curso }\end{array}$ \\
\hline PRIORIDAD 2 & $\begin{array}{l}\text { Calidad dos } \\
\text { laboratorios e espacios } \\
\text { específicos }\end{array}$ & $\begin{array}{l}\text { Calidad dos } \\
\text { laboratorios e espacios } \\
\text { específicos }\end{array}$ & $\begin{array}{l}\text { Calidad dos } \\
\text { laboratorios e espacios } \\
\text { específicos }\end{array}$ \\
\hline PRIORIDAD 3 & $\begin{array}{l}\text { Falta de Apoyo de } \\
\text { personal técnico (ex.: } \\
\text { técnico de laboratorio } \\
\text { e oficinas) }\end{array}$ & $\begin{array}{l}\text { Falta de Apoyo de } \\
\text { personal técnico (ex.: } \\
\text { técnico de laboratorio } \\
\text { e oficinas) }\end{array}$ & $\begin{array}{l}\text { Conforto e adecuación } \\
\text { de las aulas }\end{array}$ \\
\hline
\end{tabular}

Fuente: El autor

Entre los profesores y alumnos hubo coincidencia en el punto "Conforto e adecuación de las aulas", como los más deficiente del. Entre los titulados " Envolvimiento de los profesores con el curso" fue el elemento más deficiente. En el grado de importancia 02 de los tres grupos mostraron " Calidad dos laboratorios e espacios específicos " revelando una percepción igual entre los tres grupos en este factor.

También ocurrió acuerdo en las respuestas de los profesores y de los alumnos en el grado de importancia 03, con el tema "Falta de Apoyo de personal técnico (ex.: técnico de laboratorio e oficinas)" que fue nominado como el tercero más deficiente en el curso. Entre los titulados el factor, este nivel, fue señalado " Conforto e adecuación de las aulas".

Es importante destacar que en los tres grupos, los factores más mencionados fueron los relacionados con la estructura física y de personal, puntos en los que hay la necesidad de mejorar.

A los grupos de los alumnos y de los profesores se les preguntó si indicarían a un amigo que hiciera el curso de Design (cuestión 14 en de la encuesta de los 
alumnos y profesores, 19 en la de los titulados/no se hizo para esta pregunta a los profesores). En la tabla que sigue las respuestas obtenidas:

Tabla 56: Comparativos sobre las respuestas de la Cuestión en la cual eran preguntados se indicarían el curso. ALUMNOS/TITULADOS

\begin{tabular}{|l|l|l|l|l|}
\hline & \multicolumn{3}{|l|}{ ALUNOS } & \multicolumn{2}{l|}{ TITULADOS } \\
\hline & Frecuencia & $(\%)$ & Frecuencia & $(\%)$ \\
\hline SI & 78 & $90,7 \%$ & 51 & $94,4 \%$ \\
\hline NO & 8 & $9,3 \%$ & 3 & $5,6 \%$ \\
\hline
\end{tabular}

A partir de estos resultados se observa que el curso tiene una buena aceptación/imagen entre el público.

La encuesta aplicada a los titulados contenía algunas preguntas dirigidas específicamente a este grupo (preguntas 13 y 14) para evaluar su comportamiento con respecto a la generación de Innovación después de completar el curso.

Primero se les preguntó si tenían alguna patente, cuestión de la que se obtuvieron los siguientes resultados: de los 54 titulados sólo un $(1,9 \%)$ afirmó tener una patente. Luego se hizo la siguiente pregunta: "¿Ha producido, por su propia iniciativa o mediante transferencia de tecnología, un producto o proceso que haya desarrollado?", en esta cuestión sólo el $27,8 \%$ de los encuestados respondió positivamente.

Este conjunto de preguntas destinadas a los titulados identificó la baja actividad de los Designers con respecto a la generación de innovación, lo que muestra que este es un problema que no se restringe sólo al entorno académico del curso.

Las cuestiones relacionadas con el concepto de calidad de un curso de grado y sobre las fortalezas y debilidades del curso de Diseño fueron dirigidas a identificar la percepción, la imagen que cada grupo tenía sobre los diferentes aspectos del curso, un dato que es útil para establecer la aceptación de los grupos y para la construcción de ajustes del entorno interno y externo estudiado. Además, el enfoque sistémico implica la correlación de los diferentes aspectos que pueden contribuir a la consecución de los objetivos de una organización e identificar los elementos que deben ser mejorados en el curso en la percepción de sus clientes ayuda en la construcción de una estrategia para mejorar el ambiente de innovación lo que será posible si el curso no ofrece calidad. 


\section{Sistema Exterior}

Mediante el análisis del Sistema Exterior es observado que hay muchos factores que influyen en el sistema actual. Las leyes existentes, en especial las relacionadas con las directrices de grado nacionales para cursos de Diseño dirigen su operación. Las evaluaciones del MEC también son críticas para construir su imagen, ya que determinan la ubicación del curso en el ranking de las universidades federales.

Por otra parte, el aspecto económico es también un factor que influye en el curso. De acuerdo con los resultados de este estudio, presentados en el capítulo 5, hay poca ejecución de proyectos y becas con financiamiento de fuentes privadas, y por lo tanto la investigación llevada a cabo dentro del curso actualmente depende casi exclusivamente de los recursos del gobierno, principalmente de proyectos de ley y convocatorias para fomentar la investigación.

En cuanto a su imagen, el curso tiene una buena percepción junto a los titulados y es beneficiado por la solidez del histórico de la Universidad Federal de Amazonas, un factor positivo que puede ser explotado para el beneficio del curso.

\section{Sistema actual}

La observación de la composición y funciones de los diferentes niveles en el curso de la de grado en Design UFAM revela algunas debilidades que ayudan a identificar los obstáculos a la construcción de un mejor entorno para la innovación.

La conclusión más importante es que no se encontraron variables de acción, en los distintos niveles y funciones, relacionadas con el cumplimiento de los objetivos del curso relacionados con la Innovación.

Del mismo modo, no hay variables de información existentes que ayuden a controlar este aspecto del curso. Las variables de información se encuentran, en su mayoría relacionadas con el cumplimiento de ciertos requisitos institucionales, tales como los planes de estudio y la frecuencia.

El análisis de los niveles detectó la presencia de los coordinadores de núcleos y laboratorios en el nivel de explotación, un hecho que se produce debido a la falta de personal técnico para realizar las tareas cotidianas de tales espacios, lo puede reflejar el en sus resultados.

Los coordinadores que deben dedicarse más a fondo a la fijación de metas, estrategias, planificación y ejecución de proyectos a menudo son llevados a 
asumir funciones diarias tales como el manejo del espacio y el mantenimiento del equipo.

También cabe destacar que los Coordinadores del Trabajo de Conclusión de Curso (TCC) y Prácticas Supervisadas deberían hacer parte del nivel de evolución, ya que el TCC representa la mayor oportunidad para generación de Innovación en el curso en función de las características de la actividad de Design. Las Prácticas Supervisadas también es la oportunidad para una colaboración más estrecha con el sector privado que podría dar muchos frutos.

Es importante destacar que, aunque es más común esperar que la generación de Innovación se origine en cursos en Posgrado, el curso de Design, por su naturaleza específica, tiene todas las condiciones para ser un importante fabricante de soluciones innovadoras a los problemas de la sociedad, sea a través del desarrollo de productos, procesos o sistemas de información.

Por lo tanto, se presentan a continuación, en la Figura 10, la representación gráfica del actual modelo de organización del curso de Design UFAM, a través del cual es posible visualizar los componentes del sistema y sus fortalezas y debilidades.

\section{Sistema propuesto}

Al aplicar el Método de Formulación por Objetivos fue posible observar las debilidades del sistema actual, basado en los objetivos deseados por el curso estudiado y proponer mejoras en su estructura, optimizando el uso de los recursos humanos y materiales, así como los cambios en su funcionamiento estructura.

Se espera que a través de estas sugerencias reorganización se puede lograr una mejor comunicación entre los distintos niveles del sistema a fin de que el ritmo de trabajo pueda fluir mejor y también ayudar a reducir los desperdicios y mejorar el aplicación de los fondos disponibles como resultado de un entorno más propicio para la generación de la Innovación. 
Capítulo 6

CONCLUSIONES Y RECOMENDACIONES 



\section{CONCLUSIONES Y RECOMENDACIONES}

La innovación ha sido un tema bastante discutido y estudiado en la última década, e incluso señalan diversos autores con el camino a la competitividad en el mercado. Tanto a nivel internacional como en el discurso nacional, en particular del gobierno se habla de innovación como una fuente importante para el desarrollo del país, igual que otros países, en los que la colaboración entre las universidades y la industria impulsaron sus economías.

En Brasil, a pesar de que el concepto de innovación haber se fortalecido a través de una iniciativa creada por el Gobierno Federal, que incluye la legislación, las inversiones en las industrias, la formación de recursos humanos calificados a través de la inversión en educación superior, y el diseño de una política nacional para la Innovación, se sabe que todavía existe una gran laguna entre los resultados de las investigaciones realizadas en el país y la generación de la Innovación que sale al mercado.

Ante este escenario, muchos estudios se han realizado sobre el tema. Para la Innovación suceder es necesario que haya un entorno propicio para en los diferentes niveles en que ella se produce. Es común encontrar en la literatura, la investigación sobre el comportamiento de la Innovación en los negocios, pero es todavía escaso el número de estudios sobre el tema en la academia. Esto ocurre, en parte, por el hecho de que en Brasil pocos aún consideran efectivamente la universidad como parte indispensable del proceso de innovación.

La industria / sector privado sigue siendo reticente a profundizar la asociación con las universidades sobre la base de varios factores que debilitan todavía esta relación, como la incompatibilidad del tiempo de respuesta en el desarrollo de nuevos productos en el mundo académico y las necesidades aceleradas del mercado.

Además, la Innovación debe ser estudiada como un sistema que se compone de varios factores que afectan el proceso, y cada uno de estos factores tiene sus propias particularidades del entorno en el que se genera la Innovación. Los modelos estándares adoptados en otros países, debido a las peculiaridades que les rodean, como una alta incertidumbre, la fuerte dependencia de los nuevos conocimientos, la vulnerabilidad a la evolución del entorno externo local, entre otros, hacen que sea difícil alcanzar los ideales de la Innovación.

Cuando se trata de Innovación que surge en las universidades es mucho más común hacer referencia a los cursos de postgrado, sin embargo, en la actividad específica de diseño, nuevos productos y procesos, debidamente estimulados, pueden surgir incluso en los cursos de grado, sobre todo a partir 
de los proyectos de final de curso en el que, por lo general, se desarrollan propuestas de diseño de productos innovadores y de programación visual.

Dentro de esta perspectiva, se desarrolló un trabajo en el entorno de la innovación en el curso de grado en Design de la Universidad Federal de Amazonas, motivado sobre todo por dos factores: 1) la observancia de las relaciones entre grandes cantidades de TCC desarrollados y el bajo número de solicitudes de registros de propiedad Industrial relacionados con ellos. 2) La falta de un sistema de gestión de la innovación en el curso.

Así, el objetivo general de esta investigación fue "identificar y analizar, desde una perspectiva sistémica, los factores que influyen en la práctica de la innovación en el curso de Design de la Universidad Federal de Amazonas, o la falta de ellos, a fin de estimular el entorno en el marco de la innovación".

Para lograr este objetivo general se han propuesto algunos objetivos específicos que, en un análisis general, se cree que la investigación desarrollada fue exitosa en su implementación:

Objetivo específico $\mathrm{n}^{\circ}$ 1: Identificar y analizar las dimensiones y actores que influyen y forman parte del proceso de búsqueda de la innovación en el curso.

Resultados obtenidos: Partiendo de la investigación bibliográfica y documental se estableció, mediante la técnica DAFO, la identificación de los problemas y de las potencialidades relacionados a la innovación en el curso. Fue utilizado también método una metodología llamada Método de Formulación por Objetivos para la construcción del sistema actual y el sistema propuesto para la Gestión de la Innovación en el curso, teniendo en cuenta los objetivos relacionados con el tema presentes en su Proyecto Político Pedagógico.

Ambas metodologías defienden la observación del entorno estudiado en dos dimensiones principales: ambiente interno y ambiente externo, por lo que se definieron las dimensiones y los actores que conforman cada uno de los ambientes. Ambiente Interno: alumnos, profesores y técnicos. Ambiente externo: gobierno, titulados y demanda del mercado.

Objetivo específico $\mathrm{n}^{\circ} 2$ : Identificar las posibles barreras que pueden estar obstaculizando el proceso de innovación en el curso.

Resultados obtenidos: Basado en la identificación de las dimensiones y actores que forman parte del proceso de innovación en el curso se aplicaron diferentes instrumentos de evaluación (entrevistas, cuestionarios) de los que se hizo el diagnóstico de la situación actual en el curso en la percepción los diferentes grupos. 
Este análisis permitió la identificación de las fortalezas y debilidades del ambiente interno y las oportunidades y amenazas en el entorno externo del curso, desde un enfoque sistémico, con la preocupación de construir un entorno más propicio para la innovación.

Entre las principales debilidades identificadas está el hecho de que no se han identificado acciones sistematizadas con el fin de alcanzar los objetivos de innovación del curso. Por otra parte, hay que difundir entre alumnos y profesores, todas las posibilidades de que los mecanismos institucionales de apoyo a innovación pueden proporcionar además de reforzar los conceptos importantes sobre Innovación y el espíritu empresarial.

En cuanto a su potencial, está el excelente momento que la institución vive por la ejecución de acciones destinadas a innovación, como, por ejemplo la aprobación de la Política de Innovación Institucional y de la Pro-Rectoría de Innovación.

Objetivo específico 3: Contribuir con nuevos enfoques para minimizar el alcance de las posibles barreras identificadas, desde un enfoque sistémico, mediante la propuesta de directrices para la gestión de la innovación en los proyectos desarrollados en el curso de Design;

A partir de los resultados obtenidos en las entrevistas y encuestas aplicadas y del diagnóstico resultante de estos datos se construyó un sistema de sugerencias para la gestión de la innovación en el curso con el fin de establecer mecanismos que fomenten el mejoramiento del ambiente innovador, descrito en el Capítulo 6 de este trabajo.

La estrategia de acciones sugerida es basada en el concepto de actividades innovadoras, es decir, actividades que son importantes para preparar el camino de la Innovación, pero que muchas veces no forman parte de la innovación misma.

Teniendo en cuenta las consideraciones anteriores, el objetivo general del estudio fue alcanzado con éxito ya que se han identificado factores que representan obstáculos al ambiente innovador del curso y se ha propuesto un sistema para mejorar su gestión.

En conclusión, se subraya que no formaba parte de los objetivos de este estudio validar el Sistema de Gestión de la Innovación propuesto, que tiene un papel, sino de ser una contribución, un nuevo enfoque para la cuestión de la Innovación en el curso. Sin embargo, la estrategia fue compartida con los pares para su revisión y sugerencias de mejora a través de la técnica del grupo focal, paso era esencial para mejorar el sistema propuesto. 
En resumen, el análisis muestra que el entorno de la innovación en el curso de Design UFAM y la propuesta de un sistema de gestión puede ser muy útil para la mejora de las condiciones que favorecen la generación de innovación. Es de destacar que las acciones sugeridas, en la mayoría de los casos, pueden ser implementas sin la necesidad de asignar recursos significativos pero con el cambio en las estrategias para la planificación y supervisión de las acciones asociadas con los diferentes niveles del sistema.

\section{Líneas de investigación Futuras}

El estudio desarrollado a lo largo de esta tesis es el punto de partida de una serie de investigaciones que pueden derivarse de ello.

En primero lugar el sistema propuesto, presentado y evaluado por los pares mediante la realización del grupo focal deberá ser remitido al departamento de Diseño y Expresión Gráfica y a la coordinación del curso de Grado en Design/UFAM, para que sean evaluadas las posibilidades de su aplicación.

En este caso, se recomienda vigilar la aplicación de estas sugerencias para observar su eficacia y su impacto en los distintos aspectos tratados en la configuración del entorno de la Innovación en el curso.

Para el acompañamiento sistemático de cada uno de estos aspectos que influyen la innovación en el curso es recomendada la realización de estudios para el desarrollo de herramientas de evaluación apropiadas que puedan contribuir a la recopilación de datos precisos sobre el ambiente estudiado.

La modernización de la forma de "Diseño de la enseñanza" mediante la actualización de las metodologías empleadas y el material de apoyo utilizado en clase también puede generar un trabajo que puede contribuir a los mejores resultados del curso. En este tema, el autor ha aprobado un proyecto de investigación denominado "Desarrollo de Medios Interactivos para apoyar el aprendizaje y la difusión del curso de grado Diseño / UFAM" que será lanzado en el segundo semestre de 2013.

Además de supervisar la implementación del sistema propuesto, el estudio también da lugar a una futura investigación más profunda abarcando las relaciones entre la investigación desarrollada en UFAM y el éxito en la generación de innovación que resulta de ellas, a través de un análisis del entorno de la innovación en la universidad en su conjunto, así como su papel en el sistema local de innovación. 
Capítulo 7

PUBLICACIONES Y MÉRITOS 



\section{PUBLICACIONES Y MÉRITOS}

\subsection{PUBLICACIONES}

\begin{tabular}{|l|l|}
\hline \multicolumn{2}{|c|}{ Identificación de la Publicación } \\
\hline Tipo: & Publicación en eventos científicos - Paper Completo \\
\hline Título: & $\begin{array}{l}\text { A Gestão da Inovação na Geração de Produtos Desenvolvidos a Partir da } \\
\text { Biodiversidade Amazônica. }\end{array}$ \\
\hline Evento & CIPED 2011 - Congreso Internacional de Pesquisa en Design. \\
\hline Data/ Local: & Octubre de 2011 - Lisboa/ Portugal \\
\hline Situación: & Aceptado y Publicado \\
\hline
\end{tabular}
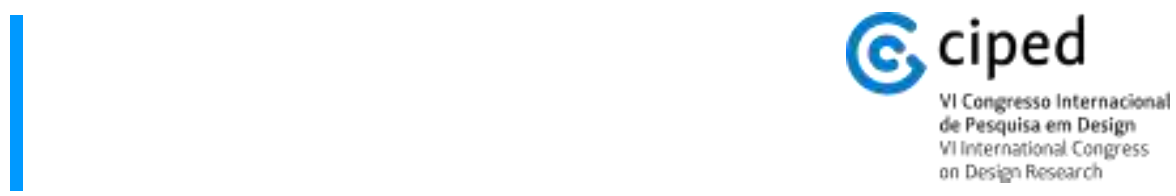

\section{A GESTÃO DA INOVAÇÃO NA GERAÇÃO DE PRODUTOS DESENVOLVIDOS A PARTIR DA BIODIVERSIDADE AMAZÔNICA.}

Patrícia dos Anjos BRAGA,1/4 Roberto Sá dos SANTOS,2 Dimas José LASMAR3, Bernabé Hernadis ORTUÑO4

1 Universidade Federal do Amazonas

2 Universidade de Valencia

3 Fundação Centro de Análise, Pesquisa e Inovação Tecnológica

4 Universidade Politécnica de Valencia

\section{SUMÁRIO}

Este artigo trata do papel desempenhado pela gestão da inovação na geração de novos produtos e processos desenvolvidos a partir de recursos naturais da Amazônia. A gestão da inovação envolve a aplicação estratégica de aspectos como o ambiente da inovação, a gestão do conhecimento, da tecnologia da informação e da propriedade intelectual, além de abordar a questão do marco legal do uso da biodiversidade no Brasil por se tratar de um fator que influencia todo o processo de desenvolvimento e de comercialização de seus produtos. O estudo discute ainda a integração do profissional de design em programas de pós-graduação stricto sensu oferecidos por Instituições de Ensino Superior do Amazonas, cuja participação tem crescido cada vez mais em pesquisas que buscam a colaboração multidisciplinar para o desenvolvimento de produtos que possam fomentar o crescimento sustentável da bioindústria na região no Amazonas.

PALAVRAS-CHAVE

Gestão da Inovação, Design, Biodiversidade 


\section{AMAZÔNIA, BIODIVERSIDADE E INOVAÇÃO}

De acordo com Rezende (2007) a Amazônia é a maior reserva florestal e hidrológica do mundo, possuindo mais de seis milhões de quilômetros quadrados distribuídos por nove países: Brasil, Colômbia, Venezuela, Equador, Peru, Bolívia, Guiana, Guiana Francesa e Suriname. Cerca de $40 \%$ da área total da Amazônia está localizada no Brasil, dado que serve para dimensionar o desafio que a sociedade e o governo têm diante de si: o de preservar e ao mesmo tempo promover o desenvolvimento da Amazônia.

Este patrimônio natural localizado no Brasil faz do país o maior possuidor de biodiversidade do mundo, detendo cerca de $20 \%$ das espécies do planeta (Ebole, 2007). O grande potencial de uso destes recursos naturais presente na Amazônia evidencia a urgente necessidade de que o país invista mais em pesquisas e recursos humanos capacitados, especialmente na Região Norte do país, que apesar de ter tido importantes avanços neste sentido ainda encontra-se em desvantagem em relação aos grandes centros.

Um estudo sobre o mapeamento da inovação no Brasil realizado pelo Instituto de Inovação em 2007 demonstra que o número de pesquisadores no Amazonas ainda é bastante abaixo do desejável uma vez que nem Manaus nem qualquer outra cidade da região Norte aparecem no mapa. Florianópolis, Campinas e Porto Alegre, além de Niterói, continuam sendo as cidades com alto número absoluto de pesquisadores e ao mesmo tempo elevado número de pesquisadores em relação à sua população economicamente ativa. A mesma situação se repete ao se observarem os dados sobre o Potencial de Aplicação do Conhecimento Tecnológico no país através da análise do número de patentes onde são 140 as maiores cidades patenteadoras do país que são responsáveis por agrupar mais de 60 mil depósitos de patentes nos últimos 10 anos, segundo dados do INPI. Como esperado, as maiores cidades do país, tais como São Paulo e Rio de Janeiro apresentam o maior número absoluto de patentes.

Moreira et al (2007) apontam que o potencial para geração de conhecimento está intimamente ligado ao potencial de geração de inovação, e que embora, no Brasil, ainda exista uma grande distância entre a ideal articulação entre esses dois aspectos, o país apresenta qualidades que são favoráveis para o desenvolvimento de inovações uma vez que possui grandes centros geradores de conhecimento, além de estar passando por um momento de relevantes mudanças estruturais no ambiente da inovação como o desenvolvimento do setor da indústria de base tecnológica e maiores investimentos públicos e privados . No contexto atual onde o conhecimento forma a base do desenvolvimento econômico, é imperativo que se estimule a exploração desse ativo em prol da geração de benefícios para a sociedade brasileira.

\section{INOVAÇÃO: CONCEITUAÇÃO E CLASSIFICAÇÕES}

De acordo com o Manual de Oslo (OCDE, 2005) uma inovação é "a implementação de um produto (bem ou serviço) novo ou significativamente melhorado, ou um processo, 
ou um novo método de marketing, ou um novo método organizacional nas práticas de negócios, na organização do local de trabalho ou nas relações externas".

O Manual delineia como avanço a inclusão de dois novos conceitos de inovação em sua última edição (2005), anteriormente não considerados nas definições tradicionais: inovação de marketing e inovação organizacional. Esta mudança é de fundamental importância, pois enfatiza o papel de dois aspectos que eram negligenciados nas demais definições e agora deixam de ser coadjuvantes nas inovações de produto e processo.

Para Sáenz e García (2002), destacadas no Manual de Oslo de 2001, as inovações classificam-se em:

a)Inovações básicas ou radicais: originam mudança histórica no modo de fazer as coisas, baseando-se em um conceito totalmente novo em relação ao que estava vigente; b)Inovações incrementais: aquelas que trazem uma melhoria a uma tecnologia já existente; c)Inovações menores: Apresentam pequenas melhorias em algo já existente, mas não trazem alterações significativas em nível tecnológico.

Os mesmos autores também apresentam uma classificação da inovação de acordo com a forma como surgiu:

a) Empurradas pela ciência (science pushed): geralmente são as radicais, originam-se de novos conhecimentos obtidos em pesquisas, que permitem identificar novas soluções para necessidades existentes, é de caráter ofertista. Geralmente produzem grandes saltos qualitativos no patamar tecnológico; b) Puxadas pela demanda: geralmente são as inovações incrementais e as menores, neste caso as inovações surgem de um necessidade social ou produtiva, explícita e vinculada a um demanda que urge por uma solução.

\section{GESTÃO DA INOVAÇÃO E DESENVOLVIMENTO DA BIOINDÚSTRIA}

A gestão da inovação para o desenvolvimento de produtos e processos a partir da biodiversidade amazônica envolve uma série de questões, algumas, próprias de todos os processos inovadores como a gestão do conhecimento (aprendizado, tecnologia da informação, etc.) e formação de redes e parcerias. Destacam-se, todavia, a legislação, as políticas públicas e questões éticas que envolvem o uso de recursos naturais e da biodiversidade, bem como os conhecimentos associados a comunidades tradicionais.

De acordo com Bueno et al (2004) a Gestão Estratégica do Conhecimento tem por objetivo "maximizar a utilização do conhecimento em conjunto com ferramentas de tecnologia da informação, proporcionando uma vantagem estratégica". Seu processo de implantação nas empresas pressupõe uma mudança cultural, visando ao comprometimento de toda a organização. Quanto mais informações disponíveis para a obtenção e disseminação do conhecimento, além da gestão sobre o conhecimento, maior será o poder de tomada de decisão na empresa. Dentro deste contexto a cultura 
organizacional influencia todo o processo da inovação, a implantação de uma estratégia institucional que propicie o compartilhamento de informações é imprescindível.

Com relação à legislação que se aplica ao setor da bioindústria devem ser considerados, durante o processo de desenvolvimento dos produtos, os aspectos relacionados desde o acesso ao patrimônio natural, até as legislações ligadas à proteção do conhecimento intelectual, propriedade industrial, acesso a recursos da biodiversidade, além, é claro, da legislação de fomento à pesquisa e de incentivo à prática da inovação.

São exemplos de legislações a serem consideradas:

- CDB - Convenção Sobre a Diversidade biológica (2000).

- MP n.o 2.186-16 de 2001 que entre outras coisas estabelece a definição de conhecimento tradicional associado.

- Decreto no. 4.339, de 22/08/2002, que institui princípios e diretrizes para a implementação da Política Nacional de Biodiversidade, inclui, entre seus objetivos específicos, o "estabelecimento e a implementação de um regime legal sui generis de proteção a direitos intelectuais coletivos relativos à biodiversidade de povos indígenas, quilombolas e outras comunidades locais.

- Decreto № 3.945 de 2001 regulamenta o acesso ao patrimônio genético existente no País.

- Lei de Direitos Autorais no 9.610/98 e Lei da Propriedade Industrial no 9.279/96

- LEI DE INOVAÇÃO - № 10.973, de 02 de dezembro de 2004 que estabelece incentivos à inovação tecnológica e à pesquisa científica e tecnológica no ambiente produtivo.

- LEI DO BEM - № 11.196, de 21 de novembro de 2005 que consolida os incentivos fiscais que as pessoas jurídicas podem usufruir de forma automática desde que realizem pesquisa tecnológica e desenvolvimento de inovação tecnológica.

O marco legal do uso da biodiversidade no Brasil e as leis de incentivo à inovação representam um dos principais aspectos a ser observados pelos gestores por se tratar de um fator que influencia todo o processo de desenvolvimento de produtos, pois regula o acesso à matéria-prima natural, os direitos e deveres do pesquisador em relação às populações tradicionais, além de ser fundamentais no que diz respeito a fontes de financiamento de pesquisas. 


\section{O PROFISSIONAL DE DESIGN E O DESENVOLVIMENTO DE PRODUTOS A PARTIR DE RECURSOS NATURAIS DA AMAZÔNIA}

De acordo com Felipe (2004) o desenvolvimento tecnológico de um País depende, em grande parte, da formação de recursos humanos capacitados, buscando a formação de competências em C\&T\&l, bem como Investimentos consistentes de longo prazo e de porte. Esta estratégia fomenta a política industrial e permitirá que empresas de base tecnológica (como exemplo, da bioindústria) gerem produtos de alta tecnologia para a sociedade brasileira. Para o autor a academia e a indústria são movidas pelo conhecimento, o que dirige um fluxo de novas idéias, conceitos, novos produtos/processos e modelos de negócios inovativos.

Dentro deste contexto observam-se, especialmente na região norte, o fortalecimento da integração entre as áreas relacionadas ao uso de recursos naturais e desenvolvimento sustentável com a demanda pelos profissionais de design, especialmente àqueles que atuam com a gestão e desenvolvimento de novos produtos, pesquisa de novos materiais, embalagens e ecodesign. Esta abertura começa a ser observada especialmente, em cursos de pós-graduação Stricto Sensu, a exemplo da Universidade Federal do Amazonas (UFAM), onde programas de mestrado e doutorado como os de Biotecnologia, Engenharia florestal e Natureza e Cultura na Amazônia, passaram a admitir em suas seleções pesquisadores com formação em diversas áreas do conhecimento, entre eles, designers, que passam a compor grupos de pesquisas, com foco, especialmente, no fomento à inovação, contribuindo para o desenvolvimento de produtos que possam gerar renda sem agredir ao meio ambiente.

No ano de 2010, por exemplo, foi estabelecida uma parceria inovadora entre o Doutorado de Biotecnologia da UFAM e o Doutorado em Desenho, Fabricação e Gestão de Projetos Industriais da Universidade Politécnica de Valencia - UPV (Espanha) que tem permitido a realização de um período de intercâmbio de alunos do doutorado brasileiro naquele país, a fim de aperfeiçoarem sua formação na área de projetos industriais.

\section{CONLUSÕES}

A gestão dos fatores relacionados à prática da inovação possui considerável relevância no processo de desenvolvimento de produtos gerados a partir de recursos naturais, principalmente em função das especificidades e possibilidades deste tipo de pesquisa. Por esta razão o pesquisador designer, que possui um perfil gestor, tem sido cada vez mais procurado para integrar equipes multidisciplinares de desenvolvimento de produtos a partir de recursos naturais e da biodiversidade, crescendo em importância no desempenho de atividades, provimento e troca de conhecimentos para o desenvolvimento da região amazônica. A realização de parcerias entre instituições e áreas distintas também oferecem a oportunidade de estabelecimento ou ampliação de redes de pesquisas que incentivam o fluxo do conhecimento e da inovação, além de promover a abertura de novos campos de atuação para o designer, particularmente no Estado do Amazonas. 


\section{REFERÊNCIAS}

[Antunes, Pereira, Ebole 2006] A. Antunes; N. J. Pereira; M. F. Ebole (org). Gestão Em Biotecnologia. Rio de Janeiro: e-papers, 2006.

[Bell, Pavitt 93] M. Bell; K. Pavitt. Technological accumulation and industrial growth: contrast between developed and developing countries. Industrial and Corporate Change, v.2, n.2, p. 157-210, 1993.

[Bueno2008] G. S. Bueno. Gestão estratégica do conhecimento. Disponível em http://www.unifae.br/

publicacoes/pdf/revista_da_fae/fae_v7_n1/rev_fae_v7_n1_07_giovatan.pdf. Acesso em 19/09/2010.

[Felipe2004]. M.S.S. Felipe. Recursos humanos em biotecnologia: Relatório técnico do Grupo de Trabalho de Recursos Humanos do Fórum de Competitividade em Biotecnologia. Centro de Gestão e Estudos Estratégicos. 2004. Disponível em http://www.anbio.org.br/pdf/2/tr01_rh.pdf. Acesso em 19/09/2010.

Manual de Oslo: Diretrizes para coleta e interpretação de dados sobre inovação. OECD/FINEP. 2005.

[Moreira, Santos, Pereira, Mamão] B. Moreira, E. Santos, G. Pereira, G. Mamão. Onde está a inovação no Brasil? Instituto de Inovação. 2007.

[Rezende2008] S. M. Rezende. Ciência e Tecnologia na Região Amazônica: onde chegamos e o que esperar. Revista T\&C Amazônia, Ano IV, N.14, junho de 2008.

[Sáenz, Capote2002] T. W. Sáenz; E. G. Capote. Ciência, Inovação e Gestão Tecnológica. Brasília: CNI/IEL/SENAI,ABPTI, 2002. 
10,11 e 12 de Outubro de 2011

\section{G ciped}

AF

vicongresso internacional

An Agenda for Design

de Pesquisa era Drisign

Expotion

Wintariational Congress

on Design Resanger

\section{Certificado \\ de Participação e Apresentação de Artigo}

Certifica-se que Patricia Braga participou no $6^{2} \mathrm{CIPED}$ - Congresso Internacional de Pesquisa em Design, que decorreu na Fundaçăo Calouste Gulbenkian em Lisboa, Portugal, nos dias 10, 11 e 12 de Outubro de 2011, tendo realizado uma apresentação oral intitulada "A GESTÃO DA INOVAC̄ÃO NA GERAÇÃO DE PRODUTOS DESENVOLVIDOS A PARTIR DA BIODIVERSIDADE AMAZÓNICA".
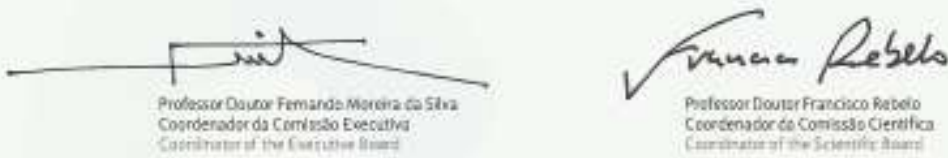

Gaditracas Quantotion

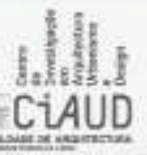




\begin{tabular}{|l|l|}
\hline \multicolumn{4}{|c|}{ Identificación de la Publicación } \\
\hline Tipo: & Publicación en eventos científicos - Paper Completo \\
\hline Título: & $\begin{array}{l}\text { Desenvolvimento de Mídia Interativa para Apoio ao } \\
\text { Aprendizado e Divulgação do Curso de Graduação em } \\
\text { Design/UFAM. (Banner) }\end{array}$ \\
\hline Evento & CONGREX 2011 - Congreso de Extensión - UFAM \\
\hline Data/ Local: & Diciembre de 2011 - Manaus/Amazonas/Brasil \\
\hline Situación: & Aceptado y Publicado \\
\hline
\end{tabular}

Valorado entre los mejores trabajos del Congreso

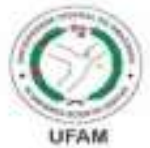

UFAM

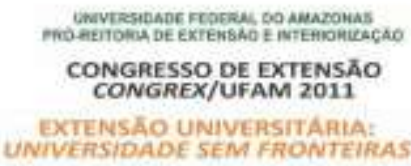

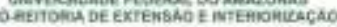

ONGRESSO DE EXTENSĀO

EXTENSALOO UNIVERSITARIA:

UNIVEASIDADE SEM FRONTEIFAS

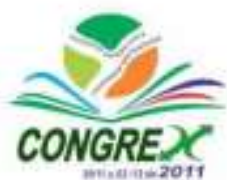

\section{DESENVOLVIMENTO DE MIDIA INTERATIVA PARA APOIO AO APRENDIZADO E DIVULGAÇĀO DO CURSO DE GRADUAÇĀO EM DESIGN/UFAM}

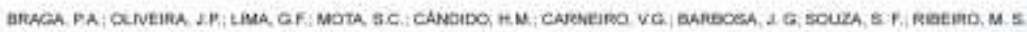

\section{OBJETIVOS}

Geral:

Produzr materiai em midia interstiva para siporte ao ensino ed divulgaça do curso de design.

\section{Especificos:}

- Desenvolver DVDs sobre temáticas ligadias as cursa a cada ano do projeta.

- Digitalzar e armazenar de forma mais duradoura Co maleriais relacionados ao design que des profectores e técnicos utilizam atuaimeme.

- Disponibilzar aos cunos. funcionárigs. professores do curso e demais interesandos. etpias opitais do material produzido ajudando sssim ns divulgaça correts ds profissso

\section{METODOLOGIA}

- Oriantacialo Acodémicar

- Planajamento do mavenial,

- Pesquisa bibiográfica para fundamentaça to material a set desenvolvido,

- Cenatruçäo de esquema da midia interativar.

- Captaça, digitalizaça e tratamemo de

imsgens:

- Desenrobimento de maverial audia visua;

- Avslaçón do material desenvolvido.

\section{JUSTIFICATIVA}

- Necessidade de desenvalumento de materias de apoio ao ensino e devulgagato do curso mais Ginamicos e atrativos para o atual perfi des alianas de design

- importancia do registro s armazenamanto destes materias de forma mais segura e permanende.

- Faciàdade de reproduçao e distribuiçao de informapoes atraves de midias digitais.

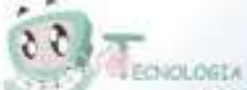

E proouche

\section{RESULTADOS}

1) Desemolvimento do nove site do curso $6 \mathrm{a}$ em funcionamento - holp: Hisesign ufam.ediu.br?
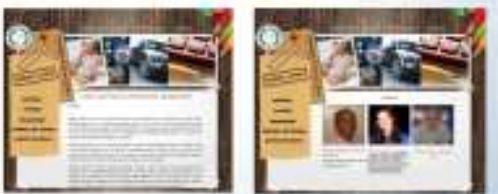

2) Deserwolvimento de um DVO scbre a evento $9^{*}$ Semana acadêmica de Design", resizado em decombro de 2010. it dispenibilaseda nos academicos.

3) Desenvolvimento de um DVD sabra o eventa Fashian Design -resuliado da discpina optativa de mesmo nome
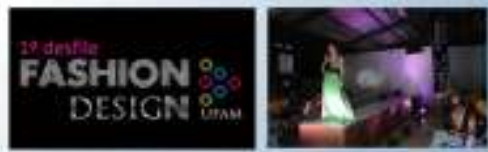

\section{CONCLUSÖES}

- Os resultados aloançados atraves do Prajato forani positives, uma vez que as objetvus foram cumaridas.

- Os discendes partcipantes tyeram a opaitunidacte de aprender fundamentas a adquir pratica sobre diferentes tecnicas, tais coma: frnagem, ediçao de video e web design

- Atraves do projeto soi posaival hiciar uma cultira de registro de forma maca pomanente, da memíra institucianat do curso de graduaçato em besigh 


\begin{tabular}{|c|c|c|c|c|c|}
\hline 70 & $\begin{array}{l}\text { PROMOC,ÁO DO ESTADO NUTRICIONAL DE } \\
\text { GESTANTES DE UM POSTO DE SAUUDE DA } \\
\text { CIOADE DE COARI - AM }\end{array}$ & PACE & $2011 / 1$ & $\begin{array}{l}\text { GRACIANA } \\
\text { TEIXEIRA COSTA }\end{array}$ & $\begin{array}{l}\text { NUTRICȦOASB } \\
\text { COARI }\end{array}$ \\
\hline 71 & 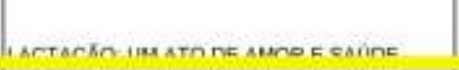 & BACE & 7 7ntis & $\begin{array}{l}\text { GRACIANA } \\
\text { TEIYEIDA F FeTA }\end{array}$ & $\begin{array}{l}\text { NUTRICABOASE } \\
\text { maDi }\end{array}$ \\
\hline 72 & $\begin{array}{l}\text { DESENVOLVIAENTO DE MIOIA INTERATIVA } \\
\text { PAFA APOOD AO APRENDIZADO E } \\
\text { DWULGACLAO DO CURSO DE GRADUAÇĀO } \\
\text { EM DESICN - UFAM }\end{array}$ & PIBEX & 20102 - & $\begin{array}{l}\text { PATRICIA DOS } \\
\text { ANUOS BRAGA }\end{array}$ & $\begin{array}{l}\text { DESIGN E } \\
\text { EXPRESSAO } \\
\text { GRAFICA }\end{array}$ \\
\hline 74 & $\begin{array}{l}\text { GRUPO OE ESTUDO EM FISIOTERAPIA } \\
\text { RESPIRATOTIA E TERAPIA INTENSIVA. } \\
\text { GEFIR. }\end{array}$ & PIBEX & $2010 / 2$ & $\begin{array}{l}\text { FLAVIA FERREIRA } \\
\text { MARTINEZ } \\
\text { PALHARES }\end{array}$ & $\begin{array}{l}\text { FISIOTERAPIA } \\
\text { HOSPITAL } \\
\text { UNIVERSITARIA }\end{array}$ \\
\hline 75 & $\begin{array}{l}\text { PEFFIL DO DESMANE VENTLATORIO NO } \\
\text { CENTRO DE TERAPIA INTENSIVA DO } \\
\text { HOSPITAL UNIVERSTARIO GETULLOO } \\
\text { VARGAS - CTIIHUSV }\end{array}$ & PIBEX & 2011 & $\begin{array}{l}\text { FLAVIA FERREIRA } \\
\text { MARTINEZ } \\
\text { PALHARES }\end{array}$ & $\begin{array}{l}\text { SERVICODE } \\
\text { FISIOTERAPIA } \\
\text { HOSPITAL. } \\
\text { UNIVERSITARIA }\end{array}$ \\
\hline 78 & $\begin{array}{l}\text { APUCACACAO DA LE } 11.645 .96 \text { E AS MATRIZES } \\
\text { CURRICULARES DE LITERATURA E CULTURA } \\
\text { AFROBRASILEIRA }\end{array}$ & PACE & $2011 / 1$ & $\begin{array}{l}\text { ALESSANDRA } \\
\text { CORREA DE } \\
\text { SOUZA } \\
\end{array}$ & $\begin{array}{l}\text { LINGUASE } \\
\text { LITERATURAS } \\
\text { ESTRANGEIRAS }\end{array}$ \\
\hline 79 & $\begin{array}{l}\text { LIXO AOUATICO: VAMOS LIMPAR OS } \\
\text { RUDSSIRENOVACAO }\end{array}$ & PIBEX & 2011 & $\begin{array}{l}\text { TÜLIO DE } \\
\text { ORLEANS } \\
\text { GADELLA COSTA }\end{array}$ & QUIMICA - ICE \\
\hline 80 & $\begin{array}{l}\text { ORGANIZACAAO E CATALOGACAO DAS } \\
\text { AMOSTRAS DIDATICAS DO LABORATORIO } \\
\text { DE SEDIMENTOLOGIA }\end{array}$ & PIBEX & 2011 & $\begin{array}{l}\text { EMILIO ALBERTO } \\
\text { AMARAL SOARES }\end{array}$ & $\begin{array}{l}\text { DEP } \\
\text { GEOCIENCIAS }\end{array}$ \\
\hline 81 & $\begin{array}{l}\text { LAMINARIOS DIDATICOS DE APOIO AS } \\
\text { PRATICAS DO LABORATORIO DE CITOLOGIA. } \\
\text { ESTREITAMENTO DA RELACAO } \\
\text { DISCENTEIDOCENTE COM INSERCAO AO }\end{array}$ & PACE & 2011 & $\begin{array}{l}\text { CLEVERSON } \\
\text { AGNER RAMOS }\end{array}$ & MORFOLOGIAICB \\
\hline 82 & $\begin{array}{l}\text { RECURSO NO ENSINO DE CIENCIAS: SUA } \\
\text { EFICIENCIA NO PROCESO } \\
\text { ENSINOVAPRENDIZAGEM E VIABILIDADE DE } \\
\text { USO EM ESCOLAS PÜBLICAS }\end{array}$ & PACE & 2011 & $\begin{array}{l}\text { CLEVERSON } \\
\text { AGNER RAMOS }\end{array}$ & MORFOLOGLAMCB \\
\hline 83 & $\begin{array}{l}\text { AVALLACAO PARA A COMUNIDADE } \\
\text { UNIVERSITARIA }\end{array}$ & PACE & 20102 & $\begin{array}{l}\text { MATEUS } \\
\text { ROSSATO }\end{array}$ & $\begin{array}{l}\text { FACULDADE DE } \\
\text { EDUCACAAO } \\
\text { FISICA E } \\
\text { FISIOTERAPIA. }\end{array}$ \\
\hline 84 & $\begin{array}{l}\text { ATIVIDADE FISICA NO COMBATE AO } \\
\text { SOBREPESO E OBESIDADE }\end{array}$ & PIBEX & 2011 & $\begin{array}{l}\text { MATEUS } \\
\text { ROSSATO }\end{array}$ & $\begin{array}{l}\text { FACULDADE DE } \\
\text { EDUCACARO } \\
\text { FISICA E } \\
\text { FISIOTERAPIA. }\end{array}$ \\
\hline 86 & $\begin{array}{l}\text { PROJETO ALFA MANAUS - PRIMEIROS } \\
\text { SOCORROS E PREVENCCĂO DE } \\
\text { ACIDENTES }\end{array}$ & PIBEX. & 201012 & $\begin{array}{l}\text { SILVANIA DA } \\
\text { CONCEICACAO } \\
\text { FURTADO }\end{array}$ & $\begin{array}{l}\text { DEP } \\
\text { MORFOLOGIAICE }\end{array}$ \\
\hline 97 & $\begin{array}{l}\text { PROGRAMA DE EDUCACAO PELO } \\
\text { TRABALHO PARA A SAUDE - PET - } \\
\text { SAUDE }\end{array}$ & & 2011 & $\begin{array}{l}\text { RODRIGO TOBLAS } \\
\text { DE SOUSA LIMA }\end{array}$ & $\begin{array}{l}\text { DEP, SAUDE } \\
\text { COLETIVANFM }\end{array}$ \\
\hline 89 & $\begin{array}{l}\text { ACOMPANHAMENTO DO CULTIVO DE } \\
\text { PIRARUCU (ARGPaing gIgas) EM TANQUES } \\
\text { REDE NA UNIDADE FAMILIAR DE } \\
\text { PROOUCBO DA REDES.TUPE. MANAUS }\end{array}$ & PACE & $2010 / 2$ & $\begin{array}{l}\text { ANA CRISTINA } \\
\text { BELARMINO DE } \\
\text { OLIVEIRA }\end{array}$ & DEPESCA \\
\hline 91 & LIXO OU RESIDUO SOLIDO? & PACE & $2011 / 1$ & $\begin{array}{l}\text { JOAO BOSCO } \\
\text { LADISLAU DE } \\
\text { ANDRADE }\end{array}$ & $\begin{array}{l}\text { HIDRAULICA E } \\
\text { SANEAMENTO }\end{array}$ \\
\hline 92 & $\begin{array}{l}\text { ACES SANEAMENTO E BÁSICO: BOMBA } \\
\text { D'AGUA MANUAL. }\end{array}$ & PACE & $2011 / 1$ & $\begin{array}{l}\text { ELIAS SIMARO } \\
\text { ASSAYAG }\end{array}$ & $\begin{array}{l}\text { HIDRAULICA E } \\
\text { SANEAMENTO }\end{array}$ \\
\hline 93 & $\begin{array}{l}\text { PEDAGOVIDA: UMA PROPOSTA } \\
\text { PEDAGOGICA NO GRUPO DE APOIO A }\end{array}$ & PIBEX & 2011 & $\begin{array}{l}\text { JOELISE } \\
\text { MASCARELLO DE }\end{array}$ & $\begin{array}{l}\text { METTODOS E } \\
\text { TÉCNICAS }\end{array}$ \\
\hline
\end{tabular}


http://portal.ufam.edu.br/index.php/component/content/article/33-arquivo-denoticias/2835-premiacao-do-congrex-2011

\section{Premiação do CONGREX 2011}

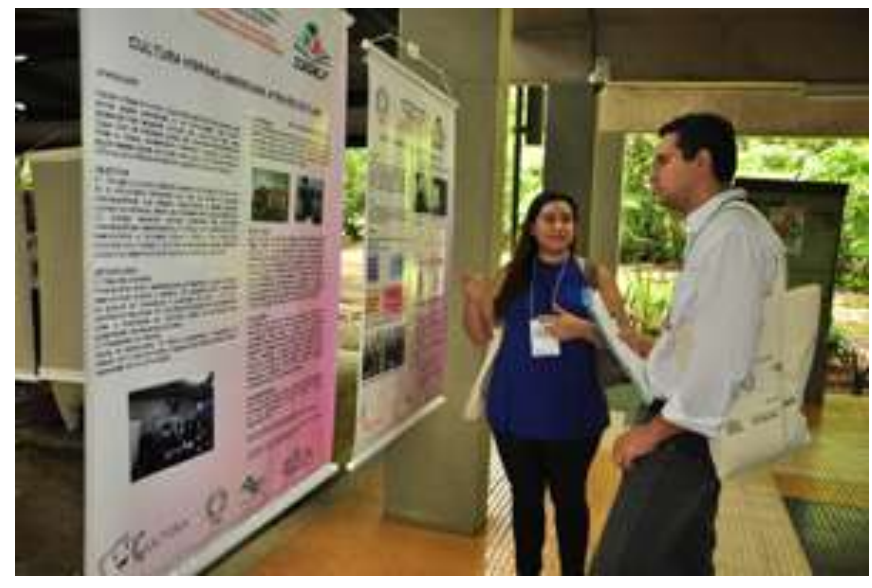

A Pró-reitoria de Extensão

e Interiorização (PROEXTI) divulga a listagem dos 30 trabalhos premiados no CONGREX 2011, os quais obtiveram as maiores notas durante a avaliação realizada por membros da Câmara de Extensão e Interiorização da Ufam. Os coordenadores dos trabalhos selecionados devem comparecer à PROEXTI para receber as medalhas.

A quantidade de trabalhos premiados por área obedeceu à proporcionalidade de inscrições nas respectivas áreas, de maneira que a cada dezenove trabalhos inscritos, dois foram premiados.

Segue, em anexo, a lista dos trabalhos premiados.

\section{Anexos: \\ STrabalhos premiados}




\begin{tabular}{|c|c|c|c|}
\hline UFAM & $\begin{array}{l}\text { UNTVERSIDATE FEDERAL. D } \\
\text { PHO-RETTORLA DE EXTENSTO F } \\
\text { CONGRESSO DE EXTE }\end{array}$ & $\begin{array}{l}\text { DO AMAZONAS } \\
\text { F NTEROORIZAÇAO } \\
\text { ESAOZOHI }\end{array}$ & 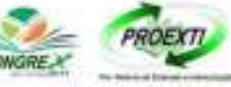 \\
\hline \multicolumn{4}{|c|}{ PREMIAC̄̄O DOS 30 MELLHORES TRABAL.HOS NA MODALIDADE BANNER-POSTER } \\
\hline 72 & $\begin{array}{l}\text { DESENVOLVIMENTO DE MIDIA INTERATIVA PARA APGID AO } \\
\text { APGENDEADO E DIVULGACAO DO CURSO DE GRADUAGAOO } \\
\text { EM OESION - UFAM }\end{array}$ & DESIGN E EXPRESSANO GRAFICA -FT & $\begin{array}{l}\text { PATRICIA DOS ANJOS } \\
\text { BRAGA }\end{array}$ \\
\hline$\pi$ & $\begin{array}{l}\text { AS CONIRIBUICOCES AFFICANAS E INDIOENAS NOS PAISES } \\
\text { HASPÁNICOS }\end{array}$ & $\begin{array}{l}\text { LINGUAS E LTERATURAS } \\
\text { ESTRANGEIRAS - ICHL }\end{array}$ & $\begin{array}{l}\text { ALESSANDRA CORREA } \\
\text { DE SOUZA }\end{array}$ \\
\hline 78 & 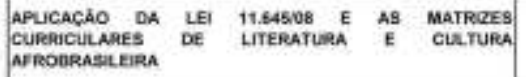 & $\begin{array}{l}\text { LINGUAS E LITERATURAS } \\
\text { ESTRANGEIRAS-ICHL }\end{array}$ & $\begin{array}{l}\text { MLESSANDFA CORAEA } \\
\text { DE SOUZA }\end{array}$ \\
\hline 112 & DESICNARTE E IDENTIOADE "I & DESIGN E EXPRESSĀOO GRÄFICA - FT: & SHELA CCACEIRO MOTA \\
\hline $22 \pi$ & $\begin{array}{l}\text { ESTUDOS DE LINCUAGEN PFE-UNIVERSITAFA } \\
\text { PREVESTIUFAM }\end{array}$ & DEP METCODS E TECENICAS - FACED & $\begin{array}{l}\text { MARCIA JOSANINE DE } \\
\text { CLIVEIRA UFA }\end{array}$ \\
\hline 245 & CONUUNIOADE E VIDA: EDUCACÁO E NEIO AMBIENTE & FACED & $\begin{array}{l}\text { VALERIA AUGUSTA } \\
\text { CEROUEIFA DE } \\
\text { MEDEIROS WEIGEL }\end{array}$ \\
\hline 266 & LITERATURA VINA & IEAA & $\begin{array}{l}\text { ZILDA GLAUCIA ELAAS } \\
\text { FRANCO DE SOUZA }\end{array}$ \\
\hline \multicolumn{4}{|c|}{ EXATAS } \\
\hline ETQ & Titulo projeto & Unidade I Departamento & Coordenador \\
\hline 22 & $\begin{array}{l}\text { DESCOARENDO COMO A OUIMECA ESTA PRESENTE NO } \\
\text { NOSSOS DAA A DAA }\end{array}$ & CET & $\begin{array}{l}\text { FAILANYR MARLA MONTERO } \\
\text { PASCHIDAL }\end{array}$ \\
\hline 54 & JOLMPIADAS DE GUMACA & DEP OUIAKA-ICE & $\begin{array}{c}\text { TEREZA CAESTINA SOUZA } \\
\text { DE OUNERA }\end{array}$ \\
\hline 92 & $\begin{array}{l}\text { ACES SANEANENTO E BASICO BONEA DAGUAA } \\
\text { MANUAL }\end{array}$ & HIDRAUUICA E SANEAMENTO-FT & ELVAS SIMVO ASSAYAG \\
\hline \multicolumn{4}{|c|}{ AGRARLAS } \\
\hline ETO & Thubo projete & Unitade I Departamento & Coodenatores \\
\hline 177 & $\begin{array}{l}\text { CULTTVO DE HOATALICAS NAO-CONVENCIONAIS EM } \\
\text { HORTA ESCOLA: UMA ALTERNATNA SUSTENTAVEL } \\
\text { PARA SEGURANCA ALIMENTAR NO MUNICIPIO DE } \\
\text { CAAPIRANGAAM }\end{array}$ & DCFDA - FCA & $\begin{array}{l}\text { ALBESAMERE PEREIRA } \\
\text { DE CASTRO }\end{array}$ \\
\hline 181 & ENFRENTANDO O PROBLEMA DO LXO & DCFDA-FCA & JOZANE LIMA SANTLACO \\
\hline 105 & $\begin{array}{l}\text { PRÉATICAS AGROECOLÓGICAS NA HORTA ESCOLA DA } \\
\text { CONUUNIOADE SĂOO FRANCISCOICOSTA DA TERRA } \\
\text { NOVA }\end{array}$ & OCFDA-FCA & JOZANE LIMA SANTIACO \\
\hline
\end{tabular}




\begin{tabular}{|l|l|l|l|}
\hline \multicolumn{5}{|c|}{ Identificación de la Publicación } \\
\hline Tipo: & Capítulo de Libro & & \\
\hline Título: & $\begin{array}{l}\text { A trajetória do PPG BIOTEC na Formação de Recursos } \\
\text { Humanos em Biotecnologia no Amazonas }\end{array}$ \\
\hline Libro: & $\begin{array}{l}\text { Biotecnologia e Negócios na Amazônia: Uma Abordagem } \\
\text { Acadêmica }\end{array}$ & & \\
\hline Data/ Local: & Diciembre de 2012 - Manaus/Amazonas/Brasil & \\
\hline Situación: & Aceptado y Aguardando publicación & \\
\hline
\end{tabular}

\section{DECLARAÇÃo}

Declaro que fol aceito para publicaçabo o Capitulo A trajetória do PPGBiotEC na Formação de Recursos Humanos em Blotecnologia no Amazonas, submetido pela doutoranda Patricia dos Anjos Braga Sá dos Santos, tendo como co-sutor o Prot. Dr. Dimas Jose Lssmar, para o livro que tem o fitulo provisorio BIOTECNOLOGLA E NEGOCIOS NA AMAZONIA - UMA ABORDAGEM ACADEMICA, que esta sendo organizado por professores da area de Gestao da Inovaça em Alotecnologia do Programa Mult-institucional de Pos-graduaçio em Biotecnoiogia (PPGasoTEC) da Universidade Federal do Amazonas.

Manaus, 27 de novembro de 2012 


\begin{tabular}{|l|l|}
\hline \multicolumn{2}{|c|}{ Identificación de la Publicación } \\
\hline Tipo: & Capítulo de Libro \\
\hline Título: & $\begin{array}{l}\text { Percepção dos agentes sobre o processo inovativo no âmbito } \\
\text { Acadêmico. }\end{array}$ \\
\hline Libro: & Inovação sócia acadêmica na Amazônia. \\
\hline Data/ Local: & Diciembre de 2012 - Manaus/Amazonas/Brasil \\
\hline Situación: & Aceptado y Aguardando publicación \\
\hline
\end{tabular}

Ministério da Educação

Universidade Federal do Amazonas

Pró-Reitoria de Inovaçăo Tecnológ̨ica

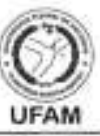

Manaus, 12 de dezembro de 2012.

\section{DECLARAÇÃo}

Declaramos para os devidos fins que foi aceito para publicação o Capitulo "Percepçáo des agentes sobre o processo inovativo no âmbito acadênico", submetido por Patrícia dos Anjos Bruga Sa dos Santos, tendo como co-autores os professores. Dimas José Lasmar e Bernabé Ortuño, para o tivro que tem o titulo de "Inovaçẫo Socioacadễnica na Amaxânia , ISBN 978-85-7401-656-6" que está setsdo organizado pela PROTEC - Pró-Reitoria de Inovaçăo Tecnolópica da Universidade Federal do Amazonas.

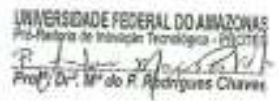

Av. Rodrigo Otśvio, 6.200, Campus Universtitinio Sensdar Arthur Virglio Filno, Corosdo, Eloco da Reitorta, CEP: 69077-000 - Manaus/AM. Telefones: (92) 3305-1758, (92) 9318-3195, E-mail: intelectusoufam.edu.be, proreitoriadeinovacao 1 gmai,coen 


\subsection{PROYECTOS APROBADOS}

\begin{tabular}{|l|l|}
\hline \multicolumn{2}{|c|}{ Identificación del Proyecto } \\
\hline Tipo: & Proyecto de investigación y desarrollo \\
\hline Título: & $\begin{array}{l}\text { Gestão Estratégica da Inovação no Curso de Graduação em } \\
\text { Design UFAM }\end{array}$ \\
\hline Convocatoria: & $\begin{array}{l}\text { Programa de Expansão e Sustentabilidade do Parque Científico e } \\
\text { Tecnológico para a Inclusão Social da UFAM }\end{array}$ \\
\hline Data/ Local: & Diciembre de 2011 - Manaus/Amazonas/Brasil \\
\hline Situación: & $\underline{\text { Aprobado / Aguardando inicio de las actividades }}$ \\
\hline
\end{tabular}

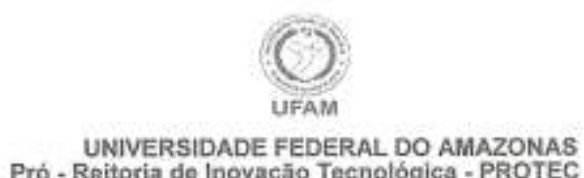

Pró - Reitoria do Inovação Tecnológica - PROTEC

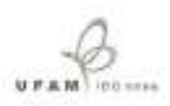

DECLARAÇ ÁO

Declaramos para os devidos fins que a Prola.

Patricla dos Anjos Braga Sá dos Santos, submetou o projeto intitulado

"Gestáo estratégica da Inovaça no curso de graduação em design da

Universidade Federal do Amazonas" o qual fol aprovado no Programa de

Expansajo Sustentabilidade do Parque Cientifico e Tecnologico para Inclusao

Social da Universidade Federal do Amazonas, e sera posteriormente apreciado

pelo Comité Técnico Cientifico para ser encaminhado a Orgão financiador.

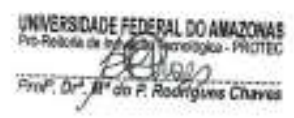




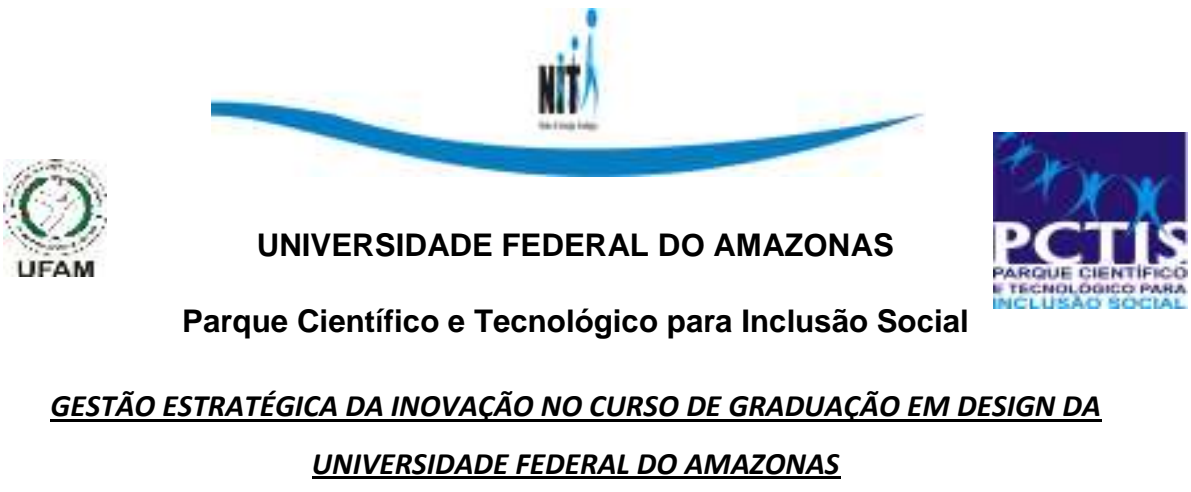

1) RESUMO (MÁXIMO 50 LINHAS);

O presente estudo busca identificar e avaliar os aspectos influenciadores da inovação no ambiente acadêmico do Curso de Graduação em Design da Universidade Federal do Amazonas a fim de estimular a sua prática a partir dos conhecimentos gerados no mesmo. Com este intuito serão realizadas análises sobre as dimensões e atores envolvidos no processo da inovação no âmbito do Curso. No ambiente interno do Curso serão estudados os atores que compõem a geração de conhecimento tais como: corpo docente, corpo discente e coordenação, além de ser analisada, também, a produção de monografias, projetos desenvolvidos e estrutura a fim de traçar um perfil sobre a sua produção e o potencial inovador desta. Além de fatores internos ao Curso serão verificados dados para estabelecer a sua interação com o ambiente externo, esferas industrial e governamental, a partir da análise da dinâmica existente entre as pesquisas desenvolvidas, interação com empresas e políticas públicas voltadas ao desenvolvimento da inovação no país e na região. Desta forma, o projeto será estruturado em quatro etapas básicas: 1) levantamento de dados, análise e diagnóstico sobre o a situação dos aspectos que influenciam o processo inovativo e potencial de inovação no Curso; 2) Proposição de um modelo de organização a fim de promover o ambiente propício à inovação no curso; 3) Desenvolvimento de produtos a partir das potencialidades identificadas; 4) Implementação de ações para viabilizar a chegada dos produtos ao mercado e aproximação entre a esfera acadêmica e industrial. $\mathrm{O}$ projeto terá uma duração inicial de 24 meses. 


\begin{tabular}{|l|l|}
\hline \multicolumn{2}{|c|}{ Identificación del Proyecto } \\
\hline Tipo: & Proyecto de investigación y desarrollo \\
\hline Título: & $\begin{array}{l}\text { Pesquisa e Desenvolvimento de Produtos Inovadores de Apoio ao } \\
\text { Ensino do Design }\end{array}$ \\
\hline Convocatoria: & $\begin{array}{l}\text { Programa de Expansão e Sustentabilidade do Parque Científico e } \\
\text { Tecnológico para a Inclusão Social da UFAM }\end{array}$ \\
\hline Data/ Local: & Dezembro de 2011 - Manaus/Amazonas/Brasil \\
\hline Situación: & $\underline{\text { Aprobado / Aguardando inicio de las actividades }}$ \\
\hline
\end{tabular}

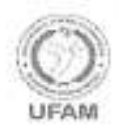

UNIVERSIDADE FEDERAL DO AMAZONAS

Pró - Reitoria de Inovaçấo Tecnológica - PROTEC

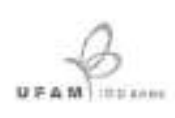

DECLARAÇĀO

Declaramos para os devidos fins que a Profa.

Patricia dos Anjos Braga Sá dos Santos, submeteu o projeto intifulado -Pesquisa e Desenvolvimento de Produtos Inovadores de Apoio ao ensino do Design'o qual foi aprovado no Programa de Expansa e Sustentabilidade do Parque Cientifico e Tecnológico para Inclusăo Social da Universidade Federal do Amazonas, e será postariomente apreciado pelo Comité Técnico Cientifico para ser encaminhado a órgåo financiador.

Manaus, 21 de dezembro de 2011.

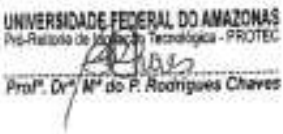




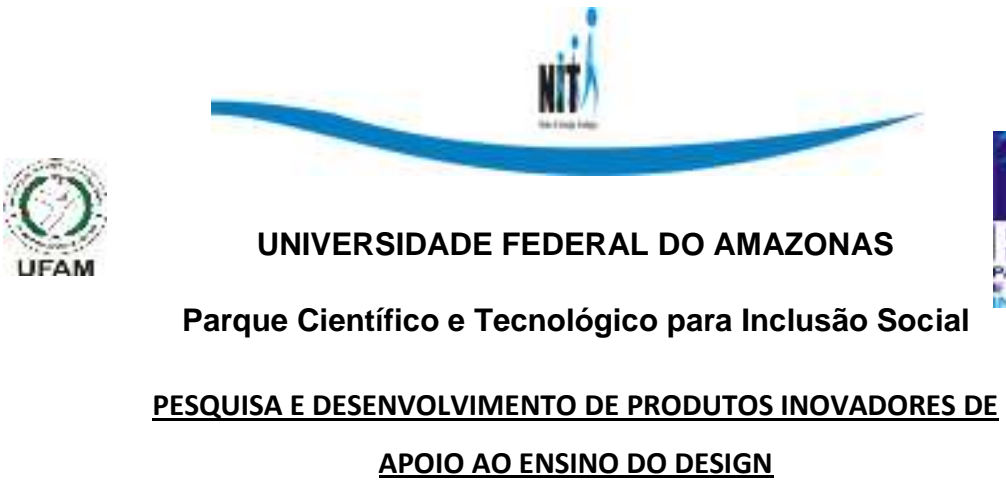

1) RESUMO (MÁXIMO 50 LINHAS);

A introdução de novos aparatos tecnológicos na vida cotidiana cresceu notoriamente nas últimas décadas. Em todas as áreas de atuação do ser humano foram desenvolvidas tecnologias para tornar possível um maior armazenamento de dados, precisão na execução de tarefas específicas e facilitar a comunicação. Estas transformações também impactaram de forma relevante a educação. O presente projeto tem por objetivo desenvolver produtos inovadores de apoio ao ensino de graduação em design, através do uso e da integração de novas mídias e plataformas interativas a fim de adaptar o material didático disponibilizado pelos professores à nova realidade e perfil dos discentes. Em termos específicos espera-se: traçar o perfil dos alunos de ensino superior de design da cidade de Manaus; produzir material em mídia interativa para suporte ao ensino e divulgação do design (Jogos, aplicativos, vídeos, interfaces de internet, etc.) tornando-o mais atrativo par os discentes; digitalizar e armazenar de forma mais duradoura os materiais que professores e técnicos utilizam atualmente; disponibilizar à sociedade, em forma digital, o material produzido. A estruturação do trabalho está formatada inicialmente em três etapas básicas: 1) Identificação do perfil e demandas dos alunos do ensino superior em design na cidade de Manaus; 2) Planejamento e desenvolvimento de novas ferramentas de disponibilização de conteúdo para o ensino de design; 3) Construção de protótipos, testes e apresentação dos resultados. Como resultado espera-se a aproximação entre a realidade do ensino superior em design da realidade vivida e esperada pelos alunos da geração do conhecimento. 


\begin{tabular}{|l|l|}
\hline \multicolumn{2}{|c|}{ Identificación del Proyecto } \\
\hline Tipo: & Proyecto de investigación y desarrollo \\
\hline Título: & Serigrafia no Coroado \\
\hline Convocatoria: & $\begin{array}{l}\text { Programa de Expansão e Sustentabilidade do Parque Científico e } \\
\text { Tecnológico para a Inclusão Social da UFAM }\end{array}$ \\
\hline Data/ Local: & Dezembro de 2011 - Manaus/Amazonas/Brasil \\
\hline Situación: & $\underline{\text { Aprobado / Aguardando inicio de las actividades }}$ \\
\hline
\end{tabular}

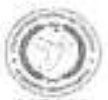

UFAM

UNIVERSIDADE FEDERAL DO AMAZONAS Pró - Reitoria de Inovação Tecnológica - PROTEC

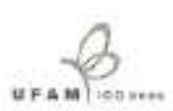

DECLARAC ĀO

Declaramos para os devidos fins que a Profa. Patricia dos Anjos Braga Sá dos Santos, submeteu o projeto intitulado 'Serigrafia no Coroado: Geracaso de renda para moradores do entorno universitário através do Design "o qual fol aprovado no Programa de Expansão e Sustentabilidade do Parque Cientifico e Tecnológica para Inclusä́o Social da Universidade Federal do Amazonas, e será posteriormente apreciado pelo Comite Ténico Cientifico para ser encaminhado a órgäo financiador-

Manaus, 21 de dezembro de 2011.

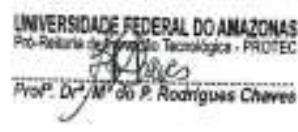




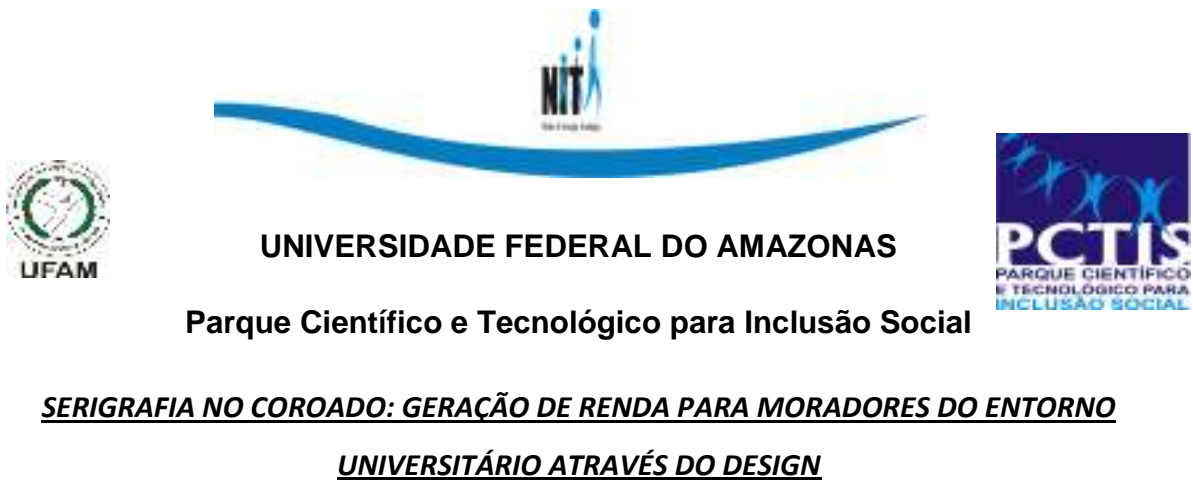

1) RESUMO (MÁXIMO 50 LINHAS);

O Projeto consiste na oferta de atividades de capacitação e assessoria em técnicas de serigrafia para comunidades de baixa renda, a fim de disponibilizar aos moradores a oportunidade de aprenderem um ofício que possa possibilitar sua inserção no mercado de trabalho e geração de renda. A capacitação abordará aspectos teóricos e principalmente práticos que permitirão ao participante adquirir conhecimentos suficientes para iniciarem um trabalho ou oferta de serviços nesta área, dentro de suas diferentes possibilidades. O Projeto também tem como um de seus objetivos a oferta de assessoria aos moradores para a instalação de um espaço comunitário dentro do bairro onde os moradores possam desenvolver serviços serigráficos, bem como para atuarem como multiplicadores dos conhecimentos que adquiriram. Além da técnica de serigrafia os moradores terão assessoria para o desenvolvimento de produtos feitos a partir de resíduos diversos e que, através da intervenção do design, possam adquirir a qualidade necessária para serem reproduzidos e vendidos pelos moradores. Desta forma o projeto está organizado da seguinte maneira: realização de capacitação na técnica de serigrafia destinada aos moradores do entorno universitário; desenvolvimento (pelos pesquisadores) de projetos de produtos que associem a serigrafia ao aproveitamento de resíduos que sirvam de superfície para a técnica; assessoria para a construção de um espaço comunitário para realizar a serigrafia. 


\title{
7.3 PARTICIPACIÓN EN GRUPOS Y COMITES
}

\section{UNIVERSIDADE FEDERAL DO AMAZONAS}

\section{Gabinete da Reitora}

UFAM

\section{P ORTARIA $\mathrm{N}^{*} 1869 / 2012$}

A REITORA DA UNIVERSIDADE FEDERAL DO AMAZONAS, usando de suas atribuiçobes estatutárias, $\mathrm{e}$

CONSIDERANDO os termos do Oficio $n^{\circ}$ 007/2012 - PIBITI/DAP/PROPESP, de 11/07/2012, protocolizado sob o $n^{\circ} 23105.008121 / 2012$, subscrito pelo Diretor do Departamento de Apoio à Pesquisa, Antônio José Inhamuns.

\author{
RESOLVE:
}

D E S I G N A R os Professores abaixo discriminados para compor como Mernbros do Comitê Cientifico do Programa Institucional de Bolsas de Iniciação em Desenvolvimento Tecnológico e Inovação - PIBITI/CNPq - 2011/2012, a contar de 17/07/2011:

\section{Coordenadora}

CINTHYA IAMILLE FRITZ BRANDĀO DE OLIVEIRA - ICB

Membros:

ELIAS CRISTIANO CANDIDO DA SILVA - ICB

JOSE LUIZ DE SOUZA PIO - ICE

PATRICIA DOS ANJOS BRAGA SÁ DOS SANTOS - FT

ROSEANE PINTO MARTINS DE OLIVEIRA - FCA

Dé-se ciència e cumpra-se.

REITORIA DA UNIVERSIDADE FEDERAL DO AMAZONAS, em Manaus, 17 de julho de 2011 .

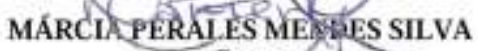

Reitora 


\section{PORTARIAN"1072/2012}

O VICE-REITOR DA UNIVERSIDADE FEDERAL DO AMAZONAS, no exercicio do cargo de Reitor, usando de suas atribuiç̨es estatutárias e,

CONSIDERANDO os termos do Oficio $n^{\circ} 003 / 2012$ - PROTECUFAM. datado de 04/01/2012, protocolizado sob o $n^{\circ} 23105,053167 / 2012$, subscrito pela Pró-Reitora de Inovaçío Tecnológica, Profa. Dra. Maria do Perpétuo Rodrigues Chaves,

\section{RESOLVE:}

ATRIBUIR a carga horiria de 10 (dez) horas semanais à Professora PATRICIA DOS ANJOS BRAGA SÁ DOS SANTOS, lotada no Departamento de Design da Faculdade de Tecnologia para atuar na Pró-Reitoria de lnovação Tecnológica junto ao Departamento de Gestão Tecnológica, Propriedade Intelectual e Transferência de Tecnológica.

De-se ciência e cumpra-se.

RETTORIA DA UNIVERSIDADE FEDERAL DO AMAZONAS, om Manaus, 18 de abril de 2012. 



\section{Referencias}

BARBOSA, Antonio de Pádua Risolia. A Formação de Competências para Inovar através de Processos de Transferência de Tecnologia: um estudo de caso. Tese de Doutorado. Rio de janeiro: UFRJ, 2009.

BARBOSA. A.L.F. Propriedade e quase propriedade no comércio de tecnologia. Brasília: CNPq, 1981.

BRESSAN, Flávio. O Método do Estudo de Caso. 2004. Disponível em <http://www. fecap.br/adm_online/art11/flavio.htm. Acesso em 10/06/2010.

BRITO, Rosa Mendonça de. 100 anos da Universidade Federal do Amazonas.

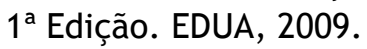

BUENO, G. S. Gestão estratégica do conhecimento. 2004. Disponível em http://www.unifae.br/publicacoespdf/revista_da_fae/fae_v7_n1/rev_fae_v7 _n1_07_giovatan.pdf. Acesso em 19/09/2010.

CAPLAN, S. Using focus group methodology for ergonomic Design. Ergonomics, v. 33, n.5, p. 527-33, 1990.

CASELLES, Antonio. Modelización y Simulación de Sistemas Complejos. Universidad de Valencia, 2008.

CAVALCANTI, Lynaldo. Histórico do Design do Amazonas. T\&C Amazônia, Ano III, Número 7, Julho de 2005.

CERVO, Amado L.; BERVIAN, Pedro A.; DA SILVA, Roberto. Metodologia Científica. $6^{a}$ edição. São Paulo: Pearson Prentice Hall, 2007.

CHAMAS, C.I.; MULLER, A.C. Gerência da Propriedade Industrial e da Transferência de Tecnologia. Anais do XXI Simpósio de Gestão da InovaçãoTecnológica.1998.

CNE - CONSELHO NACIONAL DE EDUCAÇÃO/ CES - CÂMARA DE EDUCAÇÃO SUPERIOR. RESOLUÇÃO N ${ }^{\circ}$, DE 8 DE MARÇO DE 2004. Diretrizes Curriculares Nacionais do Curso de Graduação em Design. Disponível em: http://portal.mec.gov.br/cne/arquivos/pdf/rces05_04.pdf. Acesso em 09/09/2011.

COELHO, Fábio Ulhoa. Curso Direito Comercial I. São Paulo Saraiva, 2007. COELHO, $M^{a}$ Do Perpétuo Socorro de Lima Verde. Processos de gestão da inovação em uma ICT: um estudo de caso na PROTEC/UFAM. UFAM. 2012. 
COUTINHO,P.L.A., LONGANEZI,T., BOMTEMPO,J.V. \& PEREIRA, F.M.A. Construindo Um Sistema de Gestão da Innovación Tecnológica: Atividades, Estrutura e Métricas. ANPAD, Simpósio 2006.

COUTO, Hudson de Araújo. Ergonomia aplicada ao trabalho em 18 lições. Belo Horizonte: Ergo, 2002.

CYSNE, Fátima Portela. Transferência de tecnologia entre a universidade e a indústria. BIBLI: R. eletrônica de Bibl. Ci. Inform., Florianópolis, n. 20, $2^{\circ}$ semestre de 2005.

EBOLE, M. F. O Perfil da Biotecnologia no Brasil: Investimentos, Recursos Humanos e a Indústria de Biotecnologia. 2007. Disponível em www.eq.ufrj.br/links/siquim/aulas/2007/gestao\%20em\%20biotecnologia\% 20resumida\%20-\%. Acesso em 19/09/2011.

EEN - Enterprise Europe Network. Transferência de Tecnologia. Disponível em: http://www.enterpriseeuropenetwork.pt/info/investigacao/Paginas/ trans ftec.aspx. Acesso em: 02/04/2012.

ESPARDUCER, Ignacio Martinés de Lejarza y; ORTUÑO, Bernabé Hernandis; MARCO, Carmen Lahiguera. Representación reticular de los objetivos de un sistema. Tercera Escuela Europea de Sistemas. UES - União Européia de Sistemas/ Escuela de Investigación Operativa - Universidad de Valencia (E.I.O.)/ Universidad Internacional Menéndez Pelayo (U.I.M.P). Octobre de 1994.

ESTEVÃO, Carlos. Gestão Estratégica nas Escolas. São Paulo: Editora IIE, 2001.

ETZKOWITZ, Henry. Innovation in Innovation: The Triple Helix of UniversityIndustry-Government Relations. Social Science Information: 2009.

ETZKOWITZ, Henry; LEYDESDORFF, Loet. The Triple Helix as a Model for Innovation Studies. (Conference Report), Science \& Public Policy Vol. 25(3) (1997).

FILHO,Guajarino Araújo; PIMENTA Niomar Lins; LASMAR, Dimas José. A emergência de um sistema de innovación no Estado do Amazonas: fortalecimento pela governança. Revista Parcerias Estratégicas, Número 26. Brasília: junho 2008.

FORTEC (Fórum Nacional de Gestores De Inovação e Transferência De Tecnologia). Relatório de Gestão - 2008/2010. Recife, Disponível em: <http://www.fortec-br.org/site/>.

GIL, Antonio Carlos. Como elaborar projetos de pesquisa. 4. ed. São Paulo: Atlas, 2008. 
JARAMILLO, Hernán; LUGONES, Gustavo; SALAZAR, Mónica. Manual de Bogotá: Normalización de Indicadores de Innovación Tecnológica en América Latina y el Caribe. RICYT / OEA / CYTED/COLCIENCIAS/OCYT. 2001. Disponível em: //http://www.mct.gov.br/index.php/content/view/4639.html . Acesso em: 22/07/2010.

JOHNSON, B; EDQUIST, C; LUNDVALL, B. Economic Development and the National System of Innovation Approach. Alborg University Press. 2003.

KANAANE, Roberto. Comportamento humano nas organizações: o homem rumo ao século XXI. São Paulo: Atlas, 1994.

LASMAR, Dimas José. Valorização da Biodiversidade: Capacitação e Inovação Tecnológica na Fitoindústria No Amazonas. Tese de doutorado. Rio de Janeiro: COPPE/UFRJ, 2005.

Lei de diretrizes e bases da educação nacional. LEI No 9.394, DE 20 DE DEZEMBRO DE 1996. Governo Federal. Disponível em: http://www.planalto. gov.br/ccivil_03/leis/19394.htm.

Lei da Inovação. LEI No 10.973, DE 2 DE DEZEMBRO DE 2004. Governo Federal. Disponível em: http://www.planalto.gov.br/ccivil_03/_ato2004-2006/2004 /lei/ 110.973.htm.

Lei da Propriedade Industrial. LEI N 9.279, DE 14 DE MAIO DE 1996. Governo Federal. Disponível em: http://www.planalto.gov.br/ccivil_03/leis/I9279.htm

LONGANEZI, Telma. Os sistemas de gestão da Inovação e a capacidade inovadora das empresas. Tese de Doutorado. Universidade Federal do Rio de Janeiro. 2008.

MALDONADO, Tomás. Design industrial. Lisboa: Edições 70, 2006.

MARCONI, M. A.; LAKATOS, E. M. Técnicas de Pesquisa: planejamento e execução de pesquisas, amostragens e técnicas de pesquisa, análise e interpretação de dados. São Paulo: Atlas, 2008.

MATTAR, F. Pesquisa de marketing. Ed. Atlas. 1996.

MAUÉS, Olgaíses. A Política de Avaliação Da Educação Superior e os Desafios da Implementação do Sinaes. GT: Política de Educação Superior / n.11.2008.

MELLO, F. O. T.; PAULILLO, L. F. Recursos de poder e capacidade dinâmica de aprendizado dos atores sucroalcooleiros paulistas pósdesregulamentação estatal. Informações Econômicas, v. 35, n. 6, p. 17-29, 2005.

Ministério da Educação e Cultura (MEC)/ INEP. Estrutura de avaliação dos Cursos de Graduação no Brasil. Site INEP. 
MOREIRA; SANTOS; PEREIRA; MAMÃO. Onde está a inovação no Brasil? Instituto Innovación. 2007.

Mytelka, L.K. and Smith, K.; Policy learning and innovation theory: An interactive and co-evolving process. Research Policy 31: 1467 - 1479; 2002.

NATIVIDADE, Claudia Dybas. Acertos e Erros da Política de Innovación Tecnológica Envolvendo Universidade, Empresa e Governo. Monografias Premiadas no 2o. Concurso de Monografia sobre a Relação UniversidadeEmpresa. Curitiba, IEL-PR, 2001.

NEVES, José Luiz. Pesquisa Qualitativa: Características, uso e possibilidades. 1996. Caderno de pesquisas em administração. São Paulo, Vol. 1, Núm. 3, 1996. http://www.ead.fea.usp.br/cad-pesq/arquivos/c03art06.pdf

NIEMEYER, Lucy. Design no Brasil. Origens e instalação. $2^{a}$ ed. Rio de Janeiro: 2AB, 1997.

OCDE. O Manual Frascati. 2002.

OCDE/FINEP. Manual de Oslo: Diretrizes para coleta e interpretação de dados sobre inovação. 2005.

OLIVEIRA, Natã Morais de. Metodologia \& Projeto (Apostila). UFCG, 2005.

ORTOLANI, Luiz Fernando Ballin. A Tecnologia da Informação na Administração Pública. Brasília, 1995. Disponível em: http://www.pr. gov.br/batebyte/edicoes/1995 /bb46/admpub.html. Acesso em: 17 jun 2010.

ORTUÑO, Bernabé Hernandis; NAVARRO, Emilio R. Iribarren. Diseño de Nuevos Productos - Una Perspectiva Sistémica. Valencia: UPV, 2000.

ORTUÑO, Bernabé. Desarrollo de una metodología sistémica para el diseño de productos industriales. Tesis Doctoral. Valencia: UPV, 2003.

ORTUÑO, Bernabé. Apuntes del Asignatura "Metodología del diseño" Máster en Diseño, Gestión y Desarrollo de Nuevos Productos. Valencia: UPV, 2008.

PEREIRA, Maurício Fernandes; MELO, Pedro Antônio de; DALMAU, Marcos Baptista; HARGER, Carlos Augusto. Transferência de Conhecimentos Científicos e Tecnológicos da Universidade para o Segmento Empresarial. RAl - Revista de Administração e Inovação, Vol. 6, Núm. 3, septiembrediciembre, pp. 128-144. Universidade de São Paulo: 2009. Disponível em: http://redalyc.uaemex.mx/pdf/973/97312500009.pdf.

PORTER, M. Vantagem Competitiva: criando e sustentando um desempenho superior. Rio de Janeiro: Campus, 1989. 
REZENDE, S. M. Ciência e Tecnologia na Região Amazônica: onde chegamos e o que esperar. Revista T\&C Amazônia, Ano IV, N.14, junho de 2007.

SÁENZ, Tirso w.; CAPOTE, Emílio Garcia. Ciência, inovação e Gestão Tecnológica. Brasília: CNI/IEL/SENAI,ABPTI, 2002.

SCHIFFMAN, L. \& KANUK, L. Comportamento do consumidor. LTC Editora. 6a ed. 2000.

SCHULMANN, Denis. O desenho industrial. $1^{\text {a }}$ ed. Campinas: Papirus, 1994.

SILVA, Márcia Perales Mendes; SCHERER, Elenise Faria. A Universidade Federal do Amazonas (Ufam) e a sua Inserção na Sociedade Amazônica. Temporalis, Brasilia (DF), ano 10, n.20, p.253-269, jul./dez. 2010.

SROUR, Robert Henry. Poder, cultura e ética nas organizações. Rio de Janeiro: Campus, 1998.

TAKAHASHI, A. R. W.; AMORIM, W. A. C. Reformulação e expansão dos cursos superiores de tecnologia no Brasil: as dificuldades da retomada da educação profissional. Ensaio: aval. pol. públ. Educ., Rio de Janeiro, v. 16, n. 59, p. 207-228, abr./jun. 2008

TACHIZAWA, Takeshy; ANDRADE, Rui Otávio Bernardes. Gestão de Instituições de Ensino. Rio de Janeiro: Editora FGV, 2001.

TARAPANOFF, Kira. (Org.). Inteligência Organizacional e Competitiva. Brasília: Editora Universidade de Brasília, 2001.

TEECE, David J.; PISANO, Gary; SHUEN, Amy. Strategic Management Journal, Vol. 18, No. 7. (Aug., 1997).

TIDD, J.; BESSANT, J.; PAVITT, K. Gestão da inovação. Bookman, 2008.

UFAM/FT/DEG. Projeto Político Pedagógico do Curso de Design da Universidade Federal do Amazonas. 2007.

UFAM. Política de inovação da Universidade Federal do Amazonas. 2011.

VAUGHN, S. et al. Focus group interviews in education and psychology. Thousand Oaks, CA: Sage Publications, 1996.

WOLLNER, Alexandre. Design visual 50 anos. São Paulo: Cosac Naify, 2003. 



\section{Apéndices}

\section{Apéndice A}

Estructura de entrevista de carácter semi estructurado con especialistas del área de Innovación y Design

\section{Cuestión 01:}

Em sua opinião quais os fatores que mais dificultam a relação entre a universidade e a indústria na geração de inovação?

\section{Cuestión 02:}

Como seria possível avaliar esses fatores?

\section{Cuestión 03:}

Como você acredita que a cooperação entre o Curso de Graduação em Design e o setor privado para o desenvolvimento de novos produtos e processos poderia ser viável?

\section{Cuestión 04:}

Que medidas poderiam ser tomadas para fomentar as atividades inovativas no Curso de Graduação em Design da UFAM?

\section{Cuestión 05:}

Você é favorável que os ALUMNOS e os PROFESORES/pesquisadores recebam uma formação empresarial e que sejam estimulados a desenvolver pesquisas que tenham chance de chegar ao mercado? 


\section{Apéndice B}

Modelo de encuesta aplicado al grupo de PROFESORES del Curso

\section{Introdução:}

Este questionário faz parte do desenvolvimento de uma tese para o Programa de Doutorado em Desenho, Fabricação e Gestão de Projetos Industriais da Universidade Politécnica de Valência/Espanha, cujo objetivo é Identificar e analisar, a partir de um enfoque sistêmico, os fatores que influenciam a prática da inovação no Curso de Graduação em Design da Universidade Federal do Amazonas. Agradeceria se, por favor, respondesse a este questionário, as respostas só serão utilizadas para o desenvolvimento da tese e não serão proporcionadas a terceiros.

\section{1) Gênero}
(1) Masculino
(2) Feminino

2) Idade
(1) $17-25$
(2) $26-35$
(3) $36-45$
(4) $\quad 46-55$
(5) Acima de 55

3) Estado civil
(1) Solteiro/a
(2) Casado/a
(3) Viúvo/a
(4) Separado/a
(5) União Estável 


\section{4) Em Qual Área do Design Atua ?}
(1) Projeto de Produtos
(2) Programação Visual

(3) Interfaces Gráficas Digitais (Web/jogos/aplicativos eletrônicos em geral)

\section{5) Titulação}
(1) Pós-Doutor
(2) Doutor
(3) Mestre
(4) Especialista
(5) Graduado

\section{INDICAR O GRAU DE CONCORDÂNCIA COM AS AFIRMAÇÕES DESCRITAS A} SEGUIR:

\begin{tabular}{|c|c|c|c|c|c|}
\hline & & $\begin{array}{l}\text { Concordo } \\
\text { Totalmente }\end{array}$ & $\begin{array}{l}\text { Concordo } \\
\text { Parcialmente }\end{array}$ & $\begin{array}{l}\text { Discordo } \\
\text { Parcialmente }\end{array}$ & $\begin{array}{l}\text { Discordo } \\
\text { Totalmente }\end{array}$ \\
\hline a. & $\begin{array}{l}\text { Estou familiarizado } \\
\text { com o conceito de } \\
\text { innovación. }\end{array}$ & & & & \\
\hline b. & $\begin{array}{l}\text { Estou familiarizado } \\
\text { com o conceito de } \\
\text { Empreendedorismo. }\end{array}$ & & & & \\
\hline C. & $\begin{array}{l}\text { Estou familiarizado } \\
\text { com o conceito de } \\
\text { Transferência de } \\
\text { Tecnologia. }\end{array}$ & & & & \\
\hline d. & $\begin{array}{l}\text { Estou familiarizado } \\
\text { com a legislação } \\
\text { outros procedimentos } \\
\text { relacionados à } \\
\text { Proteção da } \\
\text { Propriedade } \\
\text { Intelectual/Industrial. }\end{array}$ & & & & \\
\hline e. & $\begin{array}{l}\text { Conheço os objetivos } \\
\text { do Curso em relação } \\
\text { à innovación. }\end{array}$ & & & & \\
\hline f. & $\begin{array}{l}\text { Conheço as pesquisas } \\
\text { e projetos que estão } \\
\text { sendo desenvolvidos } \\
\text { no curso }\end{array}$ & & & & \\
\hline
\end{tabular}




\begin{tabular}{|c|c|c|c|c|c|}
\hline & & $\begin{array}{l}\text { Concordo } \\
\text { Totalmente }\end{array}$ & $\begin{array}{l}\text { Concordo } \\
\text { Parcialmente }\end{array}$ & $\begin{array}{l}\text { Discordo } \\
\text { Parcialmente }\end{array}$ & $\begin{array}{l}\text { Discordo } \\
\text { Totalmente }\end{array}$ \\
\hline g. & $\begin{array}{l}\text { O Curso incentiva a } \\
\text { prática da innovación } \\
\text { entre os ALUMNOS e } \\
\text { professores. }\end{array}$ & & & & \\
\hline h. & $\begin{array}{l}\text { A infra-estrutura } \\
\text { laboratorial } \\
\text { disponível no Curso é } \\
\text { suficiente para } \\
\text { fomentar o } \\
\text { desenvolvimento de } \\
\text { novos produtos e } \\
\text { processos. }\end{array}$ & & & & \\
\hline i. & $\begin{array}{l}\text { Considero essencial o } \\
\text { acesso a informações } \\
\text { e capacitações } \\
\text { voltadas à proteção } \\
\text { da propriedade } \\
\text { Intelectual }\end{array}$ & & & & \\
\hline j. & $\begin{array}{l}\text { Considero essencial } \\
\text { fomentar o espírito } \\
\text { empreendedor entre } \\
\text { os estudantes e } \\
\text { professores do Curso }\end{array}$ & & & & \\
\hline l. & $\begin{array}{l}\text { Considero essencial a } \\
\text { existência de projetos } \\
\text { desenvolvidos em } \\
\text { cooperação com o } \\
\text { setor privado. }\end{array}$ & & & & \\
\hline $\mathrm{m}$. & $\begin{array}{l}\text { Considero essencial a } \\
\text { existência de projetos } \\
\text { desenvolvidos em } \\
\text { cooperação com } \\
\text { outras instituições de } \\
\text { ensino e pesquisa. }\end{array}$ & & & & \\
\hline
\end{tabular}

\section{RESPONDER SIM OU NÃO PARA OS ITENS A SEGUIR:}

\begin{tabular}{|c|l|c|c|}
\hline a. & $\begin{array}{l}\text { Já ouviu falar no NIT (Núcleo de inovação } \\
\text { Tecnológica) da UFAM? }\end{array}$ & SIM & NÃO \\
\hline b. & Em caso positivo, conhece o escopo de sua atuação? & SIM & NÃO \\
\hline c. & $\begin{array}{l}\text { Já ouviu falar na PRONIT (Pró-Reitoria de inovação } \\
\text { Tecnológica) da UFAM? }\end{array}$ & SIM & NÃO \\
\hline d. & $\begin{array}{l}\text { Já ouviu falar no CDTECH (Centro de Desenvolvimento } \\
\text { Tecnológico e empresarial) da UFAM? }\end{array}$ & SIM & NÃO \\
\hline e. & $\begin{array}{l}\text { Conhece alguma incubadora de empresas que atue no } \\
\text { Amazonas? }\end{array}$ & SIM & NÃO \\
\hline
\end{tabular}




\begin{tabular}{|l|l|c|c|}
\hline & & & \\
\hline f. & $\begin{array}{l}\text { Já participei de projetos desenvolvidos com apoio da } \\
\text { iniciativa privada }\end{array}$ & SIM & NÃO \\
\hline g. & $\begin{array}{l}\text { Tenho interesse em participar de projetos } \\
\text { desenvolvidos em cooperação com o setor privado. }\end{array}$ & SIM & NÃO \\
\hline
\end{tabular}

9) EM CASO DE RESPOSTA POSITIVA DO ITEM "e" DA CUESTIÓN 8, POR FAVOR DESCREVA NO CAMPO ABAIXO O NOME(S) DA(S) INCUBADORA(S) QUE VOCÊ CONHECE:

10) DOS ITENS ABAIXO, ESCOLHA QUATRO (4) E CLASSIFIQUE POR ORDEM DE IMPORTÂNCIA SOBRE AS AÇÕES QUE PODERIAM CONTRIBUIR PARA A MELHORIA DO PROCESSO INOVATIVO NO CURSO DE GRADUAÇÃO EM DESIGN DA UFAM (1- Mais importante/ 4- Menos Importante)

\begin{tabular}{|c|c|}
\hline $\mathrm{a}$ & $\begin{array}{l}\text { Melhorar o conhecimento por parte do curso sobre as } \\
\text { demandas do setor privado para a área de Design. }\end{array}$ \\
\hline $\mathrm{b}$ & $\begin{array}{l}\text { Melhorar a Infraestrutura e laboratórios que possam dar } \\
\text { suporte ao desenvolvimento de novos processos e } \\
\text { produtos. }\end{array}$ \\
\hline $\mathrm{C}$ & $\begin{array}{l}\text { Capacitação sobre proteção da propriedade industrial } \\
\text { (Registro de marcas, patentes, etc.) }\end{array}$ \\
\hline $\mathrm{d}$ & $\begin{array}{l}\text { Melhor acompanhamento da destinação dos TITULADOS } \\
\text { para estabelecimento de uma rede de cooperação. }\end{array}$ \\
\hline e & Apoio Técnico/Gerencial para implantação de negócios \\
\hline$f$ & Apoio para Transferência de Tecnologia \\
\hline $\mathrm{g}$ & Maior articulação com Incubadoras \\
\hline $\mathrm{h}$ & Fóruns para Aproximar Pesquisador e Empresa \\
\hline$i$ & $\begin{array}{l}\text { Construção, pelo curso, de agenda de pesquisa definida } \\
\text { em conjunto com o setor produtivo }\end{array}$ \\
\hline j & Envolvimento do NIT nas pesquisas e projetos \\
\hline l & $\begin{array}{l}\text { Desenvolvimento de projetos de pesquisa e extensão } \\
\text { passíveis de geração de negócios. }\end{array}$ \\
\hline
\end{tabular}


11) Classifique em grau de importância os itens que você considera mais relevantes para a qualidade de um Curso de Graduação ( 1 para o item mais importante - 10 para o menos importante):

\begin{tabular}{|l|l|}
\hline a & Estrutura Curricular/ementas e conteúdos das disciplinas \\
\hline b & Didática dos Professores \\
\hline c & Pontualidade e assiduidade dos professores \\
\hline d & Titulação dos professores \\
\hline e & Envolvimento dos professores com o curso \\
\hline f & Conforto e adequação das salas de aula \\
\hline g & Qualidade dos laboratórios e oficinas específicas \\
\hline h & Apoio de pessoal técnico (ex.: técnico de laboratório e oficinas) \\
\hline i & Apoio da Coordenação do Curso \\
\hline j & Apoio da Secretaria dos Cursos \\
\hline
\end{tabular}

12) Dos itens citados no tópico 11 , cite 3 (também em ordem de importância) que você considera como os aspectos mais POSITIVOS em relação ao curso de Graduação em DESIGN da Universidade Federal do Amazonas:

1.

2.

3.

13) Dos itens citados no tópico 11 cite 3 (também em ordem de importância) que você considera como os aspectos mais DEFICIENTES em relação ao curso de Graduação em DESIGN da Universidade Federal do Amazonas:

1.

2.

3.

OBRIGADO POR SUA COLABORAÇÃO!

PESQUISADORA RESPONSÁVEL: Patrícia dos Anjos Braga Sá dos Santos (petbraga@hotmail.com) 


\section{Apéndice C}

Modelo de encuesta aplicado al grupo de ALUMNOS del Curso

\section{Introdução:}

Este questionário faz parte do desenvolvimento de uma tese para o Programa de Doutorado em Desenho, Fabricação e Gestão de Projetos Industriais da Universidade Politécnica de Valência/Espanha, cujo objetivo é Identificar e analisar, a partir de um enfoque sistêmico, os fatores que influenciam a prática da inovação no Curso de Graduação em Design da Universidade Federal do Amazonas. Agradeceria se, por favor, respondesse a este questionário, as respostas só serão utilizadas para o desenvolvimento da tese e não serão proporcionadas a terceiros.

\section{1) Gênero}

(1) Masculino

(2) Feminino

\section{2) Idade}

(1) $17-25$

(2) $26-35$

(3) $36-45$

(4) $46-55$

(5) Acima de 55

3) Estado civil
(1) Solteiro/a
(2) Casado/a
(3) Viúvo/a
(4) Separado/a
(5) União Estável 
5) EM QUAL ÁREA DO DESIGN VOCÊ POSSUI MAIOR INTERESSE?

(1) Projeto de Produtos

(2) Programação Visual

(3) Interfaces Gráficas Digitais (Web/jogos/aplicativos eletrônicos em geral)

\section{6) PERIODO QUE ESTÁ CURSANDO}
(1) Primeiro
(2) Segundo
(3) Terceiro
(4) Quarto
(5) Quinto
(6) Sexto
(7) Sétimo
(8) Oitavo

7. INDICAR O GRAU DE CONCORDÂNCIA COM AS AFIRMAÇÕES DESCRITAS A SEGUIR:

\begin{tabular}{|c|c|c|c|c|c|}
\hline & & $\begin{array}{l}\text { Concordo } \\
\text { Totalmente }\end{array}$ & $\begin{array}{l}\text { Concordo } \\
\text { Parcialmente }\end{array}$ & $\begin{array}{l}\text { Discordo } \\
\text { Parcialmente }\end{array}$ & $\begin{array}{l}\text { Discordo } \\
\text { Totalmente }\end{array}$ \\
\hline a. & $\begin{array}{l}\text { Estou familiarizado } \\
\text { com o conceito de } \\
\text { innovación. }\end{array}$ & & & & \\
\hline b. & $\begin{array}{l}\text { Estou familiarizado } \\
\text { com o conceito de } \\
\text { Empreendedorismo. }\end{array}$ & & & & \\
\hline c. & $\begin{array}{l}\text { Estou familiarizado } \\
\text { com o conceito de } \\
\text { Transferência de } \\
\text { Tecnologia. }\end{array}$ & & & & \\
\hline d. & $\begin{array}{l}\text { Estou familiarizado } \\
\text { com a legislação } \\
\text { outros procedimentos } \\
\text { relacionados à } \\
\text { Proteção da } \\
\text { Propriedade } \\
\text { Intelectual/Industrial. }\end{array}$ & & & & \\
\hline
\end{tabular}




\begin{tabular}{|c|c|c|c|c|c|}
\hline & & $\begin{array}{l}\text { Concordo } \\
\text { Totalmente }\end{array}$ & $\begin{array}{l}\text { Concordo } \\
\text { Parcialmente }\end{array}$ & $\begin{array}{l}\text { Discordo } \\
\text { Parcialmente }\end{array}$ & $\begin{array}{l}\text { Discordo } \\
\text { Totalmente }\end{array}$ \\
\hline e. & $\begin{array}{l}\text { Conheço os objetivos } \\
\text { do Curso em relação } \\
\text { à inovação. }\end{array}$ & & & & \\
\hline f. & $\begin{array}{l}\text { Conheço as pesquisas } \\
\text { e projetos que estão } \\
\text { sendo desenvolvidos } \\
\text { no curso }\end{array}$ & & & & \\
\hline g. & $\begin{array}{l}\text { O Curso incentiva a } \\
\text { prática da inovação } \\
\text { entre os ALUMNOS e } \\
\text { professores. }\end{array}$ & & & & \\
\hline h. & $\begin{array}{l}\text { A infraestrutura } \\
\text { laboratorial } \\
\text { disponível no Curso é } \\
\text { suficiente para } \\
\text { fomentar o } \\
\text { desenvolvimento de } \\
\text { novos produtos e } \\
\text { processos. }\end{array}$ & & & & \\
\hline i. & $\begin{array}{l}\text { Considero essencial o } \\
\text { acesso a informações } \\
\text { e capacitações } \\
\text { voltadas à proteção } \\
\text { da propriedade } \\
\text { Intelectual }\end{array}$ & & & & \\
\hline j. & $\begin{array}{l}\text { Considero essencial } \\
\text { fomentar o espírito } \\
\text { empreendedor entre } \\
\text { os estudantes e } \\
\text { professores do Curso }\end{array}$ & & & & \\
\hline l. & $\begin{array}{l}\text { Considero essencial a } \\
\text { existência de projetos } \\
\text { desenvolvidos em } \\
\text { cooperação com o } \\
\text { setor privado. }\end{array}$ & & & & \\
\hline $\mathrm{m}$. & $\begin{array}{l}\text { Considero essencial a } \\
\text { existência de projetos } \\
\text { desenvolvidos em } \\
\text { cooperação com } \\
\text { outras instituições de } \\
\text { ensino e pesquisa. }\end{array}$ & & & & \\
\hline
\end{tabular}

\section{RESPONDER SIM OU NÃO PARA OS ITENS A SEGUIR:}

\begin{tabular}{|c|l|c|c|}
\hline a. & $\begin{array}{l}\text { Já ouviu falar no NIT (Núcleo de inovação Tecnológica) } \\
\text { da UFAM? }\end{array}$ & SIM & NÃO \\
\hline b. & Em caso positivo, conhece o escopo de sua atuação? & SIM & NÃO \\
\hline
\end{tabular}




\begin{tabular}{|c|l|c|c|}
\hline c. & $\begin{array}{l}\text { Já ouviu falar na PRONIT (Pró-Reitoria de inovação } \\
\text { Tecnológica) da UFAM? }\end{array}$ & SIM & NÃO \\
\hline d. & $\begin{array}{l}\text { Já ouviu falar no CDTECH (Centro de Desenvolvimento } \\
\text { Tecnológico e empresarial) da UFAM? }\end{array}$ & SIM & NÃO \\
\hline e. & $\begin{array}{l}\text { Conhece alguma incubadora de empresas que atue no } \\
\text { Amazonas? }\end{array}$ & SIM & NÃO \\
\hline f. & $\begin{array}{l}\text { Já participei de projetos desenvolvidos com apoio da } \\
\text { iniciativa privada }\end{array}$ & SIM & NÃO \\
\hline g. & $\begin{array}{l}\text { Tenho interesse em participar de projetos } \\
\text { desenvolvidos em cooperação com o setor privado. }\end{array}$ & SIM & NÃO \\
\hline
\end{tabular}

9) EM CASO DE RESPOSTA POSITIVA DO ITEM "e" DA CUESTIÓN 8, POR FAVOR DESCREVA NO CAMPO ABAIXO O NOME(S) DA(S) INCUBADORA(S) QUE VOCÊ CONHECE:

10) DOS ITENS ABAIXO, ESCOLHA QUATRO (4) E CLASSIFIQUE POR ORDEM DE IMPORTÂNCIA SOBRE AS AÇÕES QUE PODERIAM CONTRIBUIR PARA A MELHORIA DO PROCESSO INOVATIVO NO CURSO DE GRADUAÇÃO EM DESIGN DA UFAM (1- Mais importante/ 4- Menos Importante)

\begin{tabular}{|l|l|l|}
\hline a & $\begin{array}{l}\text { Melhorar o conhecimento por parte do curso sobre as } \\
\text { demandas do setor privado para a área de Design. }\end{array}$ & \\
\hline b & $\begin{array}{l}\text { Melhorar a Infraestrutura e laboratórios que possam dar } \\
\text { suporte ao desenvolvimento de novos processos e } \\
\text { produtos. }\end{array}$ & $\begin{array}{l}\text { Capacitação sobre proteção da propriedade industrial } \\
\text { (Registro de marcas, patentes, etc.) }\end{array}$ \\
\hline d & $\begin{array}{l}\text { Melhor acompanhamento da destinação dos TITULADOS } \\
\text { para estabelecimento de uma rede de cooperação. }\end{array}$ & \\
\hline e & Apoio Técnico/Gerencial para implantação de negócios & \\
\hline f & Apoio para Transferência de Tecnologia & \\
\hline g & Maior articulação com Incubadoras & \\
\hline h & Fóruns para Aproximar Pesquisador e Empresa & $\begin{array}{l}\text { Construção, pelo curso, de agenda de pesquisa definida } \\
\text { em conjunto com o setor produtivo }\end{array}$ \\
\hline i & Envolvimento do NIT nas pesquisas e projetos & $\begin{array}{l}\text { Desenvolvimento de projetos de pesquisa e extensão } \\
\text { passíveis de geração de negócios. }\end{array}$ \\
\hline
\end{tabular}


11) Classifique em grau de importância os itens que você considera mais relevantes para a qualidade de um Curso de Graduação ( 1 para o item mais importante - 10 para o menos importante):

\begin{tabular}{|l|l|}
\hline a & Estrutura Curricular/ementas e conteúdos das disciplinas \\
\hline b & Didática dos Professores \\
\hline c & Pontualidade e assiduidade dos professores \\
\hline d & Titulação dos professores \\
\hline e & Envolvimento dos professores com o curso \\
\hline f & Conforto e adequação das salas de aula \\
\hline g & Qualidade dos laboratórios e oficinas específicas \\
\hline h & Apoio de pessoal técnico (ex.: técnico de laboratório e oficinas) \\
\hline i & Apoio da Coordenação do Curso \\
\hline j & Apoio da Secretaria dos Cursos \\
\hline
\end{tabular}

12) Dos itens citados no tópico 11, cite 3 (também em ordem de importância) que você considera como os aspectos mais POSITIVOS em relação ao curso de Graduação em DESIGN da Universidade Federal do Amazonas:

1.

2.

3.

13) Dos itens citados no tópico 11 cite 3 (também em ordem de importância) que você considera como os aspectos mais DEFICIENTES em relação ao curso de Graduação em DESIGN da Universidade Federal do Amazonas:

1.

2.

3.

14) VOCÊ RECOMENDARIA A UM AMIGO REALIZAR O CURSO DE DESIGN DA UFAM?

( ) SIM ( ) NÃO

OBRIGADO POR SUA COLABORAÇÃO!

PESQUISADORA RESPONSÁVEL: Patrícia dos Anjos Braga Sá dos Santos

(petbraga@hotmail.com) 


\section{Apéndice D}

Modelo de encuesta aplicado al grupo de TITULADOS del Curso

\section{Introdução:}

Este questionário faz parte do desenvolvimento de uma tese para o Programa de Doutorado em Desenho, Fabricação e Gestão de Projetos Industriais da Universidade Politécnica de Valência/Espanha, cujo objetivo é Identificar e analisar, a partir de um enfoque sistêmico, os fatores que influenciam a prática da Inovação no Curso de Graduação em Design da Universidade Federal do Amazonas. Agradeceria se, por favor, respondesse a este questionário, as respostas só serão utilizadas para o desenvolvimento da tese e não serão proporcionadas a terceiros.

\section{1) Gênero}
(1) Masculino
(2) Feminino

2) Idade
(1) $20-30$
(2) $31-40$
(3) $41-50$
(4) $51-60$
(5) Acima de 60

3) Estado civil
(1) Solteiro/a
(2) Casado/a
(3) Viúvo/a
(4) Separado/a
(5) União Estável

5) ANO EM QUE CONCLUIU O CURSO DE DESIGN/UFAM 
6) ESTÁ ATUANDO NA ÁREA DE DESIGN?

( ) $\operatorname{SIM}$

( ) NÃO

7) SITUAÇÃO NO MERCADO DE TRABALHO:

(1 ) Autônomo

(2) Funcionário em empresa privada

( 3) Funcionário Público

(4) Docente/pesquisador em instituição Pública

(5) Docente/pesquisador em instituição Privada

8) QUAL A SUA HABILITAÇÃO:

(1) Programação Visual

(2) Projeto de Produto

(3) Não possuo habilitação - Formado na nova estrutura curricular.

9) NO CASO DE POSSUIR HABILITAÇÃO: ATUA EXCLUSIVAMENTE EM SUA ÁREA?

( ) SIM

( ) NÃO

10) EM QUAL ÁREA DO DESIGN MAIS ATUA ?

(1) Desenvolvimento de Produtos

(2) Programação Visual

(3) Interfaces Gráficas Digitais (Web/jogos/aplicativos eletrônicos em geral)

11) TITULAÇÃO

(1) Pós-Doutor

(2) Doutor

(3) Mestre

(4) Especialista

(5) Graduado 
12) VOCÊ ESTÁ SATISFEITO COM A PROFISSÃO DE DESIGNER?

( ) SIM ( ) NÃO

13) POSSUI ALGUMA PATENTE?

( ) SIM ( ) NÃO

14) JÁ PRODUZIU, POR INICIATIVA PRÓPRIA OU ATRAVÉS DE TRANSFERÊNCIA DE TECNOLOGIA, ALGUM PRODUTO OU PROCESSO QUE VOCÊ DESENVOLVEU?

( ) SIM ( ) NÃO

15) DOS ITENS ABAIXO, ESCOLHA QUATRO (4) E CLASSIFIQUE POR ORDEM DE IMPORTÂNCIA SOBRE AS AÇÕES QUE PODERIAM CONTRIBUIR PARA A MELHORIA DO PROCESSO INOVATIVO NO CURSO DE GRADUAÇÃO EM DESIGN DA UFAM (1- Mais importante/ 4- Menos Importante)

\begin{tabular}{|c|c|}
\hline a & $\begin{array}{l}\text { Melhorar o conhecimento por parte do curso sobre as } \\
\text { demandas do setor privado para a área de Design. }\end{array}$ \\
\hline $\mathrm{b}$ & $\begin{array}{l}\text { Melhorar a Infraestrutura e laboratórios que possam dar } \\
\text { suporte ao desenvolvimento de novos processos e } \\
\text { produtos. }\end{array}$ \\
\hline C & $\begin{array}{l}\text { Capacitação sobre proteção da propriedade industrial } \\
\text { (Registro de marcas, patentes, etc.) }\end{array}$ \\
\hline $\mathrm{d}$ & $\begin{array}{l}\text { Melhor acompanhamento da destinação dos TITULADOS } \\
\text { para estabelecimento de uma rede de cooperação. }\end{array}$ \\
\hline e & Apoio Técnico/Gerencial para implantação de negócios \\
\hline f & Apoio para Transferência de Tecnologia \\
\hline g & Maior articulação com Incubadoras \\
\hline $\mathrm{h}$ & Fóruns para Aproximar Pesquisador e Empresa \\
\hline $\mathrm{i}$ & $\begin{array}{l}\text { Construção, pelo curso, de agenda de pesquisa definida } \\
\text { em conjunto com o setor produtivo }\end{array}$ \\
\hline j & Envolvimento do NIT nas pesquisas e projetos \\
\hline l & $\begin{array}{l}\text { Desenvolvimento de projetos de pesquisa e extensão } \\
\text { passíveis de geração de negócios. }\end{array}$ \\
\hline
\end{tabular}

16) Classifique em grau de importância os itens que você considera mais relevantes para a qualidade de um Curso de Graduação ( 1 para o item mais importante - 10 para o menos importante):

\begin{tabular}{|l|l|}
\hline $\mathrm{a}$ & Estrutura Curricular/ementas e conteúdos das disciplinas \\
\hline $\mathrm{b}$ & Didática dos Professores \\
\hline
\end{tabular}




\begin{tabular}{|l|l|}
\hline c & Pontualidade e assiduidade dos professores \\
\hline d & Titulação dos professores \\
\hline e & Envolvimento dos professores com o curso \\
\hline f & Conforto e adequação das salas de aula \\
\hline g & Qualidade dos laboratórios e oficinas específicas \\
\hline h & Apoio de pessoal técnico (ex.: técnico de laboratório e oficinas) \\
\hline i & Apoio da Coordenação do Curso \\
\hline j & Apoio da Secretaria dos Cursos \\
\hline
\end{tabular}

17) Dos itens citados no tópico 16, cite 3 (também em ordem de importância) que você considera como os aspectos mais POSITIVOS em relação ao curso de Graduação em DESIGN da Universidade Federal do Amazonas:

1.

2.

3.

18) Dos itens citados no tópico 16 cite 3 (também em ordem de importância) que você considera como os aspectos mais DEFICIENTES em relação ao curso de Graduação em DESIGN da Universidade Federal do Amazonas:

1.

2.

3.

19) VOCÊ RECOMENDARIA A UM AMIGO REALIZAR O CURSO DE DESIGN DA UFAM?

( ) SIM ( ) NÃO

OBRIGADO POR SUA COLABORAÇÃO!

PESQUISADORA RESPONSÁVEL: Patrícia dos Anjos Braga Sá dos Santos (petbraga@hotmail.com) 


\section{Apêndice E}

Modelo de formulário para avaliação do Sistema de Gestão da Innovación pelos pares

\begin{tabular}{|c|c|c|c|c|c|c|}
\hline Categorias & Variáveis & PERGUNTA & CT & CP & DP & DT \\
\hline $\begin{array}{l}\text { Validade } \\
\text { De } \\
\text { Construto }\end{array}$ & $\begin{array}{l}\text { Exequibilidade } \\
\text { da estratégia }\end{array}$ & $\begin{array}{l}\text { A estratégia } \\
\text { apresentada é possível } \\
\text { de ser implementada } \\
\text { no curso } \\
\text { (Exequibilidade: } \\
\text { recursos humanos; } \\
\text { estrutura física). }\end{array}$ & & & & \\
\hline \multirow[t]{2}{*}{$\begin{array}{l}\text { Validade } \\
\text { De Face e } \\
\text { Conteúdo }\end{array}$} & $\begin{array}{l}\text { Representativid } \\
\text { ade dos } \\
\text { descritores }\end{array}$ & $\begin{array}{l}\text { Os descritores sobre o } \\
\text { diagnóstico do curso } \\
\text { são uma amostra } \\
\text { representativa do } \\
\text { universo disponível do } \\
\text { curso. }\end{array}$ & & & & \\
\hline & Abrangência & $\begin{array}{l}\text { A estratégia proposta } \\
\text { abrange os principais } \\
\text { aspectos do curso que } \\
\text { podem contribuir para } \\
\text { a inovação. }\end{array}$ & & & & \\
\hline $\begin{array}{l}\text { Validade } \\
\text { De } \\
\text { Critério }\end{array}$ & $\begin{array}{l}\text { Acurácia e } \\
\text { Documentação }\end{array}$ & $\begin{array}{l}\text { A estratégia é passível } \\
\text { de ser acurada e } \\
\text { acompanhada através } \\
\text { de documentação } \\
\text { específica. }\end{array}$ & & & & \\
\hline \multirow[t]{2}{*}{$\begin{array}{l}\text { Validade } \\
\text { Preditiva }\end{array}$} & $\begin{array}{l}\text { Relação } \\
\text { estratégia/resul } \\
\text { tados }\end{array}$ & $\begin{array}{l}\text { A estratégia pode } \\
\text { promover a uma } \\
\text { melhoria no ambiente } \\
\text { da inovação no curso. }\end{array}$ & & & & \\
\hline & $\begin{array}{l}\text { Ligação com } \\
\text { objetivos do } \\
\text { curso }\end{array}$ & $\begin{array}{l}\text { A estratégia é coerente } \\
\text { com os objetivos de } \\
\text { inovação no curso. }\end{array}$ & & & & \\
\hline
\end{tabular}




\section{Apéndice $F$}

Output SPSS de las cuestiones de las encuestas - Grupos: Profesores, Alumnos y Titulados

Resultados de la Cuestión 07 de la encuesta (Grado de Concordancia) -

\section{PROFESORES}

Output SPSS - Cuestión 7.a PROFESORES

Estoy familiarizado con el concepto de innovación.

\begin{tabular}{|ll|l|l|l|l|}
\hline & & Frecuencia & Porcentaje & $\begin{array}{l}\text { Porcentaje } \\
\text { válido }\end{array}$ & $\begin{array}{l}\text { Porcentaje } \\
\text { acumulado }\end{array}$ \\
\hline Válidos & $\begin{array}{l}\text { Concordo } \\
\text { totalmente } \\
\text { concordo } \\
\text { parcialment } \\
\text { e }\end{array}$ & 9 & 60,0 & 60,0 & 60,0 \\
& 15 & 40,0 & 40,0 & 100,0 \\
& Total & 100,0 & 100,0 & \\
\hline
\end{tabular}

Output SPSS - Cuestión 7.b PROFESORES

Estoy familiarizado con el concepto Emprendedor.

\begin{tabular}{|ll|l|l|l|l|}
\hline & Frecuencia & Porcentaje & $\begin{array}{l}\text { Porcentaje } \\
\text { válido }\end{array}$ & $\begin{array}{l}\text { Porcentaje } \\
\text { acumulado }\end{array}$ \\
\hline Válidos & $\begin{array}{l}\text { concordo } \\
\text { totalmente } \\
\text { concordo } \\
\text { parcialment } \\
\text { e }\end{array}$ & 6 & 60,0 & 60,0 & 60,0 \\
& 15 & 40,0 & 40,0 & 100,0 \\
& Total & 100,0 & 100,0 & \\
\hline
\end{tabular}

Output SPSS - Cuestión 7.c PROFESORES

Estoy familiarizado con el concepto de transferencia de tecnología.

\begin{tabular}{|c|c|c|c|c|c|}
\hline & & Frecuencia & Porcentaje & $\begin{array}{l}\text { Porcentaje } \\
\text { válido }\end{array}$ & $\begin{array}{l}\text { Porcentaje } \\
\text { acumulado }\end{array}$ \\
\hline Válidos & $\begin{array}{l}\text { concordo } \\
\text { totalmente } \\
\text { concordo } \\
\text { parcialment } \\
\text { e } \\
\text { discordo } \\
\text { parcialment } \\
\text { e } \\
\text { Total }\end{array}$ & $\begin{array}{l}2 \\
15\end{array}$ & $\begin{array}{l}26,7 \\
60,0 \\
13,3 \\
100,0\end{array}$ & $\begin{array}{l}26,7 \\
60,0\end{array}$ & $\begin{array}{l}26,7 \\
86,7\end{array}$ \\
\hline
\end{tabular}


Output SPSS - Cuestión 7.d PROFESORES

Estoy familiarizado con las reglas y otros procedimientos relacionados con la Protección de la Propiedad Intelectual/Industrial.

\begin{tabular}{|c|c|c|c|c|c|}
\hline & & Frecuencia & Porcentaje & $\begin{array}{l}\text { Porcentaje } \\
\text { válido }\end{array}$ & $\begin{array}{l}\text { Porcentaje } \\
\text { acumulado }\end{array}$ \\
\hline Válidos & $\begin{array}{l}\text { concordo } \\
\text { totalmente } \\
\text { concordo } \\
\text { parcialmente } \\
\text { discordo } \\
\text { parcialmente } \\
\text { discordo } \\
\text { totalmente } \\
\text { Total }\end{array}$ & $\begin{array}{l}5 \\
8 \\
1 \\
1 \\
15\end{array}$ & $\begin{array}{l}33,3 \\
53,3 \\
6,7 \\
6,7 \\
100,0\end{array}$ & $\begin{array}{l}33,3 \\
53,3 \\
6,7 \\
6,7 \\
100,0\end{array}$ & $\begin{array}{l}33,3 \\
86,7 \\
93,3 \\
100,0\end{array}$ \\
\hline
\end{tabular}

Output SPSS - Cuestión 7.e PROFESORES

Conozco los objetivos del curso en relación a la innovación.

\begin{tabular}{|ll|l|l|l|l|}
\hline & Frecuencia & Porcentaje & $\begin{array}{l}\text { Porcentaje } \\
\text { válido }\end{array}$ & $\begin{array}{l}\text { Porcentaje } \\
\text { acumulado }\end{array}$ \\
\hline Válidos & $\begin{array}{l}\text { concordo } \\
\text { totalmente } \\
\text { concordo } \\
\text { parcialment } \\
\text { e }\end{array}$ & 8 & 53,3 & 53,3 & 53,3 \\
& 6 & 40,0 & 40,0 & 93,3 \\
$\begin{array}{l}\text { discordo } \\
\text { totalmente } \\
\text { Total }\end{array}$ & 1 & 6,7 & 6,7 & 100,0 \\
\hline
\end{tabular}

Output SPSS - Cuestión 7.f PROFESORES

Conozco la investigación y los proyectos que se desarrollan en el curso.

\begin{tabular}{|ll|l|l|l|l|}
\hline & & Frecuencia & Porcentaje & $\begin{array}{l}\text { Porcentaje } \\
\text { válido }\end{array}$ & $\begin{array}{l}\text { Porcentaje } \\
\text { acumulado }\end{array}$ \\
\hline Válidos & $\begin{array}{l}\text { concordo } \\
\text { totalmente }\end{array}$ & 5 & 33,3 & 33,3 & 33,3 \\
& $\begin{array}{l}\text { concordo } \\
\text { parcialmente } \\
\text { discordo } \\
\text { parcialmente }\end{array}$ & 8 & 53,3 & 53,3 & 86,7 \\
& 2 & 13,3 & 13,3 & 100,0 \\
\hline
\end{tabular}

Output SPSS - Cuestión 7.g PROFESORES

El curso fomenta la práctica de la innovación entre los alumnos y los profesores.

\begin{tabular}{|ll|l|l|l|l|}
\hline & Frecuencia & Porcentaje & $\begin{array}{l}\text { Porcentaje } \\
\text { válido }\end{array}$ & $\begin{array}{l}\text { Porcentaje } \\
\text { acumulado }\end{array}$ \\
\hline Válidos & $\begin{array}{l}\text { concordo } \\
\text { totalmente }\end{array}$ & 5 & 33,3 & 33,3 & 33,3 \\
$\begin{array}{l}\text { concordo } \\
\text { parcialmente } \\
\text { discordo } \\
\text { parcialmente } \\
\text { Total }\end{array}$ & 3 & 46,7 & 46,7 & 80,0 \\
& 15 & $\begin{array}{l}20,0 \\
100,0\end{array}$ & $\begin{array}{l}20,0 \\
100,0\end{array}$ & 100,0 \\
\hline
\end{tabular}


Output SPSS - Cuestión 7.h PROFESORES

La infraestructura de laboratorios disponible en el Curso es suficiente para estimular el desarrollo de nuevos productos y procesos.

\begin{tabular}{|ll|l|l|l|l|}
\hline & & Frecuencia & Porcentaje & $\begin{array}{l}\text { Porcentaje } \\
\text { válido }\end{array}$ & $\begin{array}{l}\text { Porcentaje } \\
\text { acumulado }\end{array}$ \\
\hline Válidos & $\begin{array}{l}\text { concordo } \\
\text { parcialmente } \\
\text { discordo }\end{array}$ & 6 & 40,0 & 40,0 & 40,0 \\
& $\begin{array}{l}\text { parcialmente } \\
\text { discordo } \\
\text { totalmente }\end{array}$ & 5 & 33,3 & 33,3 & 73,3 \\
& 15 & 26,7 & 26,7 & 100,0 \\
& Total & 100,0 & 100,0 & \\
\hline
\end{tabular}

Output SPSS - Cuestión 7.j PROFESORES

Creo que el acceso a la información y la formación dirigida a la protección de la propiedad intelectual es esencial.

\begin{tabular}{|ll|l|l|l|l|}
\hline & $\begin{array}{l}\text { Frecuenci } \\
\mathrm{a}\end{array}$ & $\begin{array}{l}\text { Porcentaj } \\
\mathrm{e}\end{array}$ & $\begin{array}{l}\text { Porcentaje } \\
\text { válido }\end{array}$ & $\begin{array}{l}\text { Porcentaje } \\
\text { acumulado }\end{array}$ \\
\hline Válidos & $\begin{array}{l}\text { concordo } \\
\text { totalmente } \\
\text { concordo } \\
\text { parcialmente } \\
\text { Total }\end{array}$ & 32 & 80,0 & 80,0 & 80,0 \\
& 15 & $\begin{array}{l}20,0 \\
100,0\end{array}$ & $\begin{array}{l}20,0 \\
100,0\end{array}$ & 100,0 \\
\hline
\end{tabular}

Output SPSS - Cuestión 7.I PROFESORES

Creo que es esencial fomentar el espíritu emprendedor entre los estudiantes y profesores del Curso.

\begin{tabular}{|ll|l|l|l|l|}
\hline & & Frecuencia & Porcentaje & $\begin{array}{l}\text { Porcentaje } \\
\text { válido }\end{array}$ & $\begin{array}{l}\text { Porcentaje } \\
\text { acumulado }\end{array}$ \\
\hline Válidos & $\begin{array}{l}\text { concordo } \\
\text { totalmente } \\
\text { concordo } \\
\text { parcialmente } \\
\text { Total }\end{array}$ & 12 & 80,0 & 80,0 & 80,0 \\
& 15 & $\begin{array}{l}20,0 \\
100,0\end{array}$ & $\begin{array}{l}20,0 \\
100,0\end{array}$ & 100,0 \\
\hline
\end{tabular}

Output SPSS - Cuestión 7.m PROFESORES

Creo que es esencial la existencia de proyectos desarrollados en cooperación con el sector privado.

\begin{tabular}{|ll|l|l|l|l|}
\hline & & Frecuencia & Porcentaje & $\begin{array}{l}\text { Porcentaje } \\
\text { válido }\end{array}$ & $\begin{array}{l}\text { Porcentaje } \\
\text { acumulado }\end{array}$ \\
\hline Válidos & $\begin{array}{l}\text { Concordo } \\
\text { totalmente } \\
\text { concordo } \\
\text { parcialmente } \\
\text { Total }\end{array}$ & 14 & 93,3 & 93,3 & 93,3 \\
& 15 & $\begin{array}{l}6,7 \\
100,0\end{array}$ & $\begin{array}{l}6,7 \\
100,0\end{array}$ & 100,0 \\
& \multicolumn{3}{|l}{} \\
\hline
\end{tabular}


Resultados de la Cuestión 10 de la encuesta (Acciones Inovativas)

Output SPSS - Cuestión 10.a PROFESORES

\begin{tabular}{|ll|l|l|l|l|}
\hline & Frecuencia & Porcentaje & $\begin{array}{l}\text { Porcentaje } \\
\text { válido }\end{array}$ & $\begin{array}{l}\text { Porcentaje } \\
\text { acumulado }\end{array}$ \\
\hline Válidos & $\begin{array}{l}1^{\circ} \text { mais } \\
\text { importante }\end{array}$ & 7 & 46,7 & 46,7 & 46,7 \\
& $\begin{array}{l}2^{\circ} \text { mais } \\
\text { importante } \\
\begin{array}{l}4^{\circ} \text { mais } \\
\text { importante }\end{array}\end{array}$ & 1 & 20,0 & 20,0 & 66,7 \\
& $\begin{array}{l}\text { Não foi } \\
\text { citada }\end{array}$ & 4 & 6,7 & 6,7 & 73,3 \\
Total & 15 & 100,0 & 100,0 & 100,0 \\
\hline
\end{tabular}

Output SPSS - Cuestión 10.b PROFESORES

\begin{tabular}{|ll|l|l|l|l|}
\hline & Frecuencia & Porcentaje & $\begin{array}{l}\text { Porcentaje } \\
\text { válido }\end{array}$ & $\begin{array}{l}\text { Porcentaje } \\
\text { acumulado }\end{array}$ \\
\hline Válidos & $\begin{array}{l}1^{\circ} \text { mais } \\
\text { importante } \\
2^{\circ} \text { mais } \\
\text { importante } \\
3^{\circ} \text { mais } \\
\text { importante } \\
4^{\circ} \text { mais } \\
\text { importante } \\
\text { Não foi } \\
\text { citada } \\
\text { Total }\end{array}$ & 2 & 26,7 & 26,7 & 26,7 \\
& 1 & 33,3 & 33,3 & 60,0 \\
& 15 & 13,3 & 13,3 & 93,3 \\
\end{tabular}

Output SPSS - Cuestión 10.c PROFESORES

\begin{tabular}{|ll|l|l|l|l|}
\hline & & Frecuencia & Porcentaje & $\begin{array}{l}\text { Porcentaje } \\
\text { válido }\end{array}$ & $\begin{array}{l}\text { Porcentaje } \\
\text { acumulado }\end{array}$ \\
\hline Válidos & $\begin{array}{l}3^{\circ} \text { mais } \\
\text { importante } \\
\begin{array}{l}4^{\circ} \text { mais } \\
\text { importante }\end{array}\end{array}$ & 1 & 6,7 & 6,7 & 6,7 \\
& $\begin{array}{l}\text { Não foi } \\
\text { citada } \\
\text { Total }\end{array}$ & 13 & 6,7 & 6,7 & 13,3 \\
& 15 & 100,0 & 100,0 & 100,0 \\
\hline
\end{tabular}


Output SPSS - Cuestión 10.d PROFESORES -

\begin{tabular}{|ll|l|l|l|l|}
\hline & $\begin{array}{l}\text { Frecuenci } \\
\mathrm{a}\end{array}$ & $\begin{array}{l}\text { Porcenta } \\
\text { je }\end{array}$ & $\begin{array}{l}\text { Porcentaje } \\
\text { válido }\end{array}$ & $\begin{array}{l}\text { Porcentaje } \\
\text { acumulado }\end{array}$ \\
\hline Válidos & $\begin{array}{l}1^{\circ} \text { mais } \\
\text { importante } \\
3^{\circ} \text { mais } \\
\text { importante }\end{array}$ & 1 & 6,7 & 6,7 & 6,7 \\
& 2 & 13,3 & 13,3 & 20,0 \\
$\begin{array}{l}4^{\circ} \text { mais } \\
\text { importante }\end{array}$ & 1 & 6,7 & 6,7 & 26,7 \\
$\begin{array}{l}\text { Não foi } \\
\text { citada }\end{array}$ & 11 & 73,3 & 73,3 & 100,0 \\
Total & 15 & 100,0 & 100,0 & \\
\hline
\end{tabular}

Output SPSS - Cuestión 10.e PROFESORES -

\begin{tabular}{|ll|l|l|l|l|}
\hline & $\begin{array}{l}\text { Frecuenci } \\
\mathrm{a}\end{array}$ & $\begin{array}{l}\text { Porcenta } \\
\text { je }\end{array}$ & $\begin{array}{l}\text { Porcentaje } \\
\text { válido }\end{array}$ & $\begin{array}{l}\text { Porcentaje } \\
\text { acumulado }\end{array}$ \\
\hline Válidos & $\begin{array}{l}2^{\circ} \text { mais } \\
\text { importante } \\
3^{\circ} \text { mais } \\
\text { importante } \\
4^{\circ} \text { mais } \\
\text { importante }\end{array}$ & 1 & 13,3 & 13,3 & 13,3 \\
& 1 & 6,7 & 6,7 & 20,0 \\
Não foi \\
citada \\
Total
\end{tabular}

Output SPSS - Cuestión 10.f PROFESORES -

\begin{tabular}{|ll|l|l|l|l|}
\hline & $\begin{array}{l}\text { Frecuenci } \\
\mathrm{a}\end{array}$ & $\begin{array}{l}\text { Porcenta } \\
\text { je }\end{array}$ & $\begin{array}{l}\text { Porcentaje } \\
\text { válido }\end{array}$ & $\begin{array}{l}\text { Porcentaje } \\
\text { acumulado }\end{array}$ \\
\hline Válidos & $\begin{array}{l}4^{\circ} \text { mais } \\
\text { importante }\end{array}$ & 1 & 6,7 & 6,7 & 6,7 \\
$\begin{array}{c}\text { Não foi } \\
\text { citada } \\
\text { Total }\end{array}$ & 14 & 93,3 & 93,3 & 100,0 \\
& 15 & 100,0 & 100,0 & \\
\hline
\end{tabular}

Output SPSS - Cuestión 10.g PROFESORES -

\begin{tabular}{|ll|l|l|l|l|}
\hline & $\begin{array}{l}\text { Frecuenci } \\
\text { a }\end{array}$ & $\begin{array}{l}\text { Porcentaj } \\
\text { e }\end{array}$ & $\begin{array}{l}\text { Porcentaje } \\
\text { válido }\end{array}$ & $\begin{array}{l}\text { Porcentaje } \\
\text { acumulado }\end{array}$ \\
\hline Válidos & $\begin{array}{l}\text { Não foi } \\
\text { citada }\end{array}$ & 15 & 100,0 & 100,0 & 100,0 \\
\hline
\end{tabular}

Output SPSS - Cuestión 10.h PROFESORES -

\begin{tabular}{|ll|l|l|l|l|}
\hline & $\begin{array}{l}\text { Frecuenci } \\
\mathrm{a}\end{array}$ & $\begin{array}{l}\text { Porcenta } \\
\text { je }\end{array}$ & $\begin{array}{l}\text { Porcentaje } \\
\text { válido }\end{array}$ & $\begin{array}{l}\text { Porcentaje } \\
\text { acumulado }\end{array}$ \\
\hline Válidos & $\begin{array}{l}3^{\circ} \text { mais } \\
\text { importante } \\
\text { Não foi } \\
\text { citada } \\
\text { Total }\end{array}$ & 1 & 6,7 & 6,7 & 6,7 \\
& 15 & 93,3 & 93,3 & 100,0 \\
& \multicolumn{3}{|c|}{100,0} & 100,0 & \\
\hline
\end{tabular}


Output SPSS - Cuestión 10.i PROFESORES -

\begin{tabular}{|ll|l|l|l|l|}
\hline & $\begin{array}{l}\text { Frecuenci } \\
\text { a }\end{array}$ & $\begin{array}{l}\text { Porcenta } \\
\text { je }\end{array}$ & $\begin{array}{l}\text { Porcentaje } \\
\text { válido }\end{array}$ & $\begin{array}{l}\text { Porcentaje } \\
\text { acumulado }\end{array}$ \\
\hline Válidos & $\begin{array}{l}2^{\circ} \text { mais } \\
\text { importante }\end{array}$ & 3 & 20,0 & 20,0 & 20,0 \\
& $\begin{array}{l}3^{\circ} \text { mais } \\
\text { importante }\end{array}$ & 4 & 26,7 & 26,7 & 46,7 \\
& $\begin{array}{l}\text { Não foi } \\
\text { citada } \\
\text { Total }\end{array}$ & 8 & 53,3 & 53,3 & 100,0 \\
& 15 & 100,0 & 100,0 & \\
\hline
\end{tabular}

Output SPSS - Cuestión 10.j PROFESORES -

\begin{tabular}{|ll|l|l|l|l|}
\hline & $\begin{array}{l}\text { Frecuenci } \\
\mathrm{a}\end{array}$ & $\begin{array}{l}\text { Porcenta } \\
\text { je }\end{array}$ & $\begin{array}{l}\text { Porcentaje } \\
\text { válido }\end{array}$ & $\begin{array}{l}\text { Porcentaje } \\
\text { acumulado }\end{array}$ \\
\hline Válidos & $\begin{array}{l}3^{\circ} \text { mais } \\
\text { importante } \\
4^{\circ} \text { mais } \\
\text { importante }\end{array}$ & 1 & 6,7 & 6,7 & 6,7 \\
& 3 & 20,0 & 20,0 & 26,7 \\
$\begin{array}{l}\text { Não foi } \\
\text { citada }\end{array}$ & 11 & 73,3 & 73,3 & 100,0 \\
Total & 15 & 100,0 & 100,0 & \\
\hline
\end{tabular}

Output SPSS - Cuestión 10.I PROFESORES -

\begin{tabular}{|ll|l|l|l|l|}
\hline & $\begin{array}{l}\text { Frecuenci } \\
\mathrm{a}\end{array}$ & $\begin{array}{l}\text { Porcentaj } \\
\mathrm{e}\end{array}$ & $\begin{array}{l}\text { Porcentaje } \\
\text { válido }\end{array}$ & $\begin{array}{l}\text { Porcentaje } \\
\text { acumulado }\end{array}$ \\
\hline Válidos & $\begin{array}{l}1^{\circ} \text { mais } \\
\text { importante }\end{array}$ & 3 & 20,0 & 20,0 & 20,0 \\
& $\begin{array}{l}2^{\circ} \text { mais } \\
\text { importante } \\
3^{\circ} \text { mais } \\
\text { importante } \\
4^{\circ} \text { mais } \\
\text { importante } \\
\text { Não foi } \\
\text { citada }\end{array}$ & 2 & 13,3 & 13,3 & 33,3 \\
Total & 3 & 13,3 & 13,3 & 46,7 \\
& 15 & 33,3 & 33,3 & 80,0 \\
\end{tabular}


Resultados de la Cuestión 11 de la encuesta (Calidad de un curso de grado) - PROFESORES

Output SPSS Cuestión 11.a PROFESORES

Estructura del Currículo / Contenido de las asignaturas

\begin{tabular}{|c|c|c|c|c|c|}
\hline & & Frecuencia & Porcentaje & $\begin{array}{l}\text { Porcentaje } \\
\text { válido }\end{array}$ & $\begin{array}{l}\text { Porcentaje } \\
\text { acumulado }\end{array}$ \\
\hline Válidos & $\begin{array}{l}1^{\circ} \text { mais } \\
\text { importante } \\
2^{\circ} \text { mais } \\
\text { importante } \\
3^{\circ} \text { mais } \\
\text { importante } \\
5^{\circ} \text { mais } \\
\text { importante } \\
7^{\circ} \text { mais } \\
\text { importante } \\
\text { Total }\end{array}$ & $\begin{array}{l}10 \\
1 \\
1 \\
1 \\
2 \\
15\end{array}$ & $\begin{array}{l}66,7 \\
6,7 \\
6,7 \\
6,7 \\
13,3 \\
100,0\end{array}$ & $\begin{array}{l}66,7 \\
6,7 \\
6,7 \\
6,7 \\
13,3 \\
100,0\end{array}$ & $\begin{array}{l}66,7 \\
73,3 \\
80,0 \\
86,7 \\
100,0\end{array}$ \\
\hline
\end{tabular}

Output SPSS Cuestión 11.b PROFESORES

Didáctica de los profesores

\begin{tabular}{|ll|l|l|l|l|}
\hline & Frecuencia & Porcentaje & $\begin{array}{l}\text { Porcentaje } \\
\text { válido }\end{array}$ & $\begin{array}{l}\text { Porcentaje } \\
\text { acumulado }\end{array}$ \\
\hline Válidos & $\begin{array}{l}1^{\circ} \text { mais } \\
\text { importante }\end{array}$ & 1 & 6,7 & 6,7 & 6,7 \\
& $\begin{array}{l}2^{\circ} \text { mais } \\
\text { importante } \\
3^{\circ} \text { mais } \\
\text { importante }\end{array}$ & 6 & 20,0 & 20,0 & 26,7 \\
$\begin{array}{l}4^{\circ} \text { mais } \\
\text { importante } \\
6^{\circ} \text { mais } \\
\text { importante } \\
7^{\circ} \text { mais } \\
\text { importante }\end{array}$ & 1 & 40,0 & 40,0 & 66,7 \\
Total & 15 & 20,0 & 20,0 & 86,7 \\
& 15 & 6,7 & 6,7 & 93,3 \\
\end{tabular}




\section{Output SPSS Cuestión 11.c PROFESORES}

Puntualidad y asiduidad de los profesores

\begin{tabular}{|c|c|c|c|c|c|}
\hline & & Frecuencia & Porcentaje & $\begin{array}{l}\text { Porcentaje } \\
\text { válido }\end{array}$ & $\begin{array}{l}\text { Porcentaje } \\
\text { acumulado }\end{array}$ \\
\hline Válidos & $\begin{array}{l}3^{\circ} \text { mais } \\
\text { importante } \\
4^{\circ} \text { mais } \\
\text { importante } \\
5^{\circ} \text { mais } \\
\text { importante } \\
6^{\circ} \text { mais } \\
\text { importante } \\
7^{\circ} \text { mais } \\
\text { importante } \\
8^{\circ} \text { mais } \\
\text { importante } \\
9^{\circ} \text { mais } \\
\text { importante } \\
10^{\circ} \text { mais } \\
\text { importante } \\
\text { Total }\end{array}$ & $\begin{array}{l}1 \\
4 \\
3 \\
2 \\
2 \\
1 \\
1 \\
1 \\
15\end{array}$ & $\begin{array}{l}6,7 \\
26,7 \\
20,0 \\
13,3 \\
13,3 \\
6,7 \\
6,7 \\
6,7 \\
100,0\end{array}$ & $\begin{array}{l}6,7 \\
26,7 \\
20,0 \\
13,3 \\
13,3 \\
6,7 \\
6,7 \\
6,7 \\
100,0\end{array}$ & $\begin{array}{l}6,7 \\
33,3 \\
53,3 \\
66,7 \\
80,0 \\
86,7 \\
93,3 \\
100,0\end{array}$ \\
\hline
\end{tabular}

Output SPSS Cuestión 11.d PROFESORES

Titulación de los profesores

\begin{tabular}{|c|c|c|c|c|c|}
\hline & & Frecuencia & Porcentaje & $\begin{array}{l}\text { Porcentaje } \\
\text { válido }\end{array}$ & $\begin{array}{l}\text { Porcentaje } \\
\text { acumulado }\end{array}$ \\
\hline Válidos & $\begin{array}{l}1^{\circ} \text { mais } \\
\text { importante } \\
2^{\circ} \text { mais } \\
\text { importante } \\
5^{\circ} \text { mais } \\
\text { importante } \\
6^{\circ} \text { mais } \\
\text { importante } \\
7^{\circ} \text { mais } \\
\text { importante } \\
8^{\circ} \text { mais } \\
\text { importante } \\
9^{\circ} \text { mais } \\
\text { importante } \\
\text { Total }\end{array}$ & $\begin{array}{l}1 \\
3 \\
3 \\
4 \\
1 \\
2 \\
1 \\
15\end{array}$ & $\begin{array}{l}6,7 \\
20,0 \\
20,0 \\
26,7 \\
6,7 \\
13,3 \\
6,7 \\
100,0\end{array}$ & $\begin{array}{l}6,7 \\
20,0 \\
20,0 \\
26,7 \\
6,7 \\
13,3 \\
6,7 \\
100,0\end{array}$ & $\begin{array}{l}6,7 \\
26,7 \\
46,7 \\
73,3 \\
80,0 \\
93,3 \\
100,0\end{array}$ \\
\hline
\end{tabular}


Output SPSS Cuestión 11.e PROFESORES

Envolvimiento de los profesores con el curso

\begin{tabular}{|ll|l|l|l|l|}
\hline & Frecuencia & Porcentaje & $\begin{array}{l}\text { Porcentaje } \\
\text { válido }\end{array}$ & $\begin{array}{l}\text { Porcentaje } \\
\text { acumulado }\end{array}$ \\
\hline Válidos & $\begin{array}{l}1^{\circ} \text { mais } \\
\text { importante } \\
2^{\circ} \text { mais } \\
\text { importante }\end{array}$ & 5 & 20,0 & 20,0 & 20,0 \\
& $\begin{array}{l}3^{\circ} \text { mais } \\
\text { importante } \\
4^{\circ} \text { mais } \\
\text { importante }\end{array}$ & 5 & 33,3 & 33,3 & 53,3 \\
& 1 & 33,3 & 33,3 & 86,7 \\
& 1 & 6,7 & 6,7 & 93,3 \\
& importante & 1 & 6,7 & 6,7 & 100,0 \\
Total & 15 & 100,0 & 100,0 & \\
\hline
\end{tabular}

Output SPSS Cuestión 11.f PROFESORES

Conforto e adecuación de las aulas

\begin{tabular}{|ll|l|l|l|l|}
\hline & Frecuencia & Porcentaje & $\begin{array}{l}\text { Porcentaje } \\
\text { válido }\end{array}$ & $\begin{array}{l}\text { Porcentaje } \\
\text { acumulado }\end{array}$ \\
\hline Válidos & $\begin{array}{l}3^{\circ} \text { mais } \\
\text { importante } \\
\begin{array}{l}4^{\circ} \text { mais } \\
\text { importante }\end{array}\end{array}$ & 1 & 6,7 & 6,7 & 6,7 \\
& $\begin{array}{l}5^{\circ} \text { mais } \\
\text { importante }\end{array}$ & 2 & 6,7 & 6,7 & 13,3 \\
$\begin{array}{l}6^{\circ} \text { mais } \\
\text { importante }\end{array}$ & 1 & 13,3 & 13,3 & 26,7 \\
$\begin{array}{l}7^{\circ} \text { mais } \\
\text { importante }\end{array}$ & 5 & 6,7 & 6,7 & 33,3 \\
$\begin{array}{l}8^{\circ} \text { mais } \\
\text { importante } \\
\text { 9० mais } \\
\text { importante }\end{array}$ & 2 & 33,3 & 33,3 & 66,7 \\
$\begin{array}{l}\text { 10 mais } \\
\text { importante }\end{array}$ & 2 & 13,3 & 13,3 & 80,0 \\
Total & 15 & 6,7 & 6,7 & 86,7 \\
\hline
\end{tabular}


Output SPSS Cuestión 11.g PROFESORES

Calidad de los laboratorios y espacios específicos

\begin{tabular}{|c|c|c|c|c|c|}
\hline & & Frecuencia & Porcentaje & $\begin{array}{l}\text { Porcentaje } \\
\text { válido }\end{array}$ & $\begin{array}{l}\text { Porcentaje } \\
\text { acumulado }\end{array}$ \\
\hline Válidos & $\begin{array}{l}2^{\circ} \text { mais } \\
\text { importante } \\
3^{\circ} \text { mais } \\
\text { importante } \\
4^{\circ} \text { mais } \\
\text { importante } \\
6^{\circ} \text { mais } \\
\text { importante } \\
9^{\circ} \text { mais } \\
\text { importante } \\
10^{\circ} \text { mais } \\
\text { importante } \\
\text { Total }\end{array}$ & $\begin{array}{l}3 \\
2 \\
3 \\
1 \\
5 \\
1 \\
15\end{array}$ & $\begin{array}{l}20,0 \\
13,3 \\
20,0 \\
6,7 \\
33,3 \\
6,7 \\
100,0\end{array}$ & $\begin{array}{l}20,0 \\
13,3 \\
20,0 \\
6,7 \\
33,3 \\
6,7 \\
100,0\end{array}$ & $\begin{array}{l}20,0 \\
33,3 \\
53,3 \\
60,0 \\
93,3 \\
100,0\end{array}$ \\
\hline
\end{tabular}

Output SPSS Cuestión 11.h PROFESORES

Apoyo de personal técnico

\begin{tabular}{|c|c|c|c|c|c|}
\hline & & Frecuencia & Porcentaje & $\begin{array}{l}\text { Porcentaje } \\
\text { válido }\end{array}$ & $\begin{array}{l}\text { Porcentaje } \\
\text { acumulado }\end{array}$ \\
\hline Válidos & $\begin{array}{l}3^{\circ} \text { mais } \\
\text { importante } \\
4^{\circ} \text { mais } \\
\text { importante } \\
5^{\circ} \text { mais } \\
\text { importante } \\
6^{\circ} \text { mais } \\
\text { importante } \\
7^{\circ} \text { mais } \\
\text { importante } \\
9^{\circ} \text { mais } \\
\text { importante } \\
10^{\circ} \text { mais } \\
\text { importante } \\
\text { Total }\end{array}$ & $\begin{array}{l}1 \\
2 \\
5 \\
1 \\
2 \\
2 \\
2 \\
15\end{array}$ & $\begin{array}{l}6,7 \\
13,3 \\
33,3 \\
6,7 \\
13,3 \\
13,3 \\
13,3 \\
100,0\end{array}$ & $\begin{array}{l}6,7 \\
13,3 \\
33,3 \\
6,7 \\
13,3 \\
13,3 \\
13,3 \\
100,0\end{array}$ & $\begin{array}{l}6,7 \\
20,0 \\
53,3 \\
60,0 \\
73,3 \\
86,7 \\
100,0\end{array}$ \\
\hline
\end{tabular}


Output SPSS Cuestión 11.i PROFESORES Apoio da Coordenação de curso

\begin{tabular}{|c|c|c|c|c|c|}
\hline & & Frecuencia & Porcentaje & $\begin{array}{l}\text { Porcentaje } \\
\text { válido }\end{array}$ & $\begin{array}{l}\text { Porcentaje } \\
\text { acumulado }\end{array}$ \\
\hline Válidos & $\begin{array}{l}4^{\circ} \text { mais } \\
\text { importante } \\
5^{\circ} \text { mais } \\
\text { importante } \\
6^{\circ} \text { mais } \\
\text { importante } \\
7^{\circ} \text { mais } \\
\text { importante } \\
8^{\circ} \text { mais } \\
\text { importante } \\
9^{\circ} \text { mais } \\
\text { importante } \\
10^{\circ} \text { mais } \\
\text { importante } \\
\text { Total }\end{array}$ & $\begin{array}{l}1 \\
1 \\
1 \\
2 \\
8 \\
1 \\
1 \\
15\end{array}$ & $\begin{array}{l}6,7 \\
6,7 \\
6,7 \\
13,3 \\
53,3 \\
6,7 \\
6,7 \\
100,0\end{array}$ & $\begin{array}{l}6,7 \\
6,7 \\
6,7 \\
13,3 \\
53,3 \\
6,7 \\
6,7 \\
100,0\end{array}$ & $\begin{array}{l}6,7 \\
13,3 \\
20,0 \\
33,3 \\
86,7 \\
93,3 \\
100,0\end{array}$ \\
\hline
\end{tabular}

Output SPSS Cuestión 11.j PROFESORES

Apoyo de la Coordinación del Curso

\begin{tabular}{|c|c|c|c|c|c|}
\hline & & Frecuencia & Porcentaje & $\begin{array}{l}\text { Porcentaje } \\
\text { válido }\end{array}$ & $\begin{array}{l}\text { Porcentaje } \\
\text { acumulado }\end{array}$ \\
\hline Válidos & $\begin{array}{l}6^{\circ} \text { mais } \\
\text { importante } \\
7^{\circ} \text { mais } \\
\text { importante } \\
8^{\circ} \text { mais } \\
\text { importante } \\
9^{\circ} \text { mais } \\
\text { importante } \\
10^{\circ} \text { mais } \\
\text { importante } \\
\text { Total }\end{array}$ & $\begin{array}{l}1 \\
1 \\
2 \\
4 \\
7 \\
15\end{array}$ & $\begin{array}{l}6,7 \\
6,7 \\
13,3 \\
26,7 \\
46,7 \\
100,0\end{array}$ & $\begin{array}{l}6,7 \\
6,7 \\
13,3 \\
26,7 \\
46,7 \\
100,0\end{array}$ & $\begin{array}{l}6,7 \\
13,3 \\
26,7 \\
53,3 \\
100,0\end{array}$ \\
\hline
\end{tabular}


Resultados del instrumento de evaluación del escenario de la innovación en el curso - ALUMNOS

Resultados de la Cuestión 07 de la encuesta (Grado de Concordancia) ALUMNOS

Output SPSS Cuestión 7.a ALUMNOS

Estoy familiarizado con el concepto de innovación.

\begin{tabular}{|ll|l|l|l|l|}
\hline & Frecuencia & Porcentaje & $\begin{array}{l}\text { Porcentaje } \\
\text { válido }\end{array}$ & $\begin{array}{l}\text { Porcentaje } \\
\text { acumulado }\end{array}$ \\
\hline Válidos & $\begin{array}{l}\text { concordo } \\
\text { totalmente }\end{array}$ & 33 & 38,4 & 38,4 & 38,4 \\
& $\begin{array}{l}\text { concordo } \\
\text { parcialmente } \\
\text { discordo }\end{array}$ & 49 & 57,0 & 57,0 & 95,3 \\
& 2 & 2,3 & 2,3 & 97,7 \\
parcialmente \\
discordo \\
totalmente \\
Total
\end{tabular}

Output SPSS Cuestión 7.b ALUMNOS

Estoy familiarizado con el concepto Emprendedor.

\begin{tabular}{|ll|l|l|l|l|}
\hline & Frecuencia & Porcentaje & $\begin{array}{l}\text { Porcentaje } \\
\text { válido }\end{array}$ & $\begin{array}{l}\text { Porcentaje } \\
\text { acumulado }\end{array}$ \\
\hline Válidos & 25 & 29,1 & 29,1 & 29,1 \\
& $\begin{array}{l}\text { concordo } \\
\text { totalmente } \\
\text { concordo } \\
\text { parcialmente } \\
\text { discordo } \\
\text { parcialmente } \\
\text { discordo } \\
\text { totalmente }\end{array}$ & 26 & 34,9 & 34,9 & 64,0 \\
& 5 & 30,2 & 30,2 & 94,2 \\
& 86 & 5,8 & 5,8 & 100,0 \\
& Total & 100,0 & 100,0 & \\
\hline
\end{tabular}

Output SPSS Cuestión 7.c ALUMNOS

Estoy familiarizado con el concepto de transferencia de tecnología.

\begin{tabular}{|ll|l|l|l|l|}
\hline & Frecuencia & Porcentaje & $\begin{array}{l}\text { Porcentaje } \\
\text { válido }\end{array}$ & $\begin{array}{l}\text { Porcentaje } \\
\text { acumulado }\end{array}$ \\
\hline Válidos & 9 & 10,5 & 10,5 & 10,5 \\
& $\begin{array}{l}\text { concordo } \\
\text { totalmente } \\
\text { concordo } \\
\text { parcialmente } \\
\text { discordo } \\
\text { parcialmente } \\
\text { discordo } \\
\text { totalmente }\end{array}$ & 31 & 36,0 & 36,0 & 46,5 \\
& 13 & 38,4 & 38,4 & 84,9 \\
& 86 & 15,1 & 15,1 & 100,0 \\
& Total & 100,0 & 100,0 & \\
\hline
\end{tabular}


Output SPSS Cuestión 7.d ALUMNOS

Estoy familiarizado con las reglas y otros procedimientos relacionados con la Protección de la Propiedad Intelectual/Industrial.

\begin{tabular}{|ll|l|l|l|l|}
\hline & & Frecuencia & Porcentaje & $\begin{array}{l}\text { Porcentaje } \\
\text { válido }\end{array}$ & $\begin{array}{l}\text { Porcentaje } \\
\text { acumulado }\end{array}$ \\
\hline Válidos & $\begin{array}{l}\text { concordo } \\
\text { totalmente } \\
\text { concordo } \\
\text { parcialmente } \\
\text { discordo } \\
\text { parcialmente } \\
\text { discordo } \\
\text { totalmente }\end{array}$ & 32 & 9,3 & 9,3 & 9,3 \\
& 26 & 37,2 & 37,2 & 46,5 \\
& 86,2 & 30,2 & 76,7 \\
& Total & 23,3 & 23,3 & 100,0 \\
& 86 & 100,0 & 100,0 & \\
\hline
\end{tabular}

Output SPSS Cuestión 7.e ALUMNOS

Conozco los objetivos del curso en relación a la innovación.

\begin{tabular}{|ll|l|l|l|l|}
\hline & Frecuencia & Porcentaje & $\begin{array}{l}\text { Porcentaje } \\
\text { válido }\end{array}$ & $\begin{array}{l}\text { Porcentaje } \\
\text { acumulado }\end{array}$ \\
\hline Válidos & $\begin{array}{l}\text { concordo } \\
\text { totalmente } \\
\text { concordo } \\
\text { parcialmente } \\
\text { discordo } \\
\text { parcialmente } \\
\text { discordo }\end{array}$ & 14 & 31,4 & 31,4 & 31,4 \\
& 1 & 51,2 & 51,2 & 82,6 \\
& 14 & 16,3 & 16,3 & 98,8 \\
& totalmente & 1,2 & 1,2 & 100,0 \\
& 86 & 100,0 & 100,0 & \\
\hline
\end{tabular}

\section{Output SPSS Cuestión 7.f ALUMNOS}

Conozco la investigación y los proyectos que se desarrollan en el curso.

\begin{tabular}{|c|c|c|c|c|c|}
\hline & & Frecuencia & Porcentaje & $\begin{array}{l}\text { Porcentaje } \\
\text { válido }\end{array}$ & $\begin{array}{l}\text { Porcentaje } \\
\text { acumulado }\end{array}$ \\
\hline Válidos & $\begin{array}{l}\text { concordo } \\
\text { totalmente } \\
\text { concordo } \\
\text { parcialmente } \\
\text { discordo } \\
\text { parcialmente } \\
\text { discordo } \\
\text { totalmente } \\
\text { Total }\end{array}$ & $\begin{array}{l}9 \\
53 \\
20 \\
4 \\
86\end{array}$ & $\begin{array}{l}10,5 \\
61,6 \\
23,3 \\
4,7 \\
100,0\end{array}$ & $\begin{array}{l}10,5 \\
61,6 \\
23,3 \\
4,7 \\
100,0\end{array}$ & $\begin{array}{l}10,5 \\
72,1 \\
95,3 \\
100,0\end{array}$ \\
\hline
\end{tabular}


Output SPSS Cuestión 7.g ALUMNOS

El curso fomenta la práctica de la innovación entre los alumnos y los profesores.

\begin{tabular}{|ll|l|l|l|l|}
\hline & Frecuencia & Porcentaje & $\begin{array}{l}\text { Porcentaje } \\
\text { válido }\end{array}$ & $\begin{array}{l}\text { Porcentaje } \\
\text { acumulado }\end{array}$ \\
\hline Válidos & $\begin{array}{l}\text { concordo } \\
\text { totalmente } \\
\text { concordo } \\
\text { parcialmente } \\
\text { discordo }\end{array}$ & 22 & 25,6 & 25,6 & 25,6 \\
& 15 & 55,8 & 55,8 & 81,4 \\
& $\begin{array}{l}\text { parcialmente } \\
\text { discordo } \\
\text { totalmente }\end{array}$ & 1 & 17,4 & 17,4 & 98,8 \\
& 86 & 1,2 & 1,2 & 100,0 \\
& Total & 100,0 & 100,0 & \\
\hline
\end{tabular}

\section{Output SPSS Cuestión 7.h ALUMNOS}

La infraestructura de laboratorios disponible en el Curso es suficiente para estimular el desarrollo de nuevos productos y procesos.

\begin{tabular}{|c|c|c|c|c|c|}
\hline & & Frecuencia & Porcentaje & $\begin{array}{l}\text { Porcentaje } \\
\text { válido }\end{array}$ & $\begin{array}{l}\text { Porcentaje } \\
\text { acumulado }\end{array}$ \\
\hline Válidos & $\begin{array}{l}\text { concordo } \\
\text { totalmente } \\
\text { concordo } \\
\text { parcialmente } \\
\text { discordo } \\
\text { parcialmente } \\
\text { discordo } \\
\text { totalmente } \\
\text { Total }\end{array}$ & $\begin{array}{l}6 \\
29 \\
35 \\
16 \\
86\end{array}$ & $\begin{array}{l}7,0 \\
33,7 \\
40,7 \\
18,6 \\
100,0\end{array}$ & $\begin{array}{l}7,0 \\
33,7 \\
40,7 \\
18,6 \\
100,0\end{array}$ & $\begin{array}{l}7,0 \\
40,7 \\
81,4 \\
100,0\end{array}$ \\
\hline
\end{tabular}

Output SPSS Cuestión 7.i ALUMNOS

Tengo acceso fácil a la producción de conocimientos generados en el curso (monografías, artículos publicados, los resultados de los proyectos, etc.)

\begin{tabular}{|ll|l|l|l|l|}
\hline & & & $\begin{array}{l}\text { Porcentaje } \\
\text { válido }\end{array}$ & $\begin{array}{l}\text { Porcentaje } \\
\text { acumulado }\end{array}$ \\
\hline Válidos & $\begin{array}{l}\text { concordo } \\
\text { totalmente } \\
\text { concordo }\end{array}$ & 11 & 12,8 & 12,8 & 12,8 \\
$\begin{array}{l}\text { parcialmente } \\
\text { discordo } \\
\text { parcialmente } \\
\text { discordo } \\
\text { totalmente }\end{array}$ & 33 & 38,4 & 38,4 & 51,2 \\
& 5 & 43,0 & 43,0 & 94,2 \\
& 86 & 5,8 & 5,8 & 100,0 \\
& Total & 100,0 & 100,0 & \\
\hline
\end{tabular}


Output SPSS Cuestión 7.j ALUMNOS

Creo que el acceso a la información y la formación dirigida a la protección de la propiedad intelectual es esencial.

\begin{tabular}{|ll|l|l|l|l|}
\hline & Frecuencia & Porcentaje & $\begin{array}{l}\text { Porcentaje } \\
\text { válido }\end{array}$ & $\begin{array}{l}\text { Porcentaje } \\
\text { acumulado }\end{array}$ \\
\hline Válidos & $\begin{array}{l}\text { concordo } \\
\text { totalmente } \\
\text { concordo }\end{array}$ & 62 & 72,1 & 72,1 & 72,1 \\
& $\begin{array}{l}\text { parcialmente } \\
\text { discordo }\end{array}$ & 22 & 25,6 & 25,6 & 97,7 \\
& 2 & 2,3 & 2,3 & 100,0 \\
& $\begin{array}{l}\text { parcialmente } \\
\text { Total }\end{array}$ & 86 & 100,0 & 100,0 & \\
\hline
\end{tabular}

Output SPSS Cuestión 7.l ALUMNOS

Creo que es esencial fomentar el espíritu emprendedor entre los estudiantes y profesores del Curso.

\begin{tabular}{|ll|l|l|l|l|}
\hline & Frecuencia & Porcentaje & $\begin{array}{l}\text { Porcentaje } \\
\text { válido }\end{array}$ & $\begin{array}{l}\text { Porcentaje } \\
\text { acumulado }\end{array}$ \\
\hline Válidos & $\begin{array}{l}\text { concordo } \\
\text { totalmente } \\
\text { concordo } \\
\text { parcialmente } \\
\text { discordo }\end{array}$ & 69 & 80,2 & 80,2 & 80,2 \\
& 14 & 16,3 & 16,3 & 96,5 \\
parcialmente & 3 & 3,5 & 3,5 & 100,0 \\
& 86 & 100,0 & 100,0 & \\
\hline
\end{tabular}

\section{Output SPSS Cuestión 7.m ALUMNOS}

Creo que es esencial la existencia de proyectos desarrollados en cooperación con el sector privado.

\begin{tabular}{|ll|l|l|l|l|}
\hline & Frecuencia & Porcentaje & $\begin{array}{l}\text { Porcentaje } \\
\text { válido }\end{array}$ & $\begin{array}{l}\text { Porcentaje } \\
\text { acumulado }\end{array}$ \\
\hline Válidos & $\begin{array}{l}\text { concordo } \\
\text { totalmente }\end{array}$ & 50 & 58,1 & 58,1 & 58,1 \\
& $\begin{array}{l}\text { concordo } \\
\text { parcialmente } \\
\text { discordo } \\
\text { parcialmente } \\
\text { Total }\end{array}$ & 60 & 34,9 & 34,9 & 93,0 \\
& 86 & 7,0 & 7,0 & 100,0 \\
\hline
\end{tabular}


Output SPSS Cuestión 7.n ALUMNOS

Creo que es esencial la existencia de proyectos desarrollados en cooperación con otras instituciones de educación e investigación.

\begin{tabular}{|c|c|c|c|c|c|}
\hline & & Frecuencia & Porcentaje & $\begin{array}{l}\text { Porcentaje } \\
\text { válido }\end{array}$ & $\begin{array}{l}\text { Porcentaje } \\
\text { acumulado }\end{array}$ \\
\hline Válidos & $\begin{array}{l}\text { concordo } \\
\text { totalmente } \\
\text { concordo } \\
\text { parcialmente } \\
\text { Total }\end{array}$ & $\begin{array}{l}59 \\
27 \\
86\end{array}$ & $\begin{array}{l}68,6 \\
31,4 \\
100,0\end{array}$ & $\begin{array}{l}68,6 \\
31,4 \\
100,0\end{array}$ & $\begin{array}{l}68,6 \\
100,0\end{array}$ \\
\hline
\end{tabular}

\section{Resultados de la Cuestión 10 de la encuesta (Acciones Inovativas) -}

\section{ALUMNOS}

Output SPSS Cuestión 10.a ALUMNOS

Mejorar el conocimiento de la parte del curso sobre las demandas del sector privado en el área de Design.

\begin{tabular}{|ll|l|l|l|l|}
\hline & $\begin{array}{l}\text { Frecuenci } \\
\text { a }\end{array}$ & $\begin{array}{l}\text { Porcenta } \\
\text { je }\end{array}$ & $\begin{array}{l}\text { Porcentaje } \\
\text { válido }\end{array}$ & $\begin{array}{l}\text { Porcentaje } \\
\text { acumulado }\end{array}$ \\
\hline Válidos & $\begin{array}{l}1^{\circ} \text { mais } \\
\text { importante } \\
2^{\circ} \text { mais } \\
\text { importante } \\
3^{\circ} \text { mais }\end{array}$ & 10 & 50,0 & 50,0 & 50,0 \\
importante & 6 & 11,6 & 11,6 & 61,6 \\
& $\begin{array}{l}4^{\circ} \text { mais } \\
\text { importante } \\
\text { Não foi } \\
\text { citada }\end{array}$ & 4 & 7,0 & 7,0 & 68,6 \\
Total & 86 & 26,7 & 26,7 & 100,0 \\
\end{tabular}

Output SPSS Cuestión 10.b ALUMNOS

Mejorar la infraestructura y laboratorios que puedan apoyar el desarrollo de nuevos procesos y productos.

\begin{tabular}{|c|c|c|c|c|c|}
\hline & & $\begin{array}{l}\text { Frecuenci } \\
\text { a }\end{array}$ & $\begin{array}{l}\text { Porcenta } \\
\text { je }\end{array}$ & $\begin{array}{l}\text { Porcentaje } \\
\text { válido }\end{array}$ & $\begin{array}{l}\text { Porcentaje } \\
\text { acumulado }\end{array}$ \\
\hline Válidos & $\begin{array}{l}1^{\circ} \text { mais } \\
\text { importante } \\
2^{\circ} \text { mais } \\
\text { importante } \\
3^{\circ} \text { mais } \\
\text { importante } \\
4^{\circ} \text { mais } \\
\text { importante } \\
\text { Não foi } \\
\text { citada } \\
\text { Total }\end{array}$ & $\begin{array}{l}26 \\
34 \\
5 \\
4 \\
17 \\
86\end{array}$ & $\begin{array}{l}30,2 \\
39,5 \\
5,8 \\
4,7 \\
19,8 \\
100,0\end{array}$ & $\begin{array}{l}30,2 \\
39,5 \\
5,8 \\
4,7 \\
19,8 \\
100,0\end{array}$ & $\begin{array}{l}30,2 \\
69,8 \\
75,6 \\
80,2 \\
100,0\end{array}$ \\
\hline
\end{tabular}


Output SPSS Cuestión 10.c ALUMNOS

Formación en materia de protección de la propiedad industrial (registro de marcas, patentes, etc)

\begin{tabular}{|ll|l|l|l|l|}
\hline & $\begin{array}{l}\text { Frecuenci } \\
\mathrm{a}\end{array}$ & $\begin{array}{l}\text { Porcentaj } \\
\mathrm{e}\end{array}$ & $\begin{array}{l}\text { Porcentaje } \\
\text { válido }\end{array}$ & $\begin{array}{l}\text { Porcentaje } \\
\text { acumulado }\end{array}$ \\
\hline Válidos & 1 & 1,2 & 1,2 & 1,2 \\
& $\begin{array}{l}1^{\circ} \text { mais } \\
\text { importante } \\
2^{\circ} \text { mais } \\
\text { importante } \\
3^{\circ} \text { mais } \\
\text { importante } \\
4^{\circ} \text { mais } \\
\text { importante } \\
\text { Não foi } \\
\text { citada }\end{array}$ & 10 & 11,6 & 11,6 & 12,8 \\
& 54 & 11,8 & 12,8 & 25,6 \\
Total & 86 & 62,8 & 11,6 & 37,2 \\
& & 100,0 & 100,0 & 100,0 \\
\hline
\end{tabular}

Output SPSS Cuestión 10.d ALUMNOS

Mejorar el acompañamiento de la destinación de los titulados con el fin de establecer una red de cooperación.

\begin{tabular}{|c|c|c|c|c|c|}
\hline & & $\begin{array}{l}\text { Frecuenci } \\
\mathrm{a}\end{array}$ & $\begin{array}{l}\text { Porcentaj } \\
\text { e }\end{array}$ & $\begin{array}{l}\text { Porcentaje } \\
\text { válido }\end{array}$ & $\begin{array}{l}\text { Porcentaje } \\
\text { acumulado }\end{array}$ \\
\hline Válidos & $\begin{array}{l}1^{\circ} \text { mais } \\
\text { importante } \\
2^{\circ} \text { mais } \\
\text { importante } \\
3^{\circ} \text { mais } \\
\text { importante } \\
4^{\circ} \text { mais } \\
\text { importante } \\
\text { Não foi } \\
\text { citada } \\
\text { Total }\end{array}$ & $\begin{array}{l}5 \\
2 \\
10 \\
8 \\
61 \\
86\end{array}$ & $\begin{array}{l}5,8 \\
2,3 \\
11,6 \\
9,3 \\
70,9 \\
100,0\end{array}$ & $\begin{array}{l}5,8 \\
2,3 \\
11,6 \\
9,3 \\
70,9 \\
100,0\end{array}$ & $\begin{array}{l}5,8 \\
8,1 \\
19,8 \\
29,1 \\
100,0\end{array}$ \\
\hline
\end{tabular}

Output SPSS Cuestión 10.e ALUMNOS

Apoyo técnico /de gestión implantación de negocios.

\begin{tabular}{|ll|l|l|l|l|}
\hline & $\begin{array}{l}\text { Frecuenci } \\
\text { a }\end{array}$ & $\begin{array}{l}\text { Porcenta } \\
\text { je }\end{array}$ & $\begin{array}{l}\text { Porcentaje } \\
\text { válido }\end{array}$ & $\begin{array}{l}\text { Porcentaje } \\
\text { acumulado }\end{array}$ \\
\hline Válidos & $\begin{array}{l}2^{\circ} \text { mais } \\
\text { importante }\end{array}$ & 5 & 5,8 & 5,8 & 5,8 \\
& $\begin{array}{l}3^{\circ} \text { mais } \\
\text { importante }\end{array}$ & 4 & 4,7 & 4,7 & 10,5 \\
& $\begin{array}{l}4^{\circ} \text { mais } \\
\text { importante }\end{array}$ & 5 & 5,8 & 5,8 & 16,3 \\
& $\begin{array}{l}\text { Não foi } \\
\text { citada }\end{array}$ & 72 & 83,7 & 83,7 & 100,0 \\
Total & 86 & 100,0 & 100,0 & \\
\hline
\end{tabular}


Output SPSS Cuestión 10.f ALUMNOS

Apoyo a la Transferencia de Tecnología.

\begin{tabular}{|ll|l|l|l|l|}
\hline & $\begin{array}{l}\text { Frecuenci } \\
\text { a }\end{array}$ & $\begin{array}{l}\text { Porcenta } \\
\text { je }\end{array}$ & $\begin{array}{l}\text { Porcentaje } \\
\text { válido }\end{array}$ & $\begin{array}{l}\text { Porcentaje } \\
\text { acumulado }\end{array}$ \\
\hline Válidos & $\begin{array}{l}2^{\circ} \text { mais } \\
\text { importante } \\
\begin{array}{l}3^{\circ} \text { mais } \\
\text { importante }\end{array}\end{array}$ & 2 & 2,3 & 2,3 & 2,3 \\
& 6 & 7,0 & 7,0 & 9,3 \\
& $\begin{array}{l}4^{\circ} \text { mais } \\
\text { importante }\end{array}$ & 5 & 5,8 & 5,8 & 15,1 \\
& $\begin{array}{l}\text { Não foi } \\
\text { citada }\end{array}$ & 73 & 84,9 & 84,9 & 100,0 \\
Total & 86 & 100,0 & 100,0 & \\
\hline
\end{tabular}

Output SPSS Cuestión 10.g ALUMNOS

Mayor cooperación con las incubadoras.

\begin{tabular}{|ll|l|l|l|l|}
\hline & $\begin{array}{l}\text { Frecuenci } \\
\text { a }\end{array}$ & $\begin{array}{l}\text { Porcenta } \\
\text { je }\end{array}$ & $\begin{array}{l}\text { Porcentaje } \\
\text { válido }\end{array}$ & $\begin{array}{l}\text { Porcentaje } \\
\text { acumulado }\end{array}$ \\
\hline Válidos & $\begin{array}{l}1^{\circ} \text { mais } \\
\text { importante }\end{array}$ & 1 & 1,2 & 1,2 & 1,2 \\
& $\begin{array}{l}3^{\circ} \text { mais } \\
\text { importante }\end{array}$ & 7 & 8,1 & 8,1 & 9,3 \\
& $\begin{array}{l}4^{\circ} \text { mais } \\
\text { importante }\end{array}$ & 4 & 4,7 & 4,7 & 14,0 \\
& $\begin{array}{l}\text { Não foi } \\
\text { citada } \\
\text { Total }\end{array}$ & 74 & 86,0 & 86,0 & 100,0 \\
& 86 & 100,0 & 100,0 & \\
\hline
\end{tabular}

Output SPSS Cuestión 10.h ALUMNOS

Foros para reunir los investigadores a las empresas.

\begin{tabular}{|ll|l|l|l|l|}
\hline & $\begin{array}{l}\text { Frecuenci } \\
\mathrm{a}\end{array}$ & $\begin{array}{l}\text { Porcentaj } \\
\mathrm{e}\end{array}$ & $\begin{array}{l}\text { Porcentaje } \\
\text { válido }\end{array}$ & $\begin{array}{l}\text { Porcentaje } \\
\text { acumulado }\end{array}$ \\
\hline Válidos & $\begin{array}{l}2^{\circ} \text { mais } \\
\text { importante } \\
3^{\circ} \text { mais }\end{array}$ & 1 & 1,2 & 1,2 & 1,2 \\
& 2 & 2,3 & 2,3 & 3,5 \\
$\begin{array}{l}\text { importante } \\
4^{\circ} \text { mais } \\
\text { importante }\end{array}$ & 20 & 23,3 & 23,3 & 26,7 \\
$\begin{array}{l}\text { Não foi } \\
\text { citada }\end{array}$ & 63 & 73,3 & 73,3 & 100,0 \\
Total & 86 & 100,0 & 100,0 & \\
\hline
\end{tabular}


Output SPSS Cuestión 10.i ALUMNOS

Construcción, por el curso de la agenda de investigación definida en conjunto con el sector productivo.

\begin{tabular}{|ll|l|l|l|l|}
\hline & $\begin{array}{l}\text { Frecuenci } \\
\mathrm{a}\end{array}$ & $\begin{array}{l}\text { Porcentaj } \\
\mathrm{e}\end{array}$ & $\begin{array}{l}\text { Porcentaje } \\
\text { válido }\end{array}$ & $\begin{array}{l}\text { Porcentaje } \\
\text { acumulado }\end{array}$ \\
\hline Válidos & $\begin{array}{l}1^{\circ} \text { mais } \\
\text { importante } \\
2^{\circ} \text { mais } \\
\text { importante }\end{array}$ & 7 & 4,7 & 4,7 & 4,7 \\
& $\begin{array}{l}3^{\circ} \text { mais } \\
\text { importante } \\
4^{\circ} \text { mais } \\
\text { importante }\end{array}$ & 2 & 8,1 & 8,1 & 12,8 \\
& 5 & 2,3 & 2,3 & 15,1 \\
Não foi \\
citada \\
Total
\end{tabular}

Output SPSS Cuestión 10.j ALUMNOS

Participación de la PROTEC en proyectos e Investigaciones.

\begin{tabular}{|ll|l|l|l|l|}
\hline & $\begin{array}{l}\text { Frecuenci } \\
\mathrm{a}\end{array}$ & $\begin{array}{l}\text { Porcentaj } \\
\mathrm{e}\end{array}$ & $\begin{array}{l}\text { Porcentaje } \\
\text { válido }\end{array}$ & $\begin{array}{l}\text { Porcentaje } \\
\text { acumulado }\end{array}$ \\
\hline Válidos & $\begin{array}{l}1^{\circ} \text { mais } \\
\text { importante } \\
2^{\circ} \text { mais } \\
\text { importante } \\
3^{\circ} \text { mais } \\
\text { importante } \\
4^{\circ} \text { mais } \\
\text { importante } \\
\text { Não foi } \\
\text { citada }\end{array}$ & 4 & 2,3 & 2,3 & 2,3 \\
& 6 & 4,7 & 4,7 & 7,0 \\
Total & 86 & 4,7 & 4,7 & 14,0 \\
& & 81,4 & 81,4 & 100,0 \\
\end{tabular}

Output SPSS Cuestión 10.l ALUMNOS

Desarrollo de proyectos de investigación y de extensión capaces de generar negocios.

\begin{tabular}{|ll|l|l|l|l|}
\hline & $\begin{array}{l}\text { Frecuenci } \\
\mathrm{a}\end{array}$ & $\begin{array}{l}\text { Porcentaj } \\
\mathrm{e}\end{array}$ & $\begin{array}{l}\text { Porcentaje } \\
\text { válido }\end{array}$ & $\begin{array}{l}\text { Porcentaje } \\
\text { acumulado }\end{array}$ \\
\hline Válidos & $\begin{array}{l}1^{\circ} \text { mais } \\
\text { importante } \\
2^{\circ} \text { mais } \\
\text { importante }\end{array}$ & 10 & 9,3 & 9,3 & 9,3 \\
& $\begin{array}{l}3^{\circ} \text { mais } \\
\text { importante } \\
4^{\circ} \text { mais } \\
\text { importante }\end{array}$ & 23 & 11,6 & 11,6 & 20,9 \\
& 16 & 18,6 & 18,6 & 67,7 \\
Não foi \\
citada
\end{tabular}


Output SPSS - Cuestión 7.n PROFESORES

Creo que es esencial la existencia de proyectos desarrollados en cooperación con otras instituciones de educación e investigación.

\begin{tabular}{|ll|l|l|l|l|}
\hline & Frecuencia & Porcentaje & $\begin{array}{l}\text { Porcentaje } \\
\text { válido }\end{array}$ & $\begin{array}{l}\text { Porcentaje } \\
\text { acumulado }\end{array}$ \\
\hline Válidos & $\begin{array}{l}\text { concordo } \\
\text { totalmente } \\
\text { concordo } \\
\text { parcialmente } \\
\text { Total }\end{array}$ & 12 & 80,0 & 80,0 & 80,0 \\
& 15 & 20,0 & 20,0 & 100,0 \\
& 100,0 & 100,0 & \\
\hline
\end{tabular}

Resultados de la Cuestión 11 de la encuesta (Calidad de un curso de grado) - ALUMNOS

Output SPSS Cuestión 11.a: Calidad do curso ALUMNOS

Estructura del Currículo / Contenido de las asignaturas

\begin{tabular}{|c|c|c|c|c|c|}
\hline & & Frecuencia & Porcentaje & $\begin{array}{l}\text { Porcentaje } \\
\text { válido }\end{array}$ & $\begin{array}{l}\text { Porcentaje } \\
\text { acumulado }\end{array}$ \\
\hline Válidos & $\begin{array}{l}1^{\circ} \text { mais } \\
\text { importante } \\
2^{\circ} \text { mais } \\
\text { importante } \\
3^{\circ} \text { mais } \\
\text { importante } \\
4^{\circ} \text { mais } \\
\text { importante } \\
5^{\circ} \text { mais } \\
\text { importante } \\
7^{\circ} \text { mais } \\
\text { importante } \\
8^{\circ} \text { mais } \\
\text { importante } \\
9^{\circ} \text { mais } \\
\text { importante } \\
10^{\circ} \text { mais } \\
\text { importante } \\
\text { Total }\end{array}$ & $\begin{array}{l}49 \\
10 \\
8 \\
6 \\
5 \\
2 \\
2 \\
1 \\
3 \\
86\end{array}$ & $\begin{array}{l}57,0 \\
11,6 \\
9,3 \\
7,0 \\
5,8 \\
2,3 \\
2,3 \\
1,2 \\
3,5 \\
100,0\end{array}$ & $\begin{array}{l}57,0 \\
11,6 \\
9,3 \\
7,0 \\
5,8 \\
2,3 \\
2,3 \\
1,2 \\
3,5 \\
100,0\end{array}$ & $\begin{array}{l}57,0 \\
68,6 \\
77,9 \\
84,9 \\
90,7 \\
93,0 \\
95,3 \\
96,5 \\
100,0\end{array}$ \\
\hline
\end{tabular}


Output SPSS Cuestión 11.b: Calidad do curso ALUMNOS

Didáctica de los profesores

\begin{tabular}{|c|c|c|c|c|c|}
\hline & & Frecuencia & Porcentaje & $\begin{array}{l}\text { Porcentaje } \\
\text { válido }\end{array}$ & $\begin{array}{l}\text { Porcentaje } \\
\text { acumulado }\end{array}$ \\
\hline Válidos & $\begin{array}{l}1^{\circ} \text { mais } \\
\text { importante } \\
2^{\circ} \text { mais } \\
\text { importante } \\
3^{\circ} \text { mais } \\
\text { importante } \\
4^{\circ} \text { mais } \\
\text { importante } \\
5^{\circ} \text { mais } \\
\text { importante } \\
6^{\circ} \text { mais } \\
\text { importante } \\
7^{\circ} \text { mais } \\
\text { importante } \\
9^{\circ} \text { mais } \\
\text { importante } \\
10^{\circ} \text { mais } \\
\text { importante } \\
\text { Total }\end{array}$ & $\begin{array}{l}16 \\
43 \\
6 \\
8 \\
6 \\
1 \\
3 \\
2 \\
1 \\
86\end{array}$ & $\begin{array}{l}18,6 \\
50,0 \\
7,0 \\
9,3 \\
7,0 \\
1,2 \\
3,5 \\
2,3 \\
1,2 \\
100,0\end{array}$ & $\begin{array}{l}18,6 \\
50,0 \\
7,0 \\
9,3 \\
7,0 \\
1,2 \\
3,5 \\
2,3 \\
1,2 \\
100,0\end{array}$ & $\begin{array}{l}18,6 \\
68,6 \\
75,6 \\
84,9 \\
91,9 \\
93,0 \\
96,5 \\
98,8 \\
100,0\end{array}$ \\
\hline
\end{tabular}

Output SPSS Cuestión 11.c: Calidad do curso ALUMNOS

Puntualidad y asiduidad de los profesores

\begin{tabular}{|c|c|c|c|c|c|}
\hline & & Frecuencia & Porcentaje & $\begin{array}{l}\text { Porcentaje } \\
\text { válido }\end{array}$ & $\begin{array}{l}\text { Porcentaje } \\
\text { acumulado }\end{array}$ \\
\hline Válidos & $\begin{array}{l}1^{\circ} \text { mais } \\
\text { importante } \\
2^{\circ} \text { mais } \\
\text { importante } \\
3^{\circ} \text { mais } \\
\text { importante } \\
4^{\circ} \text { mais } \\
\text { importante } \\
5^{\circ} \text { mais } \\
\text { importante } \\
6^{\circ} \text { mais } \\
\text { importante } \\
7^{\circ} \text { mais } \\
\text { importante } \\
8^{\circ} \text { mais } \\
\text { importante } \\
9^{\circ} \text { mais } \\
\text { importante } \\
10^{\circ} \text { mais } \\
\text { importante } \\
\text { Total }\end{array}$ & $\begin{array}{l}2 \\
5 \\
4 \\
10 \\
11 \\
12 \\
10 \\
12 \\
13 \\
7 \\
86\end{array}$ & $\begin{array}{l}2,3 \\
5,8 \\
4,7 \\
11,6 \\
12,8 \\
14,0 \\
11,6 \\
14,0 \\
15,1 \\
8,1 \\
100,0\end{array}$ & $\begin{array}{l}2,3 \\
5,8 \\
4,7 \\
11,6 \\
12,8 \\
14,0 \\
11,6 \\
14,0 \\
15,1 \\
8,1 \\
100,0\end{array}$ & $\begin{array}{l}2,3 \\
8,1 \\
12,8 \\
24,4 \\
37,2 \\
51,2 \\
62,8 \\
76,7 \\
91,9 \\
100,0\end{array}$ \\
\hline
\end{tabular}


Output SPSS Cuestión 11.d: Calidad do curso ALUMNOS

Titulación de los profesores

\begin{tabular}{|c|c|c|c|c|c|}
\hline & & Frecuencia & Porcentaje & $\begin{array}{l}\text { Porcentaje } \\
\text { válido }\end{array}$ & $\begin{array}{l}\text { Porcentaje } \\
\text { acumulado }\end{array}$ \\
\hline Válidos & $\begin{array}{l}2^{\circ} \text { mais } \\
\text { importante } \\
3^{\circ} \text { mais } \\
\text { importante } \\
4^{\circ} \text { mais } \\
\text { importante } \\
5^{\circ} \text { mais } \\
\text { importante } \\
6^{\circ} \text { mais } \\
\text { importante } \\
7^{\circ} \text { mais } \\
\text { importante } \\
8^{\circ} \text { mais } \\
\text { importante } \\
9^{\circ} \text { mais } \\
\text { importante } \\
10^{\circ} \text { mais } \\
\text { importante } \\
\text { Total }\end{array}$ & $\begin{array}{l}4 \\
15 \\
4 \\
10 \\
5 \\
4 \\
17 \\
11 \\
16 \\
86\end{array}$ & $\begin{array}{l}4,7 \\
17,4 \\
4,7 \\
11,6 \\
5,8 \\
4,7 \\
19,8 \\
12,8 \\
18,6 \\
100,0\end{array}$ & $\begin{array}{l}4,7 \\
17,4 \\
4,7 \\
11,6 \\
5,8 \\
4,7 \\
19,8 \\
12,8 \\
18,6 \\
100,0\end{array}$ & $\begin{array}{l}4,7 \\
22,1 \\
26,7 \\
38,4 \\
44,2 \\
48,8 \\
68,6 \\
81,4 \\
100,0\end{array}$ \\
\hline
\end{tabular}

Output SPSS Cuestión 11.e: Calidad do curso ALUMNOS

Envolvimiento de los profesores con el curso

\begin{tabular}{|c|c|c|c|c|c|}
\hline & & Frecuencia & Porcentaje & $\begin{array}{l}\text { Porcentaje } \\
\text { válido }\end{array}$ & $\begin{array}{l}\text { Porcentaje } \\
\text { acumulado }\end{array}$ \\
\hline Válidos & $\begin{array}{l}1^{\circ} \text { mais } \\
\text { importante } \\
2^{\circ} \text { mais } \\
\text { importante } \\
3^{\circ} \text { mais } \\
\text { importante } \\
4^{\circ} \text { mais } \\
\text { importante } \\
5^{\circ} \text { mais } \\
\text { importante } \\
6^{\circ} \text { mais } \\
\text { importante } \\
7^{\circ} \text { mais } \\
\text { importante } \\
8^{\circ} \text { mais } \\
\text { importante } \\
9^{\circ} \text { mais } \\
\text { importante } \\
\text { Total }\end{array}$ & $\begin{array}{l}11 \\
9 \\
24 \\
12 \\
9 \\
11 \\
5 \\
3 \\
2 \\
86\end{array}$ & $\begin{array}{l}12,8 \\
10,5 \\
27,9 \\
14,0 \\
10,5 \\
12,8 \\
5,8 \\
3,5 \\
2,3 \\
100,0\end{array}$ & $\begin{array}{l}12,8 \\
10,5 \\
27,9 \\
14,0 \\
10,5 \\
12,8 \\
5,8 \\
3,5 \\
2,3 \\
100,0\end{array}$ & $\begin{array}{l}12,8 \\
23,3 \\
51,2 \\
65,1 \\
75,6 \\
88,4 \\
94,2 \\
97,7 \\
100,0\end{array}$ \\
\hline
\end{tabular}


Output SPSS Cuestión 11.f: Calidad do curso ALUMNOS

Conforto y adecuación de las aulas

\begin{tabular}{|c|c|c|c|c|c|}
\hline & & Frecuencia & Porcentaje & $\begin{array}{l}\text { Porcentaje } \\
\text { válido }\end{array}$ & $\begin{array}{l}\text { Porcentaje } \\
\text { acumulado }\end{array}$ \\
\hline Válidos & $\begin{array}{l}1^{\circ} \text { mais } \\
\text { importante } \\
2^{\circ} \text { mais } \\
\text { importante } \\
3^{\circ} \text { mais } \\
\text { importante } \\
4^{\circ} \text { mais } \\
\text { importante } \\
5^{\circ} \text { mais } \\
\text { importante } \\
6^{\circ} \text { mais } \\
\text { importante } \\
7^{\circ} \text { mais } \\
\text { importante } \\
8^{\circ} \text { mais } \\
\text { importante } \\
9^{\circ} \text { mais } \\
\text { importante } \\
10^{\circ} \text { mais } \\
\text { importante } \\
\text { Total }\end{array}$ & $\begin{array}{l}2 \\
3 \\
4 \\
7 \\
11 \\
6 \\
12 \\
13 \\
8 \\
20 \\
86\end{array}$ & $\begin{array}{l}2,3 \\
3,5 \\
4,7 \\
8,1 \\
12,8 \\
7,0 \\
14,0 \\
15,1 \\
9,3 \\
23,3 \\
100,0\end{array}$ & $\begin{array}{l}2,3 \\
3,5 \\
4,7 \\
8,1 \\
12,8 \\
7,0 \\
14,0 \\
15,1 \\
9,3 \\
23,3 \\
100,0\end{array}$ & $\begin{array}{l}2,3 \\
5,8 \\
10,5 \\
18,6 \\
31,4 \\
38,4 \\
52,3 \\
67,4 \\
76,7 \\
100,0\end{array}$ \\
\hline
\end{tabular}

\section{Resultados de la Cuestión 15 de la encuesta - TITULADOS}

Output SPSS Cuestión 15.a TITULADOS

Mejorar el conocimiento de la parte del curso sobre las demandas del sector privado en el área de Design.

\begin{tabular}{|ll|l|l|l|l|}
\hline & Frecuencia & Porcentaje & $\begin{array}{l}\text { Porcentaje } \\
\text { válido }\end{array}$ & $\begin{array}{l}\text { Porcentaje } \\
\text { acumulado }\end{array}$ \\
\hline Válidos & $\begin{array}{l}1^{\circ} \text { mais } \\
\text { importante }\end{array}$ & 30 & 55,6 & 55,6 & 55,6 \\
& $\begin{array}{l}2^{\circ} \text { mais } \\
\text { importante }\end{array}$ & 7 & 13,0 & 13,0 & 68,5 \\
& $\begin{array}{l}3^{\circ} \text { mais } \\
\text { importante } \\
4^{\circ} \text { mais } \\
\text { importante }\end{array}$ & 4 & 7,4 & 7,4 & 75,9 \\
& 2 & 3,7 & 3,7 & 79,6 \\
$\begin{array}{l}\text { Não foi } \\
\text { citada } \\
\text { Total }\end{array}$ & 11 & 20,4 & 20,4 & 100,0 \\
\hline
\end{tabular}


Output SPSS Cuestión 15.b TITULADOS

Mejorar la infraestructura y laboratorios que puedan apoyar el desarrollo de nuevos procesos y productos.

\begin{tabular}{|ll|l|l|l|l|}
\hline & Frecuencia & Porcentaje & $\begin{array}{l}\text { Porcentaje } \\
\text { válido }\end{array}$ & $\begin{array}{l}\text { Porcentaje } \\
\text { acumulado }\end{array}$ \\
\hline Válidos & $\begin{array}{l}1^{\circ} \text { mais } \\
\text { importante } \\
2^{\circ} \text { mais } \\
\text { importante }\end{array}$ & 13 & 3,7 & 3,7 & 3,7 \\
& $\begin{array}{l}3^{\circ} \text { mais } \\
\text { importante }\end{array}$ & 9 & 24,1 & 24,1 & 27,8 \\
& $\begin{array}{l}4^{\circ} \text { mais } \\
\text { importante }\end{array}$ & 6 & 16,7 & 16,7 & 44,4 \\
& $\begin{array}{l}\text { Não foi } \\
\text { citada }\end{array}$ & 24 & 11,1 & 11,1 & 55,6 \\
& Total & 54 & 100,0 & 100,0 & 100,0 \\
\hline
\end{tabular}

Output SPSS Cuestión 15.c TITULADOS

Formación en materia de protección de la propiedad industrial (registro de marcas, patentes, etc)

\begin{tabular}{|c|c|c|c|c|c|}
\hline & & Frecuencia & Porcentaje & $\begin{array}{l}\text { Porcentaje } \\
\text { válido }\end{array}$ & $\begin{array}{l}\text { Porcentaje } \\
\text { acumulado }\end{array}$ \\
\hline Válidos & $\begin{array}{l}1^{\circ} \text { mais } \\
\text { importante } \\
2^{\circ} \text { mais } \\
\text { importante } \\
3^{\circ} \text { mais } \\
\text { importante } \\
4^{\circ} \text { mais } \\
\text { importante } \\
\text { Não foi } \\
\text { citada } \\
\text { Total }\end{array}$ & $\begin{array}{l}1 \\
2 \\
1 \\
2 \\
48 \\
54\end{array}$ & $\begin{array}{l}1,9 \\
3,7 \\
1,9 \\
3,7 \\
88,9 \\
100,0\end{array}$ & $\begin{array}{l}1,9 \\
3,7 \\
1,9 \\
3,7 \\
88,9 \\
100,0\end{array}$ & $\begin{array}{l}1,9 \\
5,6 \\
7,4 \\
11,1 \\
100,0\end{array}$ \\
\hline
\end{tabular}

Output SPSS Cuestión 15.d TITULADOS

Mejorar el acompañamiento de la destinación de los titulados con el fin de establecer una red de cooperación.

\begin{tabular}{|c|c|c|c|c|c|}
\hline & & Frecuencia & Porcentaje & $\begin{array}{l}\text { Porcentaje } \\
\text { válido }\end{array}$ & $\begin{array}{l}\text { Porcentaje } \\
\text { acumulado }\end{array}$ \\
\hline Válidos & $\begin{array}{l}1^{\circ} \text { mais } \\
\text { importante } \\
2^{\circ} \text { mais } \\
\text { importante } \\
3^{\circ} \text { mais } \\
\text { importante } \\
4^{\circ} \text { mais } \\
\text { importante } \\
\text { Não foi } \\
\text { citada } \\
\text { Total }\end{array}$ & $\begin{array}{l}3 \\
5 \\
8 \\
3 \\
35 \\
54\end{array}$ & $\begin{array}{l}5,6 \\
9,3 \\
14,8 \\
5,6 \\
64,8 \\
100,0\end{array}$ & $\begin{array}{l}5,6 \\
9,3 \\
14,8 \\
5,6 \\
64,8 \\
100,0\end{array}$ & $\begin{array}{l}5,6 \\
14,8 \\
29,6 \\
35,2 \\
100,0\end{array}$ \\
\hline
\end{tabular}


Output SPSS Cuestión 15.e TITULADOS

Apoyo técnico /de gestión implantación de negocios.

\begin{tabular}{|c|c|c|c|c|c|}
\hline & & Frecuencia & Porcentaje & $\begin{array}{l}\text { Porcentaje } \\
\text { válido }\end{array}$ & $\begin{array}{l}\text { Porcentaje } \\
\text { acumulado }\end{array}$ \\
\hline Válidos & $\begin{array}{l}1^{\circ} \text { mais } \\
\text { importante } \\
2^{\circ} \text { mais } \\
\text { importante } \\
3^{\circ} \text { mais } \\
\text { importante } \\
4^{\circ} \text { mais } \\
\text { importante } \\
\text { Não foi } \\
\text { citada } \\
\text { Total }\end{array}$ & $\begin{array}{l}2 \\
2 \\
3 \\
4 \\
43 \\
54\end{array}$ & $\begin{array}{l}3,7 \\
3,7 \\
5,6 \\
7,4 \\
79,6 \\
100,0\end{array}$ & $\begin{array}{l}3,7 \\
3,7 \\
5,6 \\
7,4 \\
79,6 \\
100,0\end{array}$ & $\begin{array}{l}3,7 \\
7,4 \\
13,0 \\
20,4 \\
100,0\end{array}$ \\
\hline
\end{tabular}

Output SPSS Cuestión 15.f TITULADOS

Apoyo a la Transferencia de Tecnología.

\begin{tabular}{|ll|l|l|l|l|}
\hline & Frecuencia & Porcentaje & $\begin{array}{l}\text { Porcentaje } \\
\text { válido }\end{array}$ & $\begin{array}{l}\text { Porcentaje } \\
\text { acumulado }\end{array}$ \\
\hline Válidos & $\begin{array}{l}1^{\circ} \text { mais } \\
\text { importante } \\
2^{\circ} \text { mais }\end{array}$ & 2 & 3,7 & 3,7 & 3,7 \\
& $\begin{array}{l}\text { importante } \\
3^{\circ} \text { mais }\end{array}$ & 2 & 9,3 & 9,3 & 13,0 \\
$\begin{array}{l}\text { importante } \\
\text { Não foi } \\
\text { citada }\end{array}$ & 45 & 3,7 & 3,7 & 16,7 \\
& Total & 54 & 83,3 & 83,3 & 100,0 \\
& & 100,0 & 100,0 & \\
\hline
\end{tabular}

Output SPSS Cuestión 15.g TITULADOS

Mayor cooperación con las incubadoras.

\begin{tabular}{|ll|l|l|l|l|}
\hline & Frecuencia & Porcentaje & $\begin{array}{l}\text { Porcentaje } \\
\text { válido }\end{array}$ & $\begin{array}{l}\text { Porcentaje } \\
\text { acumulado }\end{array}$ \\
\hline Válidos & $\begin{array}{l}1^{\circ} \text { mais } \\
\text { importante } \\
2^{\circ} \text { mais } \\
\text { importante }\end{array}$ & 1 & 1,9 & 1,9 & 1,9 \\
& $\begin{array}{l}3^{\circ} \text { mais } \\
\text { importante } \\
4^{\circ} \text { mais } \\
\text { importante }\end{array}$ & 10 & 3,7 & 3,7 & 5,6 \\
& $\begin{array}{l}\text { Não foi } \\
\text { citada }\end{array}$ & 37 & 18,5 & 18,5 & 31,5 \\
Total & 54 & 68,5 & 68,5 & 100,0 \\
& & 100,0 & 100,0 & \\
\hline
\end{tabular}


Output SPSS Cuestión 15.h TITULADOS

Foros para reunir los investigadores a las empresas.

\begin{tabular}{|c|c|c|c|c|c|}
\hline & & Frecuencia & Porcentaje & $\begin{array}{l}\text { Porcentaje } \\
\text { válido }\end{array}$ & $\begin{array}{l}\text { Porcentaje } \\
\text { acumulado }\end{array}$ \\
\hline Válidos & $\begin{array}{l}1^{\circ} \text { mais } \\
\text { importante } \\
2^{\circ} \text { mais } \\
\text { importante } \\
3^{\circ} \text { mais } \\
\text { importante } \\
4^{\circ} \text { mais } \\
\text { importante } \\
\text { Não foi } \\
\text { citada } \\
\text { Total }\end{array}$ & $\begin{array}{l}3 \\
3 \\
4 \\
5 \\
39 \\
54\end{array}$ & $\begin{array}{l}5,6 \\
5,6 \\
7,4 \\
9,3 \\
72,2 \\
100,0\end{array}$ & $\begin{array}{l}5,6 \\
5,6 \\
7,4 \\
9,3 \\
72,2 \\
100,0\end{array}$ & $\begin{array}{l}5,6 \\
11,1 \\
18,5 \\
27,8 \\
100,0\end{array}$ \\
\hline
\end{tabular}

Output SPSS Cuestión 15.i TITULADOS

Construcción, por el curso de la agenda de investigación definida en conjunto con el sector productivo.

\begin{tabular}{|c|c|c|c|c|c|}
\hline & & Frecuencia & Porcentaje & $\begin{array}{l}\text { Porcentaje } \\
\text { válido }\end{array}$ & $\begin{array}{l}\text { Porcentaje } \\
\text { acumulado }\end{array}$ \\
\hline Válidos & $\begin{array}{l}1^{\circ} \text { mais } \\
\text { importante } \\
2^{\circ} \text { mais } \\
\text { importante } \\
3^{\circ} \text { mais } \\
\text { importante } \\
4^{\circ} \text { mais } \\
\text { importante } \\
\text { Não foi } \\
\text { citada } \\
\text { Total }\end{array}$ & $\begin{array}{l}5 \\
5 \\
5 \\
8 \\
31 \\
54\end{array}$ & $\begin{array}{l}9,3 \\
9,3 \\
9,3 \\
14,8 \\
57,4 \\
100,0\end{array}$ & $\begin{array}{l}9,3 \\
9,3 \\
9,3 \\
14,8 \\
57,4 \\
100,0\end{array}$ & $\begin{array}{l}9,3 \\
18,5 \\
27,8 \\
42,6 \\
100,0\end{array}$ \\
\hline
\end{tabular}

Output SPSS Cuestión 15.j TITULADOS

Participación de la PROTEC en proyectos e Investigaciones.

\begin{tabular}{|ll|l|l|l|l|}
\hline & & & $\begin{array}{l}\text { Porcentaje } \\
\text { válido }\end{array}$ & $\begin{array}{l}\text { Porcentaje } \\
\text { acumulado }\end{array}$ \\
\hline Válidos & $\begin{array}{l}2^{\circ} \text { mais } \\
\text { importante }\end{array}$ & 1 & 1,9 & 1,9 & 1,9 \\
& $\begin{array}{l}3^{\circ} \text { mais } \\
\text { importante }\end{array}$ & 4 & 7,4 & 7,4 & 9,3 \\
& $\begin{array}{l}4^{\circ} \text { mais } \\
\text { importante }\end{array}$ & 2 & 3,7 & 3,7 & 13,0 \\
& $\begin{array}{l}\text { Não foi } \\
\text { citada }\end{array}$ & 47 & 87,0 & 87,0 & 100,0 \\
& 54 & 100,0 & 100,0 & \\
\hline
\end{tabular}


Output SPSS Cuestión 15.I TITULADOS

Desarrollo de proyectos de investigación y de extensión capaces de generar negocios.

\begin{tabular}{|ll|l|l|l|l|}
\hline & & Frecuencia & Porcentaje & $\begin{array}{l}\text { Porcentaje } \\
\text { válido }\end{array}$ & $\begin{array}{l}\text { Porcentaje } \\
\text { acumulado }\end{array}$ \\
\hline Válidos & $\begin{array}{l}1^{\circ} \text { mais } \\
\text { importante } \\
2^{\circ} \text { mais } \\
\text { importante }\end{array}$ & 5 & 9,3 & 9,3 & 9,3 \\
& $\begin{array}{l}3^{\circ} \text { mais } \\
\text { importante }\end{array}$ & 10 & 16,7 & 16,7 & 25,9 \\
& $\begin{array}{l}4^{\circ} \text { mais } \\
\text { importante }\end{array}$ & 12 & 18,5 & 18,5 & 44,4 \\
& Não foi \\
citada & 18 & 33,3 & 33,3 & 100,0 \\
Total & 54 & 100,0 & 100,0 & \\
\hline
\end{tabular}

\section{Resultados de la Cuestión 16 de la encuesta (Calidad de un curso de grado) - TITULADOS}

Output SPSS Cuestión 16 - a. TITULADOS

Estructura del Currículo / Contenido de las asignaturas

\begin{tabular}{|ll|l|l|l|l|}
\hline & Frecuencia & Porcentaje & $\begin{array}{l}\text { Porcentaje } \\
\text { válido }\end{array}$ & $\begin{array}{l}\text { Porcentaje } \\
\text { acumulado }\end{array}$ \\
\hline Válidos & $\begin{array}{l}1^{\circ} \text { mais } \\
\text { importante }\end{array}$ & 35 & 64,8 & 64,8 & 64,8 \\
& $\begin{array}{l}2^{\circ} \text { mais } \\
\text { importante }\end{array}$ & 10 & 18,5 & 18,5 & 83,3 \\
$\begin{array}{l}3^{\circ} \text { mais } \\
\text { importante } \\
4^{\circ} \text { mais } \\
\text { importante } \\
\begin{array}{l}7^{\circ} \text { mais } \\
\text { importante } \\
\text { 10 mais } \\
\text { importante }\end{array}\end{array}$ & 1 & 1 & 9,3 & 9,3 & 92,6 \\
& 1 & 1,9 & 1,9 & 96,3 \\
Total & 54 & 1,9 & 1,9 & 100,0 \\
\hline
\end{tabular}


Output SPSS Cuestión 16 - b. TITULADOS

Didáctica de los profesores

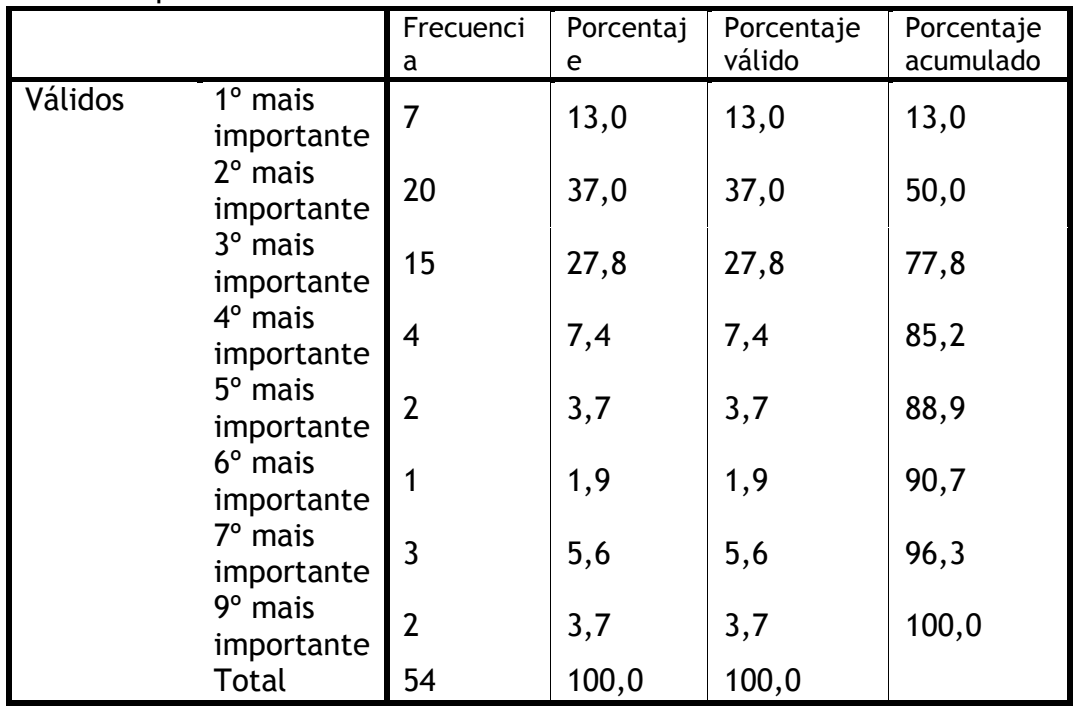

Output SPSS Cuestión 16 - c. TITULADOS

Puntualidad y asiduidad de los profesores

\begin{tabular}{|ll|l|l|l|l|}
\hline & $\begin{array}{l}\text { Frecuenci } \\
\text { a }\end{array}$ & $\begin{array}{l}\text { Porcentaj } \\
\text { e }\end{array}$ & $\begin{array}{l}\text { Porcentaje } \\
\text { válido }\end{array}$ & $\begin{array}{l}\text { Porcentaje } \\
\text { acumulado }\end{array}$ \\
\hline Válidos & $\begin{array}{l}3^{\circ} \text { mais } \\
\text { importante }\end{array}$ & 2 & 3,7 & 3,7 & 3,7 \\
$\begin{array}{l}4^{\circ} \text { mais } \\
\text { importante } \\
5^{\circ} \text { mais } \\
\text { importante }\end{array}$ & 2 & 3,7 & 3,7 & 7,4 \\
$\begin{array}{l}6^{\circ} \text { mais } \\
\text { importante }\end{array}$ & 8 & 7,4 & 7,4 & 14,8 \\
$\begin{array}{l}7^{\circ} \text { mais } \\
\text { importante }\end{array}$ & 4 & 14,8 & 14,8 & 29,6 \\
$\begin{array}{l}8^{\circ} \text { mais } \\
\text { importante } \\
\text { 9० mais } \\
\text { importante }\end{array}$ & 6 & 7,4 & 7,4 & 37,0 \\
$\begin{array}{l}\text { 10 mais } \\
\text { importante }\end{array}$ & 19 & 11,1 & 11,1 & 48,1 \\
Total & 54 & 16,7 & 16,7 & 64,8 \\
\hline
\end{tabular}


Output SPSS Cuestión 16 - d. TITULADOS

Titulación de los profesores

\begin{tabular}{|c|c|c|c|c|c|}
\hline & & $\begin{array}{l}\text { Frecuenci } \\
\mathrm{a}\end{array}$ & $\begin{array}{l}\text { Porcentaj } \\
\text { e }\end{array}$ & $\begin{array}{l}\text { Porcentaje } \\
\text { válido }\end{array}$ & $\begin{array}{l}\text { Porcentaje } \\
\text { acumulado }\end{array}$ \\
\hline Válidos & $\begin{array}{l}2^{\circ} \text { mais } \\
\text { importante } \\
3^{\circ} \text { mais } \\
\text { importante } \\
4^{\circ} \text { mais } \\
\text { importante } \\
5^{\circ} \text { mais } \\
\text { importante } \\
6^{\circ} \text { mais } \\
\text { importante } \\
7^{\circ} \text { mais } \\
\text { importante } \\
8^{\circ} \text { mais } \\
\text { importante } \\
9^{\circ} \text { mais } \\
\text { importante } \\
10^{\circ} \text { mais } \\
\text { importante } \\
\text { Total }\end{array}$ & $\begin{array}{l}3 \\
4 \\
6 \\
7 \\
7 \\
13 \\
6 \\
4 \\
4 \\
54\end{array}$ & $\begin{array}{l}5,6 \\
7,4 \\
11,1 \\
13,0 \\
13,0 \\
24,1 \\
11,1 \\
7,4 \\
7,4 \\
100,0\end{array}$ & $\begin{array}{l}5,6 \\
7,4 \\
11,1 \\
13,0 \\
13,0 \\
24,1 \\
11,1 \\
7,4 \\
7,4 \\
100,0\end{array}$ & $\begin{array}{l}5,6 \\
13,0 \\
24,1 \\
37,0 \\
50,0 \\
74,1 \\
85,2 \\
92,6 \\
100,0\end{array}$ \\
\hline
\end{tabular}

Output SPSS Cuestión 16 - e. TITULADOS

Envolvimiento de los profesores con el curso

\begin{tabular}{|c|c|c|c|c|c|}
\hline & & $\begin{array}{l}\text { Frecuenci } \\
\mathrm{a}\end{array}$ & $\begin{array}{l}\text { Porcentaj } \\
\text { e }\end{array}$ & $\begin{array}{l}\text { Porcentaje } \\
\text { válido }\end{array}$ & $\begin{array}{l}\text { Porcentaje } \\
\text { acumulado }\end{array}$ \\
\hline Válidos & $\begin{array}{l}1^{\circ} \text { mais } \\
\text { importante } \\
2^{\circ} \text { mais } \\
\text { importante } \\
3^{\circ} \text { mais } \\
\text { importante } \\
4^{\circ} \text { mais } \\
\text { importante } \\
5^{\circ} \text { mais } \\
\text { importante } \\
6^{\circ} \text { mais } \\
\text { importante } \\
7^{\circ} \text { mais } \\
\text { importante } \\
10^{\circ} \text { mais } \\
\text { importante } \\
\text { Total }\end{array}$ & $\begin{array}{l}10 \\
13 \\
17 \\
5 \\
4 \\
3 \\
1 \\
1 \\
54\end{array}$ & $\begin{array}{l}18,5 \\
24,1 \\
31,5 \\
9,3 \\
7,4 \\
5,6 \\
1,9 \\
1,9 \\
100,0\end{array}$ & $\begin{array}{l}18,5 \\
24,1 \\
31,5 \\
9,3 \\
7,4 \\
5,6 \\
1,9 \\
1,9 \\
100,0\end{array}$ & $\begin{array}{l}18,5 \\
42,6 \\
74,1 \\
83,3 \\
90,7 \\
96,3 \\
98,1 \\
100,0\end{array}$ \\
\hline
\end{tabular}


Output SPSS Cuestión $16-\mathrm{f}$. TITULADOS

Conforto y adecuación de las aulas

\begin{tabular}{|c|c|c|c|c|c|}
\hline & & $\begin{array}{l}\text { Frecuenci } \\
\mathrm{a}\end{array}$ & $\begin{array}{l}\text { Porcentaj } \\
\text { e }\end{array}$ & $\begin{array}{l}\text { Porcentaje } \\
\text { válido }\end{array}$ & $\begin{array}{l}\text { Porcentaje } \\
\text { acumulado }\end{array}$ \\
\hline Válidos & $\begin{array}{l}1^{\circ} \text { mais } \\
\text { importante } \\
2^{\circ} \text { mais } \\
\text { importante } \\
4^{\circ} \text { mais } \\
\text { importante } \\
5^{\circ} \text { mais } \\
\text { importante } \\
6^{\circ} \text { mais } \\
\text { importante } \\
7^{\circ} \text { mais } \\
\text { importante } \\
8^{\circ} \text { mais } \\
\text { importante } \\
9^{\circ} \text { mais } \\
\text { importante } \\
10^{\circ} \text { mais } \\
\text { importante } \\
\text { Total }\end{array}$ & $\begin{array}{l}1 \\
1 \\
6 \\
2 \\
4 \\
6 \\
6 \\
13 \\
15 \\
54\end{array}$ & $\begin{array}{l}1,9 \\
1,9 \\
11,1 \\
3,7 \\
7,4 \\
11,1 \\
11,1 \\
24,1 \\
27,8 \\
100,0\end{array}$ & $\begin{array}{l}1,9 \\
1,9 \\
11,1 \\
3,7 \\
7,4 \\
11,1 \\
11,1 \\
24,1 \\
27,8 \\
100,0\end{array}$ & $\begin{array}{l}1,9 \\
3,7 \\
14,8 \\
18,5 \\
25,9 \\
37,0 \\
48,1 \\
72,2 \\
100,0\end{array}$ \\
\hline
\end{tabular}

Output SPSS Cuestión 16 - g. TITULADOS

Calidad de los laboratorios y espacios específicos

\begin{tabular}{|c|c|c|c|c|c|}
\hline & & $\begin{array}{l}\text { Frecuenci } \\
\mathrm{a}\end{array}$ & $\begin{array}{l}\text { Porcentaj } \\
\text { e }\end{array}$ & $\begin{array}{l}\text { Porcentaje } \\
\text { válido }\end{array}$ & $\begin{array}{l}\text { Porcentaje } \\
\text { acumulado }\end{array}$ \\
\hline Válidos & $\begin{array}{l}2^{\circ} \text { mais } \\
\text { importante } \\
3^{\circ} \text { mais } \\
\text { importante } \\
4^{\circ} \text { mais } \\
\text { importante } \\
5^{\circ} \text { mais } \\
\text { importante } \\
6^{\circ} \text { mais } \\
\text { importante } \\
7^{\circ} \text { mais } \\
\text { importante } \\
8^{\circ} \text { mais } \\
\text { importante } \\
9^{\circ} \text { mais } \\
\text { importante } \\
10^{\circ} \text { mais } \\
\text { importante } \\
\text { Total }\end{array}$ & $\begin{array}{l}2 \\
5 \\
17 \\
12 \\
5 \\
4 \\
7 \\
1 \\
1 \\
54\end{array}$ & $\begin{array}{l}3,7 \\
9,3 \\
31,5 \\
22,2 \\
9,3 \\
7,4 \\
13,0 \\
1,9 \\
1,9 \\
100,0\end{array}$ & $\begin{array}{l}3,7 \\
9,3 \\
31,5 \\
22,2 \\
9,3 \\
7,4 \\
13,0 \\
1,9 \\
1,9 \\
100,0\end{array}$ & $\begin{array}{l}3,7 \\
13,0 \\
44,4 \\
66,7 \\
75,9 \\
83,3 \\
96,3 \\
98,1 \\
100,0\end{array}$ \\
\hline
\end{tabular}


Output SPSS Cuestión 16 - h. TITULADOS

Apoyo de personal técnico

\begin{tabular}{|c|c|c|c|c|c|}
\hline & & $\begin{array}{l}\text { Frecuenci } \\
\mathrm{a}\end{array}$ & $\begin{array}{l}\text { Porcentaj } \\
\text { e }\end{array}$ & $\begin{array}{l}\text { Porcentaje } \\
\text { válido }\end{array}$ & $\begin{array}{l}\text { Porcentaje } \\
\text { acumulado }\end{array}$ \\
\hline Válidos & $\begin{array}{l}3^{\circ} \text { mais } \\
\text { importante } \\
4^{\circ} \text { mais } \\
\text { importante } \\
5^{\circ} \text { mais } \\
\text { importante } \\
6^{\circ} \text { mais } \\
\text { importante } \\
7^{\circ} \text { mais } \\
\text { importante } \\
8^{\circ} \text { mais } \\
\text { importante } \\
9^{\circ} \text { mais } \\
\text { importante } \\
10^{\circ} \text { mais } \\
\text { importante } \\
\text { Total }\end{array}$ & $\begin{array}{l}2 \\
1 \\
5 \\
12 \\
10 \\
10 \\
10 \\
4 \\
54\end{array}$ & $\begin{array}{l}3,7 \\
1,9 \\
9,3 \\
22,2 \\
18,5 \\
18,5 \\
18,5 \\
7,4 \\
100,0\end{array}$ & $\begin{array}{l}3,7 \\
1,9 \\
9,3 \\
22,2 \\
18,5 \\
18,5 \\
18,5 \\
7,4 \\
100,0\end{array}$ & $\begin{array}{l}3,7 \\
5,6 \\
14,8 \\
37,0 \\
55,6 \\
74,1 \\
92,6 \\
100,0\end{array}$ \\
\hline
\end{tabular}

Output SPSS Cuestión 16 - i. TITULADOS

Apoyo de la Coordinación del Curso

\begin{tabular}{|c|c|c|c|c|c|}
\hline & & $\begin{array}{l}\text { Frecuenci } \\
\text { a }\end{array}$ & $\begin{array}{l}\text { Porcentaj } \\
\text { e }\end{array}$ & $\begin{array}{l}\text { Porcentaje } \\
\text { válido }\end{array}$ & $\begin{array}{l}\text { Porcentaje } \\
\text { acumulado }\end{array}$ \\
\hline Válidos & $\begin{array}{l}1^{\circ} \text { mais } \\
\text { importante } \\
2^{\circ} \text { mais } \\
\text { importante } \\
3^{\circ} \text { mais } \\
\text { importante } \\
4^{\circ} \text { mais } \\
\text { importante } \\
5^{\circ} \text { mais } \\
\text { importante } \\
6^{\circ} \text { mais } \\
\text { importante } \\
7^{\circ} \text { mais } \\
\text { importante } \\
8^{\circ} \text { mais } \\
\text { importante } \\
9^{\circ} \text { mais } \\
\text { importante } \\
10^{\circ} \text { mais } \\
\text { importante } \\
\text { Total }\end{array}$ & $\begin{array}{l}3 \\
1 \\
3 \\
3 \\
14 \\
11 \\
8 \\
8 \\
2 \\
1 \\
54\end{array}$ & $\begin{array}{l}5,6 \\
1,9 \\
5,6 \\
5,6 \\
25,9 \\
20,4 \\
14,8 \\
14,8 \\
3,7 \\
1,9 \\
100,0\end{array}$ & $\begin{array}{l}5,6 \\
1,9 \\
5,6 \\
5,6 \\
25,9 \\
20,4 \\
14,8 \\
14,8 \\
3,7 \\
1,9 \\
100,0\end{array}$ & $\begin{array}{l}5,6 \\
7,4 \\
13,0 \\
18,5 \\
44,4 \\
64,8 \\
79,6 \\
94,4 \\
98,1 \\
100,0\end{array}$ \\
\hline
\end{tabular}


Output SPSS Cuestión 16 - j. TITULADOS

Apoyo de la Secretaria del Curso

\begin{tabular}{|c|c|c|c|c|c|}
\hline & & $\begin{array}{l}\text { Frecuenci } \\
\text { a }\end{array}$ & $\begin{array}{l}\text { Porcentaj } \\
\text { e }\end{array}$ & $\begin{array}{l}\text { Porcentaje } \\
\text { válido }\end{array}$ & $\begin{array}{l}\text { Porcentaje } \\
\text { acumulado }\end{array}$ \\
\hline Válidos & $\begin{array}{l}1^{\circ} \text { mais } \\
\text { importante } \\
2^{\circ} \text { mais } \\
\text { importante } \\
3^{\circ} \text { mais } \\
\text { importante } \\
4^{\circ} \text { mais } \\
\text { importante } \\
5^{\circ} \text { mais } \\
\text { importante } \\
6^{\circ} \text { mais } \\
\text { importante } \\
7^{\circ} \text { mais } \\
\text { importante } \\
8^{\circ} \text { mais } \\
\text { importante } \\
9^{\circ} \text { mais } \\
\text { importante } \\
10^{\circ} \text { mais } \\
\text { importante } \\
\text { Total }\end{array}$ & $\begin{array}{l}3 \\
4 \\
2 \\
3 \\
3 \\
3 \\
4 \\
16 \\
10 \\
6 \\
54\end{array}$ & $\begin{array}{l}5,6 \\
7,4 \\
3,7 \\
5,6 \\
5,6 \\
5,6 \\
7,4 \\
29,6 \\
18,5 \\
11,1 \\
100,0\end{array}$ & $\begin{array}{l}5,6 \\
7,4 \\
3,7 \\
5,6 \\
5,6 \\
5,6 \\
7,4 \\
29,6 \\
18,5 \\
11,1 \\
100,0\end{array}$ & $\begin{array}{l}5,6 \\
13,0 \\
16,7 \\
22,2 \\
27,8 \\
33,3 \\
40,7 \\
70,4 \\
88,9 \\
100,0\end{array}$ \\
\hline
\end{tabular}

Output SPSS Cuestión 11.g: Calidad do curso

Calidad de los laboratorios y espacios específicos

\begin{tabular}{|c|c|c|c|c|c|}
\hline & & Frecuencia & Porcentaje & $\begin{array}{l}\text { Porcentaje } \\
\text { válido }\end{array}$ & $\begin{array}{l}\text { Porcentaje } \\
\text { acumulado }\end{array}$ \\
\hline Válidos & $\begin{array}{l}1^{\circ} \text { mais } \\
\text { importante } \\
2^{\circ} \text { mais } \\
\text { importante } \\
3^{\circ} \text { mais } \\
\text { importante } \\
4^{\circ} \text { mais } \\
\text { importante } \\
5^{\circ} \text { mais } \\
\text { importante } \\
6^{\circ} \text { mais } \\
\text { importante } \\
7^{\circ} \text { mais } \\
\text { importante } \\
8^{\circ} \text { mais } \\
\text { importante } \\
9^{\circ} \text { mais } \\
\text { importante } \\
10^{\circ} \text { mais } \\
\text { importante } \\
\text { Total }\end{array}$ & $\begin{array}{l}3 \\
6 \\
15 \\
21 \\
10 \\
14 \\
8 \\
1 \\
5 \\
3 \\
86\end{array}$ & $\begin{array}{l}3,5 \\
7,0 \\
17,4 \\
24,4 \\
11,6 \\
16,3 \\
9,3 \\
1,2 \\
5,8 \\
3,5 \\
100,0\end{array}$ & $\begin{array}{l}3,5 \\
7,0 \\
17,4 \\
24,4 \\
11,6 \\
16,3 \\
9,3 \\
1,2 \\
5,8 \\
3,5 \\
100,0\end{array}$ & $\begin{array}{l}3,5 \\
10,5 \\
27,9 \\
52,3 \\
64,0 \\
80,2 \\
89,5 \\
90,7 \\
96,5 \\
100,0\end{array}$ \\
\hline
\end{tabular}


Output SPSS Cuestión 11.h: Calidad do curso ALUMNOS

Apoyo de personal técnico

\begin{tabular}{|c|c|c|c|c|c|}
\hline & & Frecuencia & Porcentaje & $\begin{array}{l}\text { Porcentaje } \\
\text { válido }\end{array}$ & $\begin{array}{l}\text { Porcentaje } \\
\text { acumulado }\end{array}$ \\
\hline Válidos & $\begin{array}{l}1^{\circ} \text { mais } \\
\text { importante } \\
2^{\circ} \text { mais } \\
\text { importante } \\
3^{\circ} \text { mais } \\
\text { importante } \\
4^{\circ} \text { mais } \\
\text { importante } \\
5^{\circ} \text { mais } \\
\text { importante } \\
6^{\circ} \text { mais } \\
\text { importante } \\
7^{\circ} \text { mais } \\
\text { importante } \\
8^{\circ} \text { mais } \\
\text { importante } \\
9^{\circ} \text { mais } \\
\text { importante } \\
10^{\circ} \text { mais } \\
\text { importante } \\
\text { Total }\end{array}$ & $\begin{array}{l}1 \\
3 \\
1 \\
5 \\
6 \\
13 \\
19 \\
16 \\
7 \\
15 \\
86\end{array}$ & $\begin{array}{l}1,2 \\
3,5 \\
1,2 \\
5,8 \\
7,0 \\
15,1 \\
22,1 \\
18,6 \\
8,1 \\
17,4 \\
100,0\end{array}$ & $\begin{array}{l}1,2 \\
3,5 \\
1,2 \\
5,8 \\
7,0 \\
15,1 \\
22,1 \\
18,6 \\
8,1 \\
17,4 \\
100,0\end{array}$ & $\begin{array}{l}1,2 \\
4,7 \\
5,8 \\
11,6 \\
18,6 \\
33,7 \\
55,8 \\
74,4 \\
82,6 \\
100,0\end{array}$ \\
\hline
\end{tabular}

Output SPSS Cuestión 11.i: Calidad do curso ALUMNOS

Apoyo de la Coordinación del Curso

\begin{tabular}{|c|c|c|c|c|c|}
\hline & & Frecuencia & Porcentaje & $\begin{array}{l}\text { Porcentaje } \\
\text { válido }\end{array}$ & $\begin{array}{l}\text { Porcentaje } \\
\text { acumulado }\end{array}$ \\
\hline Válidos & $\begin{array}{l}1^{\circ} \text { mais } \\
\text { importante } \\
2^{\circ} \text { mais } \\
\text { importante } \\
3^{\circ} \text { mais } \\
\text { importante } \\
4^{\circ} \text { mais } \\
\text { importante } \\
5^{\circ} \text { mais } \\
\text { importante } \\
6^{\circ} \text { mais } \\
\text { importante } \\
7^{\circ} \text { mais } \\
\text { importante } \\
8^{\circ} \text { mais } \\
\text { importante } \\
9^{\circ} \text { mais } \\
\text { importante } \\
10^{\circ} \text { mais } \\
\text { importante } \\
\text { Total }\end{array}$ & $\begin{array}{l}2 \\
3 \\
4 \\
11 \\
12 \\
20 \\
9 \\
11 \\
9 \\
5 \\
86\end{array}$ & $\begin{array}{l}2,3 \\
3,5 \\
4,7 \\
12,8 \\
14,0 \\
23,3 \\
10,5 \\
12,8 \\
10,5 \\
5,8 \\
100,0\end{array}$ & $\begin{array}{l}2,3 \\
3,5 \\
4,7 \\
12,8 \\
14,0 \\
23,3 \\
10,5 \\
12,8 \\
10,5 \\
5,8 \\
100,0\end{array}$ & $\begin{array}{l}2,3 \\
5,8 \\
10,5 \\
23,3 \\
37,2 \\
60,5 \\
70,9 \\
83,7 \\
94,2 \\
100,0\end{array}$ \\
\hline
\end{tabular}


Output SPSS Cuestión 11.j: Calidad do curso ALUMNOS Apoyo de la Secretaria del Curso

\begin{tabular}{|c|c|c|c|c|c|}
\hline & & Frecuencia & Porcentaje & $\begin{array}{l}\text { Porcentaje } \\
\text { válido }\end{array}$ & $\begin{array}{l}\text { Porcentaje } \\
\text { acumulado }\end{array}$ \\
\hline Válidos & $\begin{array}{l}1^{\circ} \text { mais } \\
\text { importante } \\
2^{\circ} \text { mais } \\
\text { importante } \\
3^{\circ} \text { mais } \\
\text { importante } \\
4^{\circ} \text { mais } \\
\text { importante } \\
5^{\circ} \text { mais } \\
\text { importante } \\
6^{\circ} \text { mais } \\
\text { importante } \\
7^{\circ} \text { mais } \\
\text { importante } \\
8^{\circ} \text { mais } \\
\text { importante } \\
9^{\circ} \text { mais } \\
\text { importante } \\
10^{\circ} \text { mais } \\
\text { importante } \\
\text { Total }\end{array}$ & $\begin{array}{l}2 \\
3 \\
2 \\
2 \\
2 \\
6 \\
14 \\
11 \\
28 \\
16 \\
86\end{array}$ & $\begin{array}{l}2,3 \\
3,5 \\
2,3 \\
2,3 \\
2,3 \\
7,0 \\
16,3 \\
12,8 \\
32,6 \\
18,6 \\
100,0\end{array}$ & $\begin{array}{l}2,3 \\
3,5 \\
2,3 \\
2,3 \\
2,3 \\
7,0 \\
16,3 \\
12,8 \\
32,6 \\
18,6 \\
100,0\end{array}$ & $\begin{array}{l}2,3 \\
5,8 \\
8,1 \\
10,5 \\
12,8 \\
19,8 \\
36,0 \\
48,8 \\
81,4 \\
100,0\end{array}$ \\
\hline
\end{tabular}




\section{Anexos 01 - Lei da Inovação}

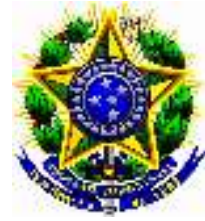

Presidência da República

Casa Civil

Subchefia para Assuntos

Jurídicos

\section{LEI N 10.973, DE 2 DE DEZEMBRO DE 2004.}

Dispõe sobre incentivos à inovação e à pesquisa científica e tecnológica no ambiente produtivo e dá outras providências.

O PRESIDENTE DA REPÚBLICA: Faço saber que o Congresso Nacional decreta e eu sanciono a seguinte Lei:

\section{CAPÍTULO I \\ DISPOSIÇÕES PRELIMINARES}

Art. 1ํㅡㄹ Esta Lei estabelece medidas de incentivo à inovação e à pesquisa científica e tecnológica no ambiente produtivo, com vistas à capacitação e ao alcance da autonomia tecnológica e ao desenvolvimento industrial do País, nos termos dos arts. $\underline{218}$ e $\underline{219}$ da Constituição.

Art. $2^{\circ}$ Para os efeitos desta Lei, considera-se:

I - agência de fomento: órgão ou instituição de natureza pública ou privada que tenha entre os seus objetivos o financiamento de ações que visem a estimular e promover o desenvolvimento da ciência, da tecnologia e da inovação;

II - criação: invenção, modelo de utilidade, desenho industrial, programa de computador, topografia de circuito integrado, nova cultivar ou cultivar essencialmente derivada e qualquer outro desenvolvimento tecnológico que acarrete ou possa acarretar o surgimento de novo produto, processo ou aperfeiçoamento incremental, obtida por um ou mais criadores;

III - criador: pesquisador que seja inventor, obtentor ou autor de criação;

IV - inovação: introdução de novidade ou aperfeiçoamento no ambiente produtivo ou social que resulte em novos produtos, processos ou serviços;

V - Instituição Científica e Tecnológica - ICT: órgão ou entidade da administração pública que tenha por missão institucional, dentre outras, executar atividades de pesquisa básica ou aplicada de caráter científico ou tecnológico;

VI - núcleo de inovação tecnológica: núcleo ou órgão constituído por uma ou mais ICT com a finalidade de gerir sua política de inovação; 
VII - instituição de apoio - fundação criada com a finalidade de dar apoio a projetos de pesquisa, ensino e extensão e de desenvolvimento institucional, científico e tecnológico de interesse das IFES e demais ICTs, registrada e credenciada nos Ministérios da Educação e da Ciência e Tecnologia, nos termos da Lei $n^{\circ} 8.958$, de 20 de dezembro de 1994; (Redação dada pela Lei $\mathrm{n}^{\circ}$ 12.349, de 2010)

VIII - pesquisador público: ocupante de cargo efetivo, cargo militar ou emprego público que realize pesquisa básica ou aplicada de caráter científico ou tecnológico; e

IX - inventor independente: pessoa física, não ocupante de cargo efetivo, cargo militar ou emprego público, que seja inventor, obtentor ou autor de criação.

\section{CAPÍTULO II}

\section{DO ESTÍMULO À CONSTRUÇÃO DE AMBIENTES ESPECIALIZADOS E COOPERATIVOS DE INNOVACIÓN}

Art. $3^{\circ}$ A União, os Estados, o Distrito Federal, os Municípios e as respectivas agências de fomento poderão estimular e apoiar a constituição de alianças estratégicas e o desenvolvimento de projetos de cooperação envolvendo empresas nacionais, ICT e organizações de direito privado sem fins lucrativos voltadas para atividades de pesquisa e desenvolvimento, que objetivem a geração de produtos e processos inovadores.

Parágrafo único. 0 apoio previsto neste artigo poderá contemplar as redes e os projetos internacionais de pesquisa tecnológica, bem como ações de empreendedorismo tecnológico e de criação de ambientes de inovação, inclusive incubadoras e parques tecnológicos.

Art. 3-.A. A Financiadora de Estudos e Projetos - FINEP, como secretaria executiva do Fundo Nacional de Desenvolvimento Científico e Tecnológico - FNDCT, o Conselho Nacional de Desenvolvimento Científico e Tecnológico - CNPq e as Agências Financeiras Oficiais de Fomento poderão celebrar convênios e contratos, nos termos do inciso XIII do art. 24 da Lei $n^{\circ} 8.666$, de 21 de junho de 1993, por prazo determinado, com as fundações de apoio, com a finalidade de dar apoio às IFES e demais ICTs, inclusive na gestão administrativa e financeira dos projetos mencionados no caput do $\underline{\operatorname{art} .1^{\circ} \text { da Lei }}$ $\mathrm{n}^{\circ}$ 8.958, de 20 de dezembro de 1994, com a anuência expressa das instituições apoiadas. (Redação dada pela Lei $\mathrm{n}^{0}$ 12.349, de 2010)

Art. $4^{\circ}$ As ICT poderão, mediante remuneração e por prazo determinado, nos termos de contrato ou convênio:

I - compartilhar seus laboratórios, equipamentos, instrumentos, materiais e demais instalações com microempresas e empresas de pequeno porte em atividades voltadas à inovação tecnológica, para a consecução de atividades de incubação, sem prejuízo de sua atividade finalística;

II - permitir a utilização de seus laboratórios, equipamentos, instrumentos, materiais e demais instalações existentes em suas próprias dependências por empresas nacionais e organizações de direito privado sem fins lucrativos voltadas para atividades de 
pesquisa, desde que tal permissão não interfira diretamente na sua atividade-fim, nem com ela conflite.

Parágrafo único. A permissão e o compartilhamento de que tratam os incisos I e II do caput deste artigo obedecerão às prioridades, critérios e requisitos aprovados e divulgados pelo órgão máximo da ICT, observadas as respectivas disponibilidades e assegurada a igualdade de oportunidades às empresas e organizações interessadas.

Art. 5ำ Ficam a União e suas entidades autorizadas a participar minoritariamente do capital de empresa privada de propósito específico que vise ao desenvolvimento de projetos científicos ou tecnológicos para obtenção de produto ou processo inovadores.

Parágrafo único. A propriedade intelectual sobre os resultados obtidos pertencerá às instituições detentoras do capital social, na proporção da respectiva participação.

\section{CAPÍTULO III}

\section{DO ESTÍMULO À PARTICIPAÇÃO DAS ICT NO PROCESSO DE INNOVACIÓN}

Art. 6o É facultado à ICT celebrar contratos de transferência de tecnologia e de licenciamento para outorga de direito de uso ou de exploração de criação por ela desenvolvida.

§ 1ํ A contratação com cláusula de exclusividade, para os fins de que trata o caput deste artigo, deve ser precedida da publicação de edital.

$\S 2^{\circ}$ Quando não for concedida exclusividade ao receptor de tecnologia ou ao licenciado, os contratos previstos no caput deste artigo poderão ser firmados diretamente, para fins de exploração de criação que deles seja objeto, na forma do regulamento.

§ $3^{\circ}$ A empresa detentora do direito exclusivo de exploração de criação protegida perderá automaticamente esse direito caso não comercialize a criação dentro do prazo e condições definidos no contrato, podendo a ICT proceder a novo licenciamento.

$\S 4^{0} 0$ licenciamento para exploração de criação cujo objeto interesse à defesa nacional deve observar o disposto no $\S 3^{\circ}$ do art. 75 da Lei $n^{\circ} 9.279$, de 14 de maio de 1996.

$\S 5^{\circ}$ A transferência de tecnologia e o licenciamento para exploração de criação reconhecida, em ato do Poder Executivo, como de relevante interesse público, somente poderão ser efetuados a título não exclusivo.

Art. 7ํA A ICT poderá obter o direito de uso ou de exploração de criação protegida.

Art. $8^{\circ}$ É facultado à ICT prestar a instituições públicas ou privadas serviços compatíveis com os objetivos desta Lei, nas atividades voltadas à inovação e à pesquisa científica e tecnológica no ambiente produtivo.

§ $1^{\circ}$ A prestação de serviços prevista no caput deste artigo dependerá de aprovação pelo órgão ou autoridade máxima da ICT.

§ $2^{\circ}$ O servidor, o militar ou o empregado público envolvido na prestação de serviço prevista no caput deste artigo poderá receber retribuição pecuniária, diretamente da ICT ou de instituição de apoio com que esta tenha firmado acordo, sempre sob a forma 
de adicional variável e desde que custeado exclusivamente com recursos arrecadados no âmbito da atividade contratada.

§ 3ㅇ 0 valor do adicional variável de que trata o $\S 2^{\circ}$ deste artigo fica sujeito à incidência dos tributos e contribuições aplicáveis à espécie, vedada a incorporação aos vencimentos, à remuneração ou aos proventos, bem como a referência como base de cálculo para qualquer benefício, adicional ou vantagem coletiva ou pessoal.

§ 40 0 adicional variável de que trata este artigo configura-se, para os fins do art. 28 da Lei $n^{\circ} 8.212$, de 24 de julho de 1991, ganho eventual.

Art. 9ํ É facultado à ICT celebrar acordos de parceria para realização de atividades conjuntas de pesquisa científica e tecnológica e desenvolvimento de tecnologia, produto ou processo, com instituições públicas e privadas.

§ 1으 0 servidor, o militar ou o empregado público da ICT envolvido na execução das atividades previstas no caput deste artigo poderá receber bolsa de estímulo à inovação diretamente de instituição de apoio ou agência de fomento.

§ 2ำ As partes deverão prever, em contrato, a titularidade da propriedade intelectual e a participação nos resultados da exploração das criações resultantes da parceria, assegurando aos signatários o direito ao licenciamento, observado o disposto nos $\S \S 4^{\circ}$ e $5^{\circ}$ do art. $6^{\circ}$ desta Lei.

§ $3^{\circ}$ A propriedade intelectual e a participação nos resultados referidas no $\S 20$ deste artigo serão asseguradas, desde que previsto no contrato, na proporção equivalente ao montante do valor agregado do conhecimento já existente no início da parceria e dos recursos humanos, financeiros e materiais alocados pelas partes contratantes.

Art. 10. Os acordos e contratos firmados entre as ICT, as instituições de apoio, agências de fomento e as entidades nacionais de direito privado sem fins lucrativos voltadas para atividades de pesquisa, cujo objeto seja compatível com a finalidade desta Lei, poderão prever recursos para cobertura de despesas operacionais e administrativas incorridas na execução destes acordos e contratos, observados os critérios do regulamento.

Art. 11. A ICT poderá ceder seus direitos sobre a criação, mediante manifestação expressa e motivada, a título não-oneroso, nos casos e condições definidos em regulamento, para que o respectivo criador os exerça em seu próprio nome e sob sua inteira responsabilidade, nos termos da legislação pertinente.

Parágrafo único. A manifestação prevista no caput deste artigo deverá ser proferida pelo órgão ou autoridade máxima da instituição, ouvido o núcleo de inovação tecnológica, no prazo fixado em regulamento.

Art. 12. É vedado a dirigente, ao criador ou a qualquer servidor, militar, empregado ou prestador de serviços de ICT divulgar, noticiar ou publicar qualquer aspecto de criações 
de cujo desenvolvimento tenha participado diretamente ou tomado conhecimento por força de suas atividades, sem antes obter expressa autorização da ICT.

Art. 13. É assegurada ao criador participação mínima de 5\% (cinco por cento) e máxima de 1/3 (um terço) nos ganhos econômicos, auferidos pela ICT, resultantes de contratos de transferência de tecnologia e de licenciamento para outorga de direito de uso ou de exploração de criação protegida da qual tenha sido o inventor, obtentor ou autor, aplicando-se, no que couber, o disposto no parágrafo único do art. 93 da Lei $n^{\circ} 9.279$, de 1996.

$\S 1^{\circ}$ A participação de que trata o caput deste artigo poderá ser partilhada pela ICT entre os membros da equipe de pesquisa e desenvolvimento tecnológico que tenham contribuído para a criação.

$\S 2^{\circ}$ Entende-se por ganhos econômicos toda forma de royalties, remuneração ou quaisquer benefícios financeiros resultantes da exploração direta ou por terceiros, deduzidas as despesas, encargos e obrigações legais decorrentes da proteção da propriedade intelectual.

$\S 3^{\circ}$ A participação prevista no caput deste artigo obedecerá ao disposto nos $\S \S 3^{\circ}$ e $4^{\circ}$ do art. $8^{\circ}$.

$\S 4^{\circ}$ A participação referida no caput deste artigo será paga pela ICT em prazo não superior a 1 (um) ano após a realização da receita que lhe servir de base.

Art. 14. Para a execução do disposto nesta Lei, ao pesquisador público é facultado o afastamento para prestar colaboração a outra ICT, nos termos do inciso II do art. 93 da Lei ${ }^{0} 8.112$, de 11 de dezembro de 1990, observada a conveniência da ICT de origem.

$\S 1^{\circ}$ As atividades desenvolvidas pelo pesquisador público, na instituição de destino, devem ser compatíveis com a natureza do cargo efetivo, cargo militar ou emprego público por ele exercido na instituição de origem, na forma do regulamento.

$\S 2^{\circ}$ Durante o período de afastamento de que trata o caput deste artigo, são assegurados ao pesquisador público o vencimento do cargo efetivo, o soldo do cargo militar ou o salário do emprego público da instituição de origem, acrescido das vantagens pecuniárias permanentes estabelecidas em lei, bem como progressão funcional e os benefícios do plano de seguridade social ao qual estiver vinculado.

$\S 3^{\circ}$ As gratificações específicas do exercício do magistério somente serão garantidas, na forma do $\S 2^{\circ}$ deste artigo, caso o pesquisador público se mantenha na atividade docente em instituição científica e tecnológica.

$\S 4^{\circ}$ No caso de pesquisador público em instituição militar, seu afastamento estará condicionado à autorização do Comandante da Força à qual se subordine a instituição militar a que estiver vinculado.

Art. 15. A critério da administração pública, na forma do regulamento, poderá ser concedida ao pesquisador público, desde que não esteja em estágio probatório, licença 
sem remuneração para constituir empresa com a finalidade de desenvolver atividade empresarial relativa à inovação.

$\S 1^{\circ} \mathrm{A}$ licença a que se refere o caput deste artigo dar-se-á pelo prazo de até 3 (três) anos consecutivos, renovável por igual período.

$\S 2^{2}$ Não se aplica ao pesquisador público que tenha constituído empresa na forma deste artigo, durante o período de vigência da licença, o disposto no inciso X do art. 117 da Lei $\mathrm{n}^{\circ} 8.112$, de 1990.

$\S 3^{\circ}$ Caso a ausência do servidor licenciado acarrete prejuízo às atividades da ICT integrante da administração direta ou constituída na forma de autarquia ou fundação, poderá ser efetuada contratação temporária nos termos da Lei $\mathrm{n}^{0} 8.745$, de 9 de dezembro de 1993, independentemente de autorização específica.

Art. 16. A ICT deverá dispor de núcleo de inovação tecnológica, próprio ou em associação com outras ICT, com a finalidade de gerir sua política de inovação.

Parágrafo único. São competências mínimas do núcleo de inovação tecnológica:

I - zelar pela manutenção da política institucional de estímulo à proteção das criações, licenciamento, inovação e outras formas de transferência de tecnologia;

II - avaliar e classificar os resultados decorrentes de atividades e projetos de pesquisa para o atendimento das disposições desta Lei;

III - avaliar solicitação de inventor independente para adoção de invenção na forma do art. 22;

IV - opinar pela conveniência e promover a proteção das criações desenvolvidas na instituição;

V - opinar quanto à conveniência de divulgação das criações desenvolvidas na instituição, passíveis de proteção intelectual;

VI - acompanhar o processamento dos pedidos e a manutenção dos títulos de propriedade intelectual da instituição.

Art. 17. A ICT, por intermédio do Ministério ou órgão ao qual seja subordinada ou vinculada, manterá o Ministério da Ciência e Tecnologia informado quanto:

I - à política de propriedade intelectual da instituição;

II - às criações desenvolvidas no âmbito da instituição;

III - às proteções requeridas e concedidas; e

IV - aos contratos de licenciamento ou de transferência de tecnologia firmados.

Parágrafo único. As informações de que trata este artigo devem ser fornecidas de forma consolidada, em periodicidade anual, com vistas à sua divulgação, ressalvadas as informações sigilosas. 
Art. 18. As ICT, na elaboração e execução dos seus orçamentos, adotarão as medidas cabíveis para a administração e gestão da sua política de inovação para permitir o recebimento de receitas e o pagamento de despesas decorrentes da aplicação do disposto nos arts. $4^{\circ}, 6^{\circ}, 8^{\circ}$ e $9^{\circ}$, o pagamento das despesas para a proteção da propriedade intelectual e os pagamentos devidos aos criadores e eventuais colaboradores.

Parágrafo único. Os recursos financeiros de que trata o caput deste artigo, percebidos pelas ICT, constituem receita própria e deverão ser aplicados, exclusivamente, em objetivos institucionais de pesquisa, desenvolvimento e inovação.

\section{CAPÍTULO IV DO ESTÍMULO À INNOVACIÓN NAS EMPRESAS}

Art. 19. A União, as ICT e as agências de fomento promoverão e incentivarão o desenvolvimento de produtos e processos inovadores em empresas nacionais e nas entidades nacionais de direito privado sem fins lucrativos voltadas para atividades de pesquisa, mediante a concessão de recursos financeiros, humanos, materiais ou de infraestrutura, a serem ajustados em convênios ou contratos específicos, destinados a apoiar atividades de pesquisa e desenvolvimento, para atender às prioridades da política industrial e tecnológica nacional. (Vide Medida Provisória nํ4 497, de 2010)

$\S 1^{\circ}$ As prioridades da política industrial e tecnológica nacional de que trata o caput deste artigo serão estabelecidas em regulamento.

$\S 2^{\circ}$ A concessão de recursos financeiros, sob a forma de subvenção econômica, financiamento ou participação societária, visando ao desenvolvimento de produtos ou processos inovadores, será precedida de aprovação de projeto pelo órgão ou entidade concedente.

$\S 3^{\circ}$ A concessão da subvenção econômica prevista no $\S 1^{\circ}$ deste artigo implica, obrigatoriamente, a assunção de contrapartida pela empresa beneficiária, na forma estabelecida nos instrumentos de ajuste específicos.

$\S 4^{\circ}$ O Poder Executivo regulamentará a subvenção econômica de que trata este artigo, assegurada a destinação de percentual mínimo dos recursos do Fundo Nacional de Desenvolvimento Científico e Tecnológico - FNDCT.

$\S 5^{\circ}$ Os recursos de que trata o $\S 4^{\circ}$ deste artigo serão objeto de programação orçamentária em categoria específica do FNDCT, não sendo obrigatória sua aplicação na destinação setorial originária, sem prejuízo da alocação de outros recursos do FNDCT destinados à subvenção econômica.

Art. 20. Os órgãos e entidades da administração pública, em matéria de interesse público, poderão contratar empresa, consórcio de empresas e entidades nacionais de direito privado sem fins lucrativos voltadas para atividades de pesquisa, de reconhecida capacitação tecnológica no setor, visando à realização de atividades de pesquisa e desenvolvimento, que envolvam risco tecnológico, para solução de problema técnico específico ou obtenção de produto ou processo inovador.

$\S 1^{\circ}$ Considerar-se-á desenvolvida na vigência do contrato a que se refere o caput deste artigo a criação intelectual pertinente ao seu objeto cuja proteção seja requerida pela empresa contratada até 2 (dois) anos após o seu término. 
$\S 2^{\circ}$ Findo o contrato sem alcance integral ou com alcance parcial do resultado almejado, o órgão ou entidade contratante, a seu exclusivo critério, poderá, mediante auditoria técnica e financeira, prorrogar seu prazo de duração ou elaborar relatório final dando-o por encerrado.

$\S 3^{\circ} \mathrm{O}$ pagamento decorrente da contratação prevista no caput deste artigo será efetuado proporcionalmente ao resultado obtido nas atividades de pesquisa e desenvolvimento pactuadas.

Art. 21. As agências de fomento deverão promover, por meio de programas específicos, ações de estímulo à inovação nas micro e pequenas empresas, inclusive mediante extensão tecnológica realizada pelas ICT.

\section{CAPÍTULO V}

\section{DO ESTÍMULO AO INVENTOR INDEPENDENTE}

Art. 22. Ao inventor independente que comprove depósito de pedido de patente é facultado solicitar a adoção de sua criação por ICT, que decidirá livremente quanto à conveniência e oportunidade da solicitação, visando à elaboração de projeto voltado a sua avaliação para futuro desenvolvimento, incubação, utilização e industrialização pelo setor produtivo.

§ 100 núcleo de inovação tecnológica da ICT avaliará a invenção, a sua afinidade com a respectiva área de atuação e o interesse no seu desenvolvimento.

§ 200 núcleo informará ao inventor independente, no prazo máximo de 6 (seis) meses, a decisão quanto à adoção a que se refere o caput deste artigo.

§ 30 Adotada a invenção por uma ICT, o inventor independente comprometerse-á, mediante contrato, a compartilhar os ganhos econômicos auferidos com a exploração industrial da invenção protegida.

\section{CAPÍTULO VI DOS FUNDOS DE INVESTIMENTO}

Art. 23. Fica autorizada a instituição de fundos mútuos de investimento em empresas cuja atividade principal seja a inovação, caracterizados pela comunhão de recursos captados por meio do sistema de distribuição de valores mobiliários, na forma da Lei $\underline{n^{0} 6.385}$, de 7 de dezembro de 1976, destinados à aplicação em carteira diversificada de valores mobiliários de emissão dessas empresas.

Parágrafo único. A Comissão de Valores Mobiliários editará normas complementares sobre a constituição, o funcionamento e a administração dos fundos, no prazo de 90 (noventa) dias da data de publicação desta Lei. 


\section{CAPÍTULO VII \\ DISPOSIÇÕES FINAIS}

Art. 24. A Lei no 8.745, de 9 de dezembro de 1993, passa a vigorar com as seguintes alterações:

"Art. $2^{\circ}$

VII - admissão de professor, pesquisador e tecnólogo substitutos para suprir a falta de professor, pesquisador ou tecnólogo ocupante de cargo efetivo, decorrente de licença para exercer atividade empresarial relativa à inovação. (NR)

"Art. $4^{\circ}$

IV - 3 (três) anos, nos casos dos incisos VI, alínea 'h', e VII do art. 2ํ;

Parágrafo único.

V - no caso do inciso VII do art. $2^{\circ}$, desde que o prazo total não exceda 6 (seis) anos." (NR)

Art. 25. O art. 24 da Lei $n^{0} 8.666$, de 21 de junho de 1993, passa a vigorar acrescido do seguinte inciso:

"Art. 24.

XXV - na contratação realizada por Instituição Científica e Tecnológica - ICT ou por agência de fomento para a transferência de tecnologia e para o licenciamento de direito de uso ou de exploração de criação protegida.

" (NR)

Art. 26. As ICT que contemplem o ensino entre suas atividades principais deverão associar, obrigatoriamente, a aplicação do disposto nesta Lei a ações de formação de recursos humanos sob sua responsabilidade.

Art. 27. Na aplicação do disposto nesta Lei, serão observadas as seguintes diretrizes:

I - priorizar, nas regiões menos desenvolvidas do País e na Amazônia, ações que visem a dotar a pesquisa e o sistema produtivo regional de maiores recursos humanos e capacitação tecnológica; 
II - atender a programas e projetos de estímulo à inovação na indústria de defesa nacional e que ampliem a exploração e o desenvolvimento da Zona Econômica Exclusiva (ZEE) e da Plataforma Continental;

III - assegurar tratamento favorecido a empresas de pequeno porte; e

IV - dar tratamento preferencial, diferenciado e favorecido, na aquisição de bens e serviços pelo poder público e pelas fundações de apoio para a execução de projetos de desenvolvimento institucional da instituição apoiada, nos termos da Lei $n^{\circ} 8.958$, de 20 de dezembro de 1994, às empresas que invistam em pesquisa e no desenvolvimento de tecnologia no País e às microempresas e empresas de pequeno porte de base tecnológica, criadas no ambiente das atividades de pesquisa das ICTs. (Redação dada pela Lei $\mathrm{n}^{0}$ 12.349, de 2010)

Art. 28. A União fomentará a inovação na empresa mediante a concessão de incentivos fiscais com vistas na consecução dos objetivos estabelecidos nesta Lei.

Parágrafo único. O Poder Executivo encaminhará ao Congresso Nacional, em até 120 (cento e vinte) dias, contados da publicação desta Lei, projeto de lei para atender o previsto no caput deste artigo.

Art. 29. Esta Lei entra em vigor na data de sua publicação.

Brasília, 2 de dezembro de 2004; $183^{\circ}$ da Independência e 116ํ da República.

LUIZ INÁCIO LULA DA SILVA

Antônio Palocci Filho

Luiz Fernando Furlan

Eduardo Campos

José Dirceu de Oliveira e Silva 


\section{Anexos 02 - \\ Diretrizes nacionais para os cursos de graduação em Design}

\section{CONSELHO NACIONAL DE EDUCAÇÃO CÂMARA DE EDUCAÇÃO SUPERIOR RESOLUÇÃO № 5, DE 8 DE MARÇO DE 2004. ${\left({ }^{*}\right)\left({ }^{* *}\right)}^{*}$}

Aprova as Diretrizes Curriculares Nacionais do Curso de Graduação em Design e dá outras providências.

O PRESIDENTE DA CÂMARA DE EDUCAÇÃO SUPERIOR DO CONSELHO NACIONAL DE EDUCAÇÃO, no uso de suas atribuições legais, com fundamento no Art. $9^{\circ}$, $\S 2^{\circ}$, alínea "c", da Lei 4.024, de 20 de dezembro de 1961, com a redação dada pela Lei 9.131, de 25 de novembro de 1995, tendo em vista as diretrizes e os princípios fixados pelos Pareceres CNE/CES 776/97, de 3/12/97 e 583/2001, de 4/4/2001, e as Diretrizes Curriculares Nacionais elaboradas pela Comissão de Especialistas de Ensino de Design, propostas ao CNE pela SESu/MEC, considerando o que consta dos Pareceres CNE/CES 67/2003 de $11 / 3 / 2003$, e 195/2003, de 5/8/2003, homologados pelo Senhor Ministro de Estado da Educação, respectivamente, em 2 de junho de 2003 e 12 de fevereiro de 2004, resolve:

Art. $1^{\circ} \mathrm{O}$ curso de graduação em Design observará as Diretrizes Curriculares Nacionais aprovadas nos termos desta Resolução.

Art. $2^{\circ} \mathrm{A}$ organização do curso de que trata esta Resolução se expressa através do seu projeto pedagógico, abrangendo o perfil do formando, as competências e habilidades, os componentes curriculares, o estágio curricular supervisionado, as atividades complementares, o sistema de avaliação, a monografia, o projeto de iniciação científica ou o projeto de atividade, como trabalho de conclusão de curso - TCC, componente opcional da Instituição, além do regime acadêmico de oferta e de outros aspectos que tornem consistente o referido projeto pedagógico.

(*) CNE. Resolução CNE/CES 5/2004. Diário Oficial da União, Brasília, 15 de março de 2004, Seção 1, p. 24

${ }_{\left.{ }^{* *}\right)}$ Republicada no Diário Oficial da União, de $1^{\circ}$ de abril de 2004, Seção 1, p. 
$\S 1^{\circ} \mathrm{O}$ Projeto Pedagógico do curso, além da clara concepção do curso de graduação em Design, com suas peculiaridades, seu currículo pleno e sua operacionalização, abrangerá, sem prejuízo de outros, os seguintes elementos estruturais:

I - objetivos gerais do curso, contextualizados em relação às suas inserções institucional, política, geográfica e social;

II - condições objetivas de oferta e a vocação do curso;

III - cargas horárias das atividades didáticas e da integralização do curso;

IV - formas de realização da interdisciplinaridade;

V - modos de integração entre teoria e prática;

$\mathrm{VI}$ - formas de avaliação do ensino e da aprendizagem;

VII - modos da integração entre graduação e pós-graduação, quando houver;

VIII - cursos de pós-graduação lato sensu, nas modalidades especialização integrada e/ou subsequente à graduação, de acordo com o surgimento das diferentes manifestações teórico-práticas e tecnológicas aplicadas à área da graduação, e de aperfeiçoamento, de acordo com as efetivas demandas do desempenho profissional;

IX - incentivo à pesquisa, como necessário prolongamento da atividade de ensino e como instrumento para a iniciação científica;

$X$ - concepção e composição das atividades de estágio curricular supervisionado, suas diferentes formas e condições de realização, observado o respectivo regulamento; XI - concepção e composição das atividades complementares; XII - inclusão opcional de trabalho de conclusão de curso sob as modalidades monografia, projeto de iniciação científica ou projetos de atividades centrados em área teórico-prática ou de formação profissional, na forma como estabelecer o regulamento próprio.

$\S 2^{\circ}$ Os Projetos Pedagógicos do curso de graduação em Design poderão admitir modalidades e linhas de formação específica, para melhor atender às necessidades do perfil profissiográfico que o mercado ou a região assim exigirem.

Art. $3^{\circ} \mathrm{O}$ curso de graduação em Design deve ensejar, como perfil desejado do formando, capacitação para a apropriação do pensamento reflexivo e da sensibilidade artística, para que o Designer seja apto a produzir projetos que envolvam sistemas de informações visuais, artísticas, estéticas culturais e tecnológicas, observados o ajustamento histórico, os traços culturais e de desenvolvimento das comunidades bem como as características dos usuários e de seu contexto socioeconômico e cultural. 
Art. $4^{\circ} \mathrm{O}$ curso de graduação em Design deve possibilitar a formação profissional que revele competências e habilidades para:

I - capacidade criativa para propor soluções inovadoras, utilizando domínio de técnicas e de processo de criação;

II - capacidade para o domínio de linguagem própria expressando conceitos e soluções, em seus projetos, de acordo com as diversas técnicas de expressão e reprodução visual;

III - capacidade de interagir com especialistas de outras áreas de modo a utilizar conhecimentos diversos e atuar em equipes interdisciplinares na elaboração e execução de pesquisas e projetos;

IV - visão sistêmica de projeto, manifestando capacidade de conceituá-lo a partir da combinação adequada de diversos componentes materiais e imateriais, processos de fabricação, aspectos econômicos, psicológicos e sociológicos do produto;

V - domínio das diferentes etapas do desenvolvimento de um projeto, a saber: definição de objetivos, técnicas de coleta e de tratamento de dados, geração e avaliação de alternativas, configuração de solução e comunicação de resultados;

VI - conhecimento do setor produtivo de sua especialização, revelando sólida visão setorial, relacionado ao mercado, materiais, processos produtivos e tecnologias abrangendo mobiliário, confecção, calçados, jóias, cerâmicas, embalagens, artefatos de qualquer natureza, traços culturais da sociedade, softwares e outras manifestações regionais;

VII - domínio de gerência de produção, incluindo qualidade, produtividade, arranjo físico de fábrica, estoques, custos e investimentos, além da administração de recursos humanos para a produção;

VIII - visão histórica e prospectiva, centrada nos aspectos socioeconômicos e culturais, revelando consciência das implicações econômicas, sociais, antropológicas, ambientais, estéticas e éticas de sua atividade.

Art. $5^{\circ} \mathrm{O}$ curso de graduação em Design deverá contemplar, em seus projetos pedagógicos e em sua organização curricular conteúdos e atividades que atendam aos seguintes eixos interligados de formação:

I - conteúdos básicos: estudo da história e das teorias do Design em seus contextos sociológicos, antropológicos, psicológicos e artísticos, abrangendo métodos e técnicas de projetos, meios de representação, comunicação e informação, estudos das relações usuário/objeto/meio ambiente, estudo de materiais, processos, gestão e outras relações com a produção e o mercado; 
II - conteúdos específicos: estudos que envolvam produções artísticas, produção industrial, comunicação visual, interface, modas, vestuários, interiores, paisagismos, Design e outras produções artísticas que revelem adequada utilização de espaços e correspondam a níveis de satisfação pessoal;

III - conteúdos teórico-práticos: domínios que integram a abordagem teórica e a prática profissional, além de peculiares desempenhos no estágio curricular supervisionado, inclusive com a execução de atividades complementares específicas, compatíveis com o perfil desejado do formando.

Art. $6^{\circ} \mathrm{A}$ organização curricular do curso de graduação em Design estabelecerá expressamente as condições para a sua efetiva conclusão e integralização curricular, de acordo com os seguintes regimes acadêmicos que as instituições de ensino superior adotarem: regime seriado anual; regime seriado semestral; sistema de créditos com matrícula por disciplina ou por módulos acadêmicos, com a adoção e pré-requisito, atendido o disposto nesta Resolução.

Art. $7^{\circ} \mathrm{O}$ Estágio Supervisionado é um componente curricular direcionado à consolidação dos desempenhos profissionais desejados, inerentes ao perfil do formando, devendo cada Instituição, por seus colegiados superiores acadêmicos, aprovar o correspondente regulamento de estágio, com suas diferentes modalidades de operacionalização.

$\S 1^{\circ} \mathrm{O}$ estágio de que trata este artigo poderá ser realizado na própria Instituição de Ensino Superior, mediante laboratórios que congreguem as diversas ordens correspondentes às diferentes técnicas de produções artísticas, industriais e de comunicação visual, ou outras produções artísticas que revelem adequada utilização de espaços e correspondam a níveis de satisfação pessoal.

$\S 2^{\circ}$ As atividades de estágio poderão ser reprogramadas e reorientadas de acordo com os resultados teórico-práticos gradualmente revelados pelo aluno, até que os responsáveis pelo acompanhamento, supervisão e avaliação do estágio curricular possam considerá-lo concluído, resguardando, como padrão de qualidade, os domínios indispensáveis ao exercício da profissão.

$\S 3^{\circ}$ Optando a Instituição por incluir, no currículo do curso de graduação em Design, o estágio supervisionado de que trata este artigo, deverá emitir regulamentação própria, aprovada pelo seu Conselho Superior Acadêmico, contendo, obrigatoriamente, critérios, procedimentos e mecanismos de avaliação, observado o disposto no parágrafo precedente.

Art. $8^{\circ}$ As Atividades Complementares são componentes curriculares que possibilitam o reconhecimento, por avaliação, de habilidades, conhecimentos e competências do aluno, inclusive adquiridas fora do ambiente escolar, 
incluindo a prática de estudos e atividades independentes, opcionais, de interdisciplinaridade, especialmente nas relações com o mundo do trabalho e com as diferentes manifestações e expressões culturais e artísticas, com as inovações tecnológicas, incluindo ações de extensão junto à comunidade.

Parágrafo único. As Atividades Complementares se constituem componentes curriculares enriquecedores e implementadores do próprio perfil do formando, sem que se confundam com estágio curricular supervisionado.

Art. $9^{\circ} \mathrm{O}$ Trabalho de Conclusão de Curso-TCC é um componente curricular opcional da Instituição de Ensino Superior que, se o adotar, poderá ser desenvolvido nas modalidades de monografia, projeto de iniciação científica ou projetos de atividades centradas em áreas teórico-práticas e de formação profissional relacionadas com o curso, na forma disposta em regulamentação específica.

Parágrafo único. Optando a Instituição por incluir, no currículo do curso de graduação em Design, Trabalho de Conclusão de Curso-TCC, nas modalidades referidas no caput deste

artigo, deverá emitir regulamentação própria, aprovado pelo seu Conselho Superior Acadêmico, contendo, obrigatoriamente, critérios, procedimentos e mecanismos de avaliação, além das diretrizes técnicas relacionadas com a sua elaboração.

Art. 10. As instituições de ensino superior deverão adotar formas específicas e alternativas de avaliação, internas e externas, sistemáticas, envolvendo todos quantos se contenham no processo do curso, observados em aspectos considerados fundamentais para a identificação do perfil do formando.

Parágrafo único. Os planos de ensino, a serem fornecidos aos ALUMNOS antes do início do período letivo, deverão conter, além dos conteúdos e das atividades, a metodologia do processo ensino-aprendizagem, os critérios de avaliação a que serão submetidos e bibliografia básica.

Art. 11. A duração do curso de graduação em Design será estabelecida em Resolução específica da Câmara de Educação Superior.

Art. 12. Os cursos de graduação em Design para formação de PROFESORES, licenciatura plena, deverão observar as normas específicas relacionadas com essa modalidade de oferta.

Art. 13. Esta Resolução entrará em vigor na data de sua publicação, revogadas as disposições em contrário.

ÉFREM DE AGUIAR MARANHÃO

Presidente da Câmara de Educação Superior 
